Artículo especial

Este artículo completo solo se encuentra disponible en versión electrónica: www.revespcardiol.org

\title{
Guía ESC 2016 sobre el diagnóstico y tratamiento de la insuficiencia cardiaca aguda y crónica
}

\author{
Grupo de Trabajo de la Sociedad Europea de Cardiología (ESC) de diagnóstico y tratamiento \\ de la insuficiencia cardiaca aguda y crónica
}

\author{
Desarrollada con la colaboración especial de la Heart Failure Association (HFA) de la ESC
}

\begin{abstract}
Autores/Miembros del Grupo de Trabajo: Piotr Ponikowski* (Presidente) (Polonia), Adriaan A. Voors*
(Copresidente) (Países Bajos), Stefan D. Anker (Alemania), Héctor Bueno (España), John G.F. Cleland (Reino Unido), Andrew J.S. Coats (Reino Unido), Volkmar Falk (Alemania), José Ramón González-Juanatey (España), Veli-Pekka Harjola (Finlandia), Ewa A. Jankowska (Polonia), Mariell Jessup (Estados Unidos), Cecilia Linde (Suecia), Petros Nihoyannopoulos (Reino Unido), John T. Parissis (Grecia), Burkert Pieske (Alemania), Jillian P. Riley (Reino Unido), Giuseppe M.C. Rosano (Reino Unido/Italia), Luis M. Ruilope (España), Frank Ruschitzka (Suiza), Frans H. Rutten (Países Bajos) y Peter van der Meer (Países Bajos)
\end{abstract}

\begin{abstract}
Revisores del documento: Gerasimos Filippatos (Coordinador de Revisión de GPC) (Grecia), John J.V. McMurray (Coordinador de Revisión de GPC) (Reino Unido), Victor Aboyans (Francia), Stephan Achenbach (Alemania), Stefan Agewall (Noruega), Nawwar Al-Attar (Reino Unido), John James Atherton (Australia), Johann Bauersachs (Alemania), A. John Camm (Reino Unido), Scipione Carerj (Italia), Claudio Ceconi (Italia), Antonio Coca (España), Perry Elliott (Reino Unido), Çetin Erol (Turquía), Justin Ezekowitz (Canadá), Covadonga Fernández-Golfín (España), Donna Fitzsimons (Reino Unido), Marco Guazzi (Italia), Maxime Guenoun (Francia), Gerd Hasenfuss (Alemania), Gerhard Hindricks (Alemania), Arno W. Hoes (Países Bajos), Bernard lung (Francia), Tiny Jaarsma (Suecia), Paulus Kirchhof (Reino Unido/Alemania), Juhani Knuuti (Finlandia), Philippe Kolh (Bélgica), Stavros Konstantinides (Alemania/Grecia), Mitja Lainscak (Slovenia), Patrizio Lancellotti (Bélgica), Gregory Y.H. Lip (Reino Unido), Francesco Maisano (Suiza), Christian Mueller (Suiza), Mark C. Petrie (Reino Unido), Massimo F. Piepoli (Italia), Silvia G. Priori (Italia), Adam Torbicki (Polonia), Hiroyuki Tsutsui (Japón), Dirk J. van Veldhuisen (Países Bajos), Stephan Windecker (Suiza), Clyde Yancy (Estados Unidos) y José Luis Zamorano (España)
\end{abstract}

Las declaraciones de conflicto de intereses de los expertos participantes en el desarrollo de esta guía están disponibles en la página web de la ESC: http://www.escardio.org/ guidelines.

VÉASE CONTENIDO RELACIONADO:

http://dx.doi.org/10.1016/j.recesp.2016.09.056, Rev Esp Cardiol. 2016;69:1119-25.

*Autores para correspondencia:

Department of Heart Diseases, Wroclaw Medical University, Centre for Heart Diseases, Military Hospital, ul.Weigla 5, 50-981 Wroclaw, Polonia.

Correo electrónico: piotrponikowski@4wsk.pl (P. Ponikowski).

Cardiology, University of Groningen, University Medical Center Groningen, Hanzeplein 1, PO Box 30.001, 9700 RB Groningen, Países Bajos.

Correo electrónico: a.a.voors@umcg.nl (A. Voors).

La lista de miembros del Comité de la ESC para la Elaboración de Guías de Práctica Clínica y revisores del documento representantes de las sociedades nacionales de cardiología se recoge en el apéndice.

Entidades de la ESC que han participado en el desarrollo de este documento:

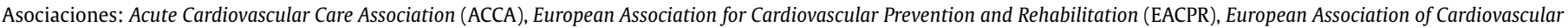
Imaging (EACVI), European Heart Rhythm Association (EHRA) y Heart Failure Association (HFA).

Consejos: Council on Cardiovascular Nursing and Allied Professions, Council for Cardiology Practice, Council on Cardiovascular Primary Care y Council on Hypertension.

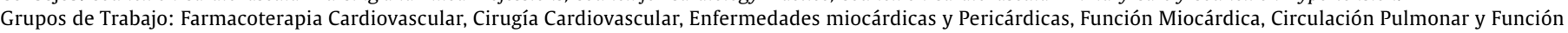
Ventricular Derecha y Valvulopatías.

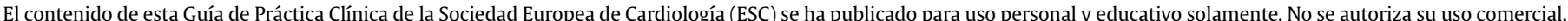

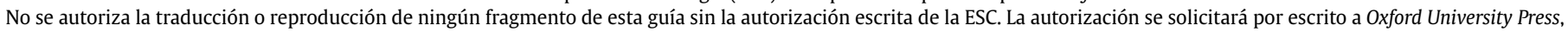
editorial del European Heart Journal, o a los representantes autorizados de la ESC (journals.permissions@oup.com).

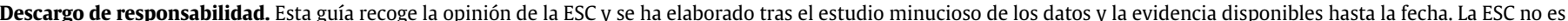

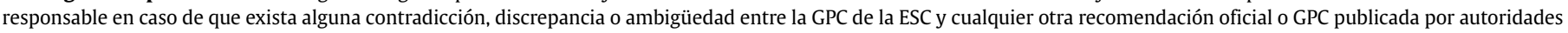

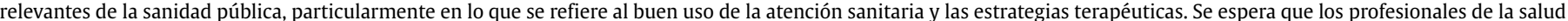

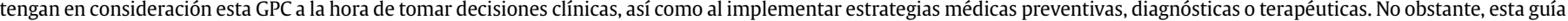

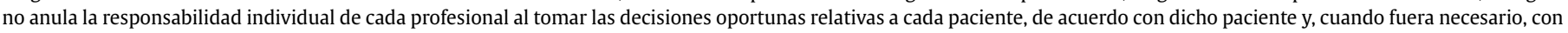

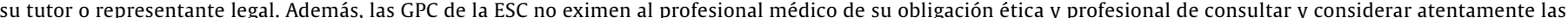

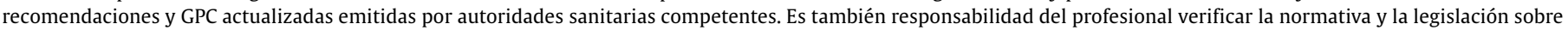
fármacos y dispositivos médicos a la hora de prescribirlos.

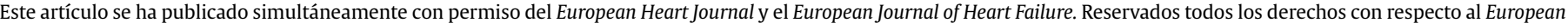
Heart Journal.

@2016 Sociedad Europea de Cardiología. Reservados todos los derechos. Para la solicitud de autorizaciones, contacte con: journals.permissions@oup.com

Palabras clave:

Guía de práctica clínica • Insuficiencia cardiaca • Péptidos natriuréticos • Fracción de eyección • Diagnóstico • Farmacoterapia • Antagonistas neurohormonales $\bullet$ Terapia de resincronización cardiaca $\bullet$ Asistencia mecánica circulatoria $\bullet$ Trasplante $\bullet$ Arritmias $\bullet$ Comorbilidades $\bullet$ Hospitalización - Abordaje multidisciplinario 


\section{TABLA DE CONTENIDOS}

Abreviaturas 3

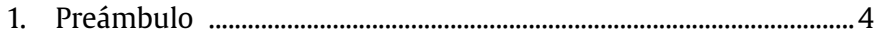

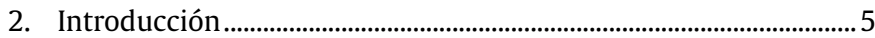

3. Definición, epidemiología y pronóstico................................................. 6

3.1. Definición de la insuficiencia cardiaca ........................................ 6

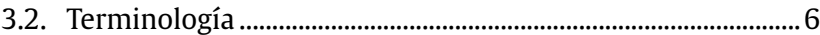

3.2.1. Insuficiencia cardiaca con fracción de eyección conservada, en rango medio o reducida........................ 6

3.2.2. Terminología relativa a la evolución temporal de la insuficiencia cardiaca................................................ 6

3.2.3. Terminología relativa a la gravedad de los síntomas de la insuficiencia cardiaca.............................................. 7

3.3. Epidemiología, etiología e historia natural de la insuficiencia cardiaca.............................................................

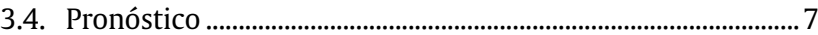

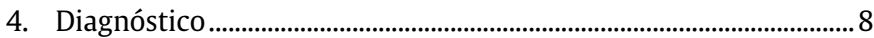

4.1. Síntomas y signos ......................................................................... 8

4.2. Pruebas iniciales básicas: péptidos natriuréticos, electrocardiograma y ecocardiografía.........................................

4.3. Algoritmo para el diagnóstico de la insuficiencia cardiaca.

4.3.1. Algoritmo para el diagnóstico de la insuficiencia cardiaca en un contexto no agudo.

4.3.2. Diagnóstico de la insuficiencia cardiaca con fracción de eyección conservada ............................10

5. Imagen cardiaca y otras pruebas diagnósticas .....................................10

5.1. Radiografía torácica ...................................................................... 10

5.2. Ecocardiografía transtorácica .................................................... 10

5.2.1. Evaluación de la función sistólica ventricular izquierda 12

5.2.2. Evaluación de la función diastólica ventricular izquierda...... 12

5.2.3. Evaluación de la función ventricular derecha y la presión arterial pulmonar.........................................12

5.3. Ecocardiografía transesofágica................................................... 12

5.4. Ecocardiografía de estrés ...............................................................12

5.5. Resonancia magnética cardiaca .................................................12

5.6. Tomografía computarizada por emisión de fotón único (SPECT) y ventriculografía con radionucleótidos ...................13

5.7. Tomografía por emisión de positrones .......................................13

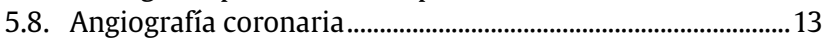

5.9. Tomografía computarizada cardiaca ......................................... 14

5.10. Otras pruebas diagnósticas.......................................................... 14

5.10.1. Pruebas genéticas en la insuficiencia cardiaca........... 14

6. Prevenir o retrasar la aparición de insuficiencia cardiaca manifiesta o prevenir la muerte antes de que aparezcan los síntomas.

7. Tratamiento farmacológico de la insuficiencia cardiaca con fracción de eyección reducida ......................................................... 15

7.1. Objetivos del tratamiento de la insuficiencia cardiaca........15

7.2. Tratamientos recomendados para todos los pacientes sintomáticos con insuficiencia cardiaca y fracción de eyección reducida 16

7.2.1. Inhibidores de la enzima de conversión de la angiotensina

7.2.2. Bloqueadores beta

7.2.3. Antagonistas de los receptores de mineralcorticoides/aldosterona.

7.3. Otros tratamientos recomendados para pacientes sintomáticos con insuficiencia cardiaca y fracción de eyección reducida seleccionados

7.3.1. Diuréticos

7.3.2. Inhibidor del receptor de angiotensina y neprilisina.
7.3.3. Inhibidor del canal $I_{\mathrm{f}}$ . .19

7.3.4. Antagonistas del receptor tipo 1 de la angiotensina II

7.3.5. Combinación de hidralazina y dinitrato de isosorbida

7.4. Otros tratamientos con beneficios más inciertos para pacientes sintomáticos con insuficiencia cardiaca y fracción de eyección reducida...................................................21

7.4.1. Digoxina y otros glucósidos digitálicos..........................21

7.4.2. Ácidos grasos poliinsaturados $\mathrm{n}-3$...................................21

7.5. Tratamientos no recomendados (beneficio no probado) para pacientes sintomáticos con insuficiencia cardiaca y fracción de eyección reducida. .21

7.5.1. Inhibidores de la 3-hidroxi-3-metilglutaril coenzima A reductasa ("estatinas»)

7.5.2. Anticoagulantes orales y tratamiento antiagregante

7.5.3. Inhibidores de la renina

7.6. Tratamientos no recomendados (considerados perjudiciales) para pacientes sintomáticos con insuficiencia cardiaca y fracción de eyección reducida .22

7.6.1. Bloqueadores de los canales del calcio .........................22

8. Tratamiento no quirúrgico de la insuficiencia cardiaca con fracción de eyección reducida mediante dispositivos ....................22

8.1. Desfibrilador automático implantable......................................22

8.1.1. Prevención secundaria de la muerte súbita cardiaca.

8.1.2. Prevención primaria de la muerte súbita

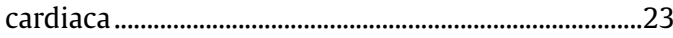

8.2. Terapia de resincronización cardiaca .........................................23

8.3. Otros dispositivos eléctricos implantables...............................25

9. Tratamiento de la insuficiencia cardiaca con fracción de eyección conservada. .25

9.1. Efecto del tratamiento en los síntomas de la insuficiencia cardiaca con fracción de eyección conservada.

9.2. Efecto del tratamiento en la hospitalización por insuficiencia cardiaca en la insuficiencia cardiaca con fracción de eyección conservada...

9.3. Efecto del tratamiento en la mortalidad en la insuficiencia cardiaca con fracción de eyección conservada.

9.4. Otras consideraciones .................................................................26

10. Arritmias y alteraciones de la conducción..........................................26

10.1. Fibrilación auricular....................................................................2.26

10.1.1. Prevención de la fibrilación auricular en pacientes con insuficiencia cardiaca .............................................26

10.1.2. Tratamiento de la fibrilación auricular rápida de nueva aparición en pacientes con insuficiencia

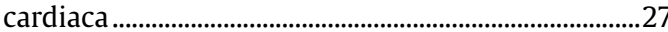

10.1.3. Control de la frecuencia cardiaca.....................................27

10.1.4. Control del ritmo cardiaco .............................................27

10.1.5. Profilaxis de la tromboembolia .....................................28

10.2. Arritmias ventriculares..................................................................29

10.3. Bradicardia sintomática, pausas y bloqueo auriculoventricular..................................................................29

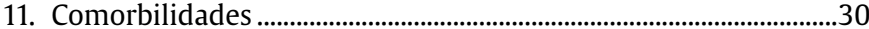

11.1. Insuficiencia cardiaca y comorbilidades .................................30

11.2. Angina y enfermedad arterial coronaria ..................................30

11.2.1. Tratamiento farmacológico............................................30

11.2.2. Revascularización miocárdica.........................................30

11.3. Caquexia y sarcopenia (para pacientes frágiles, véase la sección 14)......................................................................31

11.4. Cáncer.............................................................................................. 31

11.5. Sistema nervioso central (incluidos depresión, ictus y disfunción autonómica) 
11.6. Diabetes mellitus .32

11.7. Disfunción eréctil .32

11.8. Gota y artritis .33

11.9. Hipopotasemia e hiperpotasemia..........................................33

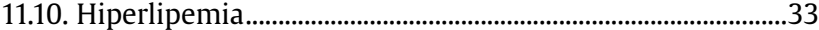

11.11. Hipertensión ......................................................................................33

11.12. Déficit de hierro y anemia..........................................................34

11.13. Disfunción renal (incluidos enfermedad renal crónica, daño renal agudo, síndrome cardiorrenal y obstrucción prostática)

11.14. Enfermedad pulmonar (incluidos asma y enfermedad pulmonar obstructiva crónica) . .35

11.15. Obesidad .35

11.16. Trastornos del sueño y trastornos respiratorios durante el sueño. .35

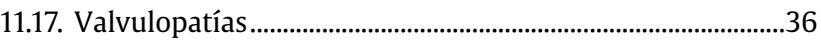

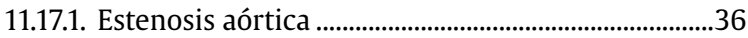

11.17.2. Regurgitación aórtica ...................................................36

11.17.3. Regurgitación mitral........................................................36

11.17.4. Regurgitación tricuspídea ...............................................37

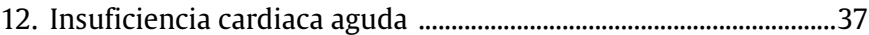

12.1. Definición y clasificación.............................................................37

12.2. Diagnóstico y evaluación pronóstica inicial ...........................38

12.3. Abordaje y tratamiento ............................................................4

12.3.1. Identificación de factores/causas desencadenantes que llevan a la descompensación y requieren tratamiento urgente. . .42

12.3.2. Criterios para la hospitalización en planta o en la unidad de cuidados intensivos/cuidados coronarios . .42

12.3.3. Tratamiento en la fase inicial . .42

12.3.4. Tratamiento de pacientes en shock cardiogénico

12.4. Tratamientos orales basados en la evidencia 47

12.5. Monitorización del estado clínico de los pacientes hospitalizados por insuficiencia cardiaca aguda. . .48

12.6. Criterios para el alta hospitalaria y seguimiento en la fase de alto riesgo. . .48

12.7. Objetivos durante las distintas fases del tratamiento de la insuficiencia cardiaca aguda. . .48

13. Asistencia mecánica circulatoria y trasplante cardiaco..................48

13.1. Asistencia mecánica circulatoria...............................................48

13.1.1. Asistencia mecánica circulatoria en la insuficiencia cardiaca aguda...............................49

13.1.2. Asistencia mecánica circulatoria en la fase terminal de la insuficiencia cardiaca crónica.........49

13.2. Trasplante cardiaco

. .51

14. Atención multidisciplinaria.

. .51

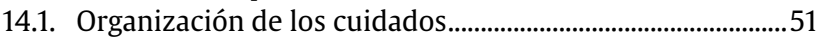

14.2. Planificación del alta .................................................................52

14.3. Consejos sobre el estilo de vida.................................................52

14.4. Entrenamiento físico....................................................................52

14.5. Seguimiento y monitorización....................................................52

14.6. El paciente de edad avanzada, fragilidad y trastorno cognitivo .54

14.7. Cuidados paliativos y la fase terminal...................................54

15. Lagunas en la evidencia ....................................................................55

16. Mensajes clave de la guía sobre qué hacer y qué no hacer............56

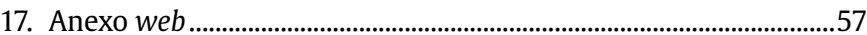

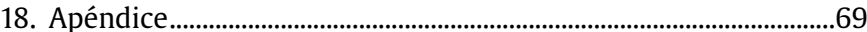

19. Bibliografía

\section{Abreviaturas}

ACC/AHA: American College of Cardiology/American Heart Association

ACCF/AHA: American College of Cardiology Foundation/American Heart Association

AINE: antiinflamatorios no esteroideos

AIT: accidente isquémico transitorio

AMC: asistencia mecánica circulatoria

AOS: apnea obstructiva del sueño

ARA-II: antagonistas del receptor de la angiotensina Il

ARM: antagonista del receptor de mineralcortidoides

ASC: apnea del sueño central

ASV: servoventilación adaptativa

BCC: bloqueadores de los canales del calcio

BCIA: balón de contrapulsación intraaórtico

BNP: péptido natriurético de tipo $B$

BRI: bloqueo de rama izquierda

BUN: nitrógeno ureico en la sangre

CABG: cirugía de revascularización coronaria

$\mathrm{CHA}_{2} \mathrm{DS}_{2}$-VASc: insuficiencia cardiaca congestiva o disfunción ventricular izquierda, hipertensión, edad $\geq 75$ (doble), diabetes mellitus, ictus (doble)-enfermedad vascular, edad 65-74 y sexo (mujer)

CK: creatincinasa

CK-MB: creatincinasa MB

CPAP: presión positiva continua en la vía aérea

DAI: desfibrilador automático implantable

DAV: dispositivo de asistencia ventricular

DAVD: dispositivo de asistencia ventricular derecha

DAVI: dispositivo de asistencia ventricular izquierda

DHA: ácido docosahexanoico

e': velocidad tisular diastólica temprana

EAC: enfermedad arterial coronaria

ECDA: ensayo controlado con distribución aleatoria

ECG: electrocardiograma

ECMO: oxigenador extracorpóreo de membrana

EHRA: European Heart Rhythm Association

EPOC: enfermedad pulmonar obstructiva crónica

ERC: enfermedad renal crónica

ESC: Sociedad Europea de Cardiología

ETE: ecocardiografía transesofágica

ETT: ecocardiografía transtorácica

FA: fibrilación auricular

FC: frecuencia cardiaca

FE: fracción de eyección

FEVI: fracción de eyección del ventrículo izquierdo

GLP-1: péptido de tipo glucagón 1

HAS-BLED: hipertensión, función renal/hepática anormal (1 punto cada una), ictus, historia o predisposición al sangrado, INR lábil, ancianos (> 65 años), consumo concomitante de drogas/alcohol (1 punto cada uno)

$\mathrm{HbA}_{1 \mathrm{c}}$ : glucohemoglobina

HFA: Heart Failure Association

i.v.: intravenoso

IAM: infarto agudo de miocardio

IAMCEST: infarto agudo de miocardio con elevación del segmento ST IC: insuficiencia cardiaca

ICA: insuficiencia cardiaca aguda

IC-FEc: insuficiencia cardiaca con fracción de eyección conservada

IC-FEm: insuficiencia cardiaca con fracción de eyección en rango medio

IC-FEr: insuficiencia cardiaca con fracción de eyección reducida ICP: intervención coronaria percutánea 
IECA: inhibidor de la enzima de conversión de la angiotensina IMC: índice de masa corporal

LMNA: gen de la lamina $\mathrm{A} / \mathrm{C}$

lpm: latidos por minuto

MAVD: miocardiopatía arritmogénica del ventrículo derecho

MCC: modulación de la contractilidad cardiaca

MCD: miocardiopatía dilatada

$\mathrm{MCH}$ : miocardiopatía hipertrófica

NACO: nuevos anticoagulantes orales no dependientes de la vitamina $\mathrm{K}$

NT-proBNP: fracción N-terminal del propéptido natriurético cerebral

NYHA: New York Heart Association

PA: presión arterial

PAS: presión arterial sistólica

PET: tomografía por emisión de positrones

PN: péptido natriurético

PUFA n-3: ácidos grasos poliinsaturados n-3

RM: receptor de mineralcorticoides

RMC: resonancia magnética cardiaca

SCA: síndrome coronario agudo

SCASEST: síndrome coronario agudo sin elevación del segmento ST

SPECT: tomografía por emisión monofotónica

$\mathrm{SpO}_{2}$ : saturación de oxígeno transcutánea

SRAA: sistema renina-angiotensina-aldosterona

TAVI: implante transcatéter de válvula aórtica

TC: tomografía computarizada

TFG: tasa de filtrado glomerular

TFGe: tasa de filtrado glomerular estimada

TMO: tratamiento médico óptimo

TRC: terapia de resincronización cardiaca

TRC-D: terapia de resincronización cardiaca con desfibrilador

TRC-MP: terapia de resincronización cardiaca con marcapasos

TSH: tirotropina

TV: taquicardia ventricular

UCC: unidad de cuidados coronarios

UCI: unidad de cuidados intensivos

VD: ventrículo derecho

VI: ventrículo izquierdo

VIH/sida: virus de la inmunodeficiencia humana/síndrome de

inmunodeficiencia adquirida

$\mathrm{VO}_{2}$ : consumo de oxígeno

VP: vena pulmonar

VRT: velocidad de regurgitación tricuspídea paciente $\mathrm{o}$, cuando proceda, con la persona encargada de sus cuidados.

En los últimos años, la Sociedad Europea de Cardiología (ESC), además de otras sociedades y organizaciones científicas, ha publicado un gran número de GPC. Debido al impacto de estas, se han establecido criterios de calidad para su elaboración de modo que todas las decisiones se presenten de manera clara y transparente al usuario. Las recomendaciones de la ESC para la elaboración y publicación de GPC están disponibles en la sección de guías de la página web de la ESC (http://www.escardio. org/Guidelines-\&-Education/Clinical-PracticeGuidelines/Guidelines-development/Writing-ESC-Guidelines). Las GPC de la ESC representan la postura oficial de la ESC sobre un tema particular y se actualizan con regularidad.

Los miembros de este Grupo de Trabajo fueron seleccionados por la ESC en representación de los profesionales de la salud dedicados a los cuidados médicos de la patología tratada en el presente documento. Los expertos seleccionados realizaron una revisión exhaustiva de la evidencia publicada sobre la atención a una entidad concreta (incluidos el diagnóstico, el tratamiento, la prevención y la rehabilitación) según las normas establecidas por el Comité de la ESC para la Elaboración de GPC. Además, llevaron a cabo la evaluación crítica de los procedimientos diagnósticos y terapéuticos, incluida la valoración de la razón riesgo/beneficio. Cuando se dispone de datos, se incluye también una estimación de los resultados sanitarios para grandes grupos de población. Se valoraron el nivel de evidencia y la fuerza de la recomendación de una opción terapéutica particular de acuerdo con escalas predefinidas, tal como se indica en las tablas 1 y 2.

Los miembros del Grupo de Trabajo y los revisores del documento han declarado por escrito cualquier relación que se pueda considerar conflicto de intereses real o potencial. Estas declaraciones escritas están archivadas y disponibles en la página web de la ESC (http:// www.escardio.org/guidelines). Durante el periodo de redacción, las modificaciones en las relaciones que se pudieran considerar conflicto de intereses se notificaron a la ESC y se actualizaron. El informe del Grupo de Trabajo fue financiado en su totalidad por la ESC y se desarrolló sin ninguna participación de la industria.

El Comité para la elaboración de GPC de la ESC supervisa y coordina la preparación de nuevas GPC elaboradas por los Grupos de Trabajo, grupos de expertos o paneles de consenso. El Comité es responsable también del proceso de aprobación de las GPC. El Comité de la ESC y expertos externos realizaron una revisión exhaustiva del documento, tras lo cual fue aprobado por todos los miembros del Grupo de Trabajo. Por último, el documento final fue aprobado por el Comité de la ESC para su publicación en European Heart Journal. La elaboración de la presente GPC se realizó tras la meticulosa evaluación del conocimiento científico y médico y de la evidencia disponible hasta la fecha de su redacción.

La tarea de elaboración de GPC incluye no solo la integración de la investigación más reciente, sino también la creación de herramientas educativas y programas de implementación de las recomendaciones. Para su implementación, se desarrollan ediciones de bolsillo, resúmenes en diapositivas y tarjetas, folletos con mensajes clave y versiones electrónicas para aplicaciones digitales (smartphones, etc.). Estas versiones son resumidas y, por lo tanto, en caso de necesidad, debe consultarse la versión completa que se encuentra disponible gratuitamente en la página web de la ESC. Se recomienda a las sociedades nacionales que forman parte de la ESC suscribir, traducir e implementar las GPC de la ESC. Los programas de implementación son necesarios porque se ha demostrado que los resultados clínicos se ven favorablemente influidos por la aplicación de las recomendaciones clínicas.

Asimismo es necesario realizar encuestas y registros para verificar si la práctica clínica en la vida real se corresponde con las recomendaciones de las guías y de esta forma se completa el ciclo entre la investigación clínica, la elaboración de las guías y su implementación en la práctica clínica. diario. No obstante, la decisión final sobre un paciente concreto debe tomarla el médico responsable de su salud, en consulta con el propio evar toda la evidencia relevante disponible durante el proces elaboración sobre un tema particular para ayudar a los médicos onar la mejor estrategia posible de tratamiento par po teniendo riesgos y los beneficios de un procedimiento diagnóstico o terapéutico concreto. Las GPC y las recomendaciones deben ayudar a los pro- 
Clases de recomendación

\begin{tabular}{lll}
\hline Grados de recomendación & Definición & Expresiones propuestas \\
\hline Clase I & $\begin{array}{l}\text { Evidencia y/o acuerdo general en que un determinado procedimiento diagnóstico/tratamiento } \\
\text { es beneficioso, útil y efectivo }\end{array}$ & Se recomienda/está indicado \\
\hline Clase II & Evidencia conflictiva y/o divergencia de opinión acerca de la utilidad/eficacia del tratamiento & Se debe considerar \\
\hline Clase IIa & El peso de la evidencia/opinión está a favor de la utilidad/eficacia & Se puede recomendar \\
\hline Clase IIb & La utilidad/eficacia está menos establecida por la evidencia/opinión & No se recomienda \\
\hline Clase III & Evidencia o acuerdo general en que el tratamiento no es útil/efectivo y en algunos casos puede & \\
\hline
\end{tabular}

Niveles de evidencia

\begin{tabular}{|ll}
\hline Nivel de evidencia A & $\begin{array}{l}\text { Datos procedentes de múltiples ensayos clínicos } \\
\text { aleatorizados o metanálisis }\end{array}$ \\
\hline Nivel de evidencia B & $\begin{array}{l}\text { Datos procedentes de un único ensayo clínico } \\
\text { aleatorizado o de grandes estudios no aleatorizados }\end{array}$ \\
\hline Nivel de evidencia C & $\begin{array}{l}\text { Consenso de opinión de expertos y/o pequeños } \\
\text { estudios, estudios retrospectivos, registros }\end{array}$ \\
\hline
\end{tabular}

Se recomienda a los profesionales de la salud que tengan en consideración la presente guía de la ESC en la toma de decisiones clínicas en su ejercicio diario, así como en la determinación y la implementación de estrategias preventivas, diagnósticas y terapéuticas; no obstante, la decisión final sobre el cuidado de un paciente concreto, en consulta con dicho paciente y, si fuera necesario, con su representante legal, debe tomarla el médico responsable de su cuidado. Además, es responsabilidad del profesional de la salud comprobar la normativa aplicable a fármacos y dispositivos médicos antes de su prescripción.

\section{INTRODUCCIÓN}

El objetivo de las guías de la ESC es ayudar a los profesionales de la salud a tomar decisiones en la práctica clínica diaria basadas en los datos disponibles. Pronto celebraremos el $30 .^{\circ}$ aniversario de los estudios clínicos que demostraron por primera vez y de manera incuestionable que la evolución de los pacientes con insuficiencia cardiaca (IC) puede mejorarse significativamente ${ }^{2}$. Desde entonces hemos sido testigos y hemos celebrado muchos más avances que retrocesos en el abordaje de la IC, que han llevado a un conocimiento más profundo de la fisiopatología de este síndrome clínico y, lo que es más importante, a una mejor atención de nuestros pacientes ${ }^{3}$. En 2016 nadie puede dudar de que, con la aplicación de los descubrimientos basados en la evidencia, la IC se ha convertido en una enfermedad más prevenible y más tratable.

El objetivo de este documento es proporcionar una guía práctica basada en la evidencia para el diagnóstico y tratamiento de la IC. Los cambios más importantes con respecto a la edición de 2012 se refieren a:

1. Un nuevo término para definir a los pacientes con IC y fracción de eyección del ventrículo izquierdo (FEVI) en la banda del $40-49 \%$, "IC con fracción de eyección en rango medio (IC-FEm)»; creemos que la identificación de la IC-FEm como grupo separado estimulará la investigación sobre las características subyacentes, la fisiopatología y el tratamiento de este grupo de población.
2. Recomendaciones claras sobre los criterios diagnósticos de la IC-FE reducida (IC-FEr), la IC-FEm y la IC-FE conservada (IC-FEc).

3. Un nuevo algoritmo para el diagnóstico de la IC en presentación no aguda según la evaluación de la probabilidad de IC.

4. Recomendaciones para prevenir o retrasar la aparición de IC manifiesta o prevenir la muerte antes de la aparición de los síntomas.

5. Indicaciones para el uso del nuevo compuesto sacubitrilo/valsartán, el primero de la clase de inhibidores del receptor de la angiotensina y neprilisina (IRAN).

6. Modificación de las indicaciones para la terapia de resincronización cardiaca (TRC).

7. El concepto de instauración de tratamiento temprana y simultánea a la realización de pruebas relevantes en la IC aguda (ICA), según la estrategia de "tiempo transcurrido hasta tratamiento" que se aplica en los síndromes coronarios agudos (SCA).

8. Un nuevo algoritmo para una estrategia combinada de diagnóstico y tratamiento de la ICA según la presencia o ausencia de congestión e hipoperfusión.

Hemos seguido el mismo formato que la guía de la ESC sobre IC publicada en 2012. Las recomendaciones terapéuticas se basan en los efectos del tratamiento según la clase y el nivel de recomendación y se presentan en tablas; en el caso de la IC crónica causada por disfunción sistólica del ventrículo izquierdo, las recomendaciones se basan en los datos sobre morbimortalidad. Se incluye información detallada sobre la evidencia más importante que respalda los tratamientos generalmente recomendados. En cuanto a las recomendaciones diagnósticas, se ha aplicado generalmente un nivel de evidencia $\mathrm{C}$, dado que para la mayoría de estas pruebas no hay datos de estudios controlados y aleatorizados (ECDA) que demuestren que su empleo conlleve una reducción de la morbimortalidad. Asimismo se proporciona una guía práctica para el uso de los fármacos modificadores de enfermedad y diuréticos más importantes. Cuando fue posible se citaron otras guías, declaraciones de consenso y artículos de posición para evitar la excesiva extensión del texto. Las tablas deben leerse junto con el texto que las acompaña y no de manera aislada.

Este documento es el resultado de una intensa interacción entre el Grupo de Trabajo, el equipo de revisores y el Comité de la ESC para las GPC, y representa la opinión consensuada de todos los expertos implicados en su desarrollo. Simultáneamente al desarrollo de la guía ESC 2016 sobre IC, otro grupo de autores elaboró independientemente el documento 2016 ACC/AHA/HFSA Focused Update on New Pharmacological Therapy for Heart Failure con recomendaciones sobre la nueva farmacoterapia para la IC. Ambos grupos de trabajo revisaron independientemente los datos, llegaron a las mismas conclusiones y establecieron recomendaciones similares, aunque no idénticas. Dada su concordancia, ambas organizaciones publicaron simultáneamente recomendaciones similares sobre el uso de los nuevos tratamientos para evitar posibles confusiones y mejorar la atención de los pacientes con IC. 


\section{DEFINICIÓN, EPIDEMIOLOGÍA Y PRONÓSTICO}

\subsection{Definición de la insuficiencia cardiaca}

La IC es un síndrome clínico caracterizado por síntomas típicos (como disnea, inflamación de tobillos y fatiga), que puede ir acompañado de signos (como presión venosa yugular elevada, crepitantes pulmonares y edema periférico) causados por una anomalía cardiaca estructural o funcional que producen una reducción del gasto cardiaco o una elevación de las presiones intracardiacas en reposo o en estrés.

La definición actual de la IC se limita a las fases de la enfermedad en que los síntomas clínicos son evidentes. Antes de la manifestación de los síntomas, los pacientes pueden presentar anomalías cardiacas estructurales o funcionales asintomáticas (disfunción sistólica o diastólica del ventrículo izquierdo), que son precursoras de la IC. La identificación de estas anomalías es importante porque se relacionan con peores resultados, y la instauración de tratamiento en esta fase podría reducir la mortalidad de los pacientes con disfunción sistólica ventricular izquierda asintomática (véase la sección 6 ) 4.5. $^{4}$.

La identificación de una causa cardiaca subyacente es fundamental para el diagnóstico de la IC. Normalmente, la miocardiopatía es la causa de la disfunción ventricular sistólica o diastólica. No obstante, las anomalías de válvulas, pericardio, endocardio, ritmo cardiaco y conducción también pueden causar IC (y a menudo hay más de una anomalía). Identificar el problema cardiaco subyacente también es crucial por razones terapéuticas, ya que cada enfermedad concreta determina el tratamiento específico que se debe emplear (p. ej., reparación o reemplazo valvular en caso de valvulopatías, tratamiento farmacológico específico para la IC-FEr, reducción de la frecuencia cardiaca en la taquimiocardiopatía, etc.).

\subsection{Terminología}

\subsubsection{Insuficiencia cardiaca con fracción de eyección conservada, en rango medio o reducida}

La terminología más importante empleada para describir la IC es histórica y se basa en la determinación de la fracción de eyección del ventrículo izquierdo (FEVI). La IC comprende un amplio espectro de pacientes, desde aquellos con FEVI normal (considerada típicamente como $\geq 50 \%$ ) o IC con FE conservada (IC-FEc) a aquellos con FEVI reducida (típicamente considerada como $<40 \%$ ) o IC-FEr (tabla 3.1). Los pacientes con FEVI en la banda del 40-49\% representan una "zona gris», que ahora definimos como IC con FEVI en rango medio (IC-FEm) (tabla 3.1). La diferenciación de los pacientes con IC según la FEVI es importante, dada su relación con diferentes etiologías subyacentes, características demográficas, comorbilidades y respuesta a los tratamientos $^{6}$. La mayoría de los estudios clínicos publicados desde 1990 seleccionaron a los pacientes según la FEVI (medida normalmente mediante ecocardiografía, una técnica con radionucleótidos o resonancia magnética cardiaca [RMC]), y solamente en pacientes con IC-FEr los tratamientos han logrado una reducción tanto de la morbilidad como de la mortalidad.

El diagnóstico de la IC-FEc es más complejo que el diagnóstico de la IC-FEr. Los pacientes con IC-FEc generalmente no presentan dilatación del VI, pero en su lugar normalmente tienen un aumento del grosor de la pared del VI o un aumento del tamaño de la aurícula izquierda como un signo del aumento de las presiones de llenado. La mayoría tiene signos adicionales de capacidad de llenado o de succión del VI afectada, también clasificada como disfunción diastólica, que se considera generalmente como la causa más probable de IC en estos pacientes (de ahí el término «IC diastólica). No obstante, gran parte de los pacientes con IC-FEr (llamada previamente "IC sistólica») tienen también disfunción diastólica y en pacientes con IC-FEc también se encuentran leves anomalías de la función sistólica. Por ello, se prefiere emplear los términos FEVI conservada o reducida en lugar de "función sistólica» conservada o reducida.

En guías anteriores se reconocía la existencia de una zona gris entre la IC-FEr y la IC-FEc 7 . Estos pacientes tienen una FEVI del 40-49\%, de ahí el término IC-FEm. La identificación de la IC-FEm como grupo separado estimulará la investigación sobre las características subyacentes, la fisiopatología y el tratamiento de este grupo de pacientes. Los pacientes con IC-FEm probablemente tengan disfunción sistólica leve, pero con características de disfunción diastólica (tabla 3.1).

Los pacientes sin enfermedad miocárdica del VI detectable pueden tener otras causas de la IC (p. ej., hipertensión pulmonar, valvulopatía, etc.). Los pacientes con enfermedades no cardiovasculares (p. ej., anemia, enfermedad pulmonar, renal o hepática) pueden tener síntomas parecidos o idénticos a los de la IC y cada uno de ellos puede complicar o exacerbar el síndrome de IC.

\subsubsection{Terminología relativa a la evolución temporal de la insuficiencia cardiaca}

En esta guía, el término IC se utiliza para describir el síndrome sintomático, evaluado según la clasificación funcional de la New York Heart Association (NYHA) (véase la sección 3.2.3 y la tabla 3.2 del anexo), aunque un paciente puede volverse asintomático por el tratamiento. Asimismo un paciente que nunca ha mostrado los síntomas o signos típicos de IC y tiene la FEVI reducida se describe como un paciente con disfunción sistólica del VI asintomática. De los pacientes que han tenido IC por algún tiempo, se dice normalmente que padecen «IC crónica». Un paciente en tratamiento con síntomas y signos

Tabla 3.1

Definición de la insuficiencia cardiaca con fracción de eyección conservada, en rango medio y reducida

\begin{tabular}{|c|c|c|c|c|}
\hline Tipo de IC & & IC-FEr & IC-FEm & IC-FEc \\
\hline \multirow[t]{3}{*}{ CRITERIOS } & 1 & Síntomas \pm signos $^{\mathrm{a}}$ & Síntomas \pm signos $^{\mathrm{a}}$ & Síntomas \pm signos $^{\mathrm{a}}$ \\
\hline & 2 & FEVI $<40 \%$ & FEVI $40-49 \%$ & FEVI $\geq 50 \%$ \\
\hline & 3 & - & $\begin{array}{l}\text { - Péptidos natriuréticos elevados } \\
\text { - Al menos un criterio adicional: } \\
\text { 1. Enfermedad estructural cardiaca relevante (HVI o DAi), } \\
\text { 2. Disfunción diastólica (véase la sección 4.3.2). }\end{array}$ & $\begin{array}{l}\text { - Péptidos natriuréticos elevados }{ }^{\mathrm{b}} \\
\text { - Al menos un criterio adicional: } \\
\text { 1. Enfermedad estructural cardiaca relevante (HVI o DAi), } \\
\text { 2. Disfunción diastólica (véase la sección 4.3.2). }\end{array}$ \\
\hline
\end{tabular}

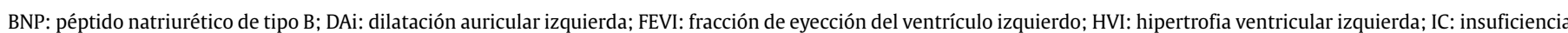

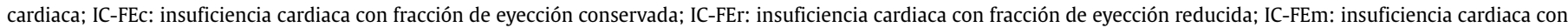
fracción de eyección en rango medio; NT-proBNP: fracción N-terminal del propéptido natriurético cerebral.

aLos signos pueden no estar presentes en las primeras fases de la IC (especialmente en la IC-FEc) y en pacientes tratados con diuréticos.

${ }^{\mathrm{b}} \mathrm{BNP}>35 \mathrm{pg} / \mathrm{ml}$ o NT-proBNP $>125 \mathrm{pg} / \mathrm{ml}$. 
que no han cambiado durante 1 mes se describe como un paciente "estable». Si la IC estable crónica se deteriora, se puede describir al paciente como "descompensado»; esto puede suceder lenta o repentinamente, suele ser necesario hospitalizar al paciente y es un acontecimiento de considerable importancia pronóstica. La IC de nueva aparición (de novo) puede presentarse aguda, por ejemplo, como consecuencia de un infarto agudo de miocardio (IAM), o subaguda, por ejemplo, en pacientes con miocardiopatía dilatada (MCD), que frecuentemente tienen síntomas durante semanas o meses antes de que se confirme el diagnóstico. Aunque los síntomas y signos de IC desaparezcan, la disfunción cardiaca subyacente puede permanecer y los pacientes seguirían en riesgo de "descompensación" recurrente.

En ocasiones, un paciente puede tener IC debido a un problema que se resuelve por completo (p. ej., miocarditis viral aguda, síndrome de tako-tsubo o taquimiocardiopatía). Otros pacientes, especialmente aquellos con MCD «idiopática», pueden presentar una recuperación sustancial o incluso completa de la función sistólica del VI con las nuevas terapias modificadoras de la enfermedad (que incluyen un inhibidor de la enzima de conversión de la angiotensina [IECA], un bloqueador beta, un antagonista del receptor de mineralocorticoides [ARM], ivabradina o TRC). IC "congestiva" es un término que todavía se emplea y puede describir la IC aguda o crónica con signos de sobrecarga de volumen. Todos o la mayoría de estos términos pueden aplicarse de manera precisa al mismo paciente en momentos distintos, dependiendo de la fase de la enfermedad.

\subsubsection{Terminología relativa a la gravedad de los síntomas de la insuficiencia cardiaca}

La clasificación funcional de la NYHA (tabla 3.2 del anexo) se ha empleado para describir la gravedad de los síntomas y la intolerancia al ejercicio. Sin embargo, la gravedad de los síntomas no se correlaciona bien con muchos de los parámetros de la función del VI; aunque hay una relación clara entre la gravedad de los síntomas y la supervivencia, los pacientes con síntomas leves pueden tener mayor riesgo de hospitalización y muerte ${ }^{8-10}$.

En ocasiones se emplea el término «IC avanzada" para describir a los pacientes con síntomas graves, descompensación recurrente y disfunción cardiaca grave ${ }^{11}$. La clasificación de la ACCF/AHA describe las fases de desarrollo de la IC según los cambios estructurales y los síntomas (tabla 3.3 del anexo) ${ }^{12}$. La clasificación Killip se puede utilizar para describir la gravedad de la enfermedad en un contexto clínico agudo después de un infarto de miocardio (véase la sección 12) ${ }^{13}$.

\subsection{Epidemiología, etiología e historia natural de la insuficiencia cardiaca}

La prevalencia de la IC depende de la definición que se use, pero se sitúa aproximadamente en el 1-2\% de la población adulta en países desarrollados, y aumenta a más del $10 \%$ entre personas de 70 o más años de edad ${ }^{14-17}$. Entre los mayores de 65 años atendidos por disnea durante el ejercicio, 1 de cada 6 tendrá IC no reconocida (fundamentalmente IC-FEc) ${ }^{18,19}$. El riesgo de IC a los 55 años es del 33\% para los varones y el $28 \%$ para las mujeres ${ }^{16}$. Los pacientes con IC-FEc varían del 22 al 73\%, dependiendo de la definición aplicada, el contexto clínico (atención primaria, consulta hospitalaria, hospital), la edad y el sexo de la población estudiada, infarto de miocardio previo y año de publicación ${ }^{17,18,20-30}$.

Los datos de tendencias temporales basados en pacientes hospitalizados indican que la incidencia de la IC puede estar disminuyendo, debido más a la IC-FEr que a la IC-FEc ${ }^{31,32}$. La IC-FEr parece tener un perfil epidemiológico y etiológico distinto que la IC-FEc. Comparados con la IC-FEr, los pacientes con IC-FEc son de más edad, más frecuentemente mujeres y más frecuentemente con antecedentes de hipertensión y fibrilación auricular (FA), mientras que una historia de infarto de miocardio es menos frecuente ${ }^{32,33}$. Las características de los pacientes con IC-FEm se encuentran entre la IC-FEr y la IC-FEc ${ }^{34}$, pero son necesarios más estudios para una mejor caracterización de este grupo de población.

La etiología de la IC es diversa y varía dentro de cada región y entre distintas regiones del mundo. No existe acuerdo sobre un sistema único de clasificación de las causas de la IC y algunas de las categorías potenciales se superponen (tabla 3.4). Numerosos pacientes presentan varias enfermedades diferentes -cardiovasculares y no cardiovasculares-, que interactúan y causan IC. La identificación de estas afecciones debe formar parte del proceso diagnóstico, ya que pueden determinar el empleo de opciones terapéuticas específicas.

Muchos pacientes con IC y miocardiopatía isquémica (MCI) tienen antecedentes de infarto de miocardio o revascularización. Sin embargo, una coronariografía normal no excluye la presencia de tejido miocárdico cicatricial (p. ej., mediante RMC) o afección de la microcirculación coronaria, como evidencia alternativa de $\mathrm{MCI}$.

En la práctica clínica sigue siendo un reto distinguir claramente entre las miocardiopatías adquiridas y las heredadas. En la mayoría de los pacientes con diagnóstico clínico de IC definitivo no se emplean sistemáticamente pruebas genéticas para confirmar el diagnóstico; sin embargo, el asesoramiento genético está recomendado para pacientes con miocardiopatía hipertrófica $(\mathrm{MCH}), \mathrm{MCD}$ «idiopática» 0 miocardiopatía arritmogénica del ventrículo derecho (MAVD) (véase la sección 5.10.1), dado que los resultados de estas pruebas pueden tener implicaciones clínicas.

En los últimos 30 años, los avances en los tratamientos y su implementación han mejorado la supervivencia y han reducido la tasa de hospitalización en pacientes con IC-FEr, aunque los resultados siguen siendo insatisfactorios. Los datos europeos más recientes (estudio piloto ESC-HF) demuestran que las tasas de mortalidad por todas las causas a los 12 meses de los pacientes hospitalizados o estables/ ambulatorios con IC son del $17 \mathrm{y}$ el $7 \%$ respectivamente, y las tasas de hospitalización a los 12 meses fueron del 44 y el 32\%35. En pacientes con IC (hospitalizados o ambulatorios), la mayoría de las muertes se deben a causas cardiovasculares, fundamentalmente muerte súbita y empeoramiento de la IC. La mortalidad por todas las causas suele ser mayor en la IC-FEr que en la IC-FEc ${ }^{35,36}$. Las hospitalizaciones se deben frecuentemente a causas no cardiovasculares, especialmente en pacientes con HF-FEc. La hospitalización por causas cardiovasculares no cambió entre los años 2000 y 2010, mientras que aumentaron las hospitalizaciones por causas no cardiovasculares ${ }^{31}$.

\subsection{Pronóstico}

La estimación del pronóstico para la morbilidad, discapacidad y muerte ayuda a los pacientes, sus familias y médicos a tomar decisiones sobre el tipo y la planificación de los tratamientos (especialmente las decisiones sobre una rápida transición a terapias avanzadas), además de la planificación de los servicios sanitarios, sociales y recursos.

Se han identificado numerosos marcadores pronósticos de muerte y hospitalización por IC (tabla 3.5 del anexo), sin embargo, su aplicación clínica es limitada y la estratificación precisa del riesgo en la IC sigue siendo un reto.

En las últimas décadas se han desarrollado escalas multivariables para el pronóstico del riesgo para distintos grupos de pacientes con IC $^{36,41}$ y algunas de ellas están disponibles en la red como aplicaciones interactivas. Las escalas de riesgo multivariables pueden ayudar a predecir la muerte de los pacientes con IC, pero no son muy útiles para la predicción de las hospitalizaciones por IC $^{37,38}$. Una revisión sistemática de 64 modelos pronósticos ${ }^{37}$ junto con un metanálisis y un estudio de regresión de 117 modelos pronósticos ${ }^{38}$ revelaron que los modelos de predicción de la mortalidad tienen una capacidad de predicción solo moderada, mientras que los modelos diseñados para predecir la variable combinada de muerte u hospitalización o solamente hospitalización tienen una capacidad de discriminación aun menor. 
Tabla 3.4

Etiologías de la insuficiencia cardiaca

Miocardio enfermo

Enfermedad cardiaca isquémica

Cicatriz miocárdica

Aturdimiento/hibernación miocárdica

Enfermedad arterial coronaria epicárdica

Microcirculación coronaria anormal

Disfunción endotelial

\begin{tabular}{|c|c|c|}
\hline \multirow[t]{4}{*}{ Daño tóxico } & Abuso de sustancias tóxicas de uso recreativo & Alcohol, cocaína, anfetaminas, esteroides anabólicos \\
\hline & Metales pesados & Cobre, hierro, plomo, cobalto \\
\hline & Medicación & $\begin{array}{l}\text { Fármacos cistostáticos (antraciclinas), fármacos inmunomoduladores (anticuerpos } \\
\text { monoclonales, interferones, como trastuzumab, cetuximab), antidepresivos, antiarrítmicos, } \\
\text { antiinflamatorios no esteroideos, anestésicos) }\end{array}$ \\
\hline & Radiación & \\
\hline \multirow[t]{2}{*}{$\begin{array}{l}\text { Daño inmunomediado e } \\
\text { inflamatorio }\end{array}$} & Relacionado con infección & $\begin{array}{l}\text { Bacteriana, por espiroquetas, fúngica, protozoica, parasítica (enfermedad de Chagas), } \\
\text { por raquitismo, viral (VIH/sida) }\end{array}$ \\
\hline & No relacionado con infección & $\begin{array}{l}\text { Miocarditis linfocítica/de células gigantes, enfermedades autoinmunitarias (enfermedad } \\
\text { de Graves, artritis reumatoide, trastornos del tejido conectivo, lupus eritematoso sistémico), } \\
\text { hipersensibilidad y miocarditis eosinofílica (Churg-Strauss) }\end{array}$ \\
\hline \multirow[t]{2}{*}{ Infiltración } & Relacionada con enfermedad maligna & Infiltraciones y metástasis directa \\
\hline & No relacionada con enfermedad maligna & $\begin{array}{l}\text { Amiloidosis, sarcoidosis, hemocromatosis (hierro), enfermedad de depósito de glucógeno } \\
\text { (enfermedad de Pompe), enfermedades de depósito lisosomal (enfermedad de Fabry) }\end{array}$ \\
\hline \multirow[t]{2}{*}{ Alteraciones metabólicas } & Hormonales & $\begin{array}{l}\text { Enfermedades de tiroides y paratiroides, acromegalia, deficiencia de GH, hipercortisolemia, } \\
\text { enfermedad de Conn, enfermedad de Addison, diabetes, síndrome metabólico, } \\
\text { feocromocitoma, enfermedades relacionadas con la gestación y el periparto }\end{array}$ \\
\hline & Nutricionales & $\begin{array}{l}\text { Deficiencias en tiaminas, carnitina-L, selenio, hierro, fosfatos, calcio, desnutrición compleja } \\
\text { (malignidad, sida, anorexia nerviosa), obesidad }\end{array}$ \\
\hline Alteraciones genéticas & Diversas formas & $\begin{array}{l}\text { MCH, MCD, VI no compactado, MAVD, miocardiopatía restrictiva (consulte literatura } \\
\text { especializada), distrofias musculares y laminopatías }\end{array}$ \\
\hline \multicolumn{3}{|c|}{ Condiciones de carga anormales } \\
\hline \multicolumn{3}{|l|}{ Hipertensión } \\
\hline \multirow{2}{*}{$\begin{array}{l}\text { Defectos estructurales } \\
\text { de válvula o miocardio }\end{array}$} & Adquiridos & Valvulopatía mitral, aórtica, tricuspídea, pulmonar \\
\hline & Congénitos & Comunicación interauricular o interventricular, otros (consulte literatura especializada) \\
\hline \multirow[t]{2}{*}{$\begin{array}{l}\text { Enfermedades pericárdicas } \\
\text { y endomiocárdicas }\end{array}$} & Pericárdicas & $\begin{array}{l}\text { Pericarditis constrictiva } \\
\text { Derrame pericárdico }\end{array}$ \\
\hline & Endomiocárdicas & SHE, FEM, fibroelastosis endomiocárdica \\
\hline Estados de gasto elevado & & Anemia grave, sepsis, tirotoxicosis, enfermedad de Paget, fístula arteriovenosa, embarazo \\
\hline Sobrecarga de volumen & & Insuficiencia renal, sobrecarga de fluidos iatrogénica \\
\hline \multicolumn{3}{|l|}{ Arritmias } \\
\hline Taquiarritmias & & Arritmias auriculares y ventriculares \\
\hline Bradiarritmias & & Disfunciones del nódulo sinusal, alteraciones de la conducción \\
\hline
\end{tabular}

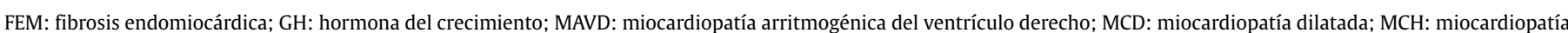
hipertrófica; SHE: síndrome hipereosinofílico; VI: ventrículo izquierdo; VIH/sida: virus de la inmunodeficiencia humana/síndrome de inmunodeficiencia adquirida.

\section{DIAGNÓSTICO}

\subsection{Síntomas y signos}

A menudo los síntomas no son específicos y, por lo tanto, no ayu-

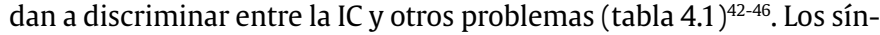

tomas y signos de IC debidos a la retención de líquidos pueden resolverse rápidamente con tratamiento diurético. Algunos signos, como la presión venosa yugular elevada y el desplazamiento del impulso apical, pueden ser más específicos, pero son más difíciles de detectar y menos reproducibles ${ }^{18,46,47}$. Los síntomas y signos pueden ser especialmente difíciles de identificar e interpretar en personas 
Tabla 4.1

Síntomas y signos típicos de insuficiencia cardiaca

\begin{tabular}{|c|c|}
\hline Síntomas & Signos \\
\hline Típicos & Más específicos \\
\hline $\begin{array}{l}\text { Disnea } \\
\text { Ortopnea } \\
\text { Disnea paroxística nocturna } \\
\text { Tolerancia al ejercicio } \\
\text { disminuida } \\
\text { Fatiga, cansancio, más tiempo } \\
\text { hasta recuperarse del ejercicio } \\
\text { Inflamación de tobillos }\end{array}$ & $\begin{array}{l}\text { Presión venosa yugular elevada } \\
\text { Reflujo hepatoyugular } \\
\text { Tercer sonido cardiaco (ritmo galopante) } \\
\text { Impulso apical desplazado lateralmente }\end{array}$ \\
\hline Menos típicos & Menos específicos \\
\hline $\begin{array}{l}\text { Tos nocturna } \\
\text { Sibilancias } \\
\text { Sensación de hinchazón } \\
\text { Pérdida de apetito } \\
\text { Confusión (especialmente } \\
\text { en ancianos) } \\
\text { Decaimiento } \\
\text { Palpitaciones } \\
\text { Mareo } \\
\text { Síncope } \\
\text { Bendopnea }^{53}\end{array}$ & $\begin{array}{l}\text { Aumento de peso (> } 2 \mathrm{~kg} / \text { semana) } \\
\text { Pérdida de peso (IC avanzada) } \\
\text { Pérdida de tejido (caquexia) } \\
\text { Soplo cardiaco } \\
\text { Edema periférico (tobillos, sacro, escroto) } \\
\text { Crepitantes pulmonares } \\
\text { Menor entrada de aire y matidez a la percusión } \\
\text { en las bases pulmonares (derrame pleural) } \\
\text { Taquicardia } \\
\text { Pulso irregular } \\
\text { Taquipnea } \\
\text { Respiración de Cheyne Stokes } \\
\text { Hepatomegalia } \\
\text { Ascitis } \\
\text { Extremidades frías } \\
\text { Oliguria } \\
\text { Presión de pulso estrecha }\end{array}$ \\
\hline
\end{tabular}

IC: insuficiencia cardiaca.

obesas, ancianas o con enfermedad pulmonar crónica ${ }^{48-50}$. Los pacientes más jóvenes con IC suelen tener etiología, presentación clínica y evolución diferentes que los de más edad ${ }^{51,52}$.

Siempre es necesario elaborar una historia clínica detallada. La IC es poco común en un sujeto sin historia clínica relevante (p. ej., una causa potencial de daño cardiaco), mientras que ciertas características, especialmente el infarto de miocardio previo, aumentan considerablemente la probabilidad de IC en un paciente con los síntomas y signos correspondientes ${ }^{42-45}$

En cada consulta hay que evaluar los síntomas y signos de IC prestando especial atención a los indicios de congestión. Los síntomas y signos son importantes para la monitorización de la respuesta del paciente al tratamiento y que esta sea estable. La persistencia de los síntomas a pesar del tratamiento suele indicar la necesidad de tratamiento adicional, y el empeoramiento de los síntomas es un acontecimiento grave (que pone al paciente en riesgo de hospitalización urgente y muerte) que requiere una pronta actuación médica.

\subsection{Pruebas iniciales básicas: péptidos natriuréticos, electrocardiograma y ecocardiografía}

La concentración plasmática de péptidos natriuréticos (PN) puede emplearse como prueba diagnóstica inicial, especialmente en un contexto no agudo cuando no se dispone inmediatamente de ecocardiografía. La elevación de PN ayuda a establecer un diagnóstico inicial de trabajo para identificar a los pacientes que requieren pruebas cardiacas adicionales; los pacientes con concentraciones inferiores al valor de corte para excluir una disfunción cardiaca importante no requieren ecocardiografía (véase también las secciones 4.3 y 12). Los pacientes con concentraciones plasmáticas de PN normales probablemente no tengan IC. El límite superior de lo normal en el contexto no agudo para péptidos natriuréticos de tipo $\mathrm{B}$ (BNP) es de $35 \mathrm{pg} / \mathrm{ml}$ y para la fracción aminoterminal del propéptido natriurético de tipo B (NT-proBNP) es de $125 \mathrm{pg} / \mathrm{ml}$; en el contexto agudo deben emplearse títulos más altos $(\mathrm{BNP}<100 \mathrm{pg} / \mathrm{ml}$, NT-proBNP $<300 \mathrm{pg} / \mathrm{ml}$ y región media del propéptido natriurético auricular de tipo A [MR-proANP] $<120 \mathrm{pmol} / \mathrm{l}$ ). Los valores diagnósticos se aplican igualmente a la IC-FEr y la IC-FEc; como media, los valores son más bajos en la IC-FEc que en la IC-FEr ${ }^{54,55}$. En los umbrales mencionados, los valores predictivos negativos son muy similares y altos $(0,94-0,98)$, tanto en agudos como en no agudos, pero los valores predictivos positivos son más bajos en no agudos $(0,44-0,57)$ y en agudos $(0,66-0,67)^{54,56-61}$. Por lo tanto, el uso de PN se recomienda para descartar la IC, pero no para establecer el diagnóstico.

La elevación de PN puede producirse por numerosas causas, cardiovasculares y no cardiovasculares, que reducen su capacidad diagnóstica en la IC. Entre ellas, la FA, la edad y la insuficiencia renal son los factores más importantes que impiden la interpretación de las determinaciones de $\mathrm{PN}^{55}$. Por otra parte, los títulos de PN pueden ser desproporcionadamente bajos en pacientes obesos (véase también la sección 12.2 y la tabla 12.3$)^{62}$.

Un electrocardiograma (ECG) anormal aumenta la probabilidad del diagnóstico de IC, pero esta prueba tiene una especificidad baja $^{18,46,63,64}$. Algunas anomalías en el ECG dan información sobre la etiología (p. ej., infarto de miocardio) y algunos hallazgos electrocardiográficos pueden proporcionar indicaciones para el tratamiento (p. ej., anticoagulación para la FA, marcapasos para la bradicardia, TRC en caso del complejo QRS) (véase las secciones 8 y 10). La IC es poco probable en pacientes con un ECG completamente normal (sensibilidad del $89 \%)^{43}$. Por lo tanto, se recomienda el uso sistemático del ECG fundamentalmente para descartar el diagnóstico de IC.

La ecocardiografía es la prueba más útil y disponible para establecer el diagnóstico en pacientes con sospecha de IC. Esta técnica proporciona información inmediata sobre el volumen de las cámaras, la función sistólica y diastólica del VI, el grosor de la pared, la función valvular y la hipertensión pulmonar ${ }^{65-74}$. Esta información es crucial para establecer el diagnóstico y determinar el tratamiento más adecuado (véase las secciones 5.2-5.4 para más información sobre ecocardiografía).

La información obtenida en la evaluación clínica detallada y con las pruebas antes mencionadas permitirá establecer un diagnóstico inicial y un plan de tratamiento para la mayoría de los pacientes. Generalmente, solo se requieren otras pruebas en caso de que el diagnóstico sea incierto (p. ej., si las imágenes ecocardiográficas no son óptimas o si se sospecha de una causa inusual para la IC) (para más información, véase las secciones 5.5-5.10).

\subsection{Algoritmo para el diagnóstico de la insuficiencia cardiaca}

\subsubsection{Algoritmo para el diagnóstico de la insuficiencia cardiaca en un contexto no agudo}

En la figura 4.1 se muestra un algoritmo para el diagnóstico de la IC en contextos no agudos. El diagnóstico de la IC en contextos agudos se trata en la sección 12 .

Para los pacientes con síntomas o signos que se presentan por primera vez en atención primaria o en consulta ambulatoria y de forma no urgente (tabla 4.1), se debe evaluar la probabilidad de IC en primer lugar con base en la historia clínica del paciente (enfermedad arterial coronaria [EAC], hipertensión arterial, uso de diuréticos), síntomas de presentación (p. ej., ortopnea), exploración física (p. ej., edema bilateral, presión venosa yugular elevada, desplazamiento de pulso apical) y ECG en reposo. Si todos estos elementos son normales, la IC es muy poco probable y es preciso considerar otros diagnósticos. Si uno de los elementos es anormal, se debe determinar la concentración plasmática de PN, si es posible, para identificar a los pacientes que requieren ecocardiografía (el ecocardiograma está indicado si el valor de PN es superior al umbral de exclusión o no se puede determinar los PN circulantes $)^{55-60,75-78}$. 


\subsubsection{Diagnóstico de la insuficiencia cardiaca con fracción de eyección conservada}

El diagnóstico de la IC-FEc sigue siendo un reto. La FEVI es normal y los signos y síntomas de la IC (tabla 4.1) suelen ser inespecíficos y no permiten diferenciar con claridad la IC de otras entidades clínicas. En esta sección se resumen las recomendaciones prácticas necesarias para el diagnóstico adecuado de esta enfermedad en la práctica clínica.

El diagnóstico de la IC-FEc, especialmente en el típico paciente mayor con comorbilidades y sin signos obvios de sobrecarga central de fluidos, es laborioso y, además, se carece de un método estándar validado. Para mejorar la especificidad del diagnóstico de IC-FEc, el diagnóstico clínico tiene que apoyarse en mediciones objetivas de disfunción cardiaca en reposo o durante el ejercicio. El diagnóstico de IC-FEc requiere las siguientes condiciones (tabla 3.1):

- Presencia de síntomas o signos de IC (tabla 4.1).

- Fracción de eyección «conservada» (definida como FEVI $\geq 50 \%$ o del 40-49\% para la IC-FEm).

- Altas concentraciones de PN (BNP > $35 \mathrm{pg} / \mathrm{ml}$ o NT-proBNP $>125 \mathrm{pg} / \mathrm{ml}$ )

- Datos objetivos de otras alteraciones cardiacas funcionales o estructurales subyacentes (más información a continuación).

- En caso de incertidumbre, podría ser necesario realizar una prueba de estrés o determinar de manera invasiva un aumento de las presiones de llenado del VI para confirmar el diagnóstico (más información a continuación).

La valoración inicial incluye el diagnóstico clínico acorde con el algoritmo presentado y la determinación de la FEVI mediante ecocardiografía. El valor de corte del 50\% para el diagnóstico de la IC-FEc es arbitrario; en estudios clínicos, se clasifica a los pacientes con FEVI entre el 40 y el $49 \%$ como con IC-FEc ${ }^{79}$. Sin embargo, en esta guía se define la IC-FEc cuando la FEVI es $\geq 50 \%$ y se considera a los pacientes con FEVI del 40 al $49 \%$ en una "zona gris» que podría denominarse IC-FEm. Los signos y síntomas clínicos son similares para la IC-FEr, la IC-FEm y la IC-FEc. Las características demográficas y las comorbilidades típicas se resumen en la tabla 4.2 del anexo. El ECG en reposo podría revelar anomalías como FA, hipertrofia del VI y alteraciones de repolarización. Un ECG normal o unas concentraciones plasmáticas de $\mathrm{BNP}<35 \mathrm{pg} / \mathrm{ml}$ o de NT-proBNP $<125 \mathrm{pg} / \mathrm{ml}$ hacen que el diagnóstico de la IC-FEc, la IC-FEm y la IC-FEr sea poco probable.

El siguiente paso consiste en realizar pruebas diagnósticas adicionales si se han observado indicios de IC-FEc/IC-FEm y demostrar objetivamente la presencia de alteraciones cardiacas estructurales o funcionales como la causa subyacente a la presentación clínica. Las alteraciones estructurales más importantes son un índice del volumen auricular izquierdo $>34 \mathrm{ml} / \mathrm{m}^{2}$ o un índice de masa del ventrículo izquierdo $\geq 115 \mathrm{~g} / \mathrm{m}^{2}$ (varones) $0 \geq 95 \mathrm{~g} / \mathrm{m}^{2}$ (mujeres) ${ }^{65,67,72}$. Las alteraciones funcionales más importantes son una $\mathrm{E} / \mathrm{e} \geq 13$ y una velocidad tisular diastólica temprana (e') media de la pared septal y late$\mathrm{ral}<9 \mathrm{~cm} / \mathrm{s}^{65,67,70,72,80-84}$. Otras mediciones derivadas indirectamente de la ecocardiografía son el strain longitudinal y la velocidad de regurgitación tricuspídea (VRT) ${ }^{72,82}$. En la tabla 4.3 del anexo se encuentran los valores normales y anormales de los parámetros ecocardiográficos relacionados con la función diastólica. No todos los valores recomendados son idénticos a los publicados en guías anteriores, debido a la inclusión de nuevos datos publicados recientemente, sobre todo por Cabarello et al. ${ }^{70}$.

Mediante ecocardiografía se puede realizar una prueba de estrés diastólico, típicamente siguiendo un protocolo con cicloergómetro en posición semisupina, que permite la evaluación del VI (E/e) y las presiones arteriales pulmonares (VRT), la disfunción sistólica (strain longitudinal) y cambios en volumen latido y gasto cardiaco durante el ejercicio $^{85,86}$. Se puede emplear distintos protocolos para la prueba de esfuerzo, de los que el cicloergómetro en posición semisupina y la ecocardiografía en reposo y ejercicio submáximo son los más usados ${ }^{85}$. También se emplea la determinación de aumentos superiores a los valores de corte de la E/e' (>13) y otras mediciones indirectas de la función sistólica y diastólica, como el strain longitudinal y la VRT. Por otro lado, mediante técnicas invasivas se puede determinar parámetros hemodinámicos en reposo para evaluar las presiones de llenado (presión de enclavamiento pulmonar $\geq 15 \mathrm{mmHg}$ o presión telediastólica ventricular izquierda $\geq 16 \mathrm{mmHg}$ ), seguido de la evaluación de estos parámetros durante el ejercicio si se observan valores inferiores a los de corte para evaluar cambios en las presiones de llenado, la presión arterial sistólica (PAS) pulmonar, el volumen latido y el gasto cardiaco $^{87}$.

El diagnóstico de la IC-FEc en pacientes con FA es difícil. Debido a que la FA se asocia a concentraciones de PN más altas, el uso de NTproBNP o BNP para el diagnóstico de la IC-FEc debería estratificarse según haya ritmo sinusal (umbrales más bajos) o FA (umbrales más altos). El índice del volumen auricular izquierdo aparece aumentado por la FA y los parámetros funcionales de disfunción diastólica están menos establecidos en la FA, y posiblemente habría que aplicar otros valores de corte. Por otra parte, la FA podría ser un signo de la presencia de IC-FEc, y los pacientes con FA e IC-FEc suelen tener las mismas características. Además, los pacientes con IC-FEc y FA podrían tener IC más avanzada, comparados con pacientes con IC-FEc y ritmo sinusal.

Los pacientes con IC-FEc forman un grupo heterogéneo que tiene etiologías subyacentes y anomalías fisiopatológicas diferentes. Con base en la sospecha de causas específicas, se puede realizar pruebas adicionales (tabla 4.4 del anexo) ${ }^{71,88-94}$. No obstante, solo se puede recomendar estas pruebas si los resultados pudieran afectar al tratamiento.

\section{IMAGEN CARDIACA Y OTRAS PRUEBAS DIAGNÓSTICAS}

Las técnicas de imagen cardiaca cumplen una función esencial para diagnosticar la IC y guiar el tratamiento. De todas las modalidades de imagen disponibles, la ecocardiografía es el método de elección en pacientes con sospecha de IC por precisión, disponibilidad (también portabilidad), seguridad y coste ${ }^{68,69,72}$. Puede complementarse con otras modalidades, elegidas según su capacidad para responder a interrogantes clínicos específicos y teniendo en cuenta las contraindicaciones y riesgos específicos de cada prueba ${ }^{71,73}$.

En general, las pruebas de imagen solo deben realizarse si tienen una consecuencia clínica importante. La fiabilidad de los resultados depende en gran medida de la modalidad de imagen, la experiencia del operador y del centro y de la calidad de la imagen. Los parámetros normales pueden variar según la edad, el sexo y la modalidad de imagen.

\subsection{Radiografía torácica}

La radiografía torácica tiene poco uso en el proceso diagnóstico de los pacientes con sospecha de IC. Probablemente es más útil para identificar una causa pulmonar alternativa para los síntomas y signos del paciente, como enfermedad pulmonar maligna o intersticial, aunque la tomografía computarizada (TC) torácica es la técnica estándar actual. Para el diagnóstico de asma o enfermedad pulmonar obstructiva crónica (EPOC), es necesario realizar una prueba de la función pulmonar con espirometría. Sin embargo, la radiografía torácica podría mostrar congestión o edema venoso pulmonar en pacientes con IC y es más útil en contextos agudos que en no agudos ${ }^{49,64}$. Es importante tener en cuenta que puede haber disfunción sistólica del VI significativa sin cardiomegalia en la radiografía torácica ${ }^{49,64}$.

\subsection{Ecocardiografía transtorácica}

El término ecocardiografía se usa en esta guía para referirse a todas las técnicas de imagen cardiaca por ultrasonidos, como la eco- 


\section{PACIENTE CON SOSPECHA DE IC}

(de presentación no aguda)

\section{EVALUACIÓN DE LA PROBABILIDAD DE IC}

\section{Historia clínica:}

Historia de EAC (IM, revascularización)

Historia de hipertensión arterial

Exposición a fármacos cardiotóxicos/radiación

Uso de diuréticos

Ortopnea/disnea paroxística nocturna

\section{Exploración física:}

Estertores

Edema bilateral de tobillo

Soplo cardiaco

Ingurgitación venosa yugular

Latido apical desplazado/ampliado lateralmente

\section{ECG:}

Cualquier anomalía

Centros en los que la determinación

de péptidos natriuréticos no es habitual en la práctica clínica

\section{Presente al menos 1}

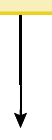

PÉPTIDOS NATRIURÉTICOS

- NT-proBNP $\geq 125 \mathrm{pg} / \mathrm{ml}$

- $B N P \geq 35 \mathrm{pg} / \mathrm{ml}$
IC improbable: considere otro diagnóstico

Si se confirma la IC (según todos los datos disponibles): determine la etiología e inicie el tratamiento adecuado

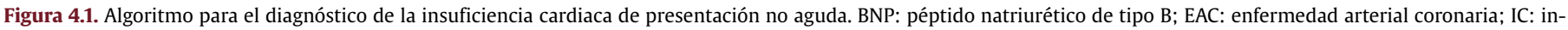
suficiencia cardiaca; IM: infarto de miocardio; NT-proBNP: fracción N-terminal del propéptido natriurético cerebral.

aPaciente que presenta síntomas típicos de IC (véase la tabla 4.1).

bVolumen y funciones ventricular y auricular normales.

'Considere otras causas para la elevación de péptidos natriuréticos (tabla 12.3). 
cardiografía bidimensional y tridimensional, el Doppler de onda continua y pulsada, el Doppler de flujo en color y las imágenes de Doppler tisular y de deformación (strain y strain rate).

La ecocardiografía transtorácica (ETT) es la técnica de elección para evaluar la función miocárdica sistólica y diastólica de los ventrículos derecho e izquierdo.

\subsubsection{Evaluación de la función sistólica ventricular izquierda}

El método recomendado para medir la FEVI es el método Simpson biplano modificado. El volumen telediastólico ventricular izquierdo y el volumen telesistólico ventricular izquierdo se obtienen con proyecciones apicales de 4 o 2 cámaras. Este método depende de un rastreo preciso del borde endocárdico. En caso de una imagen de mala calidad, se recomienda usar un medio de contraste para mejorar la delineación de los bordes endocárdicos ${ }^{72}$. La identificación de anomalías en la movilidad regional de la pared puede ser particularmente importante en pacientes con sospecha de EAC o miocarditis.

No se recomienda el uso de los métodos de Teichholz y Quiñones para calcular la FEVI a partir de dimensiones lineales, además de medir el acortamiento fraccional, porque pueden ser inexactos, especialmente en pacientes con disfunción regional o remodelado del VI. La ecocardiografía tridimensional de calidad adecuada mejora la cuantificación de los volúmenes del VI y el cálculo de la FEVI y es la técnica más precisa, comparada con la $\mathrm{RMC}^{95}$.

Las técnicas Doppler permiten calcular variables hemodinámicas, como el índice de volumen latido y el gasto cardiaco, basadas en la integral velocidad tiempo en el área del tracto de salida del VI.

En los últimos años, se ha demostrado la reproducibilidad y viabilidad en la práctica clínica de los parámetros de Doppler tisular (onda S) y las técnicas de imagen de deformación (strain y strain rate), especialmente para detectar pequeñas anomalías de la función sistólica en fases preclínicas; no obstante, las mediciones pueden variar según el fabricante y la versión del software ${ }^{74}$.

\subsubsection{Evaluación de la función diastólica ventricular izquierda}

Se considera que la disfunción diastólica del VI es la anomalía fisiopatológica subyacente en la IC-FEc, y quizá también en la IC-FEm, y por esa razón identificarla es muy importante para el diagnóstico. Aunque la ecocardiografía es actualmente la única técnica de imagen que permite el diagnóstico de disfunción diastólica, no hay ningún parámetro ecocardiográfico que por sí solo tenga suficiente precisión para diagnosticar disfunción diastólica del VI. Por lo tanto, se recomienda un examen ecocardiográfico exhaustivo que incorpore los datos de Doppler y los datos bidimensionales más relevantes (véase la sección 4.3.2).

\subsubsection{Evaluación de la función ventricular derecha y la presión arterial pulmonar}

Un elemento obligatorio del examen ecocardiográfico es la evaluación de la estructura y la función del ventrículo derecho (VD), que incluya las dimensiones del VD y de la aurícula derecha, una estimación de la función sistólica del VD y la presión arterial (PA) pulmonar. Entre los parámetros que determinan la función sistólica del VD, las siguientes mediciones tienen una importancia especial: la excursión sistólica del plano anular tricuspídeo (una TAPSE anormal < $17 \mathrm{~mm}$ indica disfunción sistólica del VD) y la velocidad sistólica del anillo tricuspídeo lateral derivada de Doppler tisular (velocidad $\mathrm{s}<9,5 \mathrm{~cm} / \mathrm{s}$ indica disfunción sistólica del VD) ${ }^{72,96}$. La PA pulmonar sistólica se deriva del registro óptimo de la velocidad máxima del chorro de regurgitación tricuspídea del gradiente sistólico tricuspídeo, junto con la estimación de la presión de la aurícula derecha según el tamaño de la vena cava inferior y su colapso relacionado con la respiración ${ }^{97}$. Hay que determinar el tamaño del VD mediante ecocardiografía bidimensional convencional, usando múltiples ventanas acústicas, y el informe debe incluir parámetros cualitativos y cuantitativos. En servicios con experiencia en ecocardiografía tridimensional, se recomienda la medición tridimensional de los volúmenes del VD, siempre que estos datos tengan importancia clínica ${ }^{95}$. La ecocardiografía tridimensional con la técnica de speckle tracking es un método cuantitativo adicional para evaluar la función del VD en centros especializados ${ }^{98}$.

\subsection{Ecocardiografía transesofágica}

La ecocardiografía transesofágica (ETE) no es necesaria en la evaluación diagnóstica habitual de la IC; sin embargo, puede ser útil en algunos contextos clínicos para pacientes con enfermedad valvular, sospecha de disección aórtica, sospecha de endocarditis o cardiopatía congénita, y para descartar la presencia de trombos intracavitarios en pacientes con FA que requieren cardioversión. Cuando el grado de enfermedad de las válvulas mitral o aórtica determinado por ETT no se corresponda con los síntomas del paciente, es preciso realizar un examen con ETE.

\subsection{Ecocardiografía de estrés}

Se puede emplear la ecocardiografía de estrés mediante ejercicio o fármacos para identificar isquemia inducible o viabilidad miocárdica ${ }^{99}$, y en algunos contextos clínicos en pacientes con enfermedad valvular (p. ej., regurgitación mitral dinámica, estenosis aórtica con flujo bajo y gradiente bajo ${ }^{99,100}$. Se ha señalado que la ecocardiografía de estrés puede detectar la disfunción diastólica durante la exposición al ejercicio de pacientes con disnea de esfuerzo, FEVI conservada y parámetros diastólicos en reposo no concluyentes ${ }^{85,86}$.

\subsection{Resonancia magnética cardiaca}

Se considera que la RMC es la técnica con mayor precisión para medir volúmenes, masa y FE de los ventrículos izquierdo y derecho. Es la mejor alternativa de imagen cardiaca para pacientes con estudios ecocardiográficos no diagnósticos (especialmente para estudiar el corazón derecho) y es el método de elección para pacientes con enfermedad cardiaca congénita compleja ${ }^{91,101,102}$.

La RMC es la técnica de imagen preferida para evaluar la fibrosis miocárdica mediante realce tardío de gadolinio y mapeo de $\mathrm{T}_{1}, \mathrm{y}$ puede ser útil para establecer la etiología de la $I^{91,103}$. Por ejemplo, la RMC con realce tardío de gadolinio permite diferenciar el origen isquémico o no isquémico de la IC y visualizar la fibrosis miocárdica o el tejido cicatricial. Además, la RMC permite caracterizar el tejido miocárdico de la miocarditis, amiloidosis, sarcoidosis, enfermedad de Chagas, miocardiopatía de Fabry y hemocromatosis ${ }^{91,101,103,104}$.

La RMC también puede emplearse para la evaluación de la isquemia miocárdica y la viabilidad en pacientes con IC y EAC (considerados aptos para revascularización coronaria). Sin embargo, los datos de ECDA no han demostrado que la viabilidad evaluada por RMC u otros medios permita identificar a los pacientes que se beneficiarían de la revascularización ${ }^{105-107}$.

Las limitaciones de la RMC son su dependencia de la experiencia del centro, la menor disponibilidad y el mayor coste que los de la ecocardiografía, las dudas sobre su seguridad para los pacientes con implantes metálicos (incluidos dispositivos cardiacos) y unas determinaciones menos fiables en pacientes con taquiarritmias. La claustrofobia es otra limitación importante de la RMC. Los medios de contraste basados en gadolinio lineal están contraindicados para individuos con tasa de filtrado glomerular (TFG) $<30 \mathrm{ml} / \mathrm{min} / 1,73 \mathrm{~m}^{2}$ porque pueden desencadenar fibrosis sistémica nefrogénica (esto es menos preocupante con los nuevos contrastes basados en gadolinio (íclico $)^{108}$. 
Recomendaciones para las pruebas de imagen cardiaca en pacientes con insuficiencia cardiaca sospechada o confirmada

\begin{tabular}{|c|c|c|c|}
\hline Recomendaciones & Clase $^{\mathrm{a}}$ & Nivel $^{\mathrm{b}}$ & $\operatorname{Ref}^{c}$ \\
\hline $\begin{array}{l}\text { Se recomienda la ETT para la evaluación de la estructura y la función miocárdica en sujetos con sospecha de IC para establecer el diagnóstico } \\
\text { de IC-FEr, IC-FEm o IC-FEc }\end{array}$ & I & C & \\
\hline $\begin{array}{l}\text { Se recomienda la ETT para evaluar la FEVI e identificar a los pacientes con IC candidatos a tratamiento farmacológico y con dispositivos (DAI, } \\
\text { TRC), basados en la evidencia y recomendados para la IC-FEr }\end{array}$ & I & C & \\
\hline $\begin{array}{l}\text { Se recomienda la ETT para la evaluación de valvulopatías, función ventricular derecha y presión arterial pulmonar en pacientes con diagnóstico } \\
\text { establecido de IC-FEr, IC-FEm o IC-FEc e identificar a los pacientes candidatos a tratamiento corrector de la valvulopatía }\end{array}$ & I & $\mathrm{C}$ & \\
\hline $\begin{array}{l}\text { Se recomienda la ETT para la evaluación de la estructura y la función miocárdicas de sujetos que van a exponerse a un tratamiento que podría } \\
\text { dañar el miocardio (p. ej., quimioterapia) }\end{array}$ & I & $C$ & \\
\hline $\begin{array}{l}\text { Se considerarán otras técnicas (incluido el Doppler tisular con medición de velocidades sistólicas e índices de deformación como strain y strain } \\
\text { rate) en los protocolos de ETT para pacientes con riesgo de IC para identificar la disfunción miocárdica en una fase preclínica }\end{array}$ & Ila & C & \\
\hline $\begin{array}{l}\text { Se recomienda la RMC para la evaluación de la estructura y la función miocárdicas (incluido el corazón derecho) de pacientes con una ventana } \\
\text { acústica inadecuada o con enfermedad cardiaca congénita compleja (teniendo en cuenta las precauciones y las contraindicaciones de la RMC) }\end{array}$ & I & $\mathrm{C}$ & \\
\hline $\begin{array}{l}\text { Se considerará la RMC con RTG para pacientes con miocardiopatía dilatada para diferenciar el daño isquémico y no isquémico en caso } \\
\text { de ambigüedad en los datos clínicos y las pruebas de imagen (teniendo en cuenta las precauciones y las contraindicaciones de la RMC) }\end{array}$ & Ila & C & \\
\hline $\begin{array}{l}\text { Se recomienda la RMC para la caracterización del tejido miocárdico en caso de sospecha de miocarditis, amiloidosis, sarcoidosis, enfermedad } \\
\text { de Chagas, enfermedad de Fabry, miocardiopatía no compactada y hematocromatosis (teniendo en cuenta las precauciones y las } \\
\text { contraindicaciones de la RMC) }\end{array}$ & I & C & \\
\hline $\begin{array}{l}\text { Se considerarán las técnicas no invasivas de imagen con estrés (RMC, ecocardiografía de estrés, SPECT, PET) para la evaluación de la isquemia } \\
\text { y la viabilidad miocárdica de los pacientes con IC y EAC (considerados candidatos para revascularización) antes de tomar una decisión sobre la } \\
\text { revascularización }\end{array}$ & IIb & B & $116-118$ \\
\hline $\begin{array}{l}\text { Se recomienda la coronariografía invasiva para pacientes con IC y angina de pecho refractaria a tratamiento farmacológico o arritmias } \\
\text { ventriculares sintomáticas o parada cardiaca abortada (considerados candidatos a una posible revascularización coronaria) para establecer el } \\
\text { diagnóstico de EAC y su gravedad }\end{array}$ & I & C & \\
\hline $\begin{array}{l}\text { Se debe considerar la coronariografía invasiva para pacientes con IC, probabilidad pretest intermedia-alta de EAC e isquemia en pruebas no } \\
\text { invasivas (considerados candidatos a una posible revascularización coronaria) para establecer el diagnóstico de EAC y su gravedad }\end{array}$ & Ila & C & \\
\hline $\begin{array}{l}\text { Se puede considerar la TC cardiaca para pacientes con IC y probabilidad pretest baja-intermedia de EAC o con resultados ambiguos en pruebas } \\
\text { de estrés no invasivas para descartar la presencia de estenosis arterial coronaria }\end{array}$ & IIb & $\mathrm{C}$ & \\
\hline $\begin{array}{l}\text { Se recomienda la revaluación de la estructura y la función cardiacas mediante técnicas de imagen no invasivas para: } \\
\text { - Pacientes que presentan un empeoramiento de los síntomas de IC (incluidos episodios de ICA) u otras complicaciones cardiovasculares } \\
\text { importantes. } \\
\text { - Pacientes con IC que han recibido tratamiento farmacológico basado en la evidencia con las dosis máximas toleradas, antes de tomar la } \\
\text { decisión de implantar un dispositivo (DAI, TRC). } \\
\text { - Pacientes expuestos a terapias que pueden dañar el miocardio (como quimioterapia) (pruebas seriadas) }\end{array}$ & I & $\mathrm{C}$ & \\
\hline
\end{tabular}

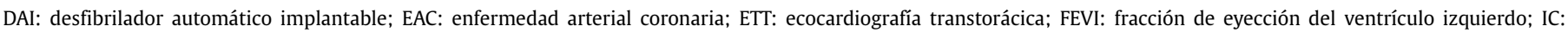

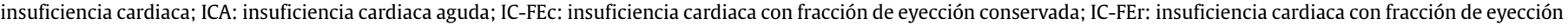

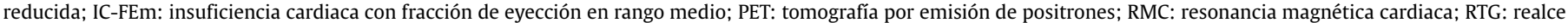
tardío de gadolinio; SPECT: tomografía por emisión monofotónica; TC: tomografía computarizada; TRC: terapia de resincronización cardiaca.

aClase de recomendación.

'Nivel de evidencia.

cReferencias que respaldan las recomendaciones.

\subsection{Tomografía computarizada por emisión de fotón único y ventriculografía con radionucleótidos}

La tomografía computarizada por emisión monofotónica (SPECT) puede ser útil para la valoración de la isquemia y la viabilidad miocárdica ${ }^{109}$. La SPECT pulsada puede ofrecer información sobre los volúmenes y la función ventricular, pero expone al paciente a radiación isotópica. La gammagrafía con ácido propano 1,2 dicarboxínico 3,3 difosfono (DPD) puede ser útil para la detección de la amiloidosis cardiaca por transtiretina ${ }^{110}$.

\subsection{Tomografía por emisión de positrones}

La tomografía por emisión de positrones (PET), sola o combinada con TC, puede ser útil para valorar la isquemia y la viabilidad, pero los trazadores de flujo (amoniaco marcado con ${ }^{13} \mathrm{~N}$ o agua marcada con ${ }^{15} \mathrm{O}$ ) requieren el uso de un ciclotrón ${ }^{92,111}$. El rubidio es un trazador alterna- tivo para las pruebas de isquemia con PET, que pueden realizarse en el centro a un coste relativamente bajo. Las limitaciones de esta técnica son la escasa disponibilidad, la exposición a la radiación y los costes.

\subsection{Angiografía coronaria}

Las indicaciones de la angiografía coronaria para pacientes con IC son las mismas que las recomendadas en otras guías de la ESC ${ }^{112-114}$. La angiografía coronaria está recomendada para pacientes con IC que sufren angina de pecho refractaria a tratamiento médico ${ }^{115}$, siempre que el paciente sea candidato a revascularización coronaria. La angiografía coronaria también se recomienda para pacientes con historia de arritmia ventricular sintomática o parada cardiaca abortada. La angiografía coronaria se debe considerar para pacientes con IC y una probabilidad pretest intermedia-alta de EAC y la presencia de isquemia en una prueba de estrés no invasiva para establecer la etiología de la isquemia y la gravedad de la EAC. 


\subsection{Tomografía computarizada cardiaca}

El uso principal de la TC en pacientes con IC es la visualización no invasiva de la anatomía coronaria de los pacientes con IC y una probabilidad pretest baja-intermedia de EAC o pacientes con resultados ambiguos en la prueba de estrés no invasiva para excluir el diagnóstico de EAC, siempre que no haya contraindicaciones relativas. No obstante, esta prueba solo se debe realizar cuando su resultado pueda afectar a las decisiones terapéuticas.

Las indicaciones clínicas más importantes para el uso de algunas técnicas de imagen en pacientes con IC sospechada o confirmada se encuentran en la tabla de recomendaciones.

\subsection{Otras pruebas diagnósticas}

La evaluación de pacientes con IC, además de la historia médica, la exploración física y las adecuadas técnicas de imagen, incluye una serie de pruebas adicionales, entre las que se incluyen variables de laboratorio, ECG, radiografía torácica, prueba de esfuerzo, valoración hemodinámica invasiva y biopsia endomiocárdica. Las indicaciones más importantes se resumen en la tabla de recomen- daciones sobre las pruebas diagnósticas para pacientes con IC. Aunque se han investigado ampliamente los biomarcadores en IC (p. ej., ST2, galectina 3, copeptina, adrenomedulina), no se dispone de suficiente evidencia para recomendar este tipo de pruebas en la práctica clínica.

\subsubsection{Pruebas genéticas en la insuficiencia cardiaca}

Se recomienda el análisis genético molecular de pacientes con miocardiopatía cuando la prevalencia de mutaciones detectables sea lo suficientemente alta y justifique el cribado genético sistemático. Las recomendaciones sobre pruebas genéticas para pacientes con IC se basan en una declaración de consenso del Grupo de Trabajo de la ESC sobre enfermedades miocárdicas y periféricas ${ }^{94}$. Para la mayoría de los pacientes con diagnóstico clínico de IC definitivo, las pruebas genéticas sistemáticas no tienen un papel confirmatorio para establecer el diagnóstico. Se recomienda el asesoramiento genético para pacientes con MCH, MCD idiopática y MAVD. La miocardiopatía restrictiva y las miocardiopatías aisladas no compactadas pueden tener origen genético, por lo que se debe considerar el diagnóstico genético.

Recomendaciones sobre pruebas diagnósticas para pacientes con insuficiencia cardiaca

\begin{tabular}{|c|c|c|c|}
\hline Recomendaciones & Clase $^{\mathrm{a}}$ & Nivel $^{\mathrm{b}}$ & $\operatorname{Ref}^{\mathrm{c}}$ \\
\hline \multicolumn{4}{|l|}{$\begin{array}{l}\text { Se recomienda o se debe considerar las siguientes pruebas diagnósticas en la evaluación inicial del paciente con IC de nuevo diagnóstico para } \\
\text { determinar si requiere tratamientos específicos y detectar causas reversibles o tratables de la IC y las comorbilidades que interfieren con esta: } \\
\text { - Hemoglobina y recuento leucocitario }\end{array}$} \\
\hline - Sodio, potasio, urea, creatinina (con TFGe) & I & $\mathrm{C}$ & \\
\hline - Función hepática (bilirrubina, AST, ALT, GGTP) & & & \\
\hline $\begin{array}{l}\text { - Glucosa, } \mathrm{HbA}_{1 \mathrm{c}} \\
\text { - Perfil lipídico }\end{array}$ & & & \\
\hline$-\mathrm{TSH}$ & & & \\
\hline - Ferritina, $\mathrm{TSAT}=\mathrm{TIBC}$ & & & \\
\hline - Péptidos natriuréticos & IIa & $\mathrm{C}$ & \\
\hline $\begin{array}{l}\text { Se debe considerar otras pruebas diagnósticas adicionales para identificar otras etiologías de la IC y comorbilidades en pacientes individuales } \\
\text { con IC cuando haya sospecha clínica de alguna etiología concreta (véase la tabla } 3.4 \text { sobre las etiologías de la IC) }\end{array}$ & Ila & $\mathrm{C}$ & \\
\hline $\begin{array}{l}\text { Se recomienda el ECG de } 12 \text { derivaciones de todo paciente con IC para determinar el ritmo cardiaco, la frecuencia cardiaca y la morfología y la } \\
\text { duración del QRS y detectar otras anomalías importantes. Esta información es necesaria para planificar y monitorizar el tratamiento }\end{array}$ & I & $\mathrm{C}$ & \\
\hline \multicolumn{4}{|l|}{ Prueba de esfuerzo en pacientes con IC: } \\
\hline $\begin{array}{l}\text { - Se recomienda como parte de la evaluación para trasplante cardiaco y para asistencia mecánica circulatoria (prueba de esfuerzo } \\
\text { cardiopulmonar) }\end{array}$ & I & C & 119,120 \\
\hline - Se debe considerar para optimizar la prescripción de entrenamiento físico (preferiblemente una prueba de esfuerzo cardiopulmonar) & Ila & $\mathrm{C}$ & \\
\hline - Se debe considerar para identificar la causa de la disnea no explicada & Ila & $\mathrm{C}$ & \\
\hline - Se puede considerar para detectar isquemia miocárdica reversible & IIb & $\mathrm{C}$ & \\
\hline $\begin{array}{l}\text { Se recomienda la radiografía de tórax para pacientes con IC para detectar/descartar enfermedades pulmonares u otras que puedan contribuir } \\
\text { a la disnea. También permite detectar congestión/edema pulmonar y es más útil en pacientes con sospecha de IC en un contexto agudo }\end{array}$ & I & $\mathrm{C}$ & \\
\hline \multicolumn{4}{|l|}{ Cateterismo de corazón derecho con catéter arterial pulmonar: } \\
\hline - Se recomienda para pacientes con IC grave evaluados para trasplante cardiaco o asistencia mecánica circulatoria & I & C & \\
\hline $\begin{array}{l}\text { - Se debe considerar para pacientes con hipertensión pulmonar probable diagnosticada mediante ecocardiografía, a efectos de confirmar su } \\
\text { presencia y su reversibilidad antes de la corrección de la enfermedad cardiaca estructural o valvular }\end{array}$ & IIa & C & \\
\hline $\begin{array}{l}\text { - Se puede considerar para ajustar el tratamiento de pacientes con IC que siguen muy sintomáticos a pesar del tratamiento estándar inicial } \\
\text { y cuyo estado hemodinámico sea incierto }\end{array}$ & IIb & C & \\
\hline $\begin{array}{l}\text { Se debe considerar la BEM para pacientes con IC de progresión rápida a pesar del tratamiento estándar inicial cuando sea probable un } \\
\text { diagnóstico específico que solo se puede confirmar mediante muestras miocárdicas y se dispone de un tratamiento específico y efectivo }\end{array}$ & IIa & C & 93 \\
\hline $\begin{array}{l}\text { Se puede considerar el uso de ultrasonidos torácicos para confirmar la presencia de congestión pulmonar y derrame pleural en pacientes } \\
\text { con ICA }\end{array}$ & IIb & C & 121 \\
\hline $\begin{array}{l}\text { Se puede considerar la medición por ultrasonidos del diámetro de la vena cava inferior para la evaluación del estado volémico de pacientes } \\
\text { con IC }\end{array}$ & IIb & C & \\
\hline
\end{tabular}

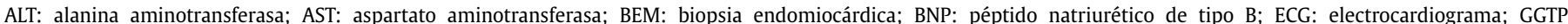

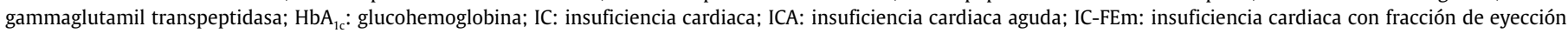

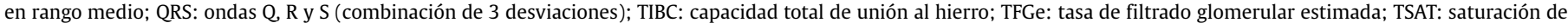
transferrina; TSH: tirotropina.

aClase de recomendación.

bNivel de evidencia.

'Referencias que respaldan las recomendaciones. 
La MCH se hereda fundamentalmente como una enfermedad autosómica dominante con expresión variable y penetración relacionada con la edad. Actualmente se han identificado más de 20 genes y 1.400 mutaciones, que en su mayoría se localizan en genes sarcómeros que codifican la cadena pesada de betamiosina cardiaca (MYH7) y la proteína $\mathrm{C}$ fijadora de miosina (MYBPC3) ${ }^{88,122}$.

La MCD es idiopática en el 50\% de los casos, y una tercera parte de ellos es hereditaria. Se han identificado más de 50 genes asociados a la MCD. Muchos genes están relacionados con el citoesqueleto. Los más frecuentes son la titina (TTN), la lamina (LMNA) y la desmina $(D E S)^{88,123}$.

La MAVD es hereditaria en la mayoría de los casos y está causada por mutaciones genéticas que codifican elementos de la desmosoma. Las mutaciones genéticas desmosómicas explican el 50\% de los casos y 10 genes están asociados actualmente con esta enfermedad ${ }^{124}$.

El asesoramiento genético debe ser realizado por un profesional con un adecuado conocimiento de las implicaciones psicológicas, sociales y médicas que se asocian al diagnóstico. La determinación del genotipo es importante, ya que algunas formas (p. ej., mutaciones del LMNA y el fosfolamban (PLN)] se asocian a peor pronóstico. El análisis de ADN también puede ser de utilidad para establecer el diagnóstico de formas raras, como las miocardiopatías mitocondriales. Se recomienda el cribado de familiares de primer grado para la detección precoz de la enfermedad desde el inicio de la adolescencia en adelante, aunque también se puede considerar antes dependiendo de la edad en que se manifiesta la enfermedad en otros miembros de la familia.

Recientemente se ha propuesto la clasificación MOGE(S) de las miocardiopatías hereditarias, que incluye el fenotipo morfofuncional $(\mathrm{M})$, la afección orgánica $(\mathrm{O})$, el patrón de herencia genética $(\mathrm{G})$, la etiología (E), incluido el defecto genético o la enfermedad/sustrato subyacente, y la clase funcional (S) de la enfermedad ${ }^{125}$.

\section{PREVENIR O RETRASAR LA APARICIÓN DE INSUFICIENCIA CARDIACA MANIFIESTA O PREVENIR LA MUERTE ANTES DE QUE APAREZCAN LOS SÍNTOMAS}

Existe un número considerable de pruebas de que la aparición de la IC se puede retrasar o prevenir mediante intervenciones destinadas a modificar los factores de riesgo de IC o el tratamiento de la disfunción sistólica del VI (tabla de recomendaciones). Muchos estudios han demostrado que el control de la hipertensión retrasa la manifestación de la IC y algunos de ellos incluso muestran que puede prolongar la vida $^{126-129}$. Se ha demostrado que algunas clases de fármacos antihipertensivos (diuréticos, IECA, antagonistas del receptor de la angiotensina II [ARA-II], bloqueadores beta) son efectivos en pacientes con o sin historia de infarto de miocardio, especialmente los ancianos ${ }^{126-128}$. En cuanto al debate sobre los objetivos óptimos de PA para sujetos hipertensos no diabéticos, el reciente estudio SPRINT ha demostrado que tratar la hipertensión con un objetivo más bajo (PAS $<120 \mathrm{mmHg}$ frente a $<140 \mathrm{mmHg}$ ) de pacientes hipertensos de edad $\geq 75$ años o hipertensos de alto riesgo reduce el riesgo de enfermedad cardiovascular, muerte y hospitalización por IC ${ }^{129}$.

Recientemente se ha demostrado que la empaglifozina (un inhibidor del cotransportador de sodio-glucosa de tipo 2) mejora los resultados (como reducción de la mortalidad y las hospitalizaciones por IC) en pacientes con diabetes mellitus tipo $2^{130}$. Otros fármacos hipoglucemiantes no han mostrado de modo convincente su capacidad para reducir el riesgo de complicaciones cardiovasculares e incluso pueden incrementar el riesgo de IC. La intensificación del tratamiento hipoglucemiante para la reducción de los títulos de glucohemoglobina $\left(\mathrm{HbA}_{1 \mathrm{c}}\right)$ con otros fármacos diferentes de empaglifozina no reduce el riesgo de IC (para más información, consulte la sección 11.6 sobre diabetes mellitus).

Aunque no se ha demostrado que dejar de fumar disminuya el riesgo de IC, su asociación epidemiológica con la aparición de enfer- medades cardiovasculares ${ }^{131}$ indica que esa medida, si se sigue, puede ser beneficiosa.

La asociación entre la ingesta de alcohol y el riesgo de aparición de IC de novo tiene forma de $\mathrm{U}$, con el menor riesgo asociado al consumo moderado de alcohol (hasta 7 bebidas por semana) ${ }^{132-134}$. El mayor consumo de alcohol puede desencadenar miocardiopatía tóxica, y en caso de que la haya, se recomienda la abstención absoluta de alcohol.

Se ha observado una relación inversa entre la actividad física y el riesgo de IC. Un reciente metanálisis encontró que son necesarias mayores dosis de actividad física que las mínimas recomendadas en las guías para obtener reducciones sustanciales del riesgo de IC $^{135}$.

Se ha demostrado que en individuos de 40 o más años con factores de riesgo o enfermedad cardiovascular (pero sin disfunción asintomática del VI ni IC manifiesta), la atención guiada por la concentración de BNP, colaborativa entre el médico de atención primaria y el servicio de cardiología, puede reducir las tasas combinadas de disfunción sistólica del VI e IC manifiesta ${ }^{136}$.

Las estatinas reducen la tasa de complicaciones cardiovasculares y la mortalidad; asimismo hay pruebas razonables de que pueden prevenir o retrasar la aparición de $\mathrm{IC}^{137-140}$. No se ha demostrado que el ácido acetilsalicílico (AAS) u otros fármacos antiagregantes y la revascularización reduzcan el riesgo de IC o de muerte de los pacientes con EAC estable. La obesidad es un factor de riesgo de $\mathrm{IC}^{141}$, pero se desconoce el impacto de los tratamientos para la obesidad en la aparición de IC.

En pacientes con EAC, sin disfunción sistólica del VI o IC, los IECA previenen o retrasan la aparición de IC y reducen la mortalidad cardiovascular y por todas las causas, aunque su beneficio puede ser pequeño en un contexto contemporáneo, especialmente en pacientes que toman $\mathrm{AAS}^{142}$. El aumento a dosis máximas toleradas de antagonistas del sistema renina-angiotensina puede mejorar la evolución, incluida la IC, de los pacientes con concentraciones plasmáticas de NP aumentadas ${ }^{136,143}$.

Una intervención coronaria percutánea (ICP) primaria en la fase más temprana del infarto de miocardio con elevación del segmento ST (IAMCEST) para reducir el tamaño del infarto disminuye el riesgo de reducción de la FEVI y la ulterior aparición de IC-FEr ${ }^{112}$. La instauración de tratamiento con un IECA, un bloqueador beta y un ARM tras el infarto de miocardio, especialmente cuando se asocia con disfunción sistólica del VI, reduce la tasa de hospitalizaciones por IC y la mortalidad $^{144-148}$, al igual que las estatinas ${ }^{137-139}$.

Para pacientes asintomáticos con FEVI crónicamente reducida, independientemente de su etiología, un IECA puede reducir el riesgo de IC que requiere hospitalización ${ }^{5,144,145}$. Este beneficio no se ha demostrado con los bloqueadores beta o los ARM.

Para los pacientes con disfunción sistólica del VI asintomática (FEVI < 30\%) de origen isquémico tras al menos 40 días desde el infarto de miocardio, se recomienda implantar un desfibrilador automático implantable (DAI) para prolongar la vida ${ }^{149}$.

\section{TRATAMIENTO FARMACOLÓGICO DE LA INSUFICIENCIA CARDIACA CON FRACCIÓN DE EYECCIÓN REDUCIDA}

\subsection{Objetivos del tratamiento de la insuficiencia cardiaca}

Los objetivos del tratamiento para los pacientes con IC son mejorar el estado clínico, la capacidad funcional y la calidad de vida, prevenir las hospitalizaciones y reducir la mortalidad. El hecho de que varios fármacos para la IC hayan mostrado efectos perjudiciales a largo plazo, aunque también beneficios a corto plazo en marcadores indirectos, ha llevado a las autoridades competentes y las guías de práctica clínica a recabar datos sobre la mortalidad/morbilidad para aprobar/recomendar intervenciones terapéuticas para la IC. Sin embargo, actualmente se reconoce que la prevención de las hospitalizaciones por IC y la mejora de la capacidad funcional son beneficios importantes que tener en cuenta, siempre que se descarte un exceso de mortalidad ${ }^{159-161}$. 
Recomendaciones para prevenir o retrasar la aparición de insuficiencia cardiaca manifiesta o retrasar la muerte antes de la aparición de los síntomas

\begin{tabular}{|c|c|c|c|}
\hline Recomendaciones & Clase $^{\mathrm{a}}$ & Nivel $^{\mathrm{b}}$ & $\operatorname{Ref}^{\mathrm{c}}$ \\
\hline Se recomienda tratar la hipertensión para prevenir o retrasar la aparición de la IC y prolongar la vida & I & A & $\begin{array}{l}126,129, \\
150,151\end{array}$ \\
\hline $\begin{array}{l}\text { Se recomienda el tratamiento con estatinas para pacientes con alto riesgo o EAC confirmada, en presencia o ausencia de disfunción sistólica } \\
\text { del VI, a efectos de prevenir o retrasar la aparición de la IC y prolongar la vida }\end{array}$ & I & A & $\begin{array}{l}137-140, \\
152\end{array}$ \\
\hline $\begin{array}{l}\text { Se recomienda el asesoramiento y el tratamiento para dejar de fumar y reducir el consumo de alcohol de fumadores y personas que } \\
\text { consumen alcohol en exceso, a efectos de prevenir o retrasar la aparición de la IC y prolongar la vida }\end{array}$ & I & $\mathrm{C}$ & $131-134$ \\
\hline Se debe considerar el tratamiento de otros factores de riesgo (como obesidad, disglucemia) para prevenir o retrasar la aparición de la IC & Ila & $\mathrm{C}$ & $\begin{array}{l}130,141, \\
153-155\end{array}$ \\
\hline $\begin{array}{l}\text { Se debe considerar el tratamiento con empagliflozina para pacientes con diabetes de tipo } 2 \text { para prevenir o retrasar la aparición de la IC } \\
\text { y prolongar la vida }\end{array}$ & IIa & B & 130 \\
\hline $\begin{array}{l}\text { Se recomienda el tratamiento con IECA para pacientes con disfunción sistólica del VI asintomática e historia de infarto de miocardio } \\
\text { para prevenir o retrasar la aparición de la IC y prolongar la vida }\end{array}$ & I & A & $\begin{array}{c}5,144, \\
145\end{array}$ \\
\hline $\begin{array}{l}\text { Se recomienda el tratamiento con IECA para pacientes con disfunción sistólica del VI asintomática sin historia de infarto de miocardio } \\
\text { para prevenir o retrasar la aparición de la IC y prolongar la vida }\end{array}$ & I & B & 5 \\
\hline $\begin{array}{l}\text { Se debe considerar el tratamiento con IECA para pacientes con EAC estable aunque no tengan disfunción sistólica del VI para prevenir } \\
\text { o retrasar la aparición de la IC }\end{array}$ & IIa & A & 142 \\
\hline $\begin{array}{l}\text { Se recomiendan los bloqueadores beta para pacientes con disfunción sistólica del VI asintomática e historia de infarto de miocardio } \\
\text { para prevenir o retrasar la aparición de la IC y prolongar la vida }\end{array}$ & I & B & 146 \\
\hline $\begin{array}{l}\text { Se recomienda implantar DAI para prevenir la muerte súbita y prolongar la vida de los pacientes: } \\
\text { 1. Con disfunción sistólica del VI asintomática (FEVI } \leq 30 \% \text { ) de origen isquémico, tras un mínimo de } 40 \text { días desde el infarto agudo } \\
\text { de miocardio } \\
\text { 2. Con miocardiopatía dilatada asintomática de origen no isquémico (FEVI } \leq 30 \% \text { ) que reciben TMO }\end{array}$ & I & B & $\begin{array}{c}149, \\
156-158\end{array}$ \\
\hline
\end{tabular}

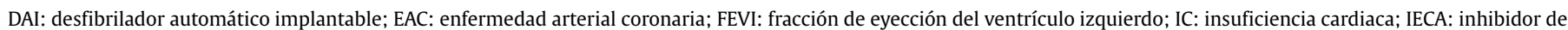
la enzima de conversión de la angiotensina; TMO: tratamiento médico óptimo; VI: ventrículo izquierdo.

aClase de recomendación.

${ }^{\mathrm{b}}$ Nivel de evidencia.

'Referencias que respaldan las recomendaciones.

La figura 7.1 muestra una estrategia de tratamiento para el uso de fármacos (y dispositivos) en pacientes con IC-FEr. Las recomendaciones para cada tratamiento se resumen a continuación.

Se ha demostrado que los antagonistas neurohormonales (IECA, ARM y bloqueadores beta) mejoran la supervivencia de los pacientes con IC-FEr y se recomienda tratar a todo paciente con IC-FEr, salvo contraindicaciones o intolerancia. Un nuevo compuesto (LCZ696) que combina un ARA-II (valsartán) y un inhibidor de la neprilisina (sacubitrilo) recientemente se ha demostrado superior a un IECA (enalapril) para la reducción del riesgo de muerte y hospitalización por IC en un solo estudio con estrictos criterios de inclusión y exclusión ${ }^{162}$. Por lo tanto, se recomienda el sacubitrilo-valsartán para sustituir a los IECA en pacientes ambulatorios con IC-FEr que siguen sintomáticos pese a recibir el tratamiento médico óptimo (TMO) y que cumplen los criterios de dicho estudio. No se ha demostrado de manera concluyente que los ARA-II reduzcan la mortalidad de los pacientes con ICFEr, y su uso debe reservarse para pacientes con intolerancia a los IECA o que tomen un IECA pero no toleren un ARM. La ivabradina reduce la frecuencia cardiaca alta que a menudo se da en la IC-FEr, y se ha demostrado que mejora los resultados, por lo que se debe considerar cuando proceda.

La medicación descrita debe emplearse combinada con diuréticos en pacientes con síntomas o signos de congestión. El uso de diuréticos debe modularse según el estado clínico del paciente.

Las pruebas clave que respaldan las recomendaciones de esta sección se encuentran en la tabla $7.1 \mathrm{del}$ anexo. Las dosis recomendadas de estos fármacos modificadores de la enfermedad se encuentran en la tabla 7.2. Las recomendaciones de las secciones 7.5 y 7.6 incluyen los fármacos que hay que evitar o emplear con precaución en pacientes con IC-FEr.

\subsection{Tratamientos recomendados para todos los pacientes sintomáticos con insuficiencia cardiaca y fracción de eyección reducida}

\subsubsection{Inhibidores de la enzima de conversión de la angiotensina}

Se ha demostrado que los IECA reducen la morbimortalidad de los pacientes con IC-FEr ${ }^{2,5,163-165}$ y están recomendados para pacientes sintomáticos siempre que no haya contraindicaciones o intolerancia. La dosis de IECA debe aumentarse hasta alcanzar la dosis máxima tolerada al objeto de conseguir una adecuada inhibición del sistema renina-angiotensina-aldosterona (SRAA). Existen pruebas de que en la práctica clínica la mayoría de los pacientes reciben dosis de IECA subóptimas ${ }^{166}$. Los IECA también están recomendados para pacientes con disfunción sistólica del VI asintomática, para reducir el riesgo de IC, hospitalizaciones por IC y muerte (véase la sección 6).

La guía práctica para el uso de IECA se encuentra en la tabla 7.4 del anexo.

\subsubsection{Bloqueadores beta}

Los bloqueadores beta reducen la morbimortalidad de los pacientes con IC-FEr asintomáticos pese al tratamiento con IECA y, en la mayoría de los casos, un diurético ${ }^{167,168,170,172,173}$, pero no se han probado en pacientes congestionados o descompensados. Hay consenso en cuanto a que los bloqueadores beta y los IECA son complementarios y se pueden instaurar al mismo tiempo cuando se confirma el diagnóstico de IC-FEr. No existen pruebas que apoyen la instauración de tratamiento con bloqueadores beta antes de iniciarse el tratamiento con IECA $^{176}$. El tratamiento con bloqueadores beta debe instaurarse en 
Tratamientos farmacológicos indicados para pacientes con insuficiencia cardiaca (NYHA II-IV) con fracción de eyección reducida

\begin{tabular}{|c|c|c|c|}
\hline Recomendaciones & Clase $^{\mathrm{a}}$ & Nivel $^{\mathrm{b}}$ & $\operatorname{Ref}^{c}$ \\
\hline $\begin{array}{l}\text { Se recomienda un IECA combinado con un } \\
\text { bloqueador beta para pacientes sintomáticos } \\
\text { con IC-FEr para reducir el riesgo de hospitalización } \\
\text { por IC y muerte }\end{array}$ & I & A & $\begin{array}{c}2, \\
163-165\end{array}$ \\
\hline $\begin{array}{l}\text { Se recomienda un bloqueador beta combinado } \\
\text { con un IECA }{ }^{d} \text { para pacientes con IC-FEr sintomática } \\
\text { estable para reducir el riesgo de hospitalización } \\
\text { por IC y muerte }\end{array}$ & I & A & $167-173$ \\
\hline $\begin{array}{l}\text { Se recomienda administrar un ARM a los pacientes } \\
\text { con IC-FEr que permanecen sintomáticos a pesar } \\
\text { del tratamiento con un IECA } \mathrm{y} \text { un bloqueador beta } \\
\text { para reducir el riesgo de hospitalización por IC } \\
\text { y muerte }\end{array}$ & I & A & 174,175 \\
\hline
\end{tabular}

ARM: antagonista del receptor de mineralcortidoides; IC: insuficiencia cardiaca; IC-FEr: insuficiencia cardiaca con fracción de eyección reducida; IECA: inhibidor de la enzima de conversión de la angiotensina; NYHA: clase funcional de la New York Heart Association.

aClase de recomendación.

Nivel de evidencia.

'Referencias que respaldan las recomendaciones.

dO un antagonista del receptor de la angiotensina II si no se tolera el IECA o está contraindicado.

pacientes clínicamente estables a dosis bajas; después se aumenta gradualmente hasta alcanzar la dosis máxima tolerada. Para los pacientes ingresados por IC aguda (ICA), la administración de bloqueadores beta se inicia con precaución una vez estabilizado el paciente.

Un metanálisis de datos individuales de pacientes incluidos en los estudios más importantes sobre bloqueadores beta en pacientes con IC-FEr no ha demostrado beneficio alguno en cuanto a hospitalizaciones y mortalidad en el subgrupo de pacientes con IC-FEr que están en $\mathrm{FA}^{177}$. Sin embargo, dado que se trata de un análisis retrospectivo de subgrupos y que los bloqueadores beta no aumentaron el riesgo, el Comité para la elaboración de la presente guía no ha establecido una recomendación aparte basada en el ritmo cardiaco. Debe considerarse el tratamiento con bloqueadores beta para pacientes con IC-FEr y FA, especialmente si la frecuencia cardiaca es alta (véase la sección 10.1 para más información).

Los bloqueadores beta están recomendados para pacientes con historia de infarto de miocardio y disfunción sistólica del VI asintomática, para reducir el riesgo de muerte (véase la sección 6).

La guía práctica sobre el uso de bloqueadores beta se encuentra en la tabla 7.5 del anexo.

\subsubsection{Antagonistas de los receptores de mineralcorticoides/ aldosterona}

Los ARM (espironolactona y eplerenona) bloquean los receptores que fijan la aldosterona y, con diferente grado de afinidad, otros receptores de hormonas esteroideas (p. ej., corticoides, andrógenos). Se recomienda espironolactona o eplerenona para todo paciente con IC-FEr sintomático (a pesar del tratamiento con un IECA y un bloqueador beta) y FEVI $\leq 35 \%$, para reducir la mortalidad y las hospitalizaciones por IC ${ }^{174,175}$.

Deben tomarse precauciones al emplear ARM en pacientes con la función renal afectada o con potasio sérico $>5,0 \mathrm{mmol} / \mathrm{l}$. Deben realizarse controles regulares de la concentración de potasio sérico y de la función renal acordes con el estado clínico del paciente.

La guía práctica sobre el uso de ARM se encuentra en la tabla 7.6 del anexo.

\subsection{Otros tratamientos recomendados para pacientes sintomáticos con insuficiencia cardiaca y fracción de eyección reducida seleccionados}

\subsubsection{Diuréticos}

Los diuréticos están recomendados para reducir los signos y síntomas de congestión de los pacientes con IC-FEr, pero no se ha estudiado en ECDA sus efectos en la morbimortalidad. Un metanálisis Crochrane muestra que los diuréticos de asa y las tiacidas parece que reducen el riesgo de los pacientes con IC crónica de muerte y empeoramiento de la IC respecto a placebo, y cuando se comparan con un grupo activo de control, parece que mejoran la capacidad de ejercicio $^{178,179}$.

Tabla 7.2

Dosis de fármacos modificadores de la enfermedad, basadas en la evidencia recabada en estudios clínicos aleatorizados clave sobre insuficiencia cardiaca y fracción de eyección reducida (o tras infarto de miocardio)

\begin{tabular}{|c|c|c|}
\hline & Dosis inicial (mg) & Dosis objetivo (mg) \\
\hline \multicolumn{3}{|l|}{ IECA } \\
\hline Captopril $^{\mathrm{a}}$ & $6,25 / 8 \mathrm{~h}$ & $50 / 8 \mathrm{~h}$ \\
\hline Enalapril & $2,5 / 12 \mathrm{~h}$ & $20 / 12 \mathrm{~h}$ \\
\hline Lisinopril $^{\mathrm{b}}$ & $2,5-5,0 / 24 \mathrm{~h}$ & $20-35 / 24 \mathrm{~h}$ \\
\hline Ramipril & $2,5 / 24 \mathrm{~h}$ & $10 / 24 \mathrm{~h}$ \\
\hline Trandolaprila $^{\mathrm{a}}$ & $0,5 / 24 \mathrm{~h}$ & $4 / 24 \mathrm{~h}$ \\
\hline \multicolumn{3}{|l|}{ Bloqueadores beta } \\
\hline Bisoprolol & $1,25 / 24 \mathrm{~h}$ & $10 / 24 \mathrm{~h}$ \\
\hline Carvedilol & $3,125 / 12 \mathrm{~h}$ & $25 / 12 \mathrm{~h}^{\mathrm{d}}$ \\
\hline Succinato de metoprolol (CR/XL) & $12,5-25 / 24 \mathrm{~h}$ & $200 / 24 \mathrm{~h}$ \\
\hline Nebivolol $^{\mathrm{c}}$ & $1,25 / 24 \mathrm{~h}$ & $10 / 24 \mathrm{~h}$ \\
\hline \multicolumn{3}{|l|}{ ARA-II } \\
\hline Candesartán & $4-8 / 24 \mathrm{~h}$ & $32 / 24 \mathrm{~h}$ \\
\hline Valsartán & $40 / 12 \mathrm{~h}$ & $160 / 12 \mathrm{~h}$ \\
\hline Losartan $^{\mathrm{b}, \mathrm{c}}$ & $50 / 24 \mathrm{~h}$ & $150 / 24 \mathrm{~h}$ \\
\hline \multicolumn{3}{|l|}{ ARM } \\
\hline Eplerenona & $25 / 24 \mathrm{~h}$ & $50 / 24 \mathrm{~h}$ \\
\hline Espironolactona & $25 / 24 \mathrm{~h}$ & $50 / 24 \mathrm{~h}$ \\
\hline \multicolumn{3}{|l|}{ INRA } \\
\hline Sacubitrilo/valsartán & $49-51 / 12 \mathrm{~h}$ & $97-103 / 12 \mathrm{~h}$ \\
\hline \multicolumn{3}{|l|}{ Bloqueadores del canal $I_{f}$} \\
\hline Ivabradina & $5 / 12 \mathrm{~h}$ & $7,5 / 12 \mathrm{~h}$ \\
\hline
\end{tabular}

ARA-II: antagonistas del receptor de la angiotensina II; ARM: antagonista del receptor de mineralcortidoides; IECA: inhibidor de la enzima de conversión de la angiotensina; INRA: inhibidor de la neprilisina y el receptor de la angiotensina.

andica un IECA cuando la dosis objetivo se deriva de estudios tras infarto de miocardio.

'Indica fármacos cuyas dosis más altas han mostrado una reducción de la morbimortalidad, comparadas con dosis más bajas, pero sin estudios controlados y aleatorizados, por lo que se desconoce la dosis óptima.

'Indica un tratamiento del que no se ha demostrado que reduzca la mortalidad cardiovascular o por todas las causas de los pacientes con insuficiencia cardiaca (o se ha demostrado no inferior a un tratamiento que sí la reduce).

dSe puede administrar una dosis máxima de $50 \mathrm{mg}$ dos veces al día a pacientes con peso $>85 \mathrm{~kg}$. 


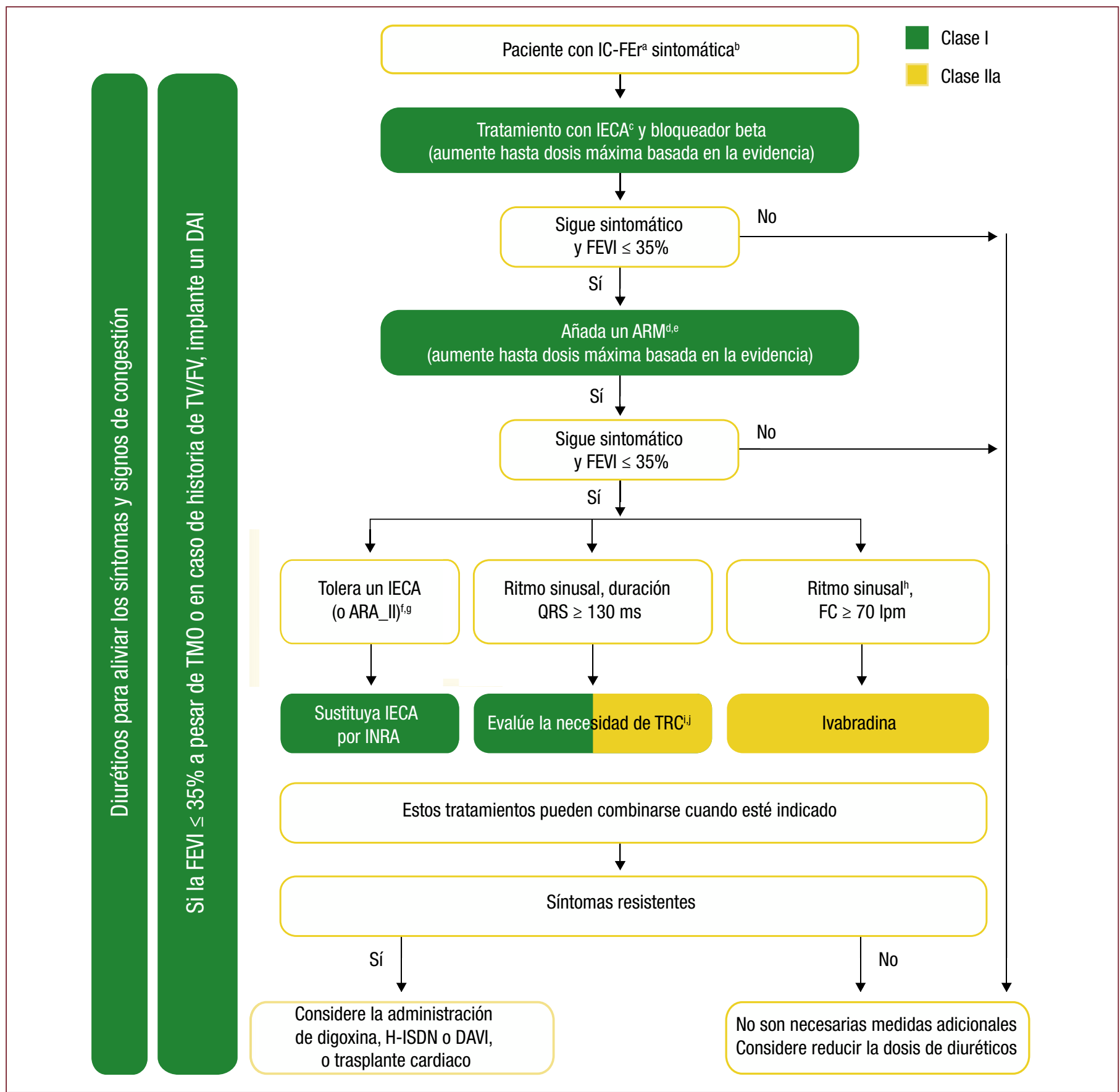

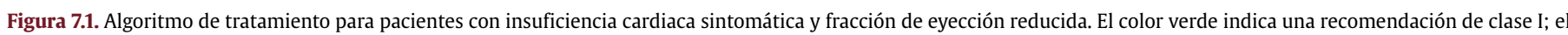

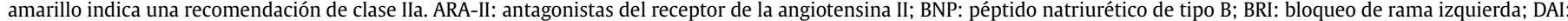

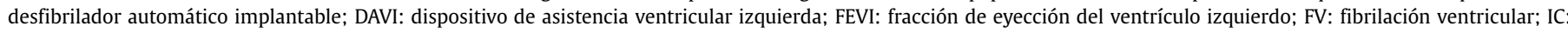

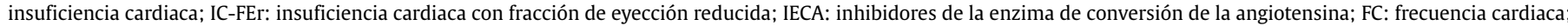

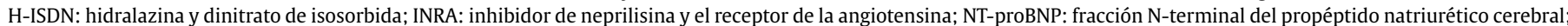

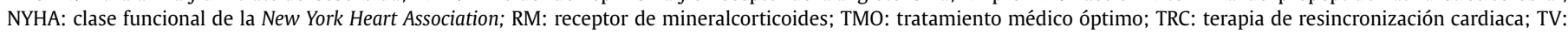
taquicardia ventricular.

aC-FEr: FEVI < 40\%.

'Sintomático: NYHA II-IV.

'En caso de intolerancia o contraindicación a IECA, utilice un ARA-II.

dEn caso de intolerancia o contraindicación a ARM, utilice un ARA-II.

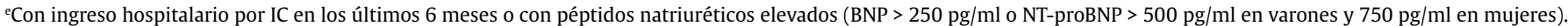

${ }^{\mathrm{f} C o n}$ péptidos natriuréticos plasmáticos elevados (BNP $\geq 150 \mathrm{pg} / \mathrm{ml}$ o NT-proBNP plasmático $\geq 600 \mathrm{pg} / \mathrm{ml}$ ) u hospitalización por IC en los últimos $12 \mathrm{meses}$ con BNP plasmático $\geq 100 \mathrm{pg} / \mathrm{ml}$ o NT-proBNP plasmático $\geq 400 \mathrm{pg} / \mathrm{ml}$.

${ }^{g}$ En dosis equivalentes a enalapril $10 \mathrm{mg} / 12 \mathrm{~h}$.

${ }^{\text {h}}$ Con un ingreso por IC en el año anterior.

'La TRC está recomendada si QRS $\geq 130 \mathrm{~ms}$ y BRI (en ritmo sinusal).

jSe debe considerar la TRC si QRS $\geq 130 \mathrm{~ms}$ sin BRI (en ritmo sinusal) o en pacientes con FA siempre que se disponga de captura biventricular (decisión individualizada). Para más información, consulte las secciones 7 y 8 y las páginas correspondientes del anexo. 
Los diuréticos de asa producen una diuresis más intensa y corta que las tiacidas, aunque actúan de manera sinérgica y la combinación de ambos puede emplearse para tratar el edema resistente. Sin embargo, los efectos adversos son más probables y esta combinación solo debe emplearse con precaución. El objetivo del tratamiento diurético es alcanzar y mantener la euvolemia con la dosis más baja posible. La dosis de diuréticos debe ajustarse a las necesidades individuales en cada momento. En pacientes euvolémicos/hipovolémicos seleccionados, puede suspenderse el tratamiento diurético (temporalmente). Se puede educar a los pacientes para que ellos mismos ajusten la dosis de diuréticos con base en la monitorización de síntomas/signos de congestión y el peso diario.

Las dosis de diuréticos empleadas normalmente para el tratamiento de la IC se encuentran en la tabla 7.3. La guía práctica sobre el uso de diuréticos se encuentra en la tabla 7.7 del anexo.

Tabla 7.3

Dosis de los diuréticos empleados normalmente en pacientes con insuficiencia cardiaca

\begin{tabular}{lll}
\hline & Dosis inicial (mg) & Dosis diaria normal (mg) \\
\hline Diuréticos del asa $^{a}$ & & \\
\hline Furosemida & $20-40$ & $40-240$ \\
\hline Bumetanida & $0,5-1,0$ & $1-5$ \\
\hline Torasemida & $5-10$ & $10-20$ \\
\hline Tiacidas $^{b}$ & & \\
\hline Bendroflumetiazida & 2,5 & $2,5-10$ \\
\hline Hidroclorotiazida & 25 & $12,5-100$ \\
\hline Metolazona & 2,5 & $2,5-10$ \\
\hline Indapamida & 2,5 & $2,5-5$
\end{tabular}

Diuréticos ahorradores de potasio

\begin{tabular}{lllll} 
& +IECA/ARA-II & -IECA/ARA-II & +IECA/ARA-II & -IECA/ARA-II \\
\hline $\begin{array}{l}\text { Espironolactona/ } \\
\text { eplerenona }\end{array}$ & $12,5-25$ & 50 & 50 & $100-200$ \\
\hline Amilorida & 2,5 & 5 & $5-10$ & $10-20$ \\
\hline Triamtereno & 25 & 50 & 100 & 200 \\
\hline
\end{tabular}

ARA-II: antaonistas del receptor de la angiotensina II; IECA: inhibidores de la enzima de conversión de la angiotensina.

aOral o intravenoso; puede ser necesario ajustar la dosis según el estado volémico/ peso; las dosis excesivas pueden causar insuficiencia renal y ototoxicidad.

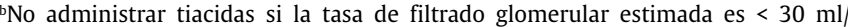
$\mathrm{min} / 1,73 \mathrm{~m}^{2}$, excepto si se prescriben en sinergia con un diurético del asa.

clndapamida es una sulfonamida no tiacídica.

dSe prefiere un antagonista del receptor de mineralocortidoides, como la espironolactona o la eplerenona. No se debe combinar la amilorida y el triamtereno con antagonistas del receptor de mineralocortidoides.

\subsubsection{Inhibidor del receptor de angiotensina y neprilisina}

Se ha desarrollado una nueva clase de fármacos que actúan en el SRAA y el sistema de las endopeptidasas neutras (inhibidor del receptor de la angiotensina y neprilisina). El primero de esta clase es el LCZ696, una molécula que combina fracciones de valsartán y sacubitrilo (inhibidor de neprilisina) en un solo compuesto. Con la inhibición de la neprilisina, se ralentiza la degradación de NP, bradicinina y otros péptidos. El péptido natriurético de tipo A altamente circulante (ANP) y el BNP ejercen efectos fisiológicos a través de su fijación a los receptores del NP y el aumento de la generación de cGMP, aumentando de esta forma la diuresis, la natriuresis, la relajación miocárdica y el anti-remodelado. Los ANP y BNP inhiben además la secreción de renina y aldosterona. El bloqueo selectivo de los receptores de AT1 reduce la vasoconstricción, la retención de sodio y agua y la hipertrofia miocárdica ${ }^{187,188}$

Un estudio reciente investigó los efectos a largo plazo del sacubitrilo-valsartán comparado con un IECA (enlapril) en la morbimortalidad de los pacientes ambulatorios con IC-FEr sintomática y FEVI $\leq 40 \%$ (se cambió a $\leq 35 \%$ durante el estudio), con títulos plasmáticos de NP aumentados (BNP $\geq 150 \mathrm{pg} / \mathrm{ml}$ o NT-proBNP $\geq 600 \mathrm{pg} / \mathrm{ml} \mathrm{o}$, en caso de hospitalización por IC en los últimos 12 meses, BNP $\geq 100 \mathrm{pg} / \mathrm{ml}$ o NT-proBNP $\geq 400 \mathrm{pg} / \mathrm{ml}$ ) y una TFG estimada (TFGe) $\geq 30 \mathrm{ml} / \mathrm{min} /$ $1,73 \mathrm{~m}^{2}$ de superficie corporal, que pudieran tolerar periodos separados de tratamiento con enalapril ( $10 \mathrm{mg} / 12 \mathrm{~h}$ ) y sacubitrilo-valsartán (97 y $103 \mathrm{mg} / 12 \mathrm{~h}$ ) durante un periodo de rodaje ${ }^{162}$. En esta población, el sacubitrilo-valsartán (97 y $103 \mathrm{mg} / 12 \mathrm{~h}$ ) fue superior al IECA (enalapril, $10 \mathrm{mg} / 12 \mathrm{~h}$ ) para la reducción de las hospitalizaciones por empeoramiento de la IC, la mortalidad cardiovascular y la mortalidad total ${ }^{162}$. Por lo tanto, el sacubitrilo-valsartán está recomendado para pacientes con IC-FEr que presenten este perfil.

A pesar de la superioridad del sacubitrilo-valsartán sobre el enalapril en el estudio PARADIGM-HF, quedan pendientes algunas cuestiones de seguridad cuando se emplea este fármaco en la práctica clínica. La hipotensión sintomática fue más frecuente en el grupo de sacubitrilo-valsartán (en los pacientes de edad $\geq 75$ años afectó al $18 \%$ del grupo de sacubitrilo-valsartán frente al $12 \%$ del de enalapril), aunque no hubo aumento de la tasa de suspensión del tratamiento ${ }^{162}$. El riesgo de angiedema en el estudio se redujo porque solo se reclutó a pacientes que toleraran el tratamiento con enalapril (10 mg/12 h) y sacubitrilo-valsartán durante una fase activa de rodaje de 5-9 semanas (que resultó en una tasa de angiedema del $0,4 \%$ del grupo de sacubitrilo-valsartán frente al $0,2 \%$ del de enalapril). Además, el grupo de pacientes afroamericanos, que tienen más riesgo de angiedema, fue relativamente pequeño en este estudio. Para minimizar el riesgo de angiedema causado por la combinación de un IECA con la inhibición de la neprilisina, el IECA debe suspenderse al menos $36 \mathrm{~h}$ antes de la administración de sacubitrilo-valsartán. El tratamiento combinado con un IECA (o ARA-II) y sacubitrilo-valsartán está contraindicado. Además hay una preocupación adicional respecto a su efecto en la degradación del péptido betaamiloide en el cerebro, que podría teóricamente acelerar la deposición de amiloides ${ }^{189-191}$. Sin embargo, un pequeño estudio de 14 días en sujetos sanos mostró una elevación de la proteína amiloide en la forma soluble más que en la agregable, lo que, si se confirma durante periodos más largos en pacientes con IC-FEr, podría indicar la seguridad cerebral del sacubitrilo-valsartán ${ }^{192}$. Es preciso investigar la seguridad de este fármaco a largo plazo.

\subsubsection{Inhibidor del canal $I_{f}$}

La ivabradina ralentiza la frecuencia cardiaca inhibiendo el canal $I_{\mathrm{f}}$ en el nódulo sinusal, por lo que solo se debe emplear en pacientes en ritmo sinusal. La ivabradina redujo la variable combinada de mortalidad y hospitalización por IC en pacientes con IC-FEr sintomática y $\mathrm{FEVI} \leq 35 \%$, en ritmo sinusal y con frecuencia cardiaca $\geq 70 \mathrm{lpm}$ hospitalizados por IC en los 12 meses previos y tratados con dosis de bloqueadores beta basadas en la evidencia (o dosis máxima tolerada), un IECA (o ARA-II) y un ARM ${ }^{180}$. La Agencia Europea del Medicamento (AEM) aprobó el uso de la ivabradina para pacientes con IC-FEr en ritmo sinusal y con frecuencia cardiaca en reposo $\geq 75 \mathrm{lpm}$, debido a que en este grupo la ivabradina confiere un beneficio relativo a la supervivencia ${ }^{193}$ según los resultados de un análisis retrospectivo de subgrupos solicitado por dicha agencia.

La guía práctica para el uso de la ivabradina se encuentra en la tabla 7.8 del anexo. 
Otros tratamientos farmacológicos recomendados para pacientes seleccionados con insuficiencia cardiaca sintomática (NYHA II-IV) y fracción de eyección reducida

\begin{tabular}{|c|c|c|c|}
\hline Recomendaciones & Clase $^{\mathrm{a}}$ & Nivel $^{\mathrm{b}}$ & $\operatorname{Ref}^{c}$ \\
\hline
\end{tabular}

Diuréticos

Los diuréticos están recomendados para mejorar los síntomas y la capacidad de ejercicio de los pacientes con signos o síntomas de congestión

Se debe considerar la administración de diuréticos para reducir el riesgo de hospitalización por IC de los pacientes con signos o síntomas de congestión

\begin{tabular}{|c|c|c|}
\hline I & B & 178,179 \\
\hline IIa & B & 178,179 \\
\hline
\end{tabular}

Inhibidor de la neprilisina y el receptor de la angiotensina

El sacubitrilo/valsartán está recomendado como sustituto de un IECA para reducir adicionalmente el riesgo de hospitalización por IC y muerte de los pacientes ambulatorios con IC-FEr que permanecen sintomáticos a pesar del tratamiento con un IECA, un bloqueador beta y un ARM ${ }^{d}$

Inhibidor del canal $I_{f}$

Se debe considerar la ivabradina para reducir el riesgo de hospitalización por IC y muerte cardiovascular de los pacientes sintomáticos con FEVI $\leq 35 \%$, en ritmo sinusal y con una frecuencia cardiaca $\geq 70 \mathrm{lpm}$ a pesar del tratamiento con dosis de bloqueadores beta basadas en la evidencia (o la dosis máxima tolerada), IECA (o ARA-II) y ARM (o ARA-II)

Se debe considerar la ivabradina para reducir el riesgo de hospitalización por IC y muerte cardiovascular de los pacientes sintomáticos con $\mathrm{FEVI} \leq 35 \%$, en ritmo sinusal y con una frecuencia cardiaca $\geq 70 \mathrm{lpm}$ que no toleran o tienen contraindicados los bloqueadores beta. Estos pacientes también deben ser tratados con IECA (o ARA-II) y ARM (o ARA-II)

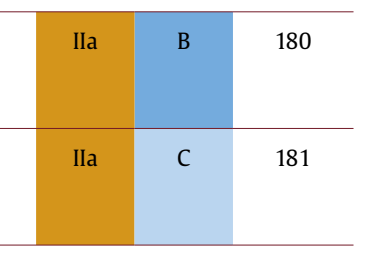

ARA-II

Se recomienda un ARA-II para reducir el riesgo de hospitalización por IC y muerte cardiovascular de los pacientes sintomáticos que no toleran los IECA (los pacientes deben ser tratados con un bloqueador beta y un ARM)

Se puede considerar la administración de un ARA-II para reducir el riesgo de hospitalización por IC y muerte de los pacientes sintomáticos a pesar del tratamiento con bloqueadores beta que no toleran un ARM

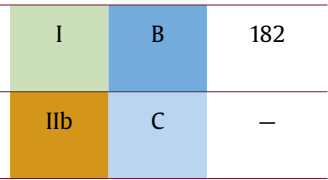

Hidralazina y dinitrato de isosorbida

Se puede considerar la administración de hidralazina y dinitrato de isosorbida a pacientes de raza negra con FEVI $\leq 35 \%$ o FEVI $<45 \%$ combinada con dilatación del VI y en NYHA III-IV a pesar del tratamiento con un IECA, un bloqueador beta y un ARM, para reducir el riesgo de hospitalización por IC y muerte

Se puede considerar la administración de hidralazina y dinitrato de isosorbida a pacientes sintomáticos con IC-FEr que no toleran un IECA ni un ARA-II (o están contraindicados) para reducir el riesgo de muerte

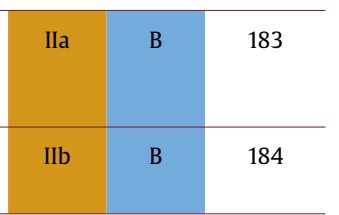

Otros tratamientos con beneficios menos claros

Digoxina

Se puede considerar la administración de digoxina a pacientes sintomáticos en ritmo sinusal a pesar del tratamiento con un IECA (o ARA-II), un bloqueador beta y un ARM para reducir el riesgo de hospitalización (por IC y por todas las causas)

PUFA $n-3$

Se puede considerar la administración de una preparación de PUFA n-3e para reducir el riesgo de hospitalización y muerte por causas cardiovasculares de los pacientes sintomáticos con IC

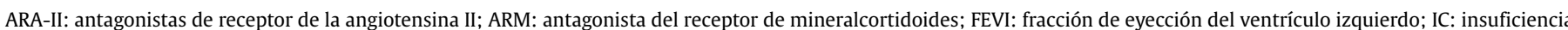

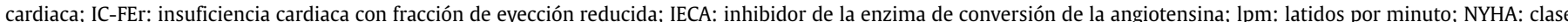

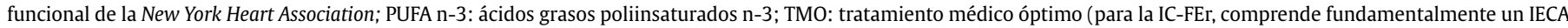
o sacubitrilo/valsartán, un bloqueador beta y un ARM).

aClase de recomendación.

bNivel de evidencia.

'Referencias que respaldan las recomendaciones.

${ }^{d}$ El paciente debe tener los péptidos natriuréticos elevados (BNP plasmático $\geq 150 \mathrm{pg} / \mathrm{ml}$ o NT-proBNP plasmático $\geq 600$ pg/ml o, en caso de hospitalización por IC en los últimos 12 meses, BNP plasmático $\geq 100 \mathrm{pg} / \mathrm{ml}$ o NT-proBNP plasmático $\geq 400 \mathrm{pg} / \mathrm{ml}$ ) y ser capaz de tolerar el enalapril $10 \mathrm{mg} / 12 \mathrm{~h}$.

eSolo aplicable a la preparación empleada en el estudio citado.

\subsubsection{Antagonistas del receptor tipo 1 de la angiotensina II}

Los ARA-II solo se recomiendan como tratamiento alternativo para pacientes que no toleran los IECA ${ }^{182}$. Se ha demostrado que el candesartán reduce la mortalidad cardiovascular ${ }^{182}$. Se observó un efecto positivo del valsartán en las hospitalizaciones por IC (pero no en las hospitalizaciones por todas las causas) de los pacientes con IC-FEr que recibían tratamiento de base con IECA $^{194}$.

La AEM revisó el tratamiento combinado con IECA y ARA-II para la IC-FEr y determinó que los beneficios superan a los riesgos solo en un grupo específico de pacientes con IC-FEr que no son candidatos a otros tratamientos. Por lo tanto, los ARA-II están indicados para la ICFEr solo en pacientes que no toleran el tratamiento con IECA debido a sus importantes efectos secundarios. La combinación de IECA y ARA-II debe restringirse a pacientes con IC-FEr sintomática que reciben tratamiento con un bloqueador beta y no toleran un ARM, y debe emplearse bajo estricta supervisión.

\subsubsection{Combinación de hidralazina y dinitrato de isosorbida}

No existen pruebas claras que apoyen el uso de un tratamiento combinado a dosis fijas para todos los pacientes con IC-FEr. La eviden- 
cia sobre la utilidad clínica de esta combinación es escasa y procede de un estudio relativamente pequeño en el que se incluyó solo a varones y se realizó antes de que los IECA o los bloqueadores beta se emplearan para el tratamiento de la IC ${ }^{184}$. Posteriormente, un estudio realizado con pacientes que se declaraban de raza negra (definida como ser descendiente de africanos) mostró que la adición de la combinación de hidralazina y dinitrato de isosorbida al tratamiento convencional (IECA, bloqueador beta y ARM) reduce la mortalidad y las hospitalizaciones por IC de los pacientes con IC-FEr y NYHA III-IV183. Los resultados de este estudio son difíciles de trasladar a pacientes de otro origen racial o étnico.

Se puede considerar la combinación de hidralazina y dinitrato de isosorbida para pacientes con IC-FEr sintomáticos que no pueden tolerar los IECA y los ARA-II (o los tienen contraindicados) para reducir la mortalidad. No obstante, esta recomendación se basa en los resultados del estudio Veterans Administration Cooperative, en el que se reclutó a pacientes con IC-FEr sintomáticos que recibían únicamente digoxina y diuréticos ${ }^{184}$.

\subsection{Otros tratamientos con beneficios más inciertos para pacientes sintomáticos con insuficiencia cardiaca y fracción de eyección reducida}

En este apartado se describen tratamientos que han mostrado beneficios en mejoría de los síntomas, reducción de las hospitalizaciones por IC o ambos, y se los considera útiles como tratamiento adicional en pacientes con IC-FEr.

\subsubsection{Digoxina y otros glucósidos digitálicos}

Se puede considerar la administración de digoxina para pacientes en ritmo sinusal con IC-FEr sintomática para reducir el riesgo de hospitalización (tanto por todas las causas como por IC) ${ }^{185}$, aunque su efecto adicional al del tratamiento con bloqueadores beta no se ha probado hasta la fecha. Los efectos de la digoxina en pacientes con IC-FEr y FA no se han estudiado en ECDA y los datos de estudios recientes indican que existe un riesgo potencial de complicaciones (mortalidad y hospitalización por IC) para los pacientes con FA tratados con digoxina ${ }^{195,196}$. Sin embargo, esta cuestión sigue siendo controvertida, ya que otro reciente metanálisis sobre datos de estudios sin distribución aleatoria mostró que la digoxina no tiene efectos perjudiciales en la mortalidad de los pacientes con FA e IC concomitantes, que en su mayoría tenían IC-FEr ${ }^{197}$.

En pacientes con IC sintomática y FA, la digoxina puede ser útil para reducir la frecuencia ventricular rápida, pero solo se recomienda para el tratamiento de pacientes con IC-FEr y FA con frecuencia ventricular rápida cuando no se puede aplicar otras opciones terapéuticas $^{196,198-201}$. Hay que señalar que no se ha establecido con claridad la frecuencia ventricular óptima en pacientes con IC y FA, pero los datos disponibles indican que un control estricto de la frecuencia ventricular puede ser perjudicial. Con base en la opinión de expertos, actualmente se recomienda una frecuencia ventricular en reposo de 70-90 lpm, aunque los resultados de un estudio indican que una frecuencia ventricular en reposo de hasta $110 \mathrm{lpm}$ podría ser aceptable $^{202}$. Estas recomendaciones todavía requieren investigación y redefinición en futuros estudios.

La digital siempre se debe prescribir bajo la supervisión de un especialista. Debido a su distribución y su aclaramiento, se debe tomar precauciones especiales en mujeres, ancianos y pacientes con función renal reducida. En estos es preferible el uso de digoxina.

\subsection{2. Ácidos grasos poliinsaturados n-3}

Los ácidos grasos poliinsaturados (PUFA) n-3 han mostrado en un ECDA solo un pequeño efecto terapéutico ${ }^{186}$. Las preparaciones de estos ácidos difieren en composición y dosis. Únicamente con las preparaciones de PUFA n-3 con ácido eicosapentanoico (EPA) y ácido docosahexanoico (DHA) como ésteres etílicos de, al menos, el 85\% $(850 \mathrm{mg} / \mathrm{g})$ se ha demostrado un efecto en la variable acumulada de muerte cardiovascular y hospitalización. No se han observado efectos terapéuticos de las preparaciones de PUFA n-3 que contienen menos de $850 \mathrm{mg} / \mathrm{g}$ ni en la IC-FEr ni tras el infarto de miocardio ${ }^{203}$. Las preparaciones de PUFA n-3 que contienen 850-882 mg de EPA y DHA como ésteres etílicos en proporción 1:1,2 se pueden considerar como tratamiento coadyuvante para los pacientes con IC-FEr sintomática que reciben tratamiento óptimo con un IECA (o ARA-II), un bloqueador beta y un ARM.

\subsection{Tratamientos no recomendados (beneficio no probado) para pacientes sintomáticos con insuficiencia cardiaca y fracción de eyección reducida}

\subsubsection{Inhibidores de la 3-hidroxi-3-metilglutaril coenzima A reductasa ("estatinas")}

Aunque las estatinas reducen la morbimortalidad de los pacientes con enfermedad ateroesclerótica, no son efectivas para mejorar el pronóstico de los pacientes con IC-FEr. La mayoría de los estudios sobre estatinas no incluyeron a pacientes con IC (debido a la incertidumbre de sus beneficios) ${ }^{204}$. Los 2 estudios más importantes sobre el efecto del tratamiento con estatinas en pacientes con IC crónica no obtuvieron evidencia de beneficio alguna ${ }^{205}$. Por ello, no existen pruebas que apoyen la instauración de tratamiento con estatinas en pacientes con IC crónica. Sin embargo, para los pacientes que ya reciben tratamiento con estatinas para la EAC o la hiperlipemia subyacentes, se debe considerar la continuación de este tratamiento.

\subsubsection{Anticoagulantes orales y tratamiento antiagregante}

Excepto en pacientes con FA (tanto con IC-FEr como con IC-FEc), no existen pruebas de que el tratamiento con un anticoagulante oral reduzca la morbimortalidad respecto a placebo o $\mathrm{AAS}^{206,207}$. Actual-

Tratamientos (o combinaciones de tratamientos) que pueden ser perjudiciales para pacientes con insuficiencia cardiaca sintomática (NYHA II-IV) y fracción de eyección reducida

\begin{tabular}{|c|c|c|c|}
\hline Recomendaciones & Clase $^{\mathrm{a}}$ & Nivel $^{\mathrm{b}}$ & $\operatorname{Ref}^{c}$ \\
\hline $\begin{array}{l}\text { No se recomiendan las tiazolidinedionas (glitazonas) } \\
\text { para pacientes con IC, ya que aumentan el riesgo de } \\
\text { empeoramiento y hospitalización por IC }\end{array}$ & III & A & 209,210 \\
\hline $\begin{array}{l}\text { No se recomiendan los AINE o inhibidores de la } \\
\text { COX-2 para pacientes con IC, ya que aumentan el } \\
\text { riesgo de empeoramiento y hospitalización por IC }\end{array}$ & III & B & $211-213$ \\
\hline $\begin{array}{l}\text { No se recomiendan el diltiazem o el verapamilo } \\
\text { para pacientes con IC-FEr, ya que aumentan el } \\
\text { riesgo de empeoramiento y hospitalización por IC }\end{array}$ & III & C & 214 \\
\hline $\begin{array}{l}\text { No se recomienda la adición de un ARA-II (o } \\
\text { inhibidor de la renina) a la combinación de un IECA } \\
\text { y un ARM para pacientes con IC por el aumento } \\
\text { de riesgo de disfunción renal e hiperpotasemia }\end{array}$ & III & C & \\
\hline
\end{tabular}

AINE: antiinflamatorios no esteroideos; ARA-II: antagonistas de receptor de la angiotensina II; ARM: antagonista del receptor de mineralcortidoides; COX-2: ciclooxigenasa-2; IC: insuficiencia cardiaca; IC-FEr: insuficiencia cardiaca con fracción de eyección reducida; IECA: inhibidor de la enzima de conversión de la angiotensina.

aClase de recomendación.

bNivel de evidencia.

'Referencias que respaldan las recomendaciones. 
mente se están desarrollando estudios para probar nuevos anticoagulantes orales no dependientes de la vitamina K (NACO) en pacientes con IC-FEr. Los pacientes con IC-FEr que reciben anticoagulación oral debido a FA concurrente o riesgo de tromboembolia venosa deben continuar con la anticoagulación. En la sección 10.1 se encuentra información detallada.

Del mismo modo, no hay pruebas de los beneficios del tratamiento antiagregante (incluido el AAS) en pacientes con IC sin EAC subyacente, y este tratamiento se asocia a un riesgo importante de sangrado gastrointestinal, especialmente en pacientes mayores.

\subsubsection{Inhibidores de la renina}

En un estudio, el aliskirén (un inhibidor directo de la renina) no logró mejorar los resultados en pacientes hospitalizados por IC a los 6 y 12 meses $^{208}$, y actualmente no se recomienda como tratamiento alternativo a los IECA o ARA-II.

\subsection{Tratamientos no recomendados (considerados perjudiciales) para pacientes sintomáticos con insuficiencia cardiaca y fracción de eyección reducida}

\subsubsection{Bloqueadores de los canales del calcio}

Los bloqueadores de los canales del calcio no dihidropiridínicos (BCC) no están indicados para el tratamiento de pacientes con IC-FEr. El diltiazem y el verapamilo se han demostrado peligrosos para los pacientes con IC-FEr ${ }^{214}$.

Existen varios BCC dihidropiridínicos; algunos de ellos aumentan el tono simpático y pueden tener un perfil de seguridad negativo en la IC-FEr. Solo existen pruebas de la seguridad del amlodipino ${ }^{215}$ y el felodipino ${ }^{216}$ en pacientes con IC-FEr, pero solo deben emplearse en estos pacientes si existe una indicación convincente.

\section{TRATAMIENTO NO QUIRÚRGICO DE LA INSUFICIENCIA CARDIACA CON FRACCIÓN DE EYECCIÓN REDUCIDA MEDIANTE DISPOSITIVOS}

En esta sección se encuentran las recomendaciones sobre el uso de DAI y TRC. Actualmente no se dispone de suficientes datos para establecer recomendaciones sobre el uso de otras tecnologías terapéuticas como la terapia de activación barorrefleja ${ }^{217}$, la estimulación vagal $^{218}$, la estimulación eléctrica diafragmática ${ }^{219,220}$ y la modulación de la contractilidad cardiaca ${ }^{221,222}$; son necesarios más estudios. Los dispositivos implantables para la monitorización de arritmias o parámetros hemodinámicos se tratan en otros apartados de esta guía.

\subsection{Desfibrilador automático implantable}

Gran parte de las muertes de pacientes con IC, especialmente aquellos con síntomas leves, ocurren de modo súbito e inesperado. Muchas de ellas se deben a alteraciones eléctricas, como arritmias ventriculares, bradicardia y asistolia, aunque otras se deben a complicaciones vasculares coronarias, cerebrales o aórticas. Los tratamientos que mejoran o retrasan la progresión de la enfermedad cardiovascular reducen la tasa anual de muerte súbita, pero tienen poco efecto en el riesgo a lo largo de la vida y no sirven para tratar las complicaciones arrítmicas cuando estas ocurren. El DAI es efectivo para la prevención de la bradicardia y la corrección de arritmias ventriculares potencialmente mortales. Algunos fármacos antiarrítmicos pueden reducir la tasa de taquiarritmias y muerte súbita, pero no reducen la tasa de mortalidad total e incluso pueden aumentarla.

\subsubsection{Prevención secundaria de la muerte súbita cardiaca}

Comparado con el tratamiento con amiodarona, el DAI reduce la mortalidad de los supervivientes a una parada cardiaca o que han

Recomendaciones para el uso de desfibrilador automático implantable en pacientes con insuficiencia cardiaca

\begin{tabular}{|c|c|c|c|}
\hline Recomendaciones & Clase $^{\mathrm{a}}$ & Nivel $^{\mathrm{b}}$ & $\operatorname{Ref}^{c}$ \\
\hline $\begin{array}{l}\text { Prevención secundaria } \\
\text { Se recomienda implantar un DAI para reducir el riesgo de muerte súbita y mortalidad por todas las causas de los pacientes que se han recuperado } \\
\text { de una arritmia ventricular causante de inestabilidad hemodinámica y tienen una esperanza de vida }>1 \text { año en buen estado funcional }\end{array}$ & I & A & $223-226$ \\
\hline
\end{tabular}

Prevención primaria

Se recomienda implantar un DAI para reducir el riesgo de muerte súbita y mortalidad por todas las causas de los pacientes con IC sintomática

(NYHA II-III) y FEVI $\leq 35 \%$ pese a recibir TMO $\geq 3$ meses, siempre que su esperanza de vida sea significativamente $>1$ año en buen estado

funcional, y que además tengan:

- Cardiopatía isquémica (excepto si han sufrido un IM en los últimos 40 días; véase a continuación)

- Miocardiopatía dilatada

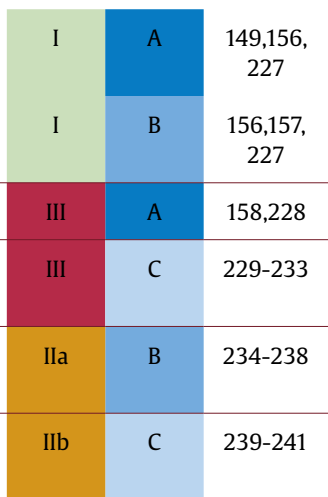

No se recomienda implantar un DAI durante los primeros 40 días tras el IM, ya que esta terapia en ese periodo no mejora el pronóstico

No se recomienda el tratamiento con DAI para pacientes en NYHA IV con síntomas graves y refractarios a tratamiento farmacológico, excepto si son candidatos a TRC, dispositivo de apoyo ventricular o trasplante cardiaco

Antes de la sustitución del generador, los pacientes deben ser evaluados cuidadosamente por un cardiólogo con experiencia, ya que los objetivos del tratamiento y las necesidades del paciente podrían haber cambiado

Se puede considerar el uso de un DAI portátil durante un tiempo corto o como tratamiento puente hasta el implante de un dispositivo para pacientes con IC y riesgo de muerte súbita

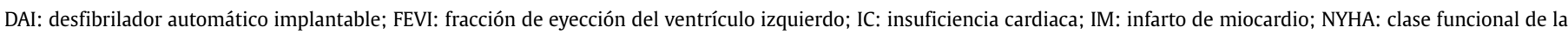
New York Heart Association; TMO: tratamiento médico óptimo; TRC: terapia de resincronización cardiaca.

aClase de recomendación.

bNivel de evidencia.

'Referencias que respaldan las recomendaciones. 
sufrido arritmias ventriculares sintomáticas persistentes. Para estos pacientes, se recomienda implantar un DAI si se pretende aumentar la supervivencia; la decisión sobre el implante debe tener en cuenta la voluntad del paciente y su calidad de vida, la FEVI (el beneficio relativo a la supervivencia es incierto cuando la FEVI es $>35 \%$ ) y la ausencia de otras enfermedades que puedan causar la muerte en un plazo de 1 año ${ }^{223-225}$.

\subsubsection{Prevención primaria de la muerte súbita cardiaca}

Aunque la amiodarona redujo la mortalidad en los estudios más antiguos $^{242,243}$, los contemporáneos realizados tras la generalización de los bloqueadores beta indican que no reduce la mortalidad de los pacientes con IC-FEr ${ }^{227,244,245}$. La dronedarona ${ }^{246,247}$ y otros fármacos antiarrítmicos de clase $\mathrm{I}^{246,248}$ no deben emplearse para la prevención de arritmias en esta población.

Algunos tratamientos recomendados en las guías de práctica clínica, como bloqueadores beta, ARM, sacubitrilo-valsartán y marcapasos con TRC (TRC-MP), reducen el riesgo de muerte súbita (véase la sección 7).

El DAI reduce la tasa de muerte súbita por arritmias de los pacientes con IC-FEr ${ }^{249,250}$. En pacientes con IC moderada o grave, la reducción de la tasa de muerte súbita puede compensarse parcial o totalmente por el aumento de muertes debido al empeoramiento de la $\mathrm{IC}^{227}$. En pacientes con IC leve (NYHA II), el implante de DAI puede prevenir aproximadamente 2 muertes anuales por cada 100 dispositivos implantados ${ }^{227}$. En promedio, los pacientes con cardiopatía isquémica tienen mayor riesgo de muerte súbita que los pacientes con MCD, de modo que, aunque los beneficios relativos sean similares, el beneficio absoluto es mayor para los pacientes con IC ${ }^{249}$. Los pacientes con duraciones QRS más largas también obtienen mayores beneficios del implante de DAI, pero se suele tratarlos con dispositivos de TRC227,251.

En 2 ECDA no se observaron beneficios en pacientes a los que se implantó un DAI durante los primeros 40 días tras un infarto de miocardio $^{158,228}$. Aunque se redujo el número de muertes súbitas por arritmias, este beneficio se equilibró con un aumento de muertes no arrítmicas. Consecuentemente, el implante de DAI está contraindicado durante ese lapso. Se puede valorar el empleo de un desfibrilador portátil si se considera que el paciente tiene un riesgo de fibrilación ventricular alto, aunque no se dispone de suficientes datos de ECDA $239-241$

Se recomienda el implante de DAI solo si, tras un periodo de prueba (mínimo 3 meses), el TMO no logra aumentar la FEVI a > 35\%. Sin embargo, 1 de los 2 artículos más importantes en que se basan estas recomendaciones incluyó a pacientes con FEVI > 30\%. En los 2 estudios más importantes, se incluyó a menos de 400 pacientes con FEVI del 30-35\% y, aunque no se observó una interacción estadística entre el efecto del tratamiento y la FEVI, la evidencia sobre el beneficio es menos robusta en este grupo de pacientes. La estrategia conservadora, en la que se espera un largo periodo ${ }^{252}$ desde la detección de la entidad hasta el implante del DAI, reduce notablemente la incidencia de shocks, tanto por implante inapropiado (debido a artefactos o FA) como por implante apropiado pero innecesario (debido a taquicardia ventricular [TV] autolimitada $)^{252-254}$.

A los pacientes con duración del complejo QRS $\geq 130 \mathrm{~ms}$, se los debe valorar para tratamiento mediante desfibrilador con TRC (CRT-D) más que con DAI. Consulte la guía sobre TRC para más información (sección 8.2).

No se recomienda el tratamiento con DAI para pacientes en NYHA IV con síntomas graves refractarios a tratamiento médico que no sean candidatos a TRC, dispositivo de asistencia ventricular (DAV) o trasplante cardiaco, dado que tienen una esperanza de vida corta y muchas probabilidades de morir por fallo de bomba.

Los pacientes con comorbilidades graves que tienen pocas probabilidades de vivir más de 1 año probablemente no obtengan un beneficio importante de un $\mathrm{DAI}^{229-233}$.
Los pacientes deben recibir información y asesoramiento sobre el propósito del DAI, las complicaciones relativas al implante (fundamentalmente shocks inapropiados) y en qué circunstancias se debe desactivar (enfermedad terminal) o explantar (infección, recuperación de la función del VI ${ }^{255}$.

En caso de deterioro por IC, se puede considerar la desactivación del DAI tras discutir esta opción con el paciente y su cuidador.

Cuando el generador del DAI alcance el final de su vida útil o requiera explantación, no se debe reemplazarlo automáticamente ${ }^{234-238}$. Un cardiólogo con experiencia debe someter a los pacientes a una evaluación minuciosa antes de sustituir el generador. Los objetivos del tratamiento podrían haber cambiado, el riesgo de arritmia mortal podría ser menor o el riesgo de muerte no arrítmica, mayor. Existe controversia en cuanto a si se debe someter al implante de otro dispositivo a los pacientes cuya FEVI haya mejorado sustancialmente y que no han requerido tratamiento del dispositivo durante la vida del DAI ${ }^{234-238}$.

Los desfibriladores subcutáneos pueden ser tan efectivos como el DAI convencional y tienen menos riesgo asociado al procedimiento de implantación ${ }^{256,257}$. Pueden ser la opción preferida para pacientes con un acceso difícil o que requieren la explantación del DAI debido a infección. Se debe seleccionar cuidadosamente a los pacientes, ya que estos desfibriladores tienen escasa capacidad para tratar bradiarritmias graves y no pueden suministrar estimulación eléctrica antitaquicardia ni TRC. Se esperan nuevos ECDA sobre estos dispositivos y más datos sobre su seguridad y su eficacia ${ }^{258,259}$.

Para pacientes seleccionados con IC y alto riesgo de muerte súbita pero que no son candidatos a implante de DAI (p. ej., FEVI reducida tras daño miocárdico agudo hasta que se recupere la función del VI o pacientes programados para trasplante), se puede considerar el uso por un tiempo breve de un DAI portátil (un desfibrilador externo con electrodos y almohadillas unidos a un chaleco) con capacidad para reconocer e interrumpir la TV/fibrilación ventricular ${ }^{239-241,260}$. Sin embargo, hasta la fecha no se ha reportado ningún ECDA prospectivo sobre este dispositivo.

Para consultar las recomendaciones sobre el uso y las indicaciones del DAI, se refiere al lector a la guía de la ESC/European Heart Rhythm Association (EHRA) sobre taquiarritmias ventriculares y muerte súbita $^{260}$.

\subsection{Terapia de resincronización cardiaca}

La TRC mejora la función cardiaca y los síntomas de pacientes seleccionados ${ }^{286}$, aumenta el bienestar ${ }^{286}$ y reduce la morbimortali$\operatorname{dad}^{266}$. En cuanto a la mejora de la calidad de vida ajustada por edad de los pacientes con IC moderada o grave con TRC, se puede atribuir 2 tercios a la mejora de la calidad de vida y 1 tercio al aumento de la longevidad ${ }^{287}$.

Solo los estudios COMPANION ${ }^{265}$ y CARE-HF 262,263 compararon el efecto de la TRC con el tratamiento médico acorde con las guías de práctica clínica. La mayoría de los estudios compararon TRC-D y DAI, y un número escaso comparó la TRC-MC con el MP de apoyo. La prevención de bradicardias mortales puede ser un mecanismo importante del beneficio compartido por todos los dispositivos de estimulación eléctrica. En la fase inicial del estudio CARE-HF, el $25 \%$ de los pacientes tenían una frecuencia cardiaca en reposo $\leq 60 \mathrm{lpm}^{262-264}$. Si la prevención de la bradicardia es importante, el efecto de la TRC parecerá mayor en los estudios cuyos grupos de control no emplean ningún dispositivo.

En la mayoría de los estudios sobre TRC se especificó que la FEVI debía ser $<35 \%$, pero los estudios RAFT ${ }^{267}$ y MADIT-CRT ${ }^{268,269}$ especificaron una FEVI $<30 \%$, mientras que el estudio REVERSE $270-272$ la especificó < 40\% y el BLOCK-HF $274,<50 \%$. Los pacientes con FEVI del $35-40 \%$ aleatorizados son relativamente pocos, pero un metanálisis de datos de pacientes individuales mostró que el efecto de la TRC no es menor en este grupo ${ }^{266}$. 
Recomendaciones sobre la terapia de resincronización cardiaca para pacientes con insuficiencia cardiaca

\begin{tabular}{|c|c|c|c|}
\hline Recomendaciones & Clase $^{\mathrm{a}}$ & Nivel $^{\mathrm{b}}$ & $\operatorname{Ref}^{\mathrm{c}}$ \\
\hline $\begin{array}{l}\text { Se recomienda la TRC para pacientes sintomáticos con IC, en ritmo sinusal con } Q R S \geq 150 \mathrm{~ms} \text { y morfología QRS de BRI, con FEVI } \leq 35 \% \text { a pesar } \\
\text { de recibir TMO, a efectos de mejorar los síntomas y reducir la morbimortalidad }\end{array}$ & I & A & $261-272$ \\
\hline $\begin{array}{l}\text { Se debe considerar la TRC para pacientes sintomáticos con IC, en ritmo sinusal con QRS } \geq 150 \text { ms y morfología QRS sin BRI, con FEVI } \leq 35 \% \\
\text { a pesar de recibir TMO, a efectos de mejorar los síntomas y reducir la morbimortalidad }\end{array}$ & IIa & B & $261-272$ \\
\hline $\begin{array}{l}\text { Se recomienda la TRC para pacientes sintomáticos con IC en ritmo sinusal con QRS de } 130-149 \text { ms y morfología QRS de BRI, con FEVI } \leq 35 \% \\
\text { a pesar de recibir TMO, a efectos de mejorar los síntomas y reducir la morbimortalidad }\end{array}$ & I & B & 266,273 \\
\hline $\begin{array}{l}\text { Se puede considerar la TRC para pacientes con IC sintomáticos, en ritmo sinusal con QRS de 130-149 ms y morfología del QRS sin BRI, con FEVI } \\
\leq 35 \% \text { a pesar de recibir TMO, a efectos de mejorar los síntomas y reducir la morbimortalidad }\end{array}$ & IIb & B & 266,273 \\
\hline $\begin{array}{l}\text { Se recomienda la TRC, en lugar de marcapasos del VD, para pacientes con IC-FEr, independientemente de la clase funcional de la NYHA, que } \\
\text { tienen una indicación para marcapasos ventricular y BAV de alto grado, a efectos de reducir la mortalidad. Esto incluye a los pacientes con FA } \\
\text { (véase la sección 10.1) }\end{array}$ & I & A & $274-277$ \\
\hline $\begin{array}{l}\text { Se debe considerar la TRC para pacientes con FEVI } \leq 35 \% \text { y NYHA III-IV }{ }^{d} \text { pese al TMO, a efectos de mejorar los síntomas y reducir la } \\
\text { morbimortalidad si el paciente está en FA y tiene una duración del } Q R S \geq 130 \mathrm{~ms} \text {, siempre que se disponga de captura biventricular o se } \\
\text { espera que el paciente vuelva a ritmo sinusal }\end{array}$ & Ila & B & $\begin{array}{c}275, \\
278-281\end{array}$ \\
\hline $\begin{array}{l}\text { Se puede considerar la TRC para los pacientes con IC-FEr que tienen un marcapasos convencional o un DAI y después sufren un } \\
\text { empeoramiento de la IC pese al TMO y tienen un porcentaje alto de estimulación del VD. Esto no es aplicable a los pacientes con IC estable }\end{array}$ & IIb & B & 282 \\
\hline La TRC está contraindicada para los pacientes con QRS $<130 \mathrm{~ms}$ & III & A & $\begin{array}{c}266 \\
283-285\end{array}$ \\
\hline
\end{tabular}

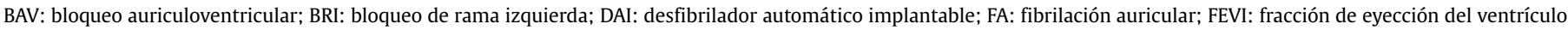

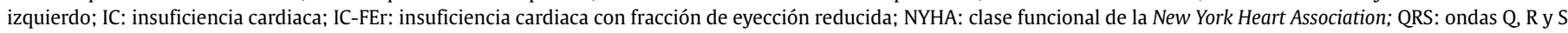
(combinación de 3 desviaciones); TRC: terapia de resincronización cardiaca; VD: ventrículo derecho.

aClase de recomendación.

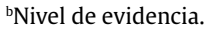

'Referencias que respaldan las recomendaciones.

dUse el juicio médico para los pacientes con IC en fase terminal tratables de manera conservadora en vez de emplear tratamientos para mejorar los síntomas o el pronóstico.

No todos los pacientes responden favorablemente a la TRC ${ }^{286}$. Varias características predicen la reducción de la morbimortalidad, y el grado de remodelado inverso es uno de los más importantes mecanismos de acción de la TRC. Los pacientes con etiología isquémica obtendrán menos mejoría de la función del VI, debido a las cicatrices del tejido miocárdico, donde es menos probable un remodelado favorable ${ }^{288}$. Sin embargo, las mujeres tienen más probabilidades que los varones de responder al tratamiento, posiblemente debido al menor tamaño de su cuerpo y de su corazón ${ }^{273,285,289}$. La amplitud del complejo QRS predice la respuesta a la TRC y fue uno de los criterios de inclusión de todos los estudios aleatorizados. Sin embargo, la morfología del QRS también se ha relacionado con una respuesta positiva a la TRC. Varios estudios han mostrado que los pacientes con morfología de bloqueo de rama izquierda (BRI) son más propensos a responder favorablemente a la TRC, mientras que hay más incertidumbre respecto a los pacientes con morfologías diferentes del BRI. Sin embargo, los pacientes con morfología de BRI suelen tener una duración del QRS más amplia, y actualmente se debate si la duración o la morfología del QRS son el predictor principal de una respuesta favorable a la TRC. Los resultados de 2 metanálisis de datos de pacientes individuales indican que, después de tener en cuenta la duración del $\mathrm{QRS}$, quedan pocas pruebas de que la morfología del QRS o la etiología de la enfermedad puedan influir en el efecto de la TRC en la morbimortalidad ${ }^{266,273}$. Además, ninguno de los estudios más importantes seleccionó a pacientes según la morfología del QRS, el sexo o la etiología isquémica ni tenía suficiente poder estadístico para el análisis de subgrupos.

El estudio Echo-CRT ${ }^{283,284}$ y un metanálisis de datos de pacientes individuales ${ }^{266}$ indican que la TRC podría ser perjudicial si la duración del QRS es < $130 \mathrm{~ms}$, por lo que no se recomienda implantar TRC en estos $\operatorname{casos}^{266,283,284}$.

Si un paciente programado para implante de DAI se encuentra en ritmo sinusal con una duración del QRS $\geq 130 \mathrm{~ms}$, se debe considerar la TRC-D si el QRS está en 130-149 ms y se recomienda si el QRS es $\geq 150 \mathrm{~ms}$. Sin embargo, si la razón principal de la TRC es el alivio de los síntomas, el médico debe decidir si implanta TRC-MP o TRC-D, lo que considere más adecuado. La práctica clínica en distintos países es muy variada. El único ECDA que comparó la TRC-MP con la TRC-D 265 no logró demostrar diferencia alguna en la morbimortalidad entre ambas técnicas ${ }^{288}$. Sin embargo, si la razón principal para el implante de TRC es mejorar el pronóstico, la evidencia indica que se debe emplear la TRC-D en pacientes en NYHA II y la TRC-MP, para pacientes en NYHA III-IV. No está claro si la TRC reduce la necesidad de un DAI (al reducir la carga arrítmica) o aumenta el beneficio del DAI (al reducir las tasas de mortalidad por empeoramiento de la IC, que conlleva mayor exposición al riesgo de arritmias).

Cuando la FEVI está reducida, la estimulación eléctrica del VD puede exacerbar la disincronía cardiaca. Esto se puede prevenir mediante TRC, que mejora los resultados de los pacientes ${ }^{274,275,277,290}$. Sin embargo, no se observó diferencia alguna en los resultados entre la TRC y la estimulación eléctrica del VD en un análisis de subgrupos del estudio RAFT ${ }^{267}$ ni en los pacientes sin IC-FEr del BioPACE ${ }^{291}$. En suma, se recomienda la TRC, más que la estimulación eléctrica del VD, para los pacientes con IC-FEr, independientemente de la clase funcional (NYHA), que tengan indicada la estimulación eléctrica ventricular para reducir la morbilidad, aunque no se ha observado un efecto claro en la mortalidad. Se debe considerar para TRC a los pacientes con ICFEr a los que se ha implantado un marcapasos convencional o un DAI y después sufren un deterioro de la IC con un porcentaje alto de estimulación eléctrica del VD pese al TMO.

Solo 2 estudios pequeños han comparado el tratamiento médico con la TRC en pacientes con FA, pero los resultados son conflictivos. Varios estudios indican que la TRC es superior a la estimulación eléctrica del VD en pacientes sometidos a ablación del nódulo auriculoventricular (NAV) $)^{275,277,290}$. Sin embargo, la TRC no es una indicación para llevar a cabo dicha ablación, a excepción de algunos casos raros en que persiste una frecuencia ventricular excesivamente alta $(>110 \mathrm{lpm})$ pese al intento de controlar la frecuencia mediante tratamiento farmacológico. Un análisis de subgrupos de pacientes con FA del estudio RAFT no mostró ningún beneficio de la TRC-D comparada con el DAI, aunque menos de la mitad de los pacientes tenían una captura biventricular $>90 \%{ }^{276}$. Los datos de algunos estudios observacionales indican que, cuando la captura biventricular es $<98 \%$, el pronóstico de los pacientes sometidos a TRC es menos favorable ${ }^{277}$. No está claro si esta asociación 
refleja una pérdida de resincronización (que se puede remediar con la programación del dispositivo), una inadecuada posición del electrodo del VI (que se puede evitar durante el implante) o una mayor dificultad para la estimulación eléctrica del miocardio enfermo (que no respondería a ninguna de las dos medidas anteriores). Esta observación no se ha confirmado en ningún estudio aleatorizado.

Las pruebas de imagen para la disincronía no se han demostrado útiles en la selección de pacientes para TRC ${ }^{292}$. Los pacientes con cicatrices extensas en el tejido miocárdico tienen menos probabilidades de que la TRC mejore la función del VI, pero esto se aplica a cualquier tratamiento para la IC-FEr y no permite predecir de manera fiable un menor beneficio clínico ${ }^{293}$. Los umbrales de estimulación eléctrica son más altos en el miocardio cicatricial y, siempre que sea posible, se debe evitar esa región para la colocación del electrodo ${ }^{294,295}$. Aunque los pacientes con cicatrices extensas tienen intrínsecamente un peor pronóstico, hay pocas pruebas de que obtengan menos beneficio pronóstico de la TRC ${ }^{266}$.

Se remite al lector a la guía sobre marcapasos y TRC donde se encuentran las recomendaciones sobre los procedimientos de implante de dispositivos. No está clara la utilidad de intentar la optimización de los intervalos AV o VV tras el implante aplicando criterios ecocardiográficos o electrocardiográficos, o la respuesta de la PA, pero se puede considerar para pacientes que no hayan respondido adecuadamente a la TRC296,297.

\subsection{Otros dispositivos eléctricos implantables}

Para los pacientes con IC-FEr que siguen sintomáticos a pesar del TMO y no tienen una indicación para la TRC, se han propuesto nuevas terapias con dispositivos y algunas de ellas han sido aprobadas para uso clínico en varios países de la Unión Europea, aunque siguen en proceso de investigación.

La modulación de la contractilidad cardiaca (MCC) es similar en su modo de inserción a la TRC, pero la estimulación eléctrica del ventrículo durante el periodo refractario absoluto no es excitatoria para potenciar el rendimiento contráctil sin activar contracciones extrasistólicas. La MCC se ha evaluado en pacientes con IC-FEr en NYHA II-III con QRS normal $(<120 \mathrm{~ms})^{221,222}$. Un metanálisis de datos de pacientes individuales demostró una mejoría en la tolerancia al ejercicio $\left(\mathrm{VO}_{2}\right.$ pico) y la calidad de vida (Minnesota Living with Heart Failure Questionnaire). Por lo tanto, se puede considerar la MCC para pacientes con IC seleccionados. Aún queda por establecer el efecto de la MCC en la morbimortalidad por IC.

La mayoría de los demás dispositivos en investigación implican alguna modificación del sistema nervioso autónomo mediante estimulación eléctrica dirigida ${ }^{298,299}$. Entre ellas, la estimulación del nervio vagal, la estimulación de la médula espinal, la ablación del cuerpo carotídeo y la denervación renal, pero hasta la fecha ninguno de estos dispositivos ha mejorado los síntomas o los resultados en los estudios realizados.

Los dispositivos para la monitorización a distancia se tratan en la sección 14

\section{TRATAMIENTO DE LA INSUFICIENCIA CARDIACA CON FRACCIÓN DE EYECCIÓN CONSERVADA}

Mientras que hay amplio acuerdo en que la definición de la IC-FEr requiere una FEVI $<40 \%$, la definición exacta de la IC-FEc está menos clara. Según la definición adoptada en esta guía, el diagnóstico de la IC-FEc requiere una $\mathrm{FEVI} \geq 50 \%$, mientras que a los pacientes con $\mathrm{FEVI}$ del $40-49 \%$ se los considera con IC y FE en rango medio (IC-FEm) (véase la sección 3). En general, los estudios sobre IC-FEc han incluido a pacientes con IC-FEm. Por ello, las consideraciones expuestas en esta sección se aplican a pacientes con IC-FEm o IC-FEc. A medida que aparezcan nuevos datos y análisis, será posible establecer recomendaciones para cada fenotipo por separado.
Comparados con los pacientes con IC-FEr, en la práctica clínica y en los estudios de investigación, parece que un número de pacientes con IC-FEc e IC-FEm apenas menor reciben tratamiento con diuréticos, bloqueadores beta, ARM e IECA o ARA-II ${ }^{16,300-302}$. Esto podría reflejar el tratamiento de comorbilidades cardiovasculares, como la hipertensión, la EAC y la FA, o la extrapolación de los resultados de estudios sobre esas afecciones que muestran una reducción de la IC de nueva aparición ${ }^{127}$, o la incapacidad para diferenciar las recomendaciones de las guías sobre la IC-FEr y la IC-FEm/IC-FEc, o la creencia de que los resultados de los estudios publicados proporcionan pruebas del beneficio de estos fármacos.

En la tabla 9.1 del anexo se resumen los estudios clínicos de fases II y III sobre pacientes con IC-FEc e IC-FEm.

La fisiopatología subyacente a la IC-FEc y la IC-FEm es heterogénea: ambas entidades se asocian a fenotipos diferentes, entre los que se incluyen enfermedades cardiovasculares concomitantes (p. ej., FA, hipertensión arterial, EAC, hipertensión pulmonar) y enfermedades no cardiovasculares (diabetes mellitus, enfermedad renal crónica [ERC], anemia, deficiencia de hierro, EPOC y obesidad) ${ }^{303,304}$. Comparados con los pacientes con IC-FEr, las hospitalizaciones y muertes de pacientes con IC-FEm/IC-FEc suelen ocurrir por causas no cardiovasculares ${ }^{305,306}$. Por esta razón, se debe cribar a los pacientes en busca de comorbilidades cardiovasculares y no cardiovasculares que, en caso de haberlas, se debe tratar con intervenciones de las que se haya demostrado que mejoran los síntomas, la calidad de vida y la evolución de los pacientes sin exacerbar la IC (véase la sección 11).

Hasta la fecha no se ha demostrado de modo convincente que ningún tratamiento reduzca la morbimortalidad de los pacientes con IC-FEc o IC-FEm. Sin embargo, dado que estos pacientes suelen ser mayores y muy sintomáticos y frecuentemente tienen mala calidad de vida ${ }^{307}$, un objetivo importante del tratamiento es aliviar los síntomas y mejorar la calidad de vida ${ }^{308}$.

\subsection{Efecto del tratamiento en los síntomas de la insuficiencia cardiaca con fracción de eyección conservada}

Los diuréticos normalmente mejoran la congestión cuando la hay y, por lo tanto, los síntomas y signos de la IC. Se ha demostrado que los diuréticos mejoran los síntomas de modo similar en todo el espectro de la FEVI ${ }^{178,179}$.

No hay pruebas de que los bloqueadores beta y los ARM mejoren los síntomas de estos pacientes. Sobre los pacientes tratados con ARA-II (solo con el candesartán se demostró una mejoría en la clase de la NYHA ${ }^{309,310}$ e IECA ${ }^{311}$, la evidencia de una mejoría de los síntomas es inconsistente.

\subsection{Efecto del tratamiento en la hospitalización por insuficiencia cardiaca en la insuficiencia cardiaca con fracción de eyección conservada}

Para pacientes en ritmo sinusal, hay algunos datos de que el nebivolol $^{173,312,313}$, la digoxina ${ }^{314}$, la espironolactona ${ }^{301}$ y el candesartán ${ }^{310}$ pueden reducir las hospitalizaciones por IC. Para los pacientes en FA, no parece que los bloqueadores beta sean efectivos y no se ha estudiado la digoxina. La evidencia sobre el uso de ARA-II ${ }^{315}$ o IECA ${ }^{311}$ no es concluyente.

\subsection{Efecto del tratamiento en la mortalidad en la insuficiencia cardiaca con fracción de eyección conservada}

Los estudios sobre IECA, ARA-II, bloqueadores beta y ARM no han demostrado una reducción de la mortalidad de los pacientes con IC-FEc o IC-FEm. Sin embargo, en pacientes mayores con IC-FEr, IC-FEc o IC-FEm, el nebivolol redujo la variable combinada de muerte u hos- 
pitalización por causas cardiovasculares ${ }^{173,312}$, sin una interacción significativa entre el efecto del tratamiento y la FEVI basal ${ }^{313}$.

\subsection{Otras consideraciones}

Los pacientes en FA deben recibir tratamiento anticoagulante para reducir el riesgo de complicaciones tromboembólicas (para más información, consulte la guía de la ESC sobre FA) ${ }^{316}$. El tratamiento antiagregante es ineficaz para este propósito. La disfunción renal, muy común en esta población, puede ser una contraindicación o aumentar el riesgo hemorrágico del tratamiento con NACO.

Para los pacientes con IC-FEm/IC-FEc y FA, la tasa óptima de la frecuencia ventricular no está claramente establecida y un control agresivo de la frecuencia puede ser perjudicial. En cuanto a la digoxina, los bloqueadores beta o los BCC limitadores de la frecuencia, o una combinación de estos, se desconoce cuál sería la opción de tratamiento preferida. No se debe combinar el verapamilo o el diltiazem con un bloqueador beta. No hay suficientes datos para recomendar estrategias de ablación (venosa pulmonar o del NAV) para la IC-FEc y la IC-FEm.

Hay pruebas circunstanciales de que el tratamiento de la hipertensión, generalmente sistólica, es importante en la IC-FEm/IC-FEc ${ }^{127,317}$. Parece que los diuréticos, IECA, ARA-II y ARM son fármacos adecuados para dicho propósito, pero los bloqueadores beta podrían ser menos efectivos para la reducción de la PAS. Un estudio reciente indica que los pacientes con hipertensión e IC-FEc o IC-FEm no deben ser tratados con un ARA-II (olmesartán) si ya están tomando un IECA $\mathrm{y}$ un bloqueador beta ${ }^{318}$.

El tratamiento hipolipemiante oral de primera línea para los pacientes con IC-FEc e IC-FEm debe ser la metformina ${ }^{319}$ (consulte también la sección 11.6). Un estudio reciente sobre la empagliflozina mostró una reducción de la PA y el peso corporal, probablemente debido a glucosuria y diuresis osmótica. Su empleo se asoció a una reducción de las hospitalizaciones por IC y de la mortalidad cardiovascular ${ }^{130}$. Sin embargo, el tratamiento agresivo de la disglucemia puede ser perjudicial ${ }^{153,320}$.

La isquemia miocárdica puede contribuir a los síntomas y la morbimortalidad, por lo que se debe tener en cuenta durante la evaluación de los pacientes. Sin embargo, no se ha demostrado que la revascularización mejore los síntomas o la evolución de los pacientes. Los pacientes con angina deben seguir la misma estrategia de tratamiento que los pacientes con IC-FEr ${ }^{112}$.

Los pacientes con IC-FEc e IC-FEm tienen reducida la tolerancia al ejercicio, generalmente acompañada de un aumento de la PA como respuesta al ejercicio e incompetencia cronotrópica. El ejercicio combinado de resistencia e intensidad parece seguro para los pacientes con IC-FEc e IC-FEm y mejora la capacidad de ejercicio (como se refleja en el aumento del consumo pico de oxígeno), los baremos de funcionamiento físico y la función diastólica ${ }^{307,321}$.

Recomendaciones para el tratamiento de pacientes con insuficiencia cardiaca y fracción de eyección conservada o en rango medio

\begin{tabular}{lccc}
\hline Recomendaciones & Clase $^{\mathrm{a}}$ & Nivel $^{\mathrm{b}}$ & Ref $^{\mathrm{c}}$ \\
\hline $\begin{array}{l}\text { Para los pacientes con IC-FEc o IC-FEm, se } \\
\text { recomienda detectar las comorbilidades } \\
\text { cardiovasculares y no cardiovasculares que, si } \\
\text { están presentes, se debe tratar siempre que haya } \\
\text { tratamientos seguros y efectivos para mejorar los } \\
\text { síntomas, el bienestar y el pronóstico }\end{array}$ & I & $\mathrm{C}$ & \\
\hline $\begin{array}{l}\text { Se recomiendan los diuréticos para los pacientes } \\
\text { congestionados con IC-FEc o IC-FEm para aliviar los } \\
\text { síntomas y signos }\end{array}$ & I & B & \multirow{2}{*}{178,179} \\
\hline
\end{tabular}

IC-FEc: insuficiencia cardiaca con fracción de eyección conservada; IC-FEm: insuficiencia cardiaca con fracción de eyección en rango medio.

aClase de recomendación.

${ }^{b}$ Nivel de evidencia.

cReferencias que respaldan las recomendaciones.

\section{ARRITMIAS Y ALTERACIONES DE LA CONDUCCIÓN}

Se puede emplear la monitorización electrocardiográfica ambulatoria para estudiar los síntomas que pudieran estar causados por arritmias ${ }^{322-324}$, pero no hay datos que respalden un uso habitual y sistemático en todos los pacientes con IC para identificar taquiarritmias y bradiarritmias. No hay pruebas de que las decisiones clínicas basadas en la monitorización electrocardiográfica ambulatoria sistemática mejoren los resultados en pacientes con IC.

Los registros electrocardiográficos ambulatorios recogen complejos ventriculares prematuros en prácticamente todos los pacientes con IC. Los episodios de TV asintomática no sostenida son frecuentes, aumentan con la gravedad de la IC y la disfunción ventricular y son indicadores de un mal pronóstico en pacientes con IC, pero proporcionan poca capacidad de discriminación entre el riesgo de muerte súbita o de muerte por progresión de la $\mathrm{IC}^{316,325}$. La bradicardia y las pausas también son frecuentes, especialmente por la noche, cuando la actividad simpática es menor y la parasimpática, mayor; las apneas del sueño pueden ser un factor desencadenante ${ }^{326-328}$. Las pausas se asocian a peor pronóstico en pacientes con EAC y disfunción del VI ${ }^{329}$. Las bradiarritmias pueden contribuir de manera importante a la muerte súbita ${ }^{330}$.

\subsection{Fibrilación auricular}

La FA es la arritmia más común en la IC independientemente de la FEVI; aumenta el riesgo de complicaciones tromboembólicas (especialmente ACV) y puede afectar a la función cardiaca, con el consiguiente empeoramiento de los síntomas de $\mathrm{IC}^{316}$. La IC incidental precipitada por FA se asocia a un pronóstico más benigno ${ }^{331}$, pero la FA de nueva aparición en un paciente con IC establecida tiene peor pronóstico, probablemente porque es un marcador de que el paciente está más enfermo y porque afecta a la función cardiaca ${ }^{332,333}$. Los pacientes con IC crónica y FA permanente tienen una evolución menos favorable que los pacientes en ritmo sinusal, aunque esto se explicaría por la edad más avanzada y la gravedad de la IC $\mathrm{IC}^{332,333}$. Las frecuencias ventriculares persistentes $>150 \mathrm{lpm}$ pueden causar IC-FEr, que se resuelve con el control de la frecuencia o la corrección del ritmo ("taquimiocardiopatía») ${ }^{334,335}$. La FA se debe clasificar y tratar según las guías actuales (primer episodio diagnosticado, paroxística, persistente, persistente sostenida o permanente), reconociendo la incertidumbre sobre la duración real del episodio y los episodios previos no detectados ${ }^{316}$.

Hay que tener en cuenta los siguientes aspectos en pacientes con IC y FA, independientemente de la FEVI, y especialmente en caso de un primer episodio diagnosticado de FA o FA paroxística ${ }^{316}$ :

- Identificación de causas potencialmente corregibles (p. ej., hipotiroidismo o hipertiroidismo, trastornos electrolíticos, hipertensión no controlada, valvulopatía mitral) y factores precipitantes (p. ej., cirugía reciente, infección torácica o exacerbación de EPOC/asma, isquemia miocárdica aguda, embriaguez), ya que pueden determinar la estrategia de tratamiento.

- Evaluación del riesgo de ACV y la necesidad de anticoagulación.

- Evaluación de la frecuencia ventricular y la necesidad de control de la frecuencia.

- Evaluación de los síntomas de IC y FA.

Para más información, se refiere al lector a la guía de la ESC sobre FA $(2016)^{316}$.

\subsubsection{Prevención de la fibrilación auricular en pacientes con insuficiencia cardiaca}

Muchos tratamientos para la IC, como IECA ${ }^{336}$, ARA-II $^{337}$, bloqueadores beta ${ }^{177,338}$ y ARM ${ }^{339,340}$, reducen la incidencia de FA, pero la ivabradina podría aumentarla ${ }^{342}$. 
La amiodarona reduce la incidencia de FA, induce la cardioversión farmacológica, mantiene a más pacientes en ritmo sinusal tras la cardioversión y se puede emplear para controlar los síntomas de pacientes con FA paroxística si los bloqueadores beta no lo consiguen ${ }^{343-346}$. El uso de amiodarona debe restringirse a periodos cortos (<6 meses) en pacientes con FA paroxística o persistente para alcanzar un ritmo sinusal y reducir la elevada tasa de FA recurrente inmediatamente después de la cardioversión. La dronedarona está contraindicada para pacientes con IC y FA $246,247,347$

\subsubsection{Tratamiento de la fibrilación auricular rápida de nueva aparición en pacientes con insuficiencia cardiaca}

Si el paciente no tiene síntomas de IC preocupantes, se puede iniciar el tratamiento con bloqueadores beta para controlar la frecuencia ventricular. Para los pacientes con congestión marcada, pero con pocos síntomas en reposo, es preferible iniciar el tratamiento con digoxina oral o intravenosa.

Para los pacientes con inestabilidad hemodinámica, se administrará un bolo i.v. de digoxina o amiodarona ${ }^{348,349}$ en una vena periférica, extremando las precauciones para evitar la extravasación a tejidos; si hubiera dudas sobre el acceso venoso, no se administrará amiodarona. En caso de infusión continua de amiodarona, es preciso

Recomendaciones sobre la atención inicial a la frecuencia ventricular rápida de pacientes con insuficiencia cardiaca y fibrilación auricular en un contexto agudo o crónico

\begin{tabular}{|c|c|c|c|}
\hline Recomendaciones & Clase $^{\mathrm{a}}$ & Nivel $^{\mathrm{b}}$ & $\operatorname{Ref}^{\mathrm{c}}$ \\
\hline $\begin{array}{l}\text { Se recomienda la cardioversión eléctrica urgente } \\
\text { si se cree que la FA contribuye al deterioro } \\
\text { hemodinámico del paciente, a efectos de mejorar } \\
\text { su estado clínico }\end{array}$ & I & C & \\
\hline $\begin{array}{l}\text { Para los pacientes en NYHA IV, además del } \\
\text { tratamiento de la ICA, se considerará la } \\
\text { administración de un bolo intravenoso de } \\
\text { amiodarona o, para quienes no se han tratado con } \\
\text { digoxina, un bolo intravenoso de esta para reducir } \\
\text { la frecuencia ventricular }\end{array}$ & IIa & B & 348,349 \\
\hline $\begin{array}{l}\text { Para los pacientes en NYHA I-III, un bloqueador } \\
\text { beta, normalmente por vía oral, es seguro y, por lo } \\
\text { tanto, se recomienda como tratamiento de primera } \\
\text { línea para controlar la frecuencia cardiaca siempre } \\
\text { que el paciente esté euvolémico }\end{array}$ & I & A & 177 \\
\hline $\begin{array}{l}\text { Para los pacientes en NYHA I-III, se debe considerar } \\
\text { la administración de digoxina cuando la frecuencia } \\
\text { ventricular continúe altad pese al tratamiento } \\
\text { con bloqueadores beta o si el paciente no los tolera } \\
\text { o los tiene contraindicados }\end{array}$ & IIa & B & 197 \\
\hline $\begin{array}{l}\text { Se puede considerar la ablación por catéter del NAV } \\
\text { para controlar la frecuencia cardiaca y aliviar los } \\
\text { síntomas de los pacientes que no responden o no } \\
\text { toleran el tratamiento farmacológico intensivo para } \\
\text { el control del ritmo y la frecuencia, aceptando que } \\
\text { estos pacientes dependerán del marcapasos }\end{array}$ & IIb & B & 290 \\
\hline $\begin{array}{l}\text { No se recomienda por problemas de seguridad } \\
\text { el tratamiento con dronedarona para mejorar el } \\
\text { control de la frecuencia ventricular }\end{array}$ & III & A & 347 \\
\hline
\end{tabular}

FA: fibrilación auricular; ICA: insuficiencia cardiaca aguda; lpm: latidos por minuto NAV: nódulo auriculoventricular; NYHA: clase funcional de la New York Heart Association.

aClase de recomendación.

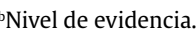

'Referencias que respaldan las recomendaciones.

${ }^{d}$ No se ha establecido la frecuencia ventricular óptima para pacientes con IC y FA pero los datos disponibles indican que un control estricto podría ser perjudicial. Según la opinión de este Grupo de Trabajo, se puede considerar una frecuencia ventricular de $60-100 \mathrm{lpm}^{350,351}$, aunque un estudio ha indicado que hasta $110 \mathrm{lpm}$ podría ser aceptable, y esto es lo que recomienda la guía actual de la ESC sobre FA ${ }^{198,316}$. Esta recomendación se debe probar y perfeccionar en futuros estudios. emplear un acceso venoso central o sonda larga para evitar la flebitis en venas periféricas. Para pacientes con colapso hemodinámico, se recomienda la cardioversión eléctrica urgente (véase también la sección 12).

\subsubsection{Control de la frecuencia cardiaca}

La evaluación del control de la frecuencia ventricular mediante el pulso radial no es el método ideal, especialmente para pacientes con IC, ya que la activación ventricular no siempre genera un pulso palpable. El control de la frecuencia se debe registrar mediante electrocardiografía. El empleo de un dispositivo portátil permite evaluar la frecuencia ventricular en reposo, en ejercicio y durante el sueño, pero no se ha establecido la utilidad de la monitorización sistemática. Se puede emplear también otros dispositivos implantables, como marcapasos, TRC o DAI, para medir la frecuencia ventricular.

La frecuencia ventricular óptima en reposo en pacientes con FA e IC no está claramente establecida, pero podría estar entre $60 \mathrm{y}$ $100 \mathrm{lpm}^{350,352-354}$. Los datos de un estudio indican que una frecuencia ventricular en reposo de $110 \mathrm{lpm}$ puede ser aceptable ${ }^{198,202}$ y la guía de la ESC sobre FA (2016) recomienda este umbral como objetivo de tratamiento para el control de la frecuencia ${ }^{316}$. Sin embargo, el Grupo de Trabajo de la presente guía considera que en pacientes con IC es preferible una frecuencia más baja $(60-100 \mathrm{lpm})$. Las frecuencias ventriculares $<70 \mathrm{lpm}$ se asocian a peores resultados ${ }^{351}$. Esto podría explicar por qué los bloqueadores beta administrados en las dosis máximas recomendadas por las guías no lograron reducir la morbilidad o la mortalidad en pacientes con IC-FEr y $\mathrm{AF}^{177}$ y podría explicar también la asociación entre la digoxina y los resultados adversos comunicados en algunos estudios observacionales sobre $\mathrm{FA}^{355-357}$. La frecuencia ventricular óptima durante el ejercicio tampoco está clara, pero podría ser $<110 \mathrm{lpm}$ durante el ejercicio de baja intensidad ${ }^{354}$. Los bloqueadores beta, la digoxina y la combinación de ambos pueden emplearse para controlar la frecuencia ventricular ${ }^{358}$. Se desconoce cuál es la estrategia óptima, pero los bloqueadores beta parecen seguros como primera línea de tratamiento, aun cuando no está claro que puedan reducir la morbimortalidad en pacientes con FA. Los bloqueadores beta reducen la frecuencia ventricular durante los periodos de actividad, mientras que la digoxina ejerce un mayor efecto durante la noche ${ }^{358}$. La frecuencia ventricular persistentemente alta puede indicar la presencia de tirotoxicosis o un exceso de actividad simpática debido a la congestión, que podría responder a la diuresis. Aunque la amiodarona y los BCC no dihidropiridínicos pueden reducir la frecuencia ventricular, estos fármacos tienen más efectos adversos $\mathrm{y}$, en general, es mejor evitar su uso en pacientes con IC-FEr y, con menos certeza, en pacientes con IC-FEc e IC-FEm. En raras ocasiones, la frecuencia ventricular no se puede reducir a menos de 100-110 lpm mediante tratamiento farmacológico, por lo que se puede considerar la ablación del NAV con marcapasos ventricular; en este contexto y para los pacientes con IC-FEr, se valorará el empleo de TRC en lugar del marcapasos VD convencional. A excepción de datos de registros, hay pocas pruebas que respalden el uso de la ablación del NAV y la TRC frente al tratamiento farmacológico en pacientes con FA y una frecuencia ventricular en reposo $<100-110 \mathrm{lpm}$ (véase la sección $8.2)^{281}$. Sin embargo, para pacientes con frecuencia ventricular rápida y síntomas intratables, se puede considerar la ablación del NAV. Además, si el paciente tiene una indicación de DAI, la ablación del NAV con implante de TRC-D puede ser la opción preferida, especialmente si el paciente tiene síntomas moderados o graves.

\subsubsection{Control del ritmo cardiaco}

No se ha demostrado en pacientes con IC crónica que una estrategia de control del ritmo cardiaco (cardioversión farmacológica o eléctrica) sea superior a una estrategia de control de la frecuencia cardiaca para reducir la mortalidad o la morbilidad ${ }^{359}$. La cardioversión urgente 
solo está indicada cuando la FA es potencialmente mortal, de otro modo, se debe controlar antes de la cardioversión tanto la IC como la frecuencia ventricular. Probablemente sea mejor reservar la estrategia de control del ritmo cardiaco para pacientes con una causa secundaria y reversible de FA ( $p$. ej., hipertiroidismo) o un factor precipitante obvio (p. ej., neumonía reciente) y pacientes con síntomas problemáticos debido a la FA tras la optimización de la frecuencia cardiaca y el tratamiento de la IC. El uso de antiarrítmicos de clase I y dronedarona aumenta la morbimortalidad de los pacientes con IC y FA, y se debe evitar ${ }^{246,247,347}$. La amiodarona puede lograr que algunos pacientes con FA crónica se reviertan a ritmo sinusal, puede reducir los paroxismos sintomáticos de la FA y ayuda a mantener a los pacientes en ritmo sinusal tras la cardioversión espontánea o eléctrica ${ }^{343-346}$. Cuando se emplea, es preciso revisar y justificar la necesidad de administración continua de amiodarona.

La seguridad y la eficacia de la ablación por catéter en aurículas y venas pulmonares (VP) como estrategia de control del ritmo cardiaco en la IC no están claras, excepto en caso de miocardiopatía inducida por taquicardia ${ }^{316}$. Los datos de un estudio pequeño indican que la ablación de la FA es superior a la ablación del NAV y la TRC ${ }^{360}$. Otro estudio, que incluyó a 203 pacientes con FA persistente, IC y un DAI o dispositivo de TRC, mostró que la ablación de la FA fue superior a la amiodarona para la corrección de la FA, y esto se asoció a un menor número de hospitalizaciones por IC y una mortalidad más baja. Dos estudios pequeños sobre la ablación de la FA comparada con el control de la frecuencia cardiaca obtuvieron resultados dispares en cuanto a las complicaciones del procedimiento y el éxito en el alivio de los síntomas ${ }^{278,279}$. Recientemente, un metanálisis que incluyó a 914 pacientes mostró una prometedora tasa de éxito de la ablación de la FA (VP) en pacientes con disfunción del VI, con mejorías en la FEVI y la capacidad funcional ${ }^{361}$. Estos resultados tienen que confirmarse en los ECDA actualmente en curso, como los estudios CASTLE AF $^{362}$, AMICA y CABANA.

Recomendaciones para la estrategia de control del ritmo cardiaco de pacientes con fibrilación auricular, insuficiencia cardiaca sintomática (NYHA II-IV) y disfunción sistólica ventricular izquierda sin evidencia de descompensación aguda

\begin{tabular}{lccc}
\hline Recomendaciones & Clase & Nivel $^{\mathrm{b}}$ & Ref $^{\mathrm{c}}$ \\
\hline $\begin{array}{l}\text { Se puede considerar la cardioversión eléctrica } \\
\text { o farmacológica con amiodarona para pacientes con } \\
\text { síntomas o signos de IC persistentes pes al TMO y } \\
\text { control adecuado de la frecuencia cardiaca, } \\
\text { para mejorar el estado clínico y los síntomas }\end{array}$ & IIb & B & 344 \\
\hline $\begin{array}{l}\text { Se puede considerar la ablación de la FA para } \\
\text { restaurar el ritmo sinusal y mejorar los síntomas/ } \\
\text { estado clínico de los pacientes con síntomas o } \\
\text { signos de IC persistentes a pesar del TMO y control } \\
\text { adecuado de la frecuencia cardiaca }\end{array}$ & IIb & B & 279,363 \\
\hline $\begin{array}{l}\text { Se puede considerar la administración de } \\
\text { amiodarona antes (y después) de la cardioversión } \\
\text { eléctrica efectiva para mantener el ritmo sinusal }\end{array}$ & IIb & B & 342,360 \\
\hline $\begin{array}{l}\text { No se recomienda la dronedarona debido al } \\
\text { aumento del riesgo de hospitalización por causas } \\
\text { cardiovasculares y el riesgo de muerte prematura } \\
\text { de los pacientes en NYHA III-IV }\end{array}$ & III & A & 247,347 \\
\hline $\begin{array}{l}\text { No se recomiendan los antiarrítmicos de clase } \\
\text { I debido a un aumento del riesgo de muerte } \\
\text { prematura }\end{array}$ & III & A & 248,364, \\
\hline
\end{tabular}

FA: fibrilación auricular; IC: insuficiencia cardiaca; NYHA: clase funcional de la New York Heart Association; TMO: tratamiento médico óptimo.

Los pacientes deben estar anticoagulados durante las 6 semanas previas a la cardioversión eléctrica.

aClase de recomendación.

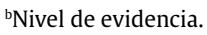

'Referencias que respaldan las recomendaciones.

\subsubsection{Profilaxis de la tromboembolia}

Generalmente los pacientes con IC y FA deben estar anticoagulados, y se debe evaluar el balance entre beneficio y riesgo hemorrágico (calculado mediante los métodos $\mathrm{CHA}_{2} \mathrm{DS}_{2}$-VASc y HAS-BLED; para más información, consulte las tablas 10.1 y 10.2 del anexo), como recomienda la guía de la ESC sobre $\mathrm{FA}^{316}$. Un porcentaje importante de pacientes con IC tendrán puntuaciones de riesgo y beneficio $\geq 3$, lo cual indica que se precisa una cuidadosa valoración del paciente antes de prescribirle un anticoagulante oral y una revisión regular si se administra este tratamiento (y tratar los factores de riesgo hemorrágico corregibles).

Recomendaciones para la prevención de tromboembolias en pacientes con insuficiencia cardiaca sintomática (NYHA II-IV) y fibrilación auricular paroxística o persistente/permanente

\begin{tabular}{|c|c|c|c|}
\hline Recomendaciones & Clase $^{\mathrm{a}}$ & Nivel $^{\mathrm{b}}$ & $\operatorname{Ref}^{c}$ \\
\hline $\begin{array}{l}\text { Las puntuaciones } \mathrm{CHA}_{2} \mathrm{DS}_{2} \text {-VASc y HAS-BLED } \\
\text { son herramientas recomendadas para calcular } \\
\text { el riesgo, respectivamente, de tromboembolias y } \\
\text { hemorrágico asociados a la anticoagulación } \\
\text { en pacientes con IC }\end{array}$ & I & B & 376,377 \\
\hline $\begin{array}{l}\text { Se recomienda la administración de un } \\
\text { anticoagulante oral para prevenir las } \\
\text { tromboembolias para todos los pacientes con } \\
\text { FA paroxística o persistente/permanente y } \\
\text { una puntuación } \mathrm{CHA}_{2} \mathrm{DS}_{2} \text {-VASc } \geq 2 \text { si no hay } \\
\text { contraindicaciones e independientemente del } \\
\text { empleo de una estrategia para el control del ritmo } \\
\text { cardiaco (incuso después de la cardioversión } \\
\text { efectiva) }\end{array}$ & I & A & $\begin{array}{c}372-375 \\
378,379\end{array}$ \\
\hline $\begin{array}{l}\text { El tratamiento con NACO está contraindicado } \\
\text { para pacientes con válvulas mecánicas o estenosis } \\
\text { mitral moderada o alta }\end{array}$ & III & B & 380 \\
\hline $\begin{array}{l}\text { Para pacientes con FA de duración } \geq 48 \text { h o } \\
\text { desconocida, se recomienda un anticoagulante } \\
\text { oral a dosis terapéuticas durante al menos las } \\
3 \text { semanas previas a la cardioversión eléctrica } \\
\text { o farmacológica }\end{array}$ & I & B & \\
\hline $\begin{array}{l}\text { Se recomienda la heparina o HBPM intravenosa } \\
\text { y una estrategia guiada por ETE para los pacientes } \\
\text { aún no tratados con un anticoagulante durante } \\
\text { al menos } 3 \text { semanas que requieren cardioversión } \\
\text { eléctrica o farmacológica urgente debido a arritmia } \\
\text { potencialmente mortal }\end{array}$ & I & C & \\
\hline $\begin{array}{l}\text { No se recomienda la combinación de un } \\
\text { anticoagulante oral y un antiagregante para los } \\
\text { pacientes con enfermedad arterial coronaria u } \\
\text { otra enfermedad arterial crónica (más de } 12 \text { meses } \\
\text { después del evento agudo) debido al alto riesgo } \\
\text { hemorrágico. El tratamiento con un anticoagulante } \\
\text { oral es preferible después de } 12 \text { meses }\end{array}$ & III & C & \\
\hline $\begin{array}{l}\text { Para los pacientes con IC y FA no valvular } \\
\text { candidatos a anticoagulación según la puntuación } \\
\mathrm{CHA}_{2} \mathrm{DS}_{2} \text {-VASc, se debe considerar el tratamiento } \\
\text { con NACO, en lugar de warfarina, ya que se asocian } \\
\text { con reducciones de los riesgos de ACV, hemorragia } \\
\text { intracraneal y mortalidad, que superan el aumento } \\
\text { del riesgo de hemorragia gastrointestinal }\end{array}$ & IIa & B & 367 \\
\hline
\end{tabular}

ACV: accidente cerebrovascular; $\mathrm{CHA}_{2} \mathrm{DS}_{2}-\mathrm{VAS}_{c}$ : insuficiencia cardiaca congestiva o disfunción ventricular izquierda, hipertensión, edad $\geq 75$ (doble), diabetes, ictus (doble)-enfermedad vascular, edad 65-74 y sexo (mujer); ETE: ecocardiografía transesofágica; FA: fibrilación auricular; HBPM: heparina de bajo peso molecular; HASBLED: hipertensión, función renal/hepática anormal (1 punto cada una), ictus, historia o predisposición al sangrado, INR lábil, ancianos (> 65 años), consumo concomitante de drogas/alcohol (1 punto cada uno); IC: insuficiencia cardiaca; NACO: nuevos anticoagulantes orales no dependientes de la vitamina K; NYHA: clase funcional de la New York Heart Association.

aClase de recomendación.

bNivel de evidencia.

'Referencias que respaldan las recomendaciones. 
Los NACO son los fármacos preferidos para pacientes con IC y FA no valvular, ya que, comparados con los antagonistas de la vitamina $\mathrm{K}$, parecen ser al menos igual de efectivos y más seguros (menos hemorragias intracraneales) para pacientes con IC que para aquellos sin IC ${ }^{316,366,367}$, aunque hay dudas sobre su seguridad en pacientes de más edad y con función renal reducida ${ }^{368,369}$ (para una descripción detallada de la interacción de los NACO con la función renal, consulte Heidbuchel et $\left.a .^{370}\right)$. Para pacientes con IC y FA que tienen válvulas cardiacas mecánicas o estenosis mitral moderada, solo se debe emplear antagonistas de la vitamina K para la prevención del ictus tromboembólico ${ }^{70}$.

Cuando el aclaramiento de creatinina sea de $30-49 \mathrm{ml} / \mathrm{min}$, se debe reducir la dosis de dabigatrán a $110 \mathrm{mg} / 12$ h; el rivaroxabán, a $15 \mathrm{mg} /$ día y el edoxabán, a $30 \mathrm{mg}$ /día cuando el aclaramiento de creatinina sea de $30-50 \mathrm{ml} / \mathrm{min}$ y el apixabán, a $2,5 \mathrm{mg} / 12 \mathrm{~h}$ si el paciente tiene 2 o más de los siguientes factores: edad $\geq 80$ años, creatinina sérica $\geq 1,5 \mathrm{mg} / \mathrm{dl}$ o peso corporal $\leq 60 \mathrm{~kg}^{370-375}$. El resumen de las recomendaciones para la prevención de tromboembolias en pacientes con IC sintomática y FA paroxística o persistente/permanente se encuentra en la tabla de recomendaciones. Para más detalles, consulte la reciente guía de la ESC sobre $\mathrm{FA}^{316}$.

Como alternativa a la anticoagulación oral, se puede considerar el uso de un dispositivo de oclusión auricular izquierda para pacientes con FA y riesgo de tromboembolia o hemorragia para evitar el riesgo hemorrágico asociado a la anticoagulación ${ }^{381,382}$.

\subsection{Arritmias ventriculares}

El abordaje inicial de las arritmias ventriculares asintomáticas incluye la corrección de las alteraciones electrolíticas, particularmente los títulos séricos de potasio y magnesio bajos, la suspensión de fármacos que puedan causar arritmias y, en pacientes con IC-FEr, la

Recomendaciones para la atención a las taquiarritmias ventriculares en la insuficiencia cardiaca

\begin{tabular}{|c|c|c|c|}
\hline Recomendaciones & Clase $^{\mathrm{a}}$ & Nivel $^{\mathrm{b}}$ & $\operatorname{Ref}^{c}$ \\
\hline $\begin{array}{l}\text { Para los pacientes con arritmias ventriculares, } \\
\text { es necesario detectar y corregir los factores } \\
\text { potencialmente agravantes/precipitantes (p. ej., } \\
\text { déficit de potasio/magnesio sérico, isquemia) }\end{array}$ & IIa & C & \\
\hline $\begin{array}{l}\text { El tratamiento con un bloqueador beta, ARM y } \\
\text { sacubitrilo/valsartán reduce el riesgo de muerte } \\
\text { súbita y se recomienda para pacientes con IC- } \\
\text { FEr y arritmias ventriculares (al igual que otros } \\
\text { pacientes; véase la sección 7) }\end{array}$ & I & A & $\begin{array}{c}162 \\
170-175\end{array}$ \\
\hline $\begin{array}{l}\text { Se recomienda implantar un DAI o TRC-D a } \\
\text { pacientes con IC-FEr seleccionados (véase la } \\
\text { sección 8) }\end{array}$ & I & A & $\begin{array}{c}223-226 \\
388\end{array}$ \\
\hline $\begin{array}{l}\text { Se debe considerar distintas estrategias para } \\
\text { reducir las arritmias sintomáticas recurrentes en } \\
\text { pacientes con DAI (o que no son candidatos a DAI), } \\
\text { que incluyan el tratamiento de los factores de } \\
\text { riesgo, el tratamiento farmacológico óptimo de la } \\
\text { IC, amiodarona, ablación por catéter y TRC }\end{array}$ & IIa & C & \\
\hline $\begin{array}{l}\text { No se recomienda el uso sistemático de } \\
\text { antiarrítmicos para pacientes con IC y arritmias } \\
\text { ventriculares asintomáticas debido a problemas } \\
\text { de seguridad (empeoramiento de la IC, proarritmia } \\
\text { y muerte) }\end{array}$ & III & A & $\begin{array}{l}247,248 \\
364,365\end{array}$ \\
\hline
\end{tabular}

ARA-II: antagonistas del receptor de la angiotensina II; ARM: antagonista del receptor de mineralocortidoides; DAI: desfibrilador automático implantable; IC: insuficiencia cardiaca; IC-FEr: insuficiencia cardiaca con fracción de eyección reducida; IECA: inhibidores de la enzima de conversión de la angiotensina; TRC: terapia de resincronización cardiaca; TRC-D: terapia de resincronización cardiaca con desfibrilador

aclase de recomendación.

bNivel de evidencia.

'Referencias que respaldan las recomendaciones. optimización del tratamiento farmacológico con IECA, bloqueadores beta, ARM y sacubitrilo-valsartán, los cuales reducen el riesgo de muerte súbita ${ }^{174,177,383,384}$

La importancia clínica de la isquemia miocárdica como causa de arritmias ventriculares es incierta, aunque se han dado casos puntuales de arritmias inducidas por isquemia. En estudios aleatorizados sobre revascularización de pacientes con IC-FEr, no se observó una reducción de la mortalidad total ${ }^{107,385}$, incluso en subgrupos de pacientes con angina o isquemia miocárdica ${ }^{15,386}$, pero análisis posteriores indican una reducción de la muerte súbita ${ }^{387}$.

La amiodarona (frecuentemente combinada con un bloqueador beta) se puede emplear para suprimir las arritmias ventriculares sintomáticas, pero puede afectar negativamente al pronóstico, especialmente en pacientes con IC más grave ${ }^{227,244}$. Debe evitarse el uso de otros fármacos antiarrítmicos ${ }^{247}$. La modificación transcatéter por radiofrecuencia del sustrato arritmogénico puede reducir el número de descargas del DAI y se puede emplear para resolver la tormenta arrítmica en pacientes con IC y taquiarritmias ventriculares frecuentes y recurrentes; por lo tanto, se debe considerar para tales pacientes. Se recomienda solicitar el consejo de los miembros del equipo de IC con experiencia en electrofisiología para los pacientes con arritmias ventriculares refractarias. Para más información, consulte la guía de la ESC/EHRA sobre arritmias ventriculares y muerte súbita ${ }^{260}$.

\subsection{Bradicardia sintomática, pausas y bloqueo auriculoventricular}

La guía de la ESC sobre marcapasos y TRC recomienda intervenir cuando las pausas excedan los $6 \mathrm{~s}$, incluso cuando no se acompañen de síntomas ${ }^{389}$. Sin embargo, estas recomendaciones se establecieron fundamentalmente para pacientes sin disfunción miocárdica obvia, y tal vez las pausas de menor duración requieran también una inter-

Recomendaciones para el tratamiento de las bradiarritmias en la insuficiencia cardiaca

\begin{tabular}{|c|c|c|c|}
\hline Recomendaciones & Clase $^{a}$ & Nivel $^{\mathrm{b}}$ & $\operatorname{Ref}^{c}$ \\
\hline $\begin{array}{l}\text { Cuando se identifiquen pausas }>3 \text { s en el ECG } \\
\text { o la bradicardia sea sintomática y la frecuencia } \\
\text { ventricular en reposo, < } 50 \mathrm{lpm} \text { en ritmo sinusal o } \\
\text { < } 60 \mathrm{lpm} \text { en } \mathrm{FA} \text {, se debe considerar la necesidad de } \\
\text { los fármacos prescritos para limitar la frecuencia; } \\
\text { para pacientes en ritmo sinusal, se reducirá o } \\
\text { interrumpirá el tratamiento con bloqueadores beta } \\
\text { solo como último recurso }\end{array}$ & IIa & C & \\
\hline $\begin{array}{l}\text { Para pacientes con pausas sintomáticas, largas o } \\
\text { frecuentes pese al ajuste de la medicación para } \\
\text { limitar la frecuencia cardiaca, se considerará la } \\
\text { suspensión del tratamiento con bloqueadores beta } \\
\text { o implantar marcapasos como siguiente medida }\end{array}$ & IIb & C & \\
\hline $\begin{array}{l}\text { No se recomienda implantar marcapasos con el } \\
\text { único objetivo de permitir el inicio o el aumento } \\
\text { de la dosis de bloqueadores beta si no hay una } \\
\text { indicación convencional de marcapasos }\end{array}$ & III & $\mathrm{C}$ & \\
\hline $\begin{array}{l}\text { Para los pacientes con IC-FEr que requieren } \\
\text { marcapasos y tienen BAV de alto grado, se } \\
\text { recomienda la TRC más que el marcapasos del VD }\end{array}$ & I & A & $\begin{array}{c}274,275 \\
290\end{array}$ \\
\hline $\begin{array}{l}\text { Para pacientes con IC-FEr que requieren marcapasos } \\
\text { y no tienen BAV de alto grado, se debe considerar } \\
\text { modalidades de estimulación eléctrica que eviten } \\
\text { inducir o exacerbar la disincronía ventricular }\end{array}$ & IIa & C & \\
\hline
\end{tabular}

BAV: bloqueo auriculoventricular; ECG: electrocardiograma; FA: fibrilación auricular; IC-FEr: insuficiencia cardiaca con fracción de eyección reducida; lpm: latidos por minuto; NYHA: clase funcional de la New York Heart Association; TRC: terapia de resincronización cardiaca; VD: ventrículo derecho.

${ }^{a}$ Clase de recomendación.

bNivel de evidencia.

'Referencias que respaldan las recomendaciones. 
vención en los pacientes con IC-FEr ${ }^{329}$. Si se identifican pausas $>3 \mathrm{~s}$ mediante electrocardiografía, será necesario revisar la medicación y se suspenderá o reducirá la dosis de los siguientes fármacos: primero los BCC limitadores de la frecuencia y después amiodarona, digoxina e ivabradina. Para pacientes con FA, se considerará una reducción de la dosis de bloqueadores beta para permitir que la frecuencia ventricular diurna en reposo ascienda a 70-90 lpm, dado que no está probado que los bloqueadores beta mejoren la evolución de los pacientes con $\mathrm{FA}^{177}$. Para los pacientes con pausas pero en ritmo sinusal, debe evitarse la reducción de la dosis de bloqueadores beta, excepto cuando las pausas sean sintomáticas, largas o frecuentes, en cuyo caso se considerará la conveniencia de reducir la dosis o suspender el bloqueador beta e implantar un marcapasos (biventricular). Sin embargo, no hay pruebas que respalden una estrategia de implante de marcapasos solamente para permitir la administración o el aumento de la dosis de un bloqueador beta en ausencia de una indicación convencional de marcapasos; no se recomienda esta estrategia. Para pacientes con IC-FEr y bloqueo auriculoventricular de alto grado, la TRC es preferible al marcapasos de VD (véase la sección 8). Cuando la causa de la bradicardia o las pausas sea la enfermedad del nódulo sinusal con la conducción auriculoventricular intacta, son preferibles las estrategias terapéuticas que eviten la inducción de disincronía ventricular, aunque son escasos los datos de estudios clínicos que respalden esta opinión de expertos en relación con los pacientes con IC. Para otras indicaciones de marcapasos, consulte la guía de la ESC sobre marcapasos y TRC ${ }^{389}$.

\section{COMORBILIDADES}

\subsection{Insuficiencia cardiaca y comorbilidades}

Las comorbilidades son muy importantes en los pacientes con IC (tabla 11.1) y pueden afectar al uso de tratamientos para esta (p. ej., cuando no es posible utilizar inhibidores del sistema renina-angiotensina en algunos pacientes con insuficiencia renal) (véase la sección 7). Los fármacos empleados para tratar las comorbilidades pueden empeorar la IC (p. ej., los AINE contra la artritis, algunos fármacos anticancerígenos) (véase la sección 7). El tratamiento de las comorbilidades es un elemento clave para la atención integral de los pacientes con IC (véase la sección 14). Muchas comorbilidades son tratadas por especialistas que siguen las guías propias de su especialidad. En las guías de práctica clínica actuales, se identifica la presencia de IC cuando esta modifica el tratamiento normal de una comorbilidad, debido a que la seguridad o la eficacia pueden variar en presencia de IC (o simplemente son desconocidas) o porque hay pruebas sobre efectos específicos en una población con IC (beneficiosos o perjudiciales). La IC-FEc tiene mayor prevalencia de comorbilidades que la IC-FEr, y muchas de ellas son fundamentales en la progresión de este síndrome ${ }^{398}$.

\subsection{Angina y enfermedad arterial coronaria}

\subsubsection{Tratamiento farmacológico}

Los bloqueadores beta y la ivabradina ${ }^{180}$ en algunos pacientes seleccionados son efectivos para el control de la angina, además de ser un componente fundamental del tratamiento para la IC-FEr. En pacientes con IC-FEc, también pueden usarse para el alivio de la angina, pero su efecto no se ha probado formalmente. En el estudio SIGNIFY en pacientes con angina limitadora de la actividad sin IC, la ivabradina aumentó el riesgo de muerte por causas cardiovasculares y el infarto de miocardio no mortal, por lo que no está recomendada en este contexto ${ }^{399}$.

Se ha demostrado que la trimetazidina tiene efecto beneficioso como fármaco añadido a los bloqueadores beta en pacientes con IC y angina ${ }^{400-406}$. Algunos datos indican que puede mejorar la capacidad
Tabla 11.1

Importancia de las comorbilidades en pacientes con insuficiencia cardiaca

1. Interfieren en el proceso diagnóstico de la IC (p. ej., la EPOC como factor de confusión en la causa de la disnea) ) $^{390,391}$

2. Empeoran los síntomas de IC y deterioran la calidad de vida ${ }^{391,392}$

3. Contribuyen al aumento de las hospitalizaciones y la mortalidad ${ }^{393}$ como causa principal de los reingresos a 1 y 3 meses $^{394}$

4. Pueden afectar al uso de tratamientos para la IC (p. ej., inhibidores del sistema renina-angiotensina, que están contraindicados para algunos pacientes con insuficiencia renal grave, o bloqueadores beta, que tienen una contraindicación relativa en el asma $)^{395,396}$

5. Hay menos evidencia para los tratamientos de la IC, ya que las comorbilidades son un criterio de exclusión de la mayoría de los estudios; por lo tanto, no se puede asegurar la eficacia y la seguridad de algunas intervenciones en presencia de comorbilidades

6. Los fármacos empleados para tratar las comorbilidades pueden empeorar la IC (p. ej., AINE para la artritis, algunos fármacos anticancerosos) ${ }^{397}$

7. La interacción entre fármacos empleados para la IC y las comorbilidades puede disminuir la eficacia y la seguridad de los tratamientos y aumentar los efectos secundarios (p. ej., bloqueadores beta para la IC y agonistas beta para la EPOC y el asma $)^{391,395,396}$

AINE: antiinflamatorios no esteroideos; EPOC: enfermedad pulmonar obstructiva crónica; IC: insuficiencia cardiaca; IC-FEr: insuficiencia cardiaca con fracción de eyección reducida.

funcional (NYHA), la duración del ejercicio y la función del VI de pacientes con IC-FEr ${ }^{402-406}$. Otros fármacos antianginosos se han estudiado en un gran número de pacientes con IC-FEr/disfunción del VI, y se ha demostrado que son efectivos y seguros (p. ej., amlodipino ${ }^{215,407}$, nicorandil ${ }^{408}$ y los nitratos ${ }^{183,184,409}$ ). La seguridad de otros fármacos antianginosos en la IC-FEr, como la ranolazina, no está clara, mientras se cree que otros fármacos, específicamente el diltiazem y el verapamilo, no son seguros para estos pacientes (aunque pueden emplearse en pacientes con IC-FEc) ${ }^{214}$. Los BCC dihidropiridínicos pueden aumentar el tono simpático y su seguridad en la IC-FEr (a excepción de amlodipino ${ }^{215}$ y felodipino ${ }^{216}$ ) y la IC-FEc no está clara.

\subsubsection{Revascularización miocárdica}

Las indicaciones de coronariografía invasiva para pacientes con IC se encuentran en la sección 5.8 .

La revascularización percutánea y la quirúrgica son estrategias complementarias para el alivio de los síntomas de angina en la IC-FEc, pero no está claro que estas intervenciones mejoren los resultados. La guía más reciente de la ESC sobre revascularización miocárdica recomienda la cirugía de revascularización coronaria (CABG) para los pacientes con estenosis significativa en tronco común izquierdo o enfermedad equivalente (estenosis proximal en las arterias descendente anterior izquierda y circunfleja izquierda) para mejorar el pronóstico ${ }^{112,113}$. Sin embargo, se debe ser consciente de la falta de estudios en pacientes con IC bien definida, de modo que esta recomendación se basa únicamente en la opinión de expertos. Según los resultados del estudio STICH (que excluyó a pacientes con enfermedad de tronco común izquierdo y angina de clase III-IV de la Canadian Cardiovascular Society), la CABG también está recomendada para los pacientes con IC-FEr, EAC significativa (arteria descendente anterior izquierda o enfermedad multivaso) y $\mathrm{FEVI} \leq 35 \%$ para reducir la mortalidad y las hospitalizaciones por causas cardiovasculares ${ }^{385}$. Los pacientes con más del $10 \%$ de miocardio del VI disfuncional pero viable se beneficiarían más de la revascularización miocárdica (y aquellos con el $10 \%$ o menos tendrían menos beneficios), aunque esta estrategia de selección de pacientes no se ha probado. En el estudio STICH, la presencia de viabilidad y el grado de remodelado del VI no permitieron identificar a los pacientes que se beneficiarían de la CABG en la reducción de la mortalidad ${ }^{118}$. La valoración de las técnicas empleadas para evaluar la viabilidad miocárdica se encuentra en la 
Recomendaciones para el tratamiento de la angina de pecho estable con insuficiencia cardiaca sintomática (NYHA II-IV) y fracción de eyección reducida ${ }^{112,113}$

\begin{tabular}{|c|c|c|c|}
\hline Recomendaciones & Clase $^{\mathrm{a}}$ & Nivel $^{\mathrm{b}}$ & $\operatorname{Ref}^{\mathrm{c}}$ \\
\hline \multicolumn{4}{|l|}{ Paso 1} \\
\hline $\begin{array}{l}\text { Se recomienda un bloqueador beta (dosis basada en la evidencia o la máxima tolerada) como tratamiento de primera línea para aliviar la } \\
\text { angina debido a los beneficios asociados a este tratamiento (reducción del riesgo de hospitalización por IC y del riesgo de muerte prematura) }\end{array}$ & I & A & $167-173$ \\
\hline \multicolumn{4}{|l|}{ Paso 2: añadido a un bloqueador beta o si este no se tolera } \\
\hline $\begin{array}{l}\text { Se debe considerar la ivabradina como fármaco antianginoso adecuado para los pacientes con IC-FEr (en ritmo sinusal y FC } \geq 70 \text { lpm), como se } \\
\text { recomienda en el manejo de la IC-FEr }\end{array}$ & Ila & B & $\begin{array}{l}180,410, \\
411\end{array}$ \\
\hline \multicolumn{4}{|l|}{ Paso 3: para mayor alivio de la angina (excepto las combinaciones no recomendadas) } \\
\hline Se debe considerar un nitrato oral o transcutáneo de acción corta (tratamiento antianginoso efectivo y seguro en la IC) & IIa & A & $\begin{array}{l}183,184, \\
409\end{array}$ \\
\hline $\begin{array}{l}\text { Se debe considerar un nitrato oral o transcutáneo de acción prolongada (tratamiento antianginoso efectivo pero no estudiado adecuadamente } \\
\text { en la IC) }\end{array}$ & Ila & B & 183,184 \\
\hline $\begin{array}{l}\text { Se puede considerar la trimetazidina cuando la angina persista a pesar del tratamiento con un bloqueador beta (o fármaco alternativo) } \\
\text { para aliviar la angina (tratamiento antianginoso efectivo y seguro en la IC) }\end{array}$ & IIb & A & 400-403 \\
\hline $\begin{array}{l}\text { Se puede considerar el amlodipino para pacientes que no toleran un bloqueador beta para aliviar la angina (tratamiento antianginoso efectivo } \\
\text { y seguro en la IC) }\end{array}$ & IIb & B & 215,407 \\
\hline $\begin{array}{l}\text { Se puede considerar el nicorandil para pacientes que no toleran un bloqueador beta para aliviar la angina (tratamiento antianginoso efectivo, } \\
\text { pero su seguridad en la IC es incierta) }\end{array}$ & IIb & C & \\
\hline $\begin{array}{l}\text { Se puede considerar la ranolazina para pacientes que no toleran un bloqueador beta para aliviar la angina (tratamiento antianginoso efectivo, } \\
\text { pero su seguridad en la IC es incierta) }\end{array}$ & IIb & C & \\
\hline \multicolumn{4}{|l|}{ Paso 4: revascularización miocárdica } \\
\hline Se recomienda la revascularización cuando la angina persista a pesar del tratamiento antianginoso & I & A & $\begin{array}{l}385,412, \\
413\end{array}$ \\
\hline $\begin{array}{l}\text { Alternativas a la revascularización miocárdica: se puede considerar la combinación de } 3 \text { o más fármacos antianginosos (ya mencionados) } \\
\text { cuando la angina persista a pesar del tratamiento con bloqueadores beta, ivabradina y un fármaco antianginoso adicional (excluidas las } \\
\text { combinaciones no recomendadas; véase a continuación) }\end{array}$ & IIb & C & \\
\hline \multicolumn{4}{|l|}{ No se recomiendan las siguientes combinaciones: } \\
\hline 1) Cualquier combinación de ivabradina, ranolazina y nicorandil, puesto que se desconoce su seguridad & III & $\mathrm{C}$ & \\
\hline 2) La combinación de nicorandil y un nitrato (debido a la falta de eficacia adicional) & III & $\mathrm{C}$ & \\
\hline No se recomiendan diltiazem ni verapamilo, debido a su acción inotrópica negativa y el riesgo de empeoramiento de la IC & III & C & 214 \\
\hline
\end{tabular}

sección 5. Análisis posteriores del estudio STICH revelaron que la presencia de isquemia miocárdica inducible (prueba de estrés con radionucleótidos o ecocardiograma de estrés con dobutamina) o de angina no permite identificar a los pacientes con peor pronóstico y mayor beneficio de la CABG frente al TMO ${ }^{115,386}$. Sin embargo, la CABG mejora la angina en mayor medida que el tratamiento farmacológico solo.

La decisión entre CABG e ICP debe ser tomada por el equipo cardiológico tras la evaluación minuciosa del estado clínico y la anatomía coronaria del paciente, el grado de revascularización esperado, la valvulopatía coexistente y las comorbilidades.

\subsection{Caquexia y sarcopenia (para pacientes frágiles, véase la sección 14)}

La caquexia se define como un proceso generalizado de debilitamiento de todos los compartimentos corporales (es decir, tejido magro -músculo esquelético-, tejido adiposo -reservas de energía- y tejido óseo -osteoporosis-). Puede ocurrir en el 5-15\% de los pacientes con IC, especialmente aquellos con IC-FEr, y un estadio de la enfermedad más avanzado ${ }^{414-416}$. Esta complicación grave se asocia con síntomas más graves, capacidad funcional reducida, hospitalizaciones más frecuentes y menor supervivencia. La caquexia en la IC se puede diagnosticar y definir como una pérdida de peso involuntaria no edematosa $\geq 6 \%$ del peso corporal total en los 6-12 meses previos ${ }^{414-417}$.

Las causas son multifactoriales y difíciles de determinar en pacientes individuales. Entre ellas, se puede incluir la activación inmunitaria proinflamatoria, las alteraciones neurohormonales, la nutrición y la absorción insuficientes, el desequilibrio caloricoproteico, la resistencia hormonal anabólica, el impulso anabólico disminuido, la inmovilización prolongada y la falta de forma física, caracterizados en conjunto como un desequilibrio catabólico/anabólico ${ }^{418}$. La pérdida de músculo esquelético, cuando se asocia a limitación de la movilidad y síntomas (lo que se denomina sarcopenia o miopenia), ocurre en un $30-50 \%$ de los pacientes con IC-FEr ${ }^{419}$. En su forma más grave se asocia con un estado de fragilidad y peor morbimortalidad ${ }^{420}$.

Los posibles tratamientos incluyen estimuladores del apetito, ejercicio físico ${ }^{120} \mathrm{y}$ agentes anabólicos, como testosterona, combinados con suplementos nutricionales e intervenciones anticatabólicas, aunque no se ha probado el beneficio de ninguno de ellos y se desconoce su seguridad ${ }^{421}$.

\subsection{Cáncer}

Algunos agentes quimioterápicos pueden causar disfunción sistólica del VI e IC o empeorarla. Los tratamientos de este tipo más reconocidos son las antraciclinas (como doxorubicina), el trastuzumab y los inhibidores de la tirosincinasa ${ }^{397,422}$. Una reciente revisión Cochrane ha mostrado que la dexrazoxana puede aportar cierta cardioprotección a pacientes tratados con antraciclinas ${ }^{423}$. La evaluación de la FEVI antes y después, si es posible mediante imagen de strain miocárdica, es fundamental en pacientes que reciben quimioterapia cardiotóxica, como se detalla en otras publicaciones ${ }^{397,422}$. Se ha desarrollado una 
clasificación de riesgo para mujeres con cáncer de mama y riesgo de IC durante el tratamiento con trastuzumab que podría ser útil y está basada en la edad, el tipo de quimioterapia, el estado cardiovascular basal y otras comorbilidades ${ }^{424}$. Se debe interrumpir la quimioterapia e iniciar tratamiento para la IC-FEr en pacientes que sufran disfunción sistólica del VI moderada o grave. Si mejora la función del VI, hay que reconsiderar los riesgos y beneficios de continuar con la quimioterapia $^{397,425,426}$. La irradiación mediastinal también puede resultar en distintas complicaciones cardiacas a largo plazo. Se puede emplear biomarcadores cardiacos (PN y troponinas) para identificar a los pacientes con mayor riesgo de cardiotoxicidad, además de ser útiles para monitorizar el uso y la dosis de citotóxicos cardiotóxicos ${ }^{397,425,426}$.

\subsection{Sistema nervioso central (incluidos depresión, ictus y disfunción autonómica)}

El ictus y la IC coexisten frecuentemente porque comparten algunos factores de riesgo. Ambos contribuyen a un peor pronóstico. El ictus puede dificultar el autocuidado del paciente con IC. El tratamiento de los pacientes con alto riesgo de ictus requiere un equilibrio de los riesgos del tratamiento anticoagulante y antiagregante.

La disfunción autonómica también es común en la IC-FEr, especialmente cuando esta es grave ${ }^{427}$. Combinada con una PA baja, puede producir desmayos y lesiones e interferir con la administración de las dosis óptimas de bloqueadores beta, IECA, ARA-II y ARM. Se puede reducir la dosis de diuréticos para disminuir la gravedad de la hipotensión postural.

La depresión es común y se asocia a un peor estado clínico y mal pronóstico en la IC ${ }^{428-430}$. También puede contribuir a mala adherencia y aislamiento social. Se necesita un alto índice de sospecha para hacer el diagnóstico, especialmente en personas mayores. Una buena práctica consiste en realizar controles sistemáticos mediante un cuestionario validado. Hasta la fecha, se ha validado formalmente el Inventario de Depresión de Beck (BDI) y la Escala de Depresión Cardiaca como herramientas fiables para la evaluación de estados depresivos de los pacientes con IC ${ }^{431,432}$, pero también se han utilizado ampliamente otros cuestionarios (Escala de Depresión Geriátrica, Escala de Depresión de Hamilton, Escala de Ansiedad y Depresión Hospitalaria, etc.).

Las intervenciones psicosociales y el tratamiento farmacológico son útiles, y también el entrenamiento físico, para los pacientes con IC-FEr y depresión ${ }^{433}$. Más allá de la atención estándar, la terapia cognitivo-conductual aplicada a pacientes con IC y depresión grave, además de un programa estructurado de educación, consiguieron reducir el grado de depresión, la ansiedad y los síntomas de fatiga, con lo que mejoraron el funcionamiento social y mental y la calidad de vida relacionada con la IC ${ }^{434}$.

Se considera que los inhibidores selectivos de la recaptación de serotonina son seguros. Sin embargo, el estudio Sertraline Antidepressant Heart Attack Randomized Trial no confirmó que, comparada con placebo, la sertralina proporcione una mayor reducción de los síntomas de depresión o una mejora del estado cardiovascular de los pacientes con IC-FEr, aunque ese estudio no tenía suficiente potencia estadística para probar el segundo punto ${ }^{435}$. Igualmente, el escitalopram no tuvo, comparado con placebo, efecto alguno en la depresión ni en los resultados clínicos durante un seguimiento de 24 meses de pacientes con IC-FEr y depresión. Es importante recordar que se debe evitar los antidepresivos tricíclicos, ya que pueden causar hipotensión, empeoramiento de la IC y arritmias ${ }^{429,435}$.

\subsection{Diabetes mellitus}

La disglucemia y la diabetes mellitus son muy frecuentes en la IC, y la diabetes se asocia a peores estado funcional y pronóstico. En pacientes con IC-FEr, las intervenciones para reducir la morbimortalidad proporcionan un beneficio similar en presencia o ausencia de dia- betes $^{320}$. Por ejemplo, los bloqueadores beta mejoran los resultados de modo similar tanto si el paciente es diabético como si no, aunque cada bloqueador beta puede tener diferente efecto en los índices glucémicos ${ }^{436}$.

No está claro si un estricto control glucémico altera el riesgo de complicaciones cardiovasculares en la IC ${ }^{437}$. En pacientes con IC que no han sido tratados para la diabetes mellitus, los títulos de $\mathrm{HbA}_{1 \mathrm{c}}$ más altos se asocian con mayor riesgo de complicaciones cardiovasculares ${ }^{438,439}$, pero esto podría ser diferente una vez iniciado el tratamiento para la diabetes ${ }^{439}$.

En pacientes con diabetes mellitus e IC, se debe implementar el control glucémico gradual y moderadamente, dando preferencia a los fármacos, como la metformina, que se han demostrado seguros y efectivos. Al contrario de lo que se creía anteriormente, la metformina es segura para los pacientes con IC-FEr y es el tratamiento de elección para pacientes con $\mathrm{IC}^{440,441}$, pero está contraindicada para pacientes con insuficiencia renal o hepática grave debido al riesgo de acidosis láctica.

La insulina es necesaria para los pacientes con diabetes mellitus tipo 1 y para tratar la hiperglucemia sintomática de los pacientes con diabetes mellitus tipo 2 e insuficiencia secretora de células beta pancreáticas. Sin embargo, la insulina es una hormona con alto poder de retención de sodio y, cuando se combina con una reducción de la glucosuria, puede exacerbar la retención de fluidos y causar un empeoramiento de la IC. Los derivados de sulfonilureas también se asocian con un aumento del riesgo de empeoramiento de la IC y deben emplearse con precaución.

Las tiazolidinedionas (glitazonas) causan retención de sodio y agua, aumentan el riesgo de empeoramiento de la IC y hospitalización, por lo cual no se recomiendan para pacientes con IC ${ }^{209,210}$. Los inhibidores de la dipeptidil peptidasa 4 (DPP4; gliptinas), que aumentan los niveles de incretina reduciendo su degradación, con lo que aumenta la liberación de insulina, y los agonistas del receptor del péptido de tipo glucagón 1 (GLP-1) de acción lenta, que actúa como mimético de la incretina, mejoran los índices glucémicos pero no reducen e incluso pueden aumentar el riesgo de complicaciones cardiovasculares y empeoramiento de la $\mathrm{IC}^{320,442,443}$. Hay que señalar que no hay datos sobre la seguridad de las gliptinas y los análogos de GLP-1 en pacientes con IC.

Recientemente, la empagliflozina, un inhibidor del cotransportador de sodio y glucosa 2, mostró una reducción de las hospitalizaciones por IC y la mortalidad, pero no del infarto de miocardio e ictus, en pacientes con diabetes mellitus y riesgo cardiovascular alto, de los que algunos tenían $\mathrm{IC}^{130}$. Debido a la falta de otros estudios con fármacos de este grupo, no se puede considerar los resultados obtenidos con empagliflozina como prueba de un efecto de clase.

A medida que avanza el deterioro glucémico, las decisiones sobre el control de la glucemia se tomarán teniendo en cuenta las condiciones cardiacas y, en caso de prescripción de nuevos fármacos antidiabéticos, un equipo de IC deberá monitorizar estrechamente el tratamiento.

\subsection{Disfunción eréctil}

La disfunción eréctil es frecuente y un factor importante en la calidad de vida de los varones con IC ${ }^{444,445}$. La terapia debe incluir el tratamiento óptimo de la enfermedad cardiovascular subyacente y otras comorbilidades (como la diabetes mellitus), además de la ansiedad y los síntomas depresivos. Algunos fármacos para la IC (como los diuréticos tiacídicos, la espironolactona y los bloqueadores beta) pueden aumentar la disfunción eréctil ${ }^{444,445}$. Se ha demostrado que los inhibidores de la fosfodiesterasa 5 (PDE5) tienen favorables efectos hemodinámicos y contra el remodelado, además de que mejoran la capacidad de ejercicio y la calidad de vida de los pacientes con IC$\mathrm{FEr}^{446,447}$, pero están contraindicados para los pacientes tratados con nitratos. 


\subsection{Gota y artritis}

La hiperuricemia y la gota son comunes en la IC, y el tratamiento diurético puede causarlas o agravarlas. La hiperuricemia se asocia con un pronóstico peor en la IC-FEr ${ }^{448}$. La guía de la European League Against Rheumatism (EULAR) para el tratamiento de la gota recomienda la terapia reductora de urato para los pacientes con ataques agudos recurrentes, artropatía, depósitos de ácido úrico (tofos) o cambios radiográficos de la gota, con el objetivo de mantener los títulos séricos de urato por debajo del punto de saturación del urato monosódico $(<357 \mu \mathrm{mol} / \mathrm{l}[<6 \mathrm{mg} / \mathrm{dl}])^{449}$.

Se puede emplear inhibidores de la xantina oxidasa (alopurinol, oxipurinol) para prevenir la gota, aunque su seguridad en la IC-FEr no está clara ${ }^{450}$. Los ataques de gota se tratan mejor con colchicina que con AINE (aunque la colchicina no se debe utilizar en pacientes con insuficiencia renal muy grave y puede causar diarrea). Los corticoides intraarticulares son una alternativa para la gota monoarticular, pero los corticoides sistémicos causan retención de sodio y agua.

La artritis es una comorbilidad común y es motivo habitual tanto de la prescripción como de la automedicación con fármacos que pueden empeorar la función renal y la IC, especialmente los AINE. La artritis reumatoide se asocia con mayor riesgo de IC-FEc. La seguridad de los fármacos modificadores de la enfermedad que se administran normalmente a los pacientes con artritis reumatoide no está claramente establecida en la IC.

\subsection{Hipopotasemia e hiperpotasemia}

Tanto la hipopotasemia como la hiperpotasemia se asocian con la IC y muchos de los fármacos empleados para tratarla ${ }^{451}$. Ambas entidades pueden agravar las arritmias ventriculares.

Los diuréticos de asa y las tiacidas reducen el potasio sérico, mientras que los IECA, ARA-II y ARM pueden aumentarlo. La amilorida y el triamtereno se emplean en ocasiones como diuréticos coadyuvantes en caso de edema resistente y para prevenir la hipopotasemia. El tratamiento de la hipopotasemia puede incluir alimentos con alto contenido en potasio o suplementos de potasio.
El tratamiento de la hiperpotasemia aguda ( $>6,0 \mathrm{mmol} / \mathrm{l})$ puede requerir la interrupción temporal de los fármacos que retienen potasio y los inhibidores del SRAA, aunque esta medida debe ser mínima, y se debe reiniciar cuidadosamente los inhibidores del SRAA tan pronto sea posible a la vez que se monitorizan las concentraciones de potasio. En una revisión Cochrane ${ }^{452}$ no se encontraron pruebas de un mayor beneficio asociado a un régimen determinado de tratamiento urgente para la hiperpotasemia. Dos nuevos fijadores de potasio (patiromer y ciclosilicato de circonio de sodio) están pendientes de aprobación por las autoridades ${ }^{453,454}$. Los resultados iniciales en pacientes con IC están disponibles y confirman la eficacia de estos fármacos para la reducción del potasio sérico ${ }^{455}$ y la prevención de la hiperpotasemia recurrente en pacientes con IC y ERC, en el contexto del tratamiento con inhibidores del SRAA ${ }^{456}$.

\subsection{Hiperlipemia}

Las concentraciones de colesterol unido a lipoproteínas de baja densidad aumentadas no son frecuentes en la IC-FEr; los pacientes con IC-FEr avanzada suelen tener bajas concentraciones de lipoproteínas de baja densidad, lo cual se asocia con peor pronóstico. La rosuvastatina no redujo la variable primaria compuesta de morbilidad y mortalidad en 2 ECDA importantes realizados en pacientes con IC, con o sin cardiopatía isquémica, pero tampoco aumentó el riesgo y podría reducir las hospitalizaciones ${ }^{205,247}$. No hay pruebas para recomendar la instauración de tratamiento con estatinas para la mayoría de los pacientes con IC. Sin embargo, para los pacientes que ya están en tratamiento con una estatina para la EAC, se puede considerar continuarlo.

\subsection{Hipertensión}

La hipertensión se asocia con un aumento del riesgo de IC; el tratamiento antihipertensivo reduce significativamente la incidencia de IC (a excepción de los inhibidores del receptor adrenérgico alfa, menos eficaces que otros antihipertensivos en la prevención de la IC $)^{458}$. Un reciente estudio prospectivo de cohortes comunicó que, en una

Recomendaciones para el tratamiento de la hipertensión de pacientes con insuficiencia cardiaca sintomática (NYHA II-IV) y fracción de eyección reducida

\begin{tabular}{|c|c|c|c|}
\hline Recomendaciones & Clase $^{\mathrm{a}}$ & Nivel $^{\mathrm{b}}$ & $\operatorname{Ref}^{c}$ \\
\hline \multicolumn{4}{|l|}{ Paso 1} \\
\hline $\begin{array}{l}\text { Se recomienda un IECA (o ARA-II), un bloqueador beta o un ARM (o una combinación) para reducir la PA como primera, segunda y tercera } \\
\text { línea de tratamiento respectivamente, debido a sus beneficios (reducción del riesgo de mortalidad y hospitalización por IC). Además son } \\
\text { seguros en la IC-FEc }\end{array}$ & I & A & $\begin{array}{c}2,164,165 \\
167,168 \\
171-174 \\
182,461-463\end{array}$ \\
\hline
\end{tabular}

Paso 2

Se recomienda un diurético tiacídico (o, si el paciente ya toma una tiacida, cambiar a un diurético del asa) para reducir la PA cuando

la hipertensión persista pese al tratamiento con una combinación de IECA (o ARA-II, pero no combinado con un IECA), un bloqueador beta y un ARM

Paso 3

Se recomienda amlodipino o hidralazina para reducir la PA cuando la hipertensión persista a pesar del tratamiento con una combinación de IECA (o ARA-II, pero no combinado con un IECA), un bloqueador beta, un ARM y un diurético

Se debe considerar el felodipino para reducir la PA cuando la hipertensión persista a pesar del tratamiento con una combinación de IECA (o ARA-II, pero no combinado con un IECA), un bloqueador beta, un ARM y un diurético

No se recomienda la monoxidina para la reducción de la PA por sus problemas de seguridad en pacientes con IC-FEr (aumento de la mortalidad)

No se recomiendan los antagonistas alfaadrenérgicos para la reducción de la PA por sus problemas de seguridad en pacientes con IC-FEr (activación neurohormonal, retención de fluidos, empeoramiento de la IC)

No se recomiendan diltiazem ni verapamilo para reducir la PA de los pacientes con IC-FEr, debido a su acción inotrópica negativa y el riesgo de empeoramiento de la IC

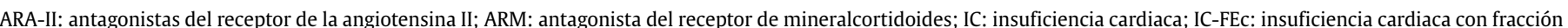

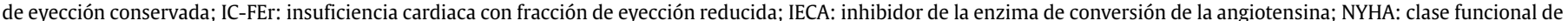
la New York Heart Association; PA: presión arterial.

aClase de recomendación.

bNivel de evidencia.

'Referencias que respaldan las recomendaciones. 
población con IC incidente, los altos valores basales de PAS, PA sistólica y presión de pulso se asociaron con una tasa de complicaciones adversas más alta, lo cual señala la importancia del control óptimo de la PA en esta población ${ }^{459}$. El control de la PA forma parte de la atención integral de los pacientes con IC.

No se debe utilizar BCC inotrópicos negativos (como diltiazem y verapamilo) para tratar la hipertensión de pacientes con IC-FEr (pero se cree que son seguros en la IC-FEc), en los que se debe evitar la moxonidina, ya que aumentó la mortalidad en $1 \mathrm{ECDA}^{460}$. Si no se controla la PA con un IECA (o un ARA-II), se puede emplear otro agente hipotensor, como un bloqueador beta, un ARM y un diurético, después hidralazina y amlodipino ${ }^{215}$ (o felodipino) ${ }^{216}$, que se han demostrado seguros en la IC sistólica. Los objetivos de PA recomendados en la guía sobre hipertensión ${ }^{317}$ son aplicables a la IC. La hipertensión no controlada es muy rara en los pacientes con IC-FEr, siempre que reciban tratamiento óptimo para la IC. Por el contrario, el tratamiento de la hipertensión es una cuestión importante en pacientes con IC-FEc. Para pacientes con ICA, se recomienda la administración i.v. de nitratos (o nitroprusiato sódico) para bajar la PA (véase la sección 12).

\subsection{Déficit de hierro y anemia}

El déficit de hierro es común en la IC, al igual que en otras enfermedades crónicas, y puede causar anemia o disfunción muscular sin anemia $^{466}$. En la población con IC, el déficit de hierro se asocia a peor pronóstico ${ }^{467,468}$. La administración i.v. de hierro se ha estudiado específicamente en 2 ECDA en pacientes con IC y déficit de hierro (ferritina sérica < $100 \mu \mathrm{g} / \mathrm{l}$ o ferritina entre 100 y $299 \mu \mathrm{g} / \mathrm{l}$ y saturación de transferrina $<20 \%)^{469,470}$ con o sin anemia. Se ha demostrado que la carboximaltosa férrica i.v. mejora el estado general de los pacientes (según autoevaluación), la calidad de vida y la clase funcional de la NYHA (durante 6 meses) en el estudio FAIR-HF ${ }^{469}$ en pacientes anémicos y no anémicos con IC ${ }^{471}$, y en el estudio CONFIRM-HF ${ }^{470}$ la capacidad de ejercicio mejoró en 24 semanas. En el análisis de variables secundarias del estudio CONFIRM-HF, el hierro i.v. redujo el riesgo de hospitalización de los pacientes con déficit de hierro e IC-FEr ${ }^{470}$. Un metanálisis sobre el tratamiento con hierro i.v. durante 52 semanas en pacientes con IC-FEr y déficit de hierro mostró una reducción de las tasas de hospitalización y mejoró los síntomas de IC, la capacidad de ejercicio y la calidad de vida ${ }^{472}$. Por lo tanto, el tratamiento con carboximaltosa férrica puede mejorar de modo duradero la capacidad funcional, los síntomas y la calidad de vida. El tratamiento también se asoció a una reducción significativa de las hospitalizaciones por empeoramiento de la IC. El número de muertes y la incidencia de

Recomendaciones para el tratamiento de otras comorbilidades de los pacientes con insuficiencia cardiaca

\begin{tabular}{lccc}
\hline Recomendaciones & Clase $^{\mathrm{a}}$ & Nivel $^{\mathrm{b}}$ & Ref $^{\mathrm{c}}$ \\
\hline Déficit de hierro & & & \\
\hline $\begin{array}{l}\text { Se debe considerar la administración intravenosa } \\
\text { de FCM a los pacientes sintomáticos con IC-FEr }\end{array}$ & Ila & $\mathrm{A}$ & 469,470 \\
y déficit de hierro (ferritina sérica $<100 \mu \mathrm{g} / \mathrm{l}$ & & \\
o de $100-299 \mu \mathrm{g} / \mathrm{l}$ con saturación de transferrina \\
< $20 \%$ ) para aliviar los síntomas de IC y mejorar la \\
capacidad de ejercicio y la calidad de vida
\end{tabular}

\section{Diabetes mellitus}

\begin{tabular}{l|lll|l}
\hline $\begin{array}{l}\text { Se debe considerar la administración de } \\
\text { metformina como tratamiento de primera línea }\end{array}$ & Ila & C & 440,441 \\
para el control glucémico de los pacientes \\
con diabetes e IC si no está contraindicado
\end{tabular}

CMF: carboximaltosa férrica; IC: insuficiencia cardiaca; IC-FEr: insuficiencia cardiaca con fracción de eyección reducida.

aClase de recomendación.

bNivel de evidencia.

${ }^{\mathrm{c}}$ Referencias que respaldan las recomendaciones.
Tratamientos no recomendados para otras comorbilidades de los pacientes con insuficiencia cardiaca

\begin{tabular}{|c|c|c|c|}
\hline Recomendaciones & Clase $^{\mathrm{a}}$ & Nivel $^{\mathrm{b}}$ & $\operatorname{Ref}^{c}$ \\
\hline \multicolumn{4}{|l|}{ Apnea del sueño } \\
\hline $\begin{array}{l}\text { No se recomienda la servoventilación adaptativa } \\
\text { para pacientes con IC-FEr y apnea del sueño } \\
\text { predominantemente central, debido a un aumento } \\
\text { de la mortalidad cardiovascular y por todas las } \\
\text { causas }\end{array}$ & III & B & 473 \\
\hline \multicolumn{4}{|l|}{ Diabetes mellitus } \\
\hline $\begin{array}{l}\text { No se recomiendan las tiazolidinedionas } \\
\text { (glitazonas) para los pacientes con IC, ya que } \\
\text { aumentan el riesgo de empeoramiento de la IC } \\
\text { y de hospitalización por IC }\end{array}$ & III & A & 209,210 \\
\hline \multicolumn{4}{|l|}{ Artritis } \\
\hline $\begin{array}{l}\text { No se recomiendan los AINE o los inhibidores de } \\
\text { la COX-2 para pacientes con IC, ya que aumentan } \\
\text { el riesgo de empeoramiento de la IC } \\
\text { y de hospitalización por IC }\end{array}$ & III & B & $211-213$ \\
\hline
\end{tabular}

AINE: antiinflamatorios no esteroideos; COX-2: ciclooxigenasa-2; IC: insuficiencia cardiaca; IC-FEr: insuficiencia cardiaca con fracción de eyección reducida.

${ }^{\mathrm{a} C l a s e}$ de recomendación.

bNivel de evidencia.

'Referencias que respaldan las recomendaciones.

complicaciones adversas fueron similares. Ninguno de estos estudios tenía potencia estadística para evaluar el efecto del tratamiento i.v. con hierro en las variables más importantes o para evaluar por separado sus efectos en pacientes anémicos y no anémicos. Se desconoce el efecto del tratamiento del déficit de hierro en pacientes con IC-FEc/ IC-FEm y la seguridad a largo plazo en pacientes con IC-FEr, IC-FEm o IC-FEc. Tampoco se conoce la seguridad del tratamiento i.v. con hierro para los pacientes con IC y hemoglobina $>15 \mathrm{~g} / \mathrm{dl}^{469,470}$. En pacientes con déficit de hierro, se buscarán causas potencialmente tratables o reversibles (p. ej., sangrado gastrointestinal).

La anemia (definida como una concentración de hemoglobina $<13,0 \mathrm{~g} / \mathrm{dl}$ en los varones $\mathrm{y}<12,0 \mathrm{~g} / \mathrm{dl}$ en las mujeres) es común en la IC, especialmente en pacientes hospitalizados. Es más frecuente en mujeres, personas mayores y pacientes con insuficiencia renal, y se asocia con el remodelado miocárdico avanzado, la inflamación y la sobrecarga de volumen ${ }^{474}$. La anemia se asocia con síntomas avanzados, mayor deterioro del estado funcional, mayor riesgo de hospitalización por IC y menor supervivencia. Ante cualquier hallazgo de anemia, está indicado seguir un proceso diagnóstico para encontrar la causa (p. ej., pérdida oculta de sangre, déficit de hierro, déficit de $B_{12} /$ folato, discrasias sanguíneas), aunque en muchos pacientes no se encuentra ninguna causa específica. La darbepoetina alfa, un estimulador de la eritropoyetina, no mejoró los resultados clínicos en pacientes con IC-FEr y anemia leve o moderada y se asoció a un exceso de complicaciones tromboembólicas, por lo que no está recomendada ${ }^{475}$.

\subsection{Disfunción renal (incluidos enfermedad renal crónica, daño renal agudo, síndrome cardiorrenal y obstrucción prostática)}

La IC y la ERC coexisten frecuentemente, comparten múltiples factores de riesgo (diabetes mellitus, hipertensión, hiperlipemia) e interactúan y empeoran el pronóstico ${ }^{476,477}$. La ERC se define generalmente como una TFGe $<60 \mathrm{ml} / \mathrm{min} / 1,73 \mathrm{~m}^{2}$ o la presencia de albuminuria (alta o muy alta: 30-300 o > 300 mg de albúmina/1 g de creatinina). Se ha excluido sistemáticamente a los pacientes con insuficiencia renal grave (TFGe $<30 \mathrm{ml} / \mathrm{min} / 1,73 \mathrm{~m}^{2}$ ) de los estudios aleatorizados, por lo cual no existen tratamientos basados en la evidencia para estos pacientes. 
El deterioro adicional de la función renal, denominado empeoramiento de la función renal, se emplea para indicar un aumento de la creatinina sérica, normalmente en más de $26,5 \mu \mathrm{mol} / \mathrm{l}(0,3 \mathrm{mg} / \mathrm{dl})$, o un aumento del $25 \%$ o una disminución del $20 \%$ de la TFG. La importancia de estos cambios aparentemente insignificantes es que son frecuentes, contribuyen a la aparición y la progresión de la $\mathrm{ERC}^{478} \mathrm{y}$, como consecuencia, pueden empeorar el pronóstico de la IC. Los aumentos de la creatinina durante una hospitalización por ICA no siempre son clínicamente relevantes, especialmente si van acompañados de descongestión, diuresis y hemoconcentración adecuadas ${ }^{479}$.

Los grandes aumentos de la creatinina sérica, denominados insuficiencia renal aguda, son relativamente raros en la IC y probablemente se asocien con la combinación del tratamiento diurético con otros fármacos potencialmente nefrotóxicos, como algunos antibióticos (gentamicina y trimetoprim), medios de contraste, IECA, ARA-II, AINE, etc. Cabe destacar que algunos de estos fármacos pueden acumularse si se excretan por vía renal. En la IC, el empeoramiento de la función renal es relativamente común, especialmente durante el inicio y el aumento de la dosis del tratamiento con inhibidores del SRAA. A pesar de que los inhibidores del SRAA causan frecuentemente una caída de la TFG en pacientes con IC, suele ser pequeña y no debe llevar a la interrupción del tratamiento, excepto cuando sea significativa, ya que, en estos pacientes, el beneficio del tratamiento suele mantenerse ${ }^{480}$. En caso de un aumento grande de creatinina sérica, el paciente debe ser sometido a una evaluación minuciosa que incluya la valoración de una posible estenosis arterial renal, hipervolemia o hipovolemia excesivas, medicación concomitante e hiperpotasemia, las cuales coinciden frecuentemente con un empeoramiento de la función renal.

Los diuréticos, especialmente las tiacidas pero también los diuréticos de asa, pueden ser menos efectivos en pacientes con una TFG muy baja y, en caso de emplearlos, hay que dosificarlos adecuadamente (dosis más altas para alcanzar efectos similares). Los fármacos que se excretan por vía renal (como la digoxina, la insulina y la heparina de bajo peso molecular) pueden acumularse en pacientes con afección renal y pueden requerir un ajuste de la dosis si empeora la función renal. Los pacientes con IC y enfermedad vascular coronaria o periférica tienen riesgo de insuficiencia renal aguda si se someten a una prueba angiográfica con medio de contraste (insuficiencia renal aguda inducida por medio de contraste). La insuficiencia y el empeoramiento de la función renal se tratan en el capítulo dedicado a la ICA (sección 12).

La obstrucción prostática es común en varones mayores y puede interferir con la función renal; por lo tanto, se debe descartar en varones con IC y deterioro de la función renal. Los inhibidores de los receptores alfa adrenérgicos pueden causar hipotensión y retención de sodio y agua, por lo que no son seguros en pacientes con IC$\mathrm{FEr}^{458,464,465}$. Por ello, generalmente se prefiere el uso de inhibidores de la reductasa alfa-5 para el tratamiento farmacológico de la obstrucción prostática en pacientes con IC.

\subsection{Enfermedad pulmonar (incluidos asma y enfermedad pulmonar obstructiva crónica)}

La IC puede dificultar el diagnóstico de la EPOC y el asma debido no solo al solapamiento de signos y síntomas, sino también a problemas en la interpretación de la espirometría, especialmente en los pacientes con IC-FEc ${ }^{48,49,391}$. En pacientes con IC, la EPOC y el asma pueden estar sobrediagnosticadas ${ }^{481}$. La espirometría se debe realizar cuando el paciente se mantenga estable y euvolémico durante al menos 3 meses para evitar el efecto de confusión de la congestión pulmonar que causa la obstrucción externa de alveolos y bronquio$\operatorname{los}^{482}$. La EPOC (clasificada tanto correcta como incorrectamente) se asocia a peor estado funcional y peor pronóstico en pacientes con IC-FEr.

Los bloqueadores beta tienen una contraindicación relativa en el asma, pero no en la EPOC, aunque se prefiere el uso de un antagonista selectivo del receptor adrenérgico beta-1 (bisoprolol, succinato de metoprolol o nebivolol $)^{48,49,391}$. La contraindicación de los bloqueadores beta en el asma, como se menciona en los prospectos farmacológicos, se basa en pequeñas series publicadas en las décadas de los años ochenta y noventa, en las que pacientes jóvenes con asma grave recibieron dosis iniciales altas. En la práctica clínica, si se comienza con dosis bajas de bloqueadores beta cardioselectivos y se vigila estrechamente los signos de obstrucción de vías aéreas (sibilancias, falta de aire con ralentización de la espiración), se puede emplear el tratamiento efectivo con bloqueadores beta en la IC-FEr, especialmente para pacientes mayores en los que el asma grave es poco frecuente. Según el informe sobre estrategia global GINA (2015) ${ }^{395,396}$, el asma no es una contraindicación absoluta, pero estos fármacos solo se deben emplear bajo la estricta supervisión de un especialista, teniendo en cuenta los riesgos y los beneficios del tratamiento. La seguridad a largo plazo de los inhaladores pulmonares cardioactivos no está clara y se debe reconsiderar su empleo para pacientes con IC-FEr, particularmente porque su beneficio en el asma y la EPOC es solamente sintomático, sin un claro efecto en la mortalidad. Los corticoides orales causan retención de sodio y agua, que puede empeorar la IC, aunque no se cree que esto ocurra con los corticoides inhalados. La hipertensión pulmonar puede complicar la EPOC grave de larga duración y aumentar la probabilidad de IC derecha y congestión. La ventilación no invasiva, combinada con tratamiento convencional, mejora los resultados de los pacientes con insuficiencia respiratoria aguda debido a la exacerbación hipercápnica de la EPOC o la IC en un contexto de edema pulmonar agudo.

\subsection{Obesidad}

La obesidad es un factor de riesgo de IC ${ }^{141}$ y complica su diagnóstico porque causa disnea, intolerancia al ejercicio e inflamación de tobillos, lo que puede resultar en imágenes ecocardiográficas de mala calidad. Los sujetos obesos también pueden tener títulos de PN reducidos $^{62}$. La obesidad es más común en la IC-FEc que en la IC-FEr, aunque es posible que el diagnóstico erróneo explique al menos parte de esta diferencia en la prevalencia. Aunque la obesidad es un factor independiente de riesgo de IC, una vez que la IC está diagnosticada, la obesidad se asocia con menor mortalidad en una amplia gama de índices de masa corporal (IMC) (véase también la sección 11.3 sobre caquexia), y este fenómeno se conoce como la "paradoja de la obesidad», que se observa también en otras enfermedades crónicas ${ }^{414,416}$. Se debe tratar la obesidad como recomienda la guía de la ESC sobre prevención de la enfermedad cardiovascular ${ }^{483}$, si el objetivo es prevenir la futura aparición de IC. Sin embargo, esa guía no hace referencia al paciente con IC para el que un IMC alto no es un factor adverso, y nunca se ha probado prospectivamente que la pérdida de peso, como intervención recomendada frecuentemente para el alivio de los síntomas y el control de factores de riesgo, sea beneficiosa o segura en la IC-FEr. En la IC, la pérdida de peso se asocia con una morbimortalidad alta, un peor estado sintomático y mala calidad de vida. Para pacientes con IC y obesidad moderada (IMC < 35), no se puede recomendar la pérdida de peso. Para la obesidad más avanzada (IMC 35-45), se puede considerar la pérdida de peso para mejorar los síntomas y la capacidad de ejercicio.

\subsection{Trastornos del sueño y trastornos respiratorios durante el sueño}

El trastorno respiratorio del sueño está presente en más de un tercio de los pacientes con IC $^{484}$ y su prevalencia es aun mayor en los pacientes con ICA ${ }^{485}$. Los tipos más comunes son: la apnea del sueño central (ASC) (similar a la respiración de Cheyne Stokes), la apnea obstructiva del sueño (AOS) y un patrón mixto de ambas. Otras causas de los trastornos del sueño son la ansiedad, la depresión, la congestión pulmonar en decúbito o paroxística (ortopnea y disnea paroxís- 
tica nocturna) y el tratamiento diurético que causa diuresis nocturna. La revisión de la historia del sueño del paciente (incluidas las preguntas a su pareja) forma parte del cuidado holístico de los pacientes con IC (véase la sección 14). La ASC y la AOS se asocian a un peor pronóstico en la IC ${ }^{485,486}$. La AOS se asocia con un aumento de riesgo de IC para los varones ${ }^{487}$. La ASC es la forma más común de los trastornos respiratorios del sueño en la IC-FEr y, a su vez, la IC-FEr es la causa más común de ASC, por lo que están estrechamente relacionadas. La detección, el diagnóstico y el tratamiento de la apnea del sueño se describen con más detalle en otras publicaciones ${ }^{484,488}$. Antes el diagnóstico requería el uso de polisomnografía nocturna, pero actualmente se han desarrollado equipos avanzados que permiten distinguir el tipo de apnea en el domicilio.

Se puede utilizar suplementación de oxígeno nocturna, presión positiva continua en la vía aérea (CPAP), presión positiva con 2 niveles de presión en la vía aérea (BiPAP) y servoventilación adaptativa (ASV) para tratar la hipoxemia nocturna en la AOS, como se recomienda en otras guías ${ }^{489,490}$. Un índice de apneas-hipopneas $>30 /$ h se puede tratar mediante cualquiera de estos métodos (CPAP, BiPAP, ASV y suplementación de oxígeno nocturna), los cuales se han demostrado efectivos para este fin. Sin embargo, de ninguna de estas intervenciones se ha demostrado prospectivamente un beneficio en los resultados más importantes en la IC-FEr.

Se ha demostrado que la CPAP en la ASC relacionada con IC reduce la frecuencia de los episodios de apneas e hipopneas, mejora la FEVI y la distancia recorrida en el test de los 6 min de marcha, pero no el pronóstico ni la tasa de hospitalizaciones por IC ${ }^{491}$.

El estudio recientemente publicado SERVE-HF ${ }^{473}$ ha mostrado que la ASV en pacientes con IC-FEr y ASC predominante tuvo un efecto neutral en la variable primaria combinada (mortalidad por todas las causas, intervención cardiovascular para salvar la vida -trasplante cardiaco, implante de un DAV, resucitación tras parada cardiaca súbita o choque apropiado que salva la vida - u hospitalización no programada por empeoramiento de la IC) pero, lo que es más importante, la ASV llevó a un aumento de la mortalidad cardiovascular y por todas las causas. Por lo tanto, no se recomienda la ASV para pacientes con IC-FEr y ASC predominante.

La seguridad y la eficacia de otras técnicas alternativas para tratar la ASC en pacientes con IC-FEr, como el implante de un dispositivo de estimulación del nervio frénico ${ }^{219,220,492}$, están en estudio y probablemente requieran estudios adicionales a largo plazo.

\subsection{Valvulopatías}

Las valvulopatías pueden causar o agravar la IC. En este apartado se tratan brevemente los problemas particularmente relevantes en la IC. Para más información se refiere al lector a las recientes guías sobre valvulopatías ${ }^{493,494}$.

Los pacientes con IC y valvulopatía concomitante constituyen un grupo de alto riesgo. Por lo tanto, del proceso de toma de decisiones mediante una evaluación minuciosa de los riesgos y beneficios de diferentes tratamientos debe encargarse un equipo cardiológico multidisciplinario con experiencia en valvulopatías, que incluya cardiólogos con experiencia en IC, cirujanos cardiacos, un cardiólogo intervencionista con experiencia en enfermedad estructural si se considera el tratamiento percutáneo, especialistas en imagen cardiaca, anestesistas y, si fuera necesario, un médico general y especialistas en geriatría y cuidados intensivos. Esto es especialmente conveniente para los pacientes con IC a los que se valora para cirugía, implante transcatéter de válvula aórtica (TAVI) o intervención transcatéter de válvula mitral.

Todos los pacientes deben recibir el TMO. Para los pacientes con IC-FEr, el tratamiento farmacológico se debe planificar de acuerdo con el algoritmo previamente expuesto (véase la sección 7). Es preciso tomar precauciones especiales si se administra vasodilatadores (IECA, ARA-II, BCC, hidralazina y nitratos) a los pacientes con estenosis aórtica grave, para evitar la hipotensión.

\subsubsection{Estenosis aórtica}

El mayor problema en pacientes con estenosis aórtica grave y FEVI reducida es el fenómeno de «bajo flujo, bajo gradiente» (área valvular $<1 \mathrm{~cm}^{2}$, FEVI $<40 \%$, gradiente medio de presión $<40 \mathrm{mmHg}$ ). Para estos individuos, se debe considerar la ecocardiografía de estrés con bajas dosis de dobutamina para diferenciar a los pacientes con estenosis aórtica moderada de aquellos con estenosis grave y bajo flujo a través de la válvula debido a un bajo volumen latido, y para evaluar la contractilidad y la reserva de flujo.

Si el gradiente medio es $>40 \mathrm{mmHg}$, teóricamente no existe un límite inferior de FEVI para indicar la sustitución valvular a pacientes sintomáticos con estenosis aórtica grave.

Se recomienda TAVI para los pacientes con estenosis aórtica grave que no sean candidatos a cirugía según la evaluación del equipo cardiológico, y tengan una supervivencia estimada $>1$ año tras la intervención. El TAVI también se debe considerar para los pacientes de alto riesgo con estenosis aórtica grave que pueden ser candidatos a cirugía pero el equipo cardiológico considera que el TAVI es más conveniente según el perfil individual de riesgo y la viabilidad anatómica ${ }^{495,496}$. En un estudio reciente en pacientes con estenosis aórtica grave, el TAVI con bioprótesis autoexpandible se asoció a una tasa de supervivencia significativamente más alta al año y también a los 2 años $^{497,498}$.

\subsubsection{Regurgitación aórtica}

Se recomienda la reparación o sustitución valvular para los pacientes sintomáticos o asintomáticos con regurgitación aórtica grave y FEVI en reposo $\leq 50 \%$ que sean candidatos a cirugía ${ }^{499,500}$.

\subsubsection{Regurgitación mitral}

Este apartado se refiere a los contextos crónicos, mientras que los contextos agudos se tratan en la sección 12.

\section{Regurgitación mitral primaria (orgánica)}

La cirugía está indicada para pacientes sintomáticos con regurgitación mitral orgánica grave que no tengan contraindicaciones para el tratamiento quirúrgico. La decisión de sustituir o reparar la válvula depende fundamentalmente de la anatomía de la válvula, la experiencia del equipo quirúrgico disponible y el estado del paciente.

Cuando la FEVI sea $<30 \%$, una reparación quirúrgica duradera puede mejorar los síntomas, aunque se desconoce su efecto en la supervivencia. En esta situación, la decisión de operar debe tener en cuenta la respuesta al tratamiento farmacológico, las comorbilidades y la probabilidad de reparación de la válvula (en lugar de su sustitución).

\section{Regurgitación mitral secundaria}

Ocurre por el agrandamiento y remodelado del VI, que lleva al cierre inadecuado de las valvas. El tratamiento médico efectivo (incluida la TRC para pacientes seleccionados) para invertir el remodelado del VI puede reducir la regurgitación mitral funcional, por lo que se debe optimizar en estos pacientes.

Se debe considerar la cirugía valvular y coronaria combinadas en pacientes sintomáticos con disfunción sistólica del VI (FEVI < 30\%), arterias coronarias aptas para revascularización y evidencia de viabilidad. La cirugía también está recomendada en pacientes con regurgitación mitral grave y FEVI > 30\% que van a someterse a CABG.

Sin embargo, un reciente estudio en pacientes con regurgitación mitral isquémica, secundaria y moderada no probó que la adición de la reparación de válvula mitral a la CABG resultó en un mayor grado de remodelado inverso del $\mathrm{VI}^{501}$. Tampoco se obtuvieron pruebas de que la reparación sea más beneficiosa que la sustitución valvular en cuanto 
a los resultados y la magnitud del remodelado del VI502. En presencia de FA, se puede considerar la ablación auricular y el cierre del apéndice de la aurícula izquierda durante la cirugía de válvula mitral.

La utilidad de la cirugía de válvula mitral aislada en pacientes con regurgitación mitral funcional grave y disfunción sistólica del VI grave (FEVI < 30\%) a los que no se puede revascularizar o que tienen miocardiopatía no isquémica es cuestionable, y para la mayoría de los pacientes se prefiere el tratamiento médico convencional y con dispositivos. En algunos casos seleccionados se puede considerar la reparación valvular para evitar o retrasar el trasplante. La decisión debe ser valorada por el equipo cardiológico y basarse en una evaluación exhaustiva que incluya ecocardiografía con strain o resonancia magnética cardiaca ${ }^{499,503}$.

Para los pacientes con IC y regurgitación mitral secundaria moderada o grave a los que se considera inoperables o con riesgo quirúrgico alto, se puede considerar la reparación percutánea de las valvas «borde con borde» (plicatura de las valvas) para mejorar los síntomas y la calidad de vida, aunque esta opción no se ha probado en ningún ECDA y solo se dispone de datos de registros ${ }^{504-506}$.

\subsubsection{Regurgitación tricuspídea}

La regurgitación tricuspídea secundaria (funcional) frecuentemente complica el curso natural de la IC debido a la dilatación anular y al aumento del roce de las valvas por la presión del VD o la sobrecarga de volumen. La regurgitación tricuspídea grave causa o empeora los síntomas y signos de IC derecha, por lo que el tratamiento diurético se emplea para reducir el edema periférico. Debido a que suele haber congestión hepática (que además contribuye al hiperaldosteronismo), se puede añadir un ARM (con dosis altas de natriuréticos) para mejorar la descongestión ${ }^{507}$. Se debe optimizar el tratamiento de la IC subyacente a regurgitación mitral secundaria, ya que esta puede disminuir si se trata la causa desencadenante. Las indicaciones para la corrección quirúrgica de la regurgitación tricuspídea secundaria que complica la IC no están claramente establecidas ${ }^{493,494}$. La necesidad de corrección de la regurgitación tricuspídea se suele considerar en el momento de la corrección quirúrgica de lesiones valvulares izquierdas ${ }^{493,494}$. Un primer informe publicado recientemente indica que las intervenciones transcatéter pueden ser una opción terapéutica para la regurgitación tricuspídea ${ }^{508}$.

\section{INSUFICIENCIA CARDIACA AGUDA}

\subsection{Definición y clasificación}

La ICA se define como la aparición rápida o el empeoramiento de los síntomas o signos de IC. Es una entidad potencialmente mortal que requiere evaluación y tratamiento urgentes y típicamente conlleva la hospitalización urgente.

La ICA se puede presentar como primera manifestación de la IC (de novo) o, más frecuentemente, como consecuencia de una descompensación aguda de la IC crónica y puede estar causada por una disfunción cardiaca primaria o precipitada por factores extrínsecos, más frecuente en pacientes con IC crónica. La disfunción miocárdica aguda (isquémica, inflamatoria o tóxica), la insuficiencia valvular aguda o el taponamiento pericárdico son las más frecuentes causas cardiacas primarias de la ICA. La descompensación de la IC crónica puede ocurrir sin que existan factores desencadenantes conocidos, pero generalmente están presentes uno o más factores, como la infección, la hipertensión no controlada, alteraciones del ritmo o la falta de adherencia al tratamiento o la dieta (tabla 12.1).

Se han propuesto numerosas clasificaciones de la ICA basadas en distintos criterios que se superponen ${ }^{510-513}$. En la práctica, las clasificaciones más útiles son las que están basadas en la presentación clínica al ingreso, que permite a los médicos identificar a los pacientes con alto riesgo de complicaciones y dirigir el tratamiento hacia objetivos específicos, lo cual permite proporcionar una atención personalizada. En la mayoría de los casos, los pacientes con ICA presentan una PAS normal (90-140 mmHg) o elevada (> $140 \mathrm{mmHg}$; ICA hipertensiva). Solo el 5-8\% de los pacientes presentan una PAS baja $(<90 \mathrm{mmHg}$; ICA hipotensiva), la cual se asocia con un mal pronóstico, especialmente en presencia de hipoperfusión ${ }^{514,515}$.

Otra estrategia consiste en clasificar a los pacientes según la presencia de las siguientes causas o factores desencadenantes de la descompensación, que requieren tratamiento o corrección urgente (véase la sección 12.3.1): SCA, emergencia hipertensiva, arritmias rápidas o bradicardia/alteraciones del ritmo graves, causa mecánica aguda subyacente a la ICA o embolia pulmonar aguda.

La clasificación clínica se basa en la exploración física a pie de cama para detectar la presencia de síntomas/signos clínicos de congestión («húmeda» frente a "seca», presente o ausente) o hipo-

Recomendaciones para el tratamiento de las valvulopatías de los pacientes con insuficiencia cardiaca

\begin{tabular}{|c|c|c|c|}
\hline Recomendaciones & Clase $^{\mathrm{a}}$ & Nivel $^{\mathrm{b}}$ & $\operatorname{Ref}^{c}$ \\
\hline $\begin{array}{l}\text { Para los pacientes sintomáticos con FEVI reducida y estenosis aórtica de «bajo flujo, bajo gradiente» (área valvular }<1 \mathrm{~cm}^{2} \text {, FEVI }<40 \% \text {, } \\
\text { gradiente medio de presión }<40 \mathrm{mmHg} \text { ), se debe considerar la ecocardiografía de estrés con dosis bajas de dobutamina para identificar } \\
\text { a aquellos con estenosis aórtica grave que podrían ser candidatos a reemplazo de la válvula }\end{array}$ & IIa & C & \\
\hline $\begin{array}{l}\text { Se recomienda el TAVI para pacientes con estenosis aórtica grave que no sean candidatos para cirugía según la valoración del equipo } \\
\text { cardiológico y tengan una supervivencia estimada > } 1 \text { año tras la intervención }\end{array}$ & I & B & $\begin{array}{l}495,496, \\
509\end{array}$ \\
\hline $\begin{array}{l}\text { Se debe considerar el TAVI para pacientes de alto riesgo con estenosis aórtica grave que pueden ser candidatos a cirugía si el equipo } \\
\text { cardiológico considera que el TAVI es más conveniente por el perfil individual de riesgo y la viabilidad anatómica }\end{array}$ & Ila & A & 497,498 \\
\hline $\begin{array}{l}\text { Se recomienda la reparación o sustitución valvular para todos los pacientes con regurgitación aórtica grave sintomáticos o asintomáticos pero } \\
\text { con FEVI en reposo } \leq 50 \% \text { y candidatos a cirugía }\end{array}$ & I & C & 317 \\
\hline $\begin{array}{l}\text { Se recomiendan los tratamientos farmacológicos basados en la evidencia para los pacientes con IC-FEr para reducir la regurgitación mitral } \\
\text { funcional }\end{array}$ & I & C & \\
\hline $\begin{array}{l}\text { Se debe considerar la cirugía combinada para la regurgitación mitral secundaria y la revascularización coronaria de pacientes sintomáticos } \\
\text { con disfunción sistólica del VI (FEVI < 30\%) que requieran revascularización por angina refractaria a tratamiento farmacológico }\end{array}$ & IIa & C & \\
\hline $\begin{array}{l}\text { Se debe considerar la cirugía aislada para la regurgitación mitral no isquémica de pacientes con regurgitación mitral funcional grave } \\
\text { y disfunción sistólica del VI grave (FEVI < } 30 \% \text { ) seleccionados, para evitar o posponer el trasplante cardiaco }\end{array}$ & IIb & C & \\
\hline
\end{tabular}

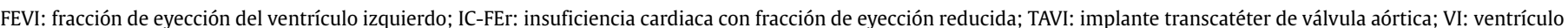
izquierdo.

aClase de recomendación.

${ }^{b}$ Nivel de evidencia.

'Referencias que respaldan las recomendaciones. 
Tabla 12.1

Factores desencadenantes de la insuficiencia cardiaca aguda

\begin{tabular}{l}
\hline Síndrome coronario agudo \\
\hline Taquiarritmia (p. ej., fibrilación auricular, taquicardia ventricular) \\
\hline Aumento excesivo de la presión arterial \\
\hline Infección (p. ej., neumonía, endocarditis infecciosa, sepsis) \\
\hline Falta de adherencia a la restricción de sal/fluidos o medicación \\
\hline Bradiarritmia \\
\hline Sustancias tóxicas (alcohol, drogas) \\
\hline
\end{tabular}

Sustancias tóxicas (alcohol, drogas)

Fármacos (p. ej., AINE, corticoides, sustancias inotrópicas negativas, quimioterapia cardiotóxica)

Exacerbación de la enfermedad pulmonar obstructiva crónica

Embolia pulmonar

Cirugía y complicaciones perioperatorias

Aumento del impulso simpático, miocardiopatía relacionada con estrés

Alteraciones hormonales/metabólicas (p. ej., disfunción tiroidea, cetoacidosis

diabética, disfunción adrenal, embarazo y alteraciones pericárdicas)

Daño cerebrovascular

Causa mecánica aguda: SCA complicado con rotura miocárdica (rotura de la pared libre, comunicación interventricular, regurgitación mitral aguda), traumatismo torácico o intervención cardiaca, incompetencia de válvula nativa o protésica secundaria a endocarditis, disección o trombosis aórtica)

AINE: antiinflamatorios no esteroideos; SCA: síndrome coronario agudo.

perfusión periférica ("fría» frente a "caliente», presente o ausente) (figura 12.1 $)^{514,515}$. La combinación de estas opciones permite identificar 4 grupos de pacientes: caliente y húmedo (bien perfundido y congestionado), es la combinación más frecuente; frío y húmedo (hipoperfundido y congestionado); frío y seco (hipoperfundido sin congestión), y caliente y seco (compensado, bien perfundido, sin congestión). Esta clasificación puede ser útil para guiar la fase inicial del tratamiento y además aporta información pronóstica ${ }^{510,514,515}$.
Se puede clasificar a los pacientes con IAM que complica la IC según la clasificación de Killip y Kimball ${ }^{13}$ en: clase I, sin signos clínicos de IC; clase II, IC con estertores y S3 galopante; clase III, con edema pulmonar agudo franco; clase IV, shock cardiogénico, hipotensión (PAS < $90 \mathrm{mmHg}$ ) y evidencia de vasoconstricción periférica, como oliguria, cianosis y diaforesis.

La definición de los términos relativos a la presentación clínica de la ICA empleados en este apartado se encuentra en la tabla 12.2.

\subsection{Diagnóstico y evaluación pronóstica inicial}

El proceso diagnóstico se debe iniciar en el contexto prehospitalario y continuar en el servicio de urgencias para establecer el diagnóstico e iniciar el tratamiento adecuado lo antes posible. El beneficio del tratamiento precoz en los SCA está bien establecido y se debe considerar en el contexto de la ICA ${ }^{516,517}$. En paralelo, se debe identificar y manejar las entidades potencialmente mortales o factores desencadenantes coexistentes que requieren tratamiento o corrección urgente (figura 12.2). Normalmente, un paso inicial del proceso diagnóstico de la ICA es descartar otras causas alternativas de los síntomas y signos del paciente (infección pulmonar, anemia grave, insuficiencia renal aguda).

Cuando se confirma el diagnóstico de ICA es imprescindible realizar una evaluación clínica para decidir el posterior tratamiento.

Se recomienda que el diagnóstico inicial de ICA se base en una minuciosa historia clínica para valorar los síntomas, la historia cardiovascular previa y los desencadenantes potenciales, cardiacos y no cardiacos, así como en la evaluación de los signos/síntomas de congestión o hipoperfusión mediante exploración física, y se confirme posteriormente mediante pruebas adicionales, como ECG, radiografía torácica, pruebas de laboratorio (con biomarcadores específicos) y ecocardiografía.

Para los pacientes que se presentan con ICA, el inicio precoz del tratamiento adecuado (así como las pruebas necesarias) es de suma importancia ${ }^{516-518}$

Típicamente, los síntomas y signos de ICA reflejan sobrecarga de fluidos (congestión pulmonar o edema periférico) o, menos frecuen-

Tabla 12.2

Definición de los términos empleados en la sección 12 sobre insuficiencia cardiaca aguda

\begin{tabular}{|c|c|}
\hline Término & Definición \\
\hline Síntomas/signos de congestión (lado izquierdo) & Ortopnea, disnea paroxística nocturna, estertores pulmonares (bilaterales), edema periférico (bilateral) \\
\hline Síntomas/signos de congestión (lado derecho) & $\begin{array}{l}\text { Ingurgitacion venosa yugular, edema periférico (bilateral), hepatomegalia congestiva, reflujo hepatoyugular, ascitis, } \\
\text { síntomas de congestión intestinal }\end{array}$ \\
\hline Síntomas/signos de hipoperfusión & $\begin{array}{l}\text { Clínicos: extremidades frías y sudorosas, oliguria, confusión mental, mareos, presión de pulso estrecha } \\
\text { Determinaciones de laboratorio: acidosis metabólica, lactato sérico elevado, creatinina sérica elevada } \\
\text { La hipoperfusión no es sinónimo de hipotensión, pero frecuentemente la hipoperfusión se acompaña de hipotensión }\end{array}$ \\
\hline Hipotensión & PAS $<90 \mathrm{mmHg}$ \\
\hline Bradicardia & Frecuencia cardiaca $<40 \mathrm{lpm}$ \\
\hline Taquicardia & Frecuencia cardiaca > $120 \mathrm{lpm}$ \\
\hline Esfuerzo respiratorio anormal & Tasa respiratorio $>25 \mathrm{rpm}$ con uso de músculos accesorios o tasa respiratoria $<8 \mathrm{rpm}$ a pesar de disnea \\
\hline $\mathrm{SaO}_{2}$ baja & $\begin{array}{l}\mathrm{SaO}_{2}<90 \% \text { en oximetría de pulso } \\
\mathrm{SaO}_{2} \text { normal no excluye la hipoxemia }\left(\mathrm{PaO}_{2} \text { bajo }\right) \text { ni la hipoxia }\end{array}$ \\
\hline Hipoxemia & $\mathrm{PaO}_{2}$ en sangre arterial $<80 \mathrm{mmHg}(<10,67 \mathrm{kPa})$ (análisis de gases arteriales) \\
\hline Insuficiencia respiratoria hipoxémica (tipo I) & $\mathrm{PaO}_{2}<60 \mathrm{mmHg}(<8 \mathrm{kPa})$ \\
\hline Hipercapnia & $\mathrm{PaCO}_{2}$ en sangre arterial > $45 \mathrm{mmHg}$ (> $6 \mathrm{kPa}$ ) (análisis de gases arteriales) \\
\hline Insuficiencia respiratoria hipercápnica (tipo II) & $\mathrm{PaCO}_{2}>50 \mathrm{mmHg}(>6,65 \mathrm{kPa})$ \\
\hline Acidosis & $\mathrm{pH}<7,35$ \\
\hline Lactato sérico elevado & $>2 \mathrm{mmol} / \mathrm{l}$ \\
\hline Oliguria & Diuresis $<0,5 \mathrm{ml} / \mathrm{kg} / \mathrm{h}$ \\
\hline
\end{tabular}

$\mathrm{PaCO}_{2}$ : presión parcial de dióxido de carbono en sangre arterial; $\mathrm{PaO}_{2}$ : presión parcial de oxígeno en sangre arterial; PAS: presión arterial sistólica; SaO ${ }_{2}$ : saturación de oxígeno. 


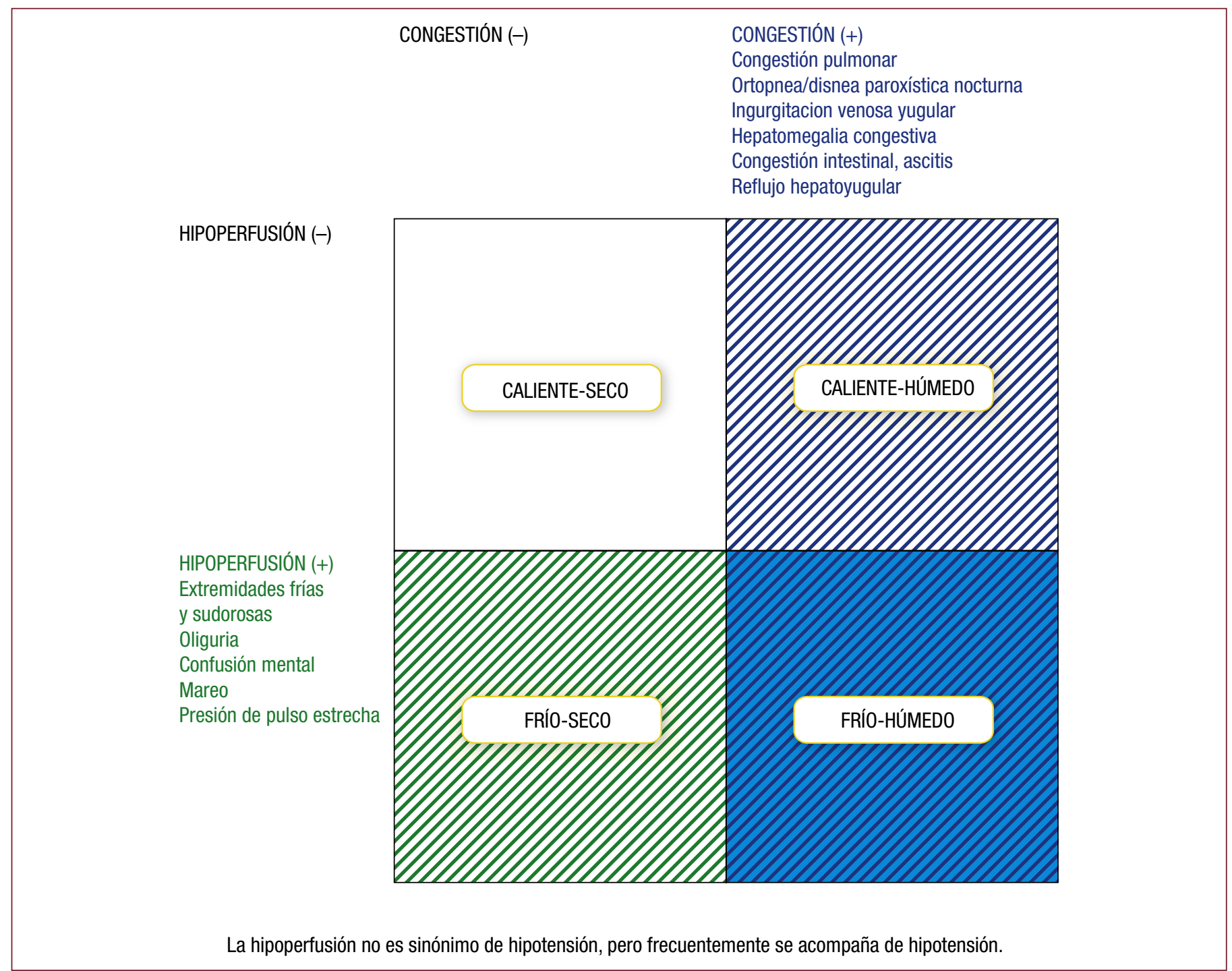

Figura 12.1. Perfil clínico de los pacientes con insuficiencia cardiaca aguda según la presencia/ausencia de congestión o hipoperfusión.

temente, gasto cardiaco reducido con hipoperfusión periférica (tabla 12.2). Dado que la sensibilidad y la especificidad de los síntomas y signos no suelen ser satisfactorias, la evaluación clínica inicial debe incluir las siguientes pruebas adicionales:

- La radiografía torácica puede ser una prueba útil para el diagnóstico de la ICA. La congestión venosa pulmonar, el derrame pleural, el edema intersticial o alveolar y la cardiomegalia suelen ser los hallazgos más específicos de la ICA, aunque en hasta un 20\% de los pacientes con ICA la radiografía torácica es prácticamente normal $^{519}$. La radiografía de tórax en decúbito supino tiene poca utilidad en la ICA. La radiografía torácica también es útil para identificar causas alternativas no cardiacas que pueden causar o contribuir a los síntomas (neumonía, infecciones pulmonares no consolidadas).

- El ECG rara vez es normal en la ICA (valor predictivo negativo alto $)^{520}$. También es útil para identificar enfermedades cardiacas subyacentes y factores desencadenantes potenciales (FA rápida, isquemia miocárdica aguda).

- La ecocardiografía inmediata solo es imprescindible en pacientes con inestabilidad hemodinámica (especialmente en shock cardiogénico) y en pacientes con sospecha de alteraciones cardiacas estructurales o funcionales que pueden ser potencialmente mortales (complicaciones mecánicas, regurgitación valvular aguda, disección aórtica). Se debe considerar la ecocardiografía precoz para todos los pacientes con ICA de novo o con función cardiaca desconocida (preferiblemente en las primeras $48 \mathrm{~h}$ desde el ingreso si se dispone de experiencia). La ecocardiografía de bolsillo puede emplearse como un complemento de la exploración clínica inicial si está disponible. Normalmente no es necesario repetir la ecocardiografía, excepto cuando el estado clínico del paciente se deteriora significativamente. Los ultrasonidos torácicos a pie de cama para identificar signos de edema intersticial y derrame pleural pueden ayudar a detectar la ICA si se dispone de experiencia.

- Pruebas de laboratorio:

- Péptidos natriuréticos.

- Tras el ingreso en el servicio de urgencias o unidad de cuidados coronarios (UCC)/unidad de cuidados intensivos (UCI), se determinará la concentración plasmática de PN (BNP, NT-proBNP o MR-proANP) de todos los pacientes con disnea aguda y sospecha de ICA para diferenciar la disnea aguda causada por ICA o por otras causas no cardiacas. Los PN tienen una sensibilidad alta y, en pacientes con valores de PN normales y sospecha de ICA, este diagnóstico es improbable (umbrales: BNP $<100$ pg/ml, NT-pro$\mathrm{BNP}<300 \mathrm{pg} / \mathrm{ml}$, MR-proANP $<120 \mathrm{pg} / \mathrm{ml})^{57-61,77,78,521}$. No obstante, las cifras de PN elevadas no confirman automáticamente el diagnóstico de ICA, ya que pueden darse por numerosas cau- 


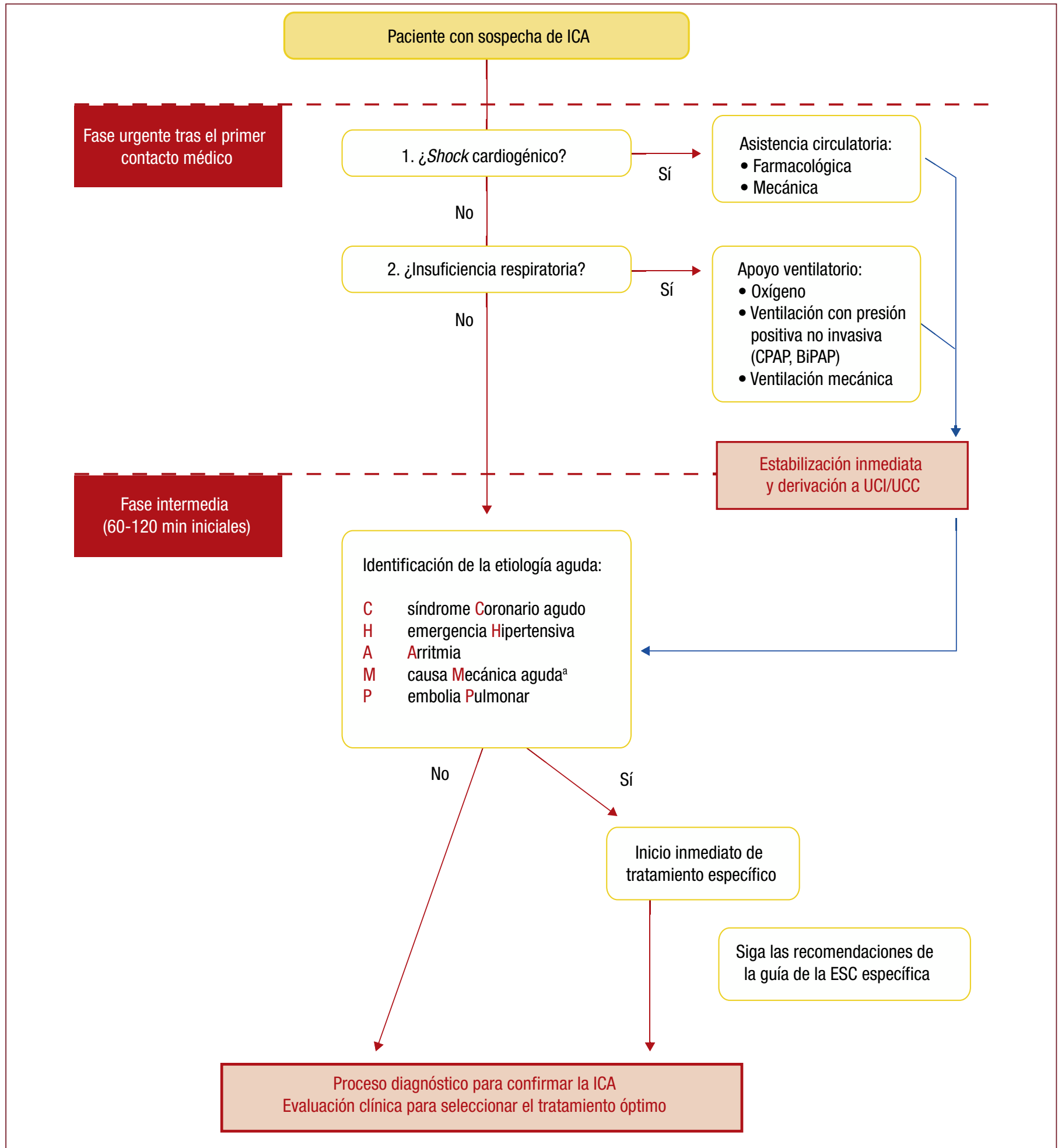

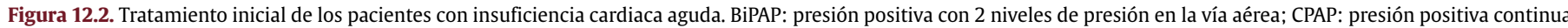
en la vía aérea; ESC: Sociedad Europea de Cardiología; ICA: insuficiencia cardiaca aguda; UCC: unidad de cuidados coronarios; UCI: unidad de cuidados intensivos.

aCausa mecánica aguda: rotura miocárdica que complica el síndrome coronario agudo (rotura de la pared libre, comunicación interventricular, regurgitación mitral aguda), traumatismo torácico o intervención cardiaca, incompetencia aguda de válvula nativa o protésica secundaria a endocarditis, disección o trombosis aórtica.

sas cardiacas y no cardiacas (tabla 12.3). Se puede detectar valores de PN inesperadamente bajos en algunos pacientes con IC terminal descompensada, edema pulmonar de tipo «flash» o ICA derecha.

Otras pruebas de laboratorio al ingreso:

- Se deben realizar las siguientes pruebas de laboratorio al ingreso de todos los pacientes con ICA: troponina cardiaca, nitrógeno ureico en sangre (BUN), creatinina, electrolitos (sodio, potasio), pruebas de función hepática, tirotropina (TSH), glucosa y recuento sanguíneo completo; la prueba de dímero D está indicada para pacientes con sospecha de embolia pulmonar aguda. - La determinación sistemática de gases arteriales no es necesaria y se debe restringir a los pacientes cuya oxigenación no se puede evaluar rápidamente con oximetría de pulso. Sin 
Tabla 123

Causas de aumento de péptidos natriuréticos ${ }^{522-524}$

\begin{tabular}{ll}
\hline Cardiacas & Insuficiencia cardiaca \\
& Síndromes coronarios agudos \\
& Embolia pulmonar \\
& Miocarditis \\
& Hipertrofia ventricular izquierda \\
& Miocardiopatía hipertrófica o restrictiva \\
& Valvulopatías \\
& Cardiopatía congénita \\
& Taquiarritmias auriculares y ventriculares \\
& Contusión cardiaca \\
& Cardioversión, shock por DAI \\
& Procedimientos quirúrgicos que implican al corazón \\
& Hipertensión pulmonar \\
& Edad avanzada \\
Ictus isquémico & Hemorragia subaracnoidea \\
& Disfunción renal \\
& Disfunción hepática (fundamentalmente cirrosis hepática con \\
& ascitis) \\
Síndrome paraneoplásico & Enfermedad pulmonar obstructiva crónica \\
Infecciones graves (incluidas neumonía y sepsis) & Quemaduras graves \\
Anemia & Alteraciones metabólicas y hormonales graves \\
& (p. ej., tirotoxicosis, cetoacidosis diabética) \\
\hline &
\end{tabular}

DAI: desfibrilador automático implantable.

embargo, puede ser útil cuando sea preciso medir las presiones parciales de $\mathrm{O}_{2}$ y $\mathrm{CO}_{2}$. Una muestra de sangre venosa puede indicar aceptablemente el $\mathrm{pH}$ y el $\mathrm{CO}_{2}$.

- Cabe destacar que la determinación de troponinas cardiacas es útil para la detección de SCA como causa subyacente de la ICA. Sin embargo, en la gran mayoría de los pacientes con ICA se detectan altas concentraciones de troponinas circulantes, frecuentemente sin isquemia miocárdica obvia ni una complicación coronaria aguda, lo cual indica la presencia de daño o necrosis de miocitos en estos pacientes ${ }^{525}$. También en pacientes con embolia pulmonar aguda como causa subyacente de la descompensación, la determinación de altas concentraciones de troponinas es útil para la estratificación del riesgo y la toma de decisiones ${ }^{526}$.

- Se recomienda medir la creatinina, BUN y electrolitos cada 1-2 días durante la hospitalización y antes del alta. No obstante, la gravedad del caso podría justificar una mayor frecuencia de las determinaciones. Se puede considerar la determinación de PN antes del alta para la evaluación pronóstica.
- Se puede considerar la evaluación de la concentración de procalcitonina en pacientes con ICA y sospecha de infección coexistente, especialmente para el diagnóstico diferencial de la neumonía y guiar el tratamiento antibiótico ${ }^{527}$ si se considera necesario.

- La función hepática suele estar afectada en los pacientes con ICA debido a alteraciones hemodinámicas (gasto cardiaco disminuido y congestión venosa aumentada). Los resultados anormales en las pruebas de la función hepática permiten identificar a los pacientes con mayor riesgo de un pronóstico desfavorable y pueden ser útiles para optimizar el tratamiento ${ }^{528-530}$.

- Dado que el hipotiroidismo y el hipertiroidismo pueden precipitar la ICA, se debe determinar la TSH de los pacientes con ICA de nuevo diagnóstico.

- Se ha estudiado el valor diagnóstico y pronóstico de otros biomarcadores en la ICA, como los marcadores de inflamación, estrés oxidativo, trastornos neurohormonales y remodelado miocárdico o de la matriz, pero ninguno de estos marcadores está recomendado en la práctica clínica habitual.

- La evaluación hemodinámica invasiva sistemática con catéter arterial pulmonar no está indicada para el diagnóstico de la ICA. Puede ser útil en casos seleccionados de pacientes hemodinámicamente inestables con un mecanismo de deterioro desconocido. Tampoco está indicado el uso sistemático de una vía arterial o venosa central con objetivos diagnósticos.

Numerosas variables clínicas y de laboratorio son predictores independientes de complicaciones intrahospitalarias y resultados a largo plazo en los síndromes de ICA, pero su impacto en el tratamiento de la enfermedad no está adecuadamente establecido.

\subsection{Abordaje y tratamiento}

La ICA es una enfermedad potencialmente mortal, por lo que se debe trasladar al paciente rápidamente a un hospital, preferiblemente a un centro con servicio de cardiología o UCC/UCI.

El diagnóstico precoz es importante en la ICA, por ello, el proceso diagnóstico y el tratamiento farmacológico y no farmacológico se iniciarán lo antes posible y en paralelo en todos los pacientes con sospecha de ICA.

La evaluación inicial y la monitorización no invasiva continua de las funciones vitales cardiorrespiratorias, que incluye oximetría de pulso, presión sanguínea, frecuencia respiratoria y ECG inmediato y continuo, son esenciales para evaluar si la ventilación, la perfusión periférica, la oxigenación, la frecuencia cardiaca y la PA son adecua-

Recomendaciones sobre las determinaciones diagnósticas aplicadas

\begin{tabular}{|c|c|c|c|}
\hline Recomendaciones & Clase $^{a}$ & Nivel $^{\mathrm{b}}$ & $\operatorname{Ref}^{c}$ \\
\hline $\begin{array}{l}\text { Durante la presentación, se recomienda determinar los péptidos natriuréticos plasmáticos (BNP, NT-proBNP o MR-proANP) de todo paciente } \\
\text { con disnea aguda y sospecha de ICA para diferenciarla de la disnea por causas no cardiacas }\end{array}$ & I & A & $531-534$ \\
\hline \multicolumn{4}{|l|}{ Se recomiendan las siguientes pruebas diagnósticas durante el ingreso de todos los pacientes con sospecha de ICA: } \\
\hline a. ECG de 12 derivaciones & I & C & \\
\hline $\begin{array}{l}\text { b. Radiografía torácica para evaluar los signos de congestión pulmonar y detectar otras enfermedades cardiacas y no cardiacas que podrían } \\
\text { causar o contribuir a los síntomas del paciente }\end{array}$ & I & C & \\
\hline $\begin{array}{l}\text { c. Determinaciones de laboratorio: troponinas cardiacas, BUN (o urea), creatinina, electrolitos (sodio, potasio), glucosa, hemograma completo, } \\
\text { prueba de la función hepática y TSH }\end{array}$ & I & C & \\
\hline $\begin{array}{l}\text { Se recomienda ecocardiografía inmediata para los pacientes con ICA hemodinámicamente inestables y en las primeras } 48 \text { h cuando se } \\
\text { desconozca la estructura y la función cardiacas o estas hayan podido cambiar desde pruebas realizadas con anterioridad }\end{array}$ & I & C & \\
\hline
\end{tabular}

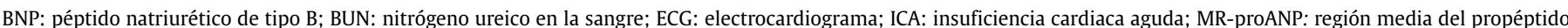
natriurético auricular; NT-proBNP: fracción N-terminal del propéptido natriurético cerebral; TSH: tirotropina.

aClase de recomendación.

bNivel de evidencia.

'Referencias que respaldan las recomendaciones. 
das. También se debe monitorizar la diuresis, aunque no está recomendado el cateterismo urinario por sistema.

Los pacientes con trastorno/insuficiencia respiratoria o deterioro hemodinámico deben ser transferidos a una zona del hospital donde se pueda proporcionar apoyo respiratorio y cardiovascular inmediatamente (figura 12.2).

\subsubsection{Identificación de factores/causas desencadenantes que llevan a la descompensación y requieren tratamiento urgente}

El siguiente paso consiste en identificar los factores desencadenantes/las causas principales que producen la descompensación, que se debe tratar urgentemente para evitar un mayor deterioro (figura 12.2). Entre ellas se incluye:

- Síndrome coronario agudo. Se debe tratar a los pacientes con SCA según la guía de la ESC sobre SCA sin elevación del segmento ST (SCASEST) e infarto agudo de miocardio con elevación del segmento ST (IAMCEST) ${ }^{114,535}$. La coexistencia de estas 2 entidades clínicas (SCA e ICA) caracteriza a un grupo de pacientes de riesgo muy alto para los que se recomienda una estrategia invasiva inmediata $(<2 \mathrm{~h}$ desde el ingreso en el hospital para pacientes con IAMSEST, de modo similar que para el tratamiento del IAMCEST) con la intención de llevar a cabo la revascularización, independientemente de los hallazgos electrocardiográficos o de biomarcadores $^{114,535}$. Más adelante se describe el tratamiento de los pacientes con inestabilidad hemodinámica persistente debido a una complicación mecánica del SCA.

- Emergencia hipertensiva. La ICA precipitada por un aumento rápido y excesivo de la PA se manifiesta típicamente como edema pulmonar agudo. Se debe considerar la inmediata reducción de la PA como objetivo terapéutico prioritario y se aplicará tan pronto como sea posible. Está recomendada la reducción intensiva de la PA (alrededor del 25\% durante las primeras horas y con precaución después) con vasodilatadores intravenosos combinados con diuréticos del asa ${ }^{317,536,537}$.

- Arritmias rápidas o bradicardia/alteraciones de la conducción graves. Las alteraciones graves del ritmo cardiaco en pacientes con ICA y condiciones inestables se deben corregir urgentemente con tratamiento farmacológico, cardioversión eléctrica o marcapasos temporal ${ }^{260,316,389}$ (véase también la sección 10.1 para el tratamiento de la FA). Si se cree que la arritmia auricular o ventricular contribuye al deterioro hemodinámico del paciente, se recomienda la cardioversión eléctrica para restaurar el rimo sinusal y mejorar el estado clínico del paciente. Los pacientes con ICA $\mathrm{y}$ arritmias ventriculares incesantes suponen un reto, ya que las arritmias y la inestabilidad hemodinámica operan como un círculo vicioso en el que se perpetúan la una a la otra. Para casos seleccionados se puede considerar la angiografía inmediata (seguida de revascularización si fuera necesario) y estudio electrocardiográfico con ablación por radiofrecuencia ${ }^{260}$.

- Causa mecánica aguda subyacente a la ICA. Se puede presentar como una complicación mecánica del SCA (rotura de la pared libre, comunicación interventricular, regurgitación mitral aguda), traumatismo torácico o intervención cardiaca o como incompetencia aguda de válvula nativa o protésica secundaria a endocarditis, disección o trombosis aórtica, además de causas de obstrucción raras (p. ej., tumores cardiacos). La ecocardiografía es fundamental para el diagnóstico; el tratamiento requiere normalmente apoyo circulatorio con intervención quirúrgica o percutánea.

- Embolia pulmonar aguda. Cuando se confirma la embolia pulmonar aguda como la causa de shock o hipotensión, se recomienda el tratamiento de reperfusión primaria con trombolisis, intervención percutánea o embolectomía quirúrgica ${ }^{526}$. A los pacientes con embolia pulmonar aguda se los debe tratar según las recomendaciones de las guías específicas ${ }^{526}$.
La identificación de la etiología/factores desencadenantes agudos se debe realizar en la fase inicial del tratamiento de la ICA (60-120 min) (figura 12.2).

\subsubsection{Criterios para la hospitalización en planta o en la unidad de cuidados intensivos/cuidados coronarios}

- Los pacientes con disnea persistente y significativa o inestabilidad hemodinámica deben ser transferidos a una sala del hospital donde se pueda aplicar medidas de resucitación si fueran necesarias.

- Para los pacientes de alto riesgo (disnea persistente y significativa, inestabilidad hemodinámica, arritmias recurrentes, ICA y SCA asociados), los cuidados iniciales se proporcionarán en una sala de alta dependencia (UCI/UCC). Los algoritmos clínicos para la predicción de la mortalidad intrahospitalaria de pacientes con ICA pueden ayudar a determinar qué pacientes del servicio de urgencias requieren el nivel más alto de cuidados hospitalarios ${ }^{538,539}$.

- Los criterios para el ingreso en la UCI/UCC incluyen cualquiera de los siguientes factores:

- Necesidad de intubación (o paciente intubado).

- Signos/síntomas de hipoperfusión.

- Saturación de oxígeno $\left(\mathrm{SpO}_{2}\right)<90 \%$ (a pesar de suplemento de oxígeno).

- Uso de los músculos accesorios de la respiración, frecuencia respiratoria $>25 \mathrm{rpm}$.

- Frecuencia cardiaca $<40$ o $>130 \mathrm{lpm}$, PAS $<90 \mathrm{mmHg}^{540}$.

- Los demás pacientes con ICA requieren el ingreso en una planta hospitalaria normal. Solo un pequeño porcentaje de pacientes con ICA ingresados en el servicio de urgencias (fundamentalmente por la exacerbación de los síntomas de IC con signos leves de congestión) reciben el alta directamente tras la administración de una pequeña dosis de diuréticos y el ajuste de las dosis del tratamiento médico y la recomendación de acudir a la consulta ambulatoria.

- La salida del paciente de la UCI/UCC está dictada por la estabilización clínica y la resolución de otras comorbilidades. Un equipo multidisciplinario se encargará de continuar el tratamiento y planificar el alta.

\subsubsection{Tratamiento en la fase inicial}

\section{Tratamiento con oxígeno y apoyo ventilatorio}

En la ICA no se debe utilizar sistemáticamente oxígeno en pacientes no hipoxémicos, ya que causa vasoconstricción y reducción del gasto cardiaco ${ }^{546,547}$. En la EPOC, la hiperoxigenación puede aumentar el desajuste ventilación-perfusión, suprimir la ventilación y producir hipercapnia. Durante el tratamiento con oxígeno es preciso monitorizar el equilibrio acidobásico y el $\mathrm{SpO}_{2}$ transcutáneo.

La ventilación no invasiva con presión positiva incluye la CPAP y la ventilación con presión positiva en 2 niveles (PPV). La PPV permite también la presión durante la inspiración, mejora la ventilación minuto y es especialmente útil en pacientes con hipercapnia, típicamente pacientes con EPOC.

La congestión afecta a la función pulmonar y aumenta los cortocircuitos intrapulmonares, con lo que se produce hipercapnia. La fracción de oxígeno inspirado $\left(\mathrm{FiO}_{2}\right)$ debe incrementarse al $100 \%$ si fuera necesario y no está contraindicado, teniendo en cuenta el $\mathrm{SpO}_{2}$. No obstante, debe evitarse la hiperoxia ${ }^{546,547}$. La ventilación no invasiva con presión positiva reduce los trastornos respiratorios ${ }^{541-545}$ y puede reducir la necesidad de intubación y las tasas de mortalidad ${ }^{543}$, aunque los datos sobre mortalidad son menos concluyentes. La CPAP es una técnica factible en un contexto prehospitalario, ya que es más sencilla que la presión de soporte y presión positiva al final de la espi- 
Recomendaciones para la atención de pacientes con insuficiencia cardiaca aguda: tratamiento con oxígeno y apoyo ventilatorio

\begin{tabular}{|c|c|c|c|}
\hline Recomendaciones & Clase $^{\mathrm{a}}$ & Nivel $^{\mathrm{b}}$ & $\operatorname{Ref}^{\mathrm{c}}$ \\
\hline Se recomienda la monitorización de la $\mathrm{SpO}_{2}$ & I & C & \\
\hline $\begin{array}{l}\text { Se debe considerar la determinación del pH sanguíneo y la } \mathrm{PaCO}_{2} \text { (posiblemente también el lactato) en sangre venosa, especialmente en } \\
\text { pacientes con edema pulmonar agudo o historia de EPOC. Para los pacientes en shock cardiogénico es preferible emplear sangre arterial }\end{array}$ & IIa & C & \\
\hline Se recomienda el tratamiento con oxígeno para los pacientes con ICA y $\mathrm{SpO}_{2}<90 \%$ o $\mathrm{PaO}_{2}<60 \mathrm{mmHg}(8,0 \mathrm{kPa})$ para corregir la hipoxemia & I & C & \\
\hline $\begin{array}{l}\text { Se debe considerar la ventilación no invasiva con presión positiva (CPAP, BiPAP) para los pacientes con trastorno respiratorio (frecuencia } \\
\left.\text { respiratoria }>25 \mathrm{rpm}, \mathrm{SpO}_{2}<90 \%\right) \text {, que se aplicará lo antes posible para disminuir el déficit respiratorio y la tasa de intubación endotraqueal } \\
\text { mecánica } \\
\text { La ventilación no invasiva con presión positiva puede reducir la presión arterial y se empleará con precaución en pacientes hipotensos. Se debe } \\
\text { tomar regularmente la presión arterial mientras se utilice este tratamiento }\end{array}$ & Ila & B & $541-545$ \\
\hline $\begin{array}{l}\text { Se recomienda intubación en caso de insuficiencia respiratoria que conlleve hipoxemia }\left(\mathrm{PaO}_{2}<60 \mathrm{mmHg} ; 8,0 \mathrm{kPa}\right) \text {, hipercapnia }(\mathrm{PaCO} \\
>50 \mathrm{mmHg} ; 6,65 \mathrm{kPa}) \text { y acidosis }(\mathrm{pH}<7,35) \text { y no se puede tratar de manera no invasiva }\end{array}$ & I & C & \\
\hline
\end{tabular}

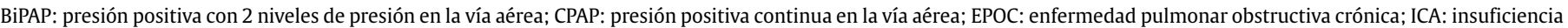
cardiaca aguda; $\mathrm{PaCO}_{2}$ : presión parcial de dióxido de carbono en sangre arterial; $\mathrm{PaO}_{2}$ : presión parcial de oxígeno en sangre arterial; SpO ${ }_{2}$ : saturación transcutánea de oxígeno.

aClase de recomendación.

'Nivel de evidencia.

cReferencias que respaldan las recomendaciones.

ración (PS-PEEP) y requiere un entrenamiento mínimo y menos equipo. Al llegar al hospital, los pacientes que todavía presentan signos de trastorno respiratorio deben continuar con la ventilación no invasiva, preferiblemente PS-PEEP, en caso de acidosis e hipercapnia, especialmente aquellos con historia de EPOC o signos de fatiga ${ }^{540}$.

Se tomarán precauciones con respecto a los efectos secundarios de fármacos anestésicos; el propofol puede inducir hipotensión y tener efectos cardiodepresores. En cambio, el midazolam tiene pocos efectos secundarios cardiacos y por ello se lo prefiere para pacientes con ICA o shock cardiogénico.

El algoritmo de tratamiento para los pacientes con ICA basado en el perfil clínico durante la fase inicial se encuentra en la figura 12.3.

\section{Tratamiento farmacológico}

\section{Diuréticos}

Los diuréticos son la piedra angular del tratamiento de los pacientes con ICA y signos de sobrecarga de fluidos y congestión. Los diuréticos aumentan la secreción renal de agua y sal y además tienen cierto efecto vasodilatador. En pacientes con ICA y signos de hipoperfusión, se debe evitar la administración de diuréticos hasta que se logre una perfusión adecuada.

La estrategia inicial para el tratamiento de la congestión incluye diuréticos intravenosos con la adición de vasodilatadores para el alivio de la disnea si la PA lo permite. Para aumentar la diuresis o superar la resistencia diurética, las opciones incluyen el bloqueo doble de la nefrona mediante diuréticos del asa (furosemida o torasemida) y tiacidas o dosis natriuréticas de $\mathrm{ARM}^{570,571}$. Esta combinación requiere una monitorización minuciosa para evitar la hipopotasemia, la disfunción renal y la hipovolemia.
Los datos para definir el régimen óptimo de tratamiento (dosis, tiempo y vía de administración) son insuficientes. En el grupo de "dosis alta» del estudio DOSE, el aumento a 2,5 veces de la dosis oral previa de furosemida llevó a un mayor alivio de la disnea, un mayor cambio de peso y pérdida de fluidos, a costa de un empeoramiento transitorio de la función renal ${ }^{548}$. En la ICA, la furosemida intravenosa es el diurético de primera línea más empleado. Se debe limitar la dosis a la menor cantidad necesaria para lograr un efecto clínico adecuado y modificarla según la función renal y las dosis de diuréticos previas. La dosis intravenosa inicial debe ser, como mínimo, igual a la dosis administrada en el domicilio. Consecuentemente, los pacientes con ICA de nueva aparición o aquellos con IC crónica sin historia de insuficiencia renal ni tratamiento previo con diuréticos pueden responder adecuadamente a un bolo intravenoso de $20-40 \mathrm{mg}$, mientras que los tratados previamente con diuréticos pueden requerir dosis más altas. Como alternativa se puede considerar la administración de un bolo de 10-20 mg de torasemida.

Vasodilatadores

Los vasodilatadores intravenosos (tabla 12.4) son los segundos fármacos más utilizados en la ICA para el alivio de los síntomas; sin embargo, no existen pruebas definitivas que confirmen su efecto beneficioso.

Ejercen un efecto beneficioso doble al disminuir el tono venoso (que optimiza la precarga) y el tono arterial (que disminuye la poscarga), por lo que también pueden aumentar el volumen latido. Los vasodilatadores son especialmente útiles para los pacientes con ICA hipertensiva, mientras que los pacientes con PAS $<90 \mathrm{mmHg}$ (o con hipotensión sintomática) deben evitarlos. La dosis se debe controlar con cuidado para evitar una reducción excesiva de la PA, que se asocia con peores resultados. Los vasodilatadores se emplearán con precaución en pacientes con estenosis mitral o aórtica significativa.

Tabla 12.4

Vasodilatadores intravenosos empleados para el tratamiento de la insuficiencia cardiaca aguda

\begin{tabular}{|c|c|c|c|}
\hline Vasodilatador & Dosis & Efectos secundarios principales & Otros \\
\hline Nitroglicerina & Comience con $10-20 \mu \mathrm{g} / \mathrm{min}$, aumente hasta $200 \mu \mathrm{g} / \mathrm{min}$ & Hipotensión, cefalea & Tolerancia con uso continuo \\
\hline Dinitrato de isosorbida & Comience con $1 \mathrm{mg} / \mathrm{h}$, aumente hasta $10 \mathrm{mg} / \mathrm{h}$ & Hipotensión, cefalea & Tolerancia con uso continuo \\
\hline Nitroprusiato & Comience con $0,3 \mu \mathrm{g} / \mathrm{kg} / \mathrm{min}$ y aumente hasta $5 \mu \mathrm{g} / \mathrm{kg} / \mathrm{min}$ & Hipotensión, toxicidad del isocianato & Fotosensibilidad \\
\hline Nesiritida $^{a}$ & Bolo de $2 \mu \mathrm{g} / \mathrm{kg}+$ infusión de $0,01 \mu \mathrm{g} / \mathrm{kg} / \mathrm{min}$ & Hipotensión & \\
\hline
\end{tabular}

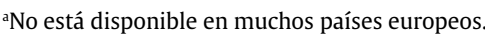




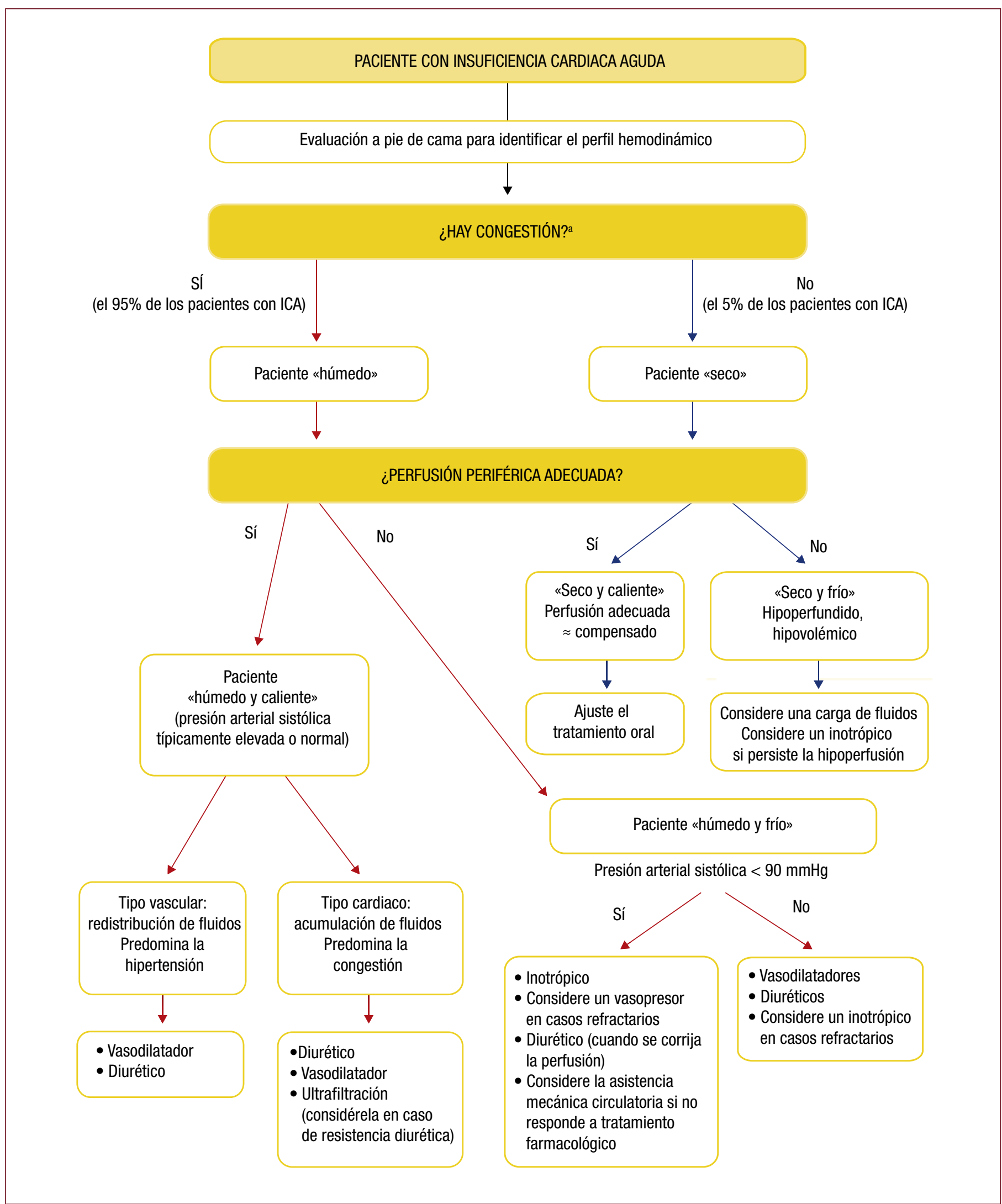

Figura 12.3. Tratamiento de los pacientes con insuficiencia cardiaca aguda según el perfil clínico durante la fase inicial.

áíntomas/signos de congestión: ortopnea, disnea paroxística nocturna, dificultad al respirar, estertores bibasales, respuesta anormal de la presión arterial a la maniobra de Valsalva (izquierda); síntomas de congestión intestinal, distensión venosa yugular, reflujo hepatoyugular, hepatomegalia, ascitis y edema periférico (derecho). 
Recomendaciones para la atención de pacientes con insuficiencia cardiaca aguda: farmacoterapia

\begin{tabular}{|c|c|c|c|}
\hline Recomendaciones & Clase $^{\mathrm{a}}$ & Nivel $^{\mathrm{b}}$ & $\operatorname{Ref}^{c}$ \\
\hline \multicolumn{4}{|l|}{ Diuréticos } \\
\hline $\begin{array}{l}\text { Se recomiendan los diuréticos de asa i.v. para todo paciente con ICA ingresado con signos/síntomas de sobrecarga de fluidos, para mejorar los } \\
\text { síntomas. Se recomienda monitorizar regularmente los síntomas, la diuresis, la función renal y los electrolitos durante el uso de diuréticos i.v. }\end{array}$ & I & C & \\
\hline $\begin{array}{l}\text { Para pacientes con ICA de nueva aparición o con IC crónica descompensada que no estén tratados con diuréticos orales, la dosis inicial } \\
\text { recomendada es de } 20-40 \text { mg de furosemida i.v. (o equivalente); para los pacientes que reciben tratamiento diurético indefinido, la dosis i.v. } \\
\text { inicial debe ser, como mínimo, equivalente a la dosis oral }\end{array}$ & I & B & 540,548 \\
\hline $\begin{array}{l}\text { Se recomienda la administración de diuréticos en bolos intermitentes o en infusión continua; la dosis y la duración se ajustarán a los síntomas } \\
\text { y el estado clínico del paciente }\end{array}$ & I & B & 548 \\
\hline $\begin{array}{l}\text { Se puede considerar la combinación de un diurético de asa con una tiacida o con espironolactona para pacientes con edema resistente } \\
\text { o con respuesta sintomática insuficiente }\end{array}$ & IIb & C & 549 \\
\hline \multicolumn{4}{|l|}{ Vasodilatadores } \\
\hline $\begin{array}{l}\text { Se debe considerar la administración de vasodilatadores i.v. para el alivio sintomático de los pacientes con ICA y PAS > } 90 \text { mmHg } \\
\text { (sin hipotensión sintomática) } \\
\text { Se debe monitorizar frecuentemente los síntomas y la PA durante la administración de vasodilatadores i.v. }\end{array}$ & IIa & B & $\begin{array}{c}537, \\
550-555\end{array}$ \\
\hline $\begin{array}{l}\text { Para los pacientes con ICA hipertensiva, se debe considerar la administración de vasodilatadores i.v. como tratamiento inicial para mejorar los } \\
\text { síntomas y reducir la congestión }\end{array}$ & IIa & B & $\begin{array}{l}537, \\
551-554\end{array}$ \\
\hline \multicolumn{4}{|l|}{ Agentes inotrópicos: dobutamina, dopamina, levosimendán, inhibidores de la fosfodiesterasa III } \\
\hline $\begin{array}{l}\text { Se debe considerar la infusión i.v. a corto plazo de agentes inotrópicos en pacientes con hipotensión (PAS }<90 \mathrm{mmHg} \text { ) o signos/síntomas } \\
\text { de hipoperfusión a pesar de un estado de llenado correcto, para aumentar el gasto cardiaco y la PA, mejorar la perfusión periférica y mantener } \\
\text { la función de órganos vitales }\end{array}$ & IIb & $\mathrm{C}$ & \\
\hline $\begin{array}{l}\text { Se puede considerar la infusión i.v. de levosimendán o un inhibidor de la PDE3 para revertir el efecto de los bloqueadores beta, si se cree que } \\
\text { estos contribuyen a la hipotensión y la posterior hipoperfusión }\end{array}$ & IIb & $\mathrm{C}$ & \\
\hline $\begin{array}{l}\text { Debido a problemas de seguridad, no se recomienda la administración de agentes inotrópicos, excepto para pacientes con hipotensión } \\
\text { sintomática o hipoperfusión }\end{array}$ & III & A & 556,557 \\
\hline \multicolumn{4}{|l|}{ Vasopresores } \\
\hline $\begin{array}{l}\text { Se puede considerar la administración de un vasopresor (noradrenalina preferiblemente) para pacientes en shock cardiogénico pese } \\
\text { al tratamiento con otro inotrópico, para aumentar la PA y la perfusión de órganos vitales }\end{array}$ & IIb & B & 558 \\
\hline $\begin{array}{l}\text { Se recomienda la monitorización de la PA y electrocardiográfica (ECG) cuando se usen agentes inotrópicos y vasopresores, ya que pueden } \\
\text { causar arritmia, isquemia miocárdica y, en el caso de levosimendán y los inhibidores de la PDE3, también hipotensión }\end{array}$ & I & $\mathrm{C}$ & $\begin{array}{l}540,559- \\
563\end{array}$ \\
\hline En estos casos se puede considerar la medición intraarterial de la presión & IIb & C & \\
\hline \multicolumn{4}{|l|}{ Profilaxis de tromboembolias } \\
\hline $\begin{array}{l}\text { Se recomienda la profilaxis de tromboembolias (p. ej., con HBPM) para los pacientes que no estén anticoagulados ni tengan contraindicaciones } \\
\text { para la anticoagulación, a efectos de reducir el riesgo de trombosis venosa profunda y embolia pulmonar }\end{array}$ & I & $\mathrm{B}$ & 564 \\
\hline \multicolumn{4}{|l|}{ Otros fármacos } \\
\hline \multicolumn{4}{|l|}{ Para el control inmediato de la frecuencia ventricular de los pacientes con fibrilación auricular: } \\
\hline a. Digoxina/bloqueador beta como primera línea de tratamiento ${ }^{d}$ & IIa & $\mathrm{C}$ & \\
\hline b. Se puede considerar la administración de amiodarona & IIb & B & $565-567$ \\
\hline $\begin{array}{l}\text { Se puede considerar el uso con precaución de opiáceos para aliviar la disnea y la ansiedad de los pacientes con disnea grave, pero pueden } \\
\text { inducir náuseas e hipopnea }\end{array}$ & IIb & B & 568,569 \\
\hline
\end{tabular}

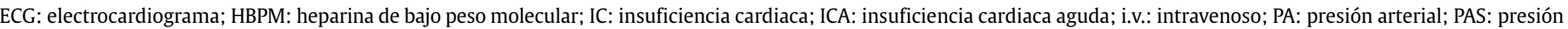
arterial sistólica.

aClase de recomendación.

bNivel de evidencia.

'Referencias que respaldan las recomendaciones.

dLos bloqueadores beta deben emplearse con precaución si el paciente es hipotenso.

El uso de un inotrópico (tabla 12.5) debería estar reservado a los pacientes con gasto cardiaco muy reducido que afecta a la perfusión de órganos vitales, lo cual ocurre más frecuentemente en la ICA hipotensiva. Los agentes inotrópicos no están recomendados para la ICA hipotensiva cuya causa subyacente sea la hipovolemia u otros factores potencialmente corregibles antes de la corrección de dichas causas. El levosimendán es preferible a la dobutamina para revertir el efecto de los bloqueadores beta si se cree que estos contribuyen a la hipoperfusión ${ }^{572}$. Sin embargo, el levosimendán es un vasodilatador, por lo que no es adecuado para el tratamiento de pacientes con hipotensión (PAS $<85 \mathrm{mmHg}$ ) o shock cardiogénico, excepto si se combina con otro inotrópico o vasopresor ${ }^{559,573,574}$. Los inotrópicos, especialmente los que tienen mecanismos adrenérgicos, pueden causar taquicardia sinusal e inducir isquemia miocárdica y arritmias, por lo que es precisa la monitorización electrocardiográfica. Con base en los resultados de estudios en los que se administraron infusiones intermitentes o continuas de inotrópicos ${ }^{559-563,575}$, preocupa que puedan aumentar la mortalidad. En cualquier caso, los inotrópicos deben emplearse con precaución, empezando por dosis relativamente bajas seguidas de un aumento gradual de la dosis bajo estrecha vigilancia.

\section{Vasopresores}

Los pacientes con hipotensión significativa son tratados con fármacos con potente acción vasoconstrictora arterial periférica, como la noradrenalina y la dopamina a dosis altas ( $>5 \mu \mathrm{g} / \mathrm{kg} / \mathrm{min}$ ). Estos fár- 
Tabla 12.5

Inotrópicos positivos y vasopresores usados para el tratamiento de la insuficiencia cardiaca aguda

\begin{tabular}{|c|c|c|}
\hline Vasodilatador & Bolo & Tasa de infusión \\
\hline Dobutamina $^{\mathrm{a}}$ & No & $2-20 \mu \mathrm{g} / \mathrm{kg} / \mathrm{min}$ (beta + ) \\
\hline \multirow[t]{2}{*}{ Dopamina } & No & $\begin{array}{l}\text { 3-5 } \mu \mathrm{g} / \mathrm{kg} / \mathrm{min} \text {; inotrópico } \\
\text { (beta+) }\end{array}$ \\
\hline & & $\begin{array}{l}>5 \mu \mathrm{g} / \mathrm{kg} / \mathrm{min}:\left(\text { beta }^{+}\right) \\
\text {vasopresor }\left(\text { alfa }^{+}\right)\end{array}$ \\
\hline Milrinona $a^{\mathrm{a}, \mathrm{b}}$ & $\begin{array}{l}25-75 \mu \mathrm{g} / \mathrm{kg} \text { durante } \\
10-20 \mathrm{~min}\end{array}$ & $0,375-0,75 \mu \mathrm{g} / \mathrm{kg} / \mathrm{min}$ \\
\hline Enoximona $^{\mathrm{a}}$ & $\begin{array}{l}0,5-1,0 \mathrm{mg} / \mathrm{kg} \text { durante } \\
5-10 \mathrm{~min}\end{array}$ & $5-20 \mu \mathrm{g} / \mathrm{kg} / \mathrm{min}$ \\
\hline Levosimendán ${ }^{\mathrm{a}}$ & $\begin{array}{l}12 \mu \mathrm{g} / \mathrm{kg} \text { durante } 10 \mathrm{~min} \\
\text { (opcional) }{ }^{c}\end{array}$ & $\begin{array}{l}0,1 \mu \mathrm{g} / \mathrm{kg} / \mathrm{min} \text {, que puede } \\
\text { rebajarse a } 0,05 \text { o aumentarse } \\
\text { a } 0,2 \mu \mathrm{g} / \mathrm{kg} / \mathrm{min}\end{array}$ \\
\hline Noradrenalina & No & $0,2-1,0 \mu \mathrm{g} / \mathrm{kg} / \mathrm{min}$ \\
\hline Epinefrina & $\begin{array}{l}\text { Bolo: se puede administrar } \\
1 \mathrm{mg} \text { i.v. durante la } \\
\text { reanimación y repetir cada } \\
3-5 \text { min }\end{array}$ & $0,05-0,5 \mu \mathrm{g} / \mathrm{kg} / \mathrm{min}$ \\
\hline
\end{tabular}

i.v.: intravenoso.

aTambién vasodilatador

${ }^{b}$ No se recomienda en la insuficiencia cardiaca isquémica que empeora de manera aguda.

'No se recomienda en bolo para pacientes hipotensos.

macos se administran para aumentar la PA y redistribuir el aporte sanguíneo hacia órganos vitales. No obstante, esto es a costa de un aumento de la poscarga del VI.

Se comparó dopamina con noradrenalina para el tratamiento de pacientes con distintos tipos de shock. El análisis de subgrupos indica que la noradrenalina tiene menos efectos secundarios y una mortalidad más baja ${ }^{558}$. La epinefrina (adrenalina) se debe reservar para pacientes con hipotensión persistente a pesar de presiones de llenado adecuadas y uso de otros fármacos vasoactivos, y también para protocolos de resucitación ${ }^{576}$.

\section{Profilaxis de las tromboembolias}

Está recomendada la profilaxis de las tromboembolias con heparina u otro anticoagulante, salvo que esté contraindicado o sea innecesario (por estar ya en curso un tratamiento con anticoagulantes orales).

\section{Digoxina}

La digoxina está indicada fundamentalmente para pacientes con FA y frecuencia ventricular rápida (>110 lpm) y se administra en bolos intravenosos de $0,25-0,5 \mathrm{mg}$ si no se administró previamente (0,0625-0,125 mg puede ser una dosis adecuada para pacientes con disfunción renal moderada o grave). Sin embargo, para los pacientes con comorbilidades u otros factores que afecten al metabolismo de la digoxina (incluidos otros fármacos) o los pacientes mayores, es difícil establecer teóricamente la dosis de mantenimiento; en esta situación, la dosis se establecerá empíricamente según las concentraciones de digoxina en sangre periférica.

\section{Antagonistas de la vasopresina}

Los antagonistas de la vasopresina, como el tolvaptán, bloquean la acción de la arginina-vasopresina (AVP) en el receptor $\mathrm{V}_{2}$ en los túbulos renales y promueven la acuaresis. El tolvaptán se puede emplear para el tratamiento de pacientes con sobrecarga de volumen e hiponatremia refractaria (la sed y la deshidratación son efectos adversos reconocidos $)^{577}$.

\section{Opiáceos}

Los opiáceos alivian la disnea y la ansiedad. En la ICA, no se recomienda el uso sistemático de opiáceos y deben utilizarse con precau- ción solo en pacientes con disnea grave, fundamentalmente con edema pulmonar. Los efectos secundarios dependientes de la dosis incluyen náuseas, hipotensión, bradicardia y depresión respiratoria (que puede requerir ventilación invasiva). La cuestión sobre el aumento potencial del riesgo de mortalidad en pacientes tratados con morfina sigue siendo controvertida ${ }^{568,569}$.

\section{Ansiolíticos y sedantes}

El tratamiento con ansiolíticos o sedantes puede ser necesario para pacientes que sufren agitación o delirio. La precaución en el uso de benzodiacepinas (diazepam o lorazepam) es la estrategia más segura.

\section{Tratamiento con dispositivos}

Recomendaciones sobre la terapia de reemplazo renal para pacientes con insuficiencia cardiaca aguda

\begin{tabular}{lccc}
\hline Recomendaciones & Clase $^{\mathrm{a}}$ & Nivel $^{\mathrm{b}}$ & Ref $^{\mathrm{c}}$ \\
\hline $\begin{array}{l}\text { Se puede considerar la ultrafiltración para } \\
\text { pacientes con congestión refractaria que no } \\
\text { respondan a tratamientos diuréticos }\end{array}$ & Ilb & B & 578-580 \\
\hline $\begin{array}{l}\text { Se debe considerar la terapia de reemplazo } \\
\text { renal para pacientes con sobrecarga de volumen } \\
\text { refractaria e insuficiencia renal aguda }\end{array}$ & Ila & C & \\
\hline
\end{tabular}

aClase de recomendación.

bNivel de evidencia.

'Referencias que respaldan las recomendaciones.

\section{Terapia de reemplazo renal}

La ultrafiltración consiste en la retirada de agua plasmática a través de una membrana semipermeable en respuesta a un gradiente de presión transmembrana. No hay pruebas a favor de la ultrafiltración frente a los diuréticos del asa como primera línea de tratamiento en pacientes con ICA ${ }^{571,578}$. Actualmente no se recomienda el uso sistemático de la ultrafiltración, que se debe reservar para pacientes que no responden al tratamiento con diuréticos.

Los siguientes criterios pueden indicar la necesidad de terapia de reemplazo renal para pacientes con sobrecarga refractaria de volumen: oliguria que no responde a medidas de control de fluidos, hiperpotasemia grave $\left(\mathrm{K}^{+}>6,5 \mathrm{mmol} / \mathrm{l}\right)$, acidemia grave $(\mathrm{pH}<7,2)$, urea sérica $>25 \mathrm{mmol} /(150 \mathrm{mg} / \mathrm{dl})$ y creatinina sérica $>300 \mu \mathrm{mol} / \mathrm{l}$ $(>3,4 \mathrm{mg} / \mathrm{dl})$.

\section{Dispositivos de asistencia mecánica}

Balón de contrapulsasión intraaórtico. Las indicaciones convencionales del balón de contrapulsación intraaórtico (BCIA) son el apoyo circulatorio antes de la corrección quirúrgica de problemas mecánicos agudos (p. ej., rotura de comunicación interventricular y regurgitación mitral aguda), durante miocarditis aguda grave y en pacientes seleccionados con isquemia o infarto agudo de miocardio, durante y después de la revascularización percutánea o quirúrgica. No hay pruebas concluyentes de que el BCIA sea beneficioso en presencia de otras causas de shock cardiogénico (más información a continuación).

Dispositivos de asistencia ventricular. Los dispositivos de asistencia ventricular y otras formas de asistencia mecánica circulatoria (AMC) pueden emplearse como «tratamiento puente a la decisión» o a más largo plazo para pacientes seleccionados (véase la sección 13).

\section{Otras intervenciones}

Para pacientes con ICA y derrame pleural, se puede considerar la pleurocentesis con evacuación de fluidos, si fuera factible, para aliviar los síntomas de disnea.

Para pacientes con ascitis, se puede considerar la paracentesis de líquido ascítico con evacuación de fluidos para aliviar los síntomas. 
Debido a la reducción de la presión intraabdominal, este procedimiento puede normalizar parcialmente el gradiente de presión transrenal, con lo que mejoraría la filtración renal ${ }^{581}$.

\subsubsection{Tratamiento de pacientes en shock cardiogénico}

El shock cardiogénico se define como hipotensión (PAS $<90 \mathrm{mmHg}$ ) a pesar de un estado de llenado adecuado y signos de hipoperfusión (tabla 12.2). Los cuadros patogénicos de shock cardiogénico van desde la IC crónica, de bajo gasto y fase avanzada, a los episodios agudos de novo debidos frecuentemente al IAMCEST, pero también causados por otras etiologías diferentes del SCA. Los pacientes en shock cardiogénico deben someterse inmediatamente a una evaluación exhaustiva. A todo paciente con sospecha de shock cardiogénico se le debe realizar inmediatamente ECG y ecocardiografía. Para pacientes con SCA complicado por shock cardiogénico, se recomienda realizar inmediatamente una coronariografía (durante las primeras $2 \mathrm{~h}$ tras el ingreso) con intención de revascularizar al paciente ${ }^{114,535}$. También se considerará la monitorización invasiva con catéter arterial.

No hay consenso sobre el método más conveniente de monitorización hemodinámica, incluido el cateterismo arterial pulmonar, para evaluar y tratar a los pacientes en shock cardiogénico.

El objetivo del tratamiento farmacológico es mejorar la perfusión orgánica mediante el aumento del gasto cardiaco y la PA. Tras realizar una carga de fluidos, el tratamiento farmacológico consiste en la administración de un inotrópico y un vasopresor, según se requiera. El tratamiento está guiado por la monitorización continua de la perfusión orgánica y de los parámetros hemodinámicos. Se puede considerar el cateterismo arterial pulmonar. La noradrenalina, como agente vasopresor, está recomendada cuando la PA media requiere apoyo farmacológico. La dobutamina es el inotrópico adrenérgico más utilizado. El levosimendán también se puede emplear combinado con un vasopresor ${ }^{582,583}$. En pacientes en shock cardiogénico tras el IAM, la infusión de levosimendán añadido a dobutamina y noradrenalina mejoró el estado hemodinámico sin producir hipotensión ${ }^{582,583}$. Los inhibidores de la PDE3 también pueden ser una opción, especialmente para pacientes no isquémi$\cos ^{561,584}$
Sin embargo, cuando la respuesta no es adecuada, se debe considerar la terapia con dispositivos en vez de emplear una combinación de inotrópicos. Recientemente, el estudio IABP-SHOCK II mostró que el uso de BCIA no mejoró los resultados de los pacientes en shock cardiogénico tras un IAM ${ }^{585,586}$. Por lo tanto, no se puede recomendar el uso sistemático de BCIA.

\subsection{Tratamientos orales basados en la evidencia}

El tratamiento oral modificador de la enfermedad para la IC se debe mantener tras el ingreso por ICA, excepto en presencia de inestabilidad hemodinámica (hipotensión sintomática, hipoperfusión, bradicardia), hiperpotasemia o función renal muy deteriorada. En estos casos, la dosis diaria del tratamiento oral se puede reducir o interrumpir hasta que el paciente esté estabilizado. El tratamiento con bloqueadores beta se puede mantener de manera segura durante la presentación de ICA, excepto en los casos de shock cardiogénico. Un metanálisis reciente ha demostrado que la interrupción de los bloqueadores beta a los pacientes hospitalizados por ICA se asoció con un aumento significativo de la mortalidad hospitalaria, la mortalidad a corto plazo y la variable combinada de rehospitalización a corto plazo o mortalidad ${ }^{585}$.

\section{Recomendaciones sobre tratamientos basados en la evidencia y modificadores} de la enfermedad para pacientes con insuficiencia cardiaca aguda

\begin{tabular}{lcc}
\hline Recomendaciones & Clase $^{\mathrm{a}}$ & Nivel $^{\mathrm{b}}$ \\
\hline $\begin{array}{l}\text { En caso de empeoramiento de la IC-FEr crónica se debe hacer } \\
\text { todo lo posible para mantener los tratamientos basados en la } \\
\text { evidencia y modificadores de la enfermedad, en ausencia } \\
\text { de inestabilidad hemodinámica y contraindicaciones }\end{array}$ & I & $\mathrm{C}$ \\
\hline $\begin{array}{l}\text { En caso de IC-FEr de novo, se debe hacer todo lo posible para } \\
\text { instaurar dichos tratamientos después de la estabilización } \\
\text { hemodinámica }\end{array}$ & $\mathrm{I}$ & $\mathrm{C}$ \\
\hline
\end{tabular}

ICA: insuficiencia cardiaca aguda; IC-FEr: insuficiencia cardiaca con fracción de eyección reducida.

aClase de recomendación.

bNivel de evidencia.

Recomendaciones sobre la atención de pacientes en shock cardiogénico

\begin{tabular}{|c|c|c|c|}
\hline Recomendaciones & Clase $^{\mathrm{a}}$ & Nivel $^{\mathrm{b}}$ & $\operatorname{Ref}^{\mathrm{c}}$ \\
\hline Se recomienda realizar inmediatamente un ECG y ecocardiografía a todo paciente con sospecha de shock cardiogénico & I & $\mathrm{C}$ & \\
\hline $\begin{array}{l}\text { A todo paciente con shock cardiogénico, se lo debe trasladar rápidamente a un hospital terciario, con servicio permanente de cateterismo } \\
\text { cardiaco y UCI/UCC con capacidad de asistencia mecánica circulatoria a corto plazo }\end{array}$ & I & $\mathrm{C}$ & \\
\hline $\begin{array}{l}\text { Para los pacientes con SCA complicado por shock cardiogénico, se recomienda una coronariografía inmediata (en las primeras } 2 \mathrm{~h} \text { tras el } \\
\text { ingreso) con intención de realizar revascularización coronaria }\end{array}$ & I & $\mathrm{C}$ & \\
\hline Se recomienda la monitorización continua de la presión arterial y ECG & I & C & \\
\hline Se recomienda la monitorización invasiva con una vía arterial & I & $\mathrm{C}$ & \\
\hline $\begin{array}{l}\text { Se recomienda administrar una carga de fluidos (salino o lactato de Ringer, > } 200 \mathrm{ml} / 15-30 \mathrm{~min} \text { ) como primera línea de tratamiento si no hay } \\
\text { signos manifiestos de sobrecarga de fluidos }\end{array}$ & I & $\mathrm{C}$ & \\
\hline Se puede considerar la administración i.v. de inotrópicos (dobutamina) para aumentar el gasto cardiaco & IIb & $\mathrm{C}$ & \\
\hline $\begin{array}{l}\text { Se puede considerar la administración de vasopresores (noradrenalina mejor que dopamina) si es necesario mantener la PAS en presencia } \\
\text { de hipoperfusión persistente }\end{array}$ & IIb & B & 558 \\
\hline No se recomienda usar sistemáticamente el BCIA en el shock cardiogénico & III & B & 585,586 \\
\hline $\begin{array}{l}\text { Se puede considerar la asistencia mecánica circulatoria a corto plazo en el shock cardiogénico refractario, dependiendo de la edad del paciente, } \\
\text { las comorbilidades y la función neurológica }\end{array}$ & IIb & $\mathrm{C}$ & \\
\hline
\end{tabular}

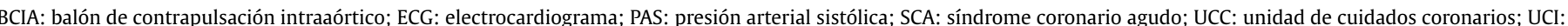
unidad de cuidados intensivos.

aClase de recomendación.

bNivel de evidencia.

'Referencias que respaldan las recomendaciones. 


\subsection{Monitorización del estado clínico de los pacientes hospitalizados por insuficiencia cardiaca aguda}

Recomendaciones sobre la monitorización del estado clínico de pacientes hospitalizados por insuficiencia cardiaca aguda

\begin{tabular}{lcc}
\hline Recomendaciones & Clase $^{\mathrm{a}}$ & Nivel $^{\mathrm{b}}$ \\
\hline $\begin{array}{l}\text { Se recomienda la monitorización estándar no invasiva de la } \\
\text { frecuencia cardiaca, el ritmo, la frecuencia respiratoria, } \\
\text { la saturación de oxígeno y la presión arterial }\end{array}$ & $\mathrm{I}$ & $\mathrm{C}$ \\
\hline $\begin{array}{l}\text { Se recomienda mantener un registro diario del peso y el } \\
\text { balance de fluidos }\end{array}$ & $\mathrm{I}$ & $\mathrm{C}$ \\
\hline $\begin{array}{l}\text { Se recomienda vigilar diariamente los signos y síntomas } \\
\text { relevantes a la IC (p. ej., disnea, estertores pulmonares, edema } \\
\text { periférico, peso) para evaluar la corrección de la sobrecarga de } \\
\text { fluidos }\end{array}$ & $\mathrm{I}$ & $\mathrm{C}$ \\
\hline $\begin{array}{l}\text { Se recomienda la determinación frecuente, generalmente } \\
\text { a diario, de la función renal (urea en sangre, creatinina) y } \\
\text { electrolitos (potasio, sodio) durante el tratamiento i.v. o cuando } \\
\text { se instaure tratamiento con inhibidores del sistema renina- } \\
\text { angiotensina-aldosterona }\end{array}$ & I & $\mathrm{C}$ \\
\hline $\begin{array}{l}\text { Se debe considerar el uso de una vía intraarterial en } \\
\text { pacientes con hipotensión y síntomas persistentes a pesar } \\
\text { del tratamiento }\end{array}$ & Ila \\
\hline $\begin{array}{l}\text { Se puede considerar el cateterismo arterial pulmonar } \\
\text { para pacientes con síntomas refractarios (especialmente } \\
\text { hipotensión e hipoperfusión) pese al tratamiento } \\
\text { farmacológico }\end{array}$ & C \\
\hline
\end{tabular}

IC: insuficiencia cardiaca; i.v.: intravenoso.

aClase de recomendación.

${ }^{b}$ Nivel de evidencia.

Se mantendrá un registro diario del peso y el balance de fluidos del paciente. Se debe monitorizar la función renal con la determinación diaria de BUN/urea, creatinina y electrolitos. No está recomendado el uso sistemático de catéter urinario.

La función renal suele estar afectada al ingreso, pero puede mejorar o empeorar con la diuresis. Se debe mantener la monitorización sistemática del pulso, la tasa respiratoria y la PA. Ningún estudio ha demostrado la utilidad de la monitorización hemodinámica invasiva en pacientes con ICA, excepto en pacientes en shock cardiogénico. Algunos datos respaldan que la determinación de PN durante la hospitalización puede ayudar a planificar el alta hospitalaria. Los pacientes cuyos títulos de PN disminuyen durante la hospitalización tienen tasas más bajas de mortalidad cardiovascular y rehospitalización a los 6 meses $^{588-590}$.

\subsection{Criterios para el alta hospitalaria y seguimiento en la fase de alto riesgo}

Los pacientes ingresados por ICA pueden recibir el alta médica si ${ }^{552}$ :

- Se encuentran hemodinámicamente estables, euvolémicos, estabilizados con medicación oral basada en la evidencia y con la función renal estable durante al menos $24 \mathrm{~h}$ antes del alta.

- Han recibido formación y asesoramiento sobre autocuidados.

Preferiblemente, los pacientes deben:

- Estar incluidos en un programa de tratamiento; la planificación del seguimiento debe estar preparada antes del alta y se debe comunicar claramente al equipo de atención primaria.

- Acudir a la consulta de su médico de familia durante la primera semana después del alta.
- Acudir al hospital para consulta con el equipo cardiológico durante las primeras 2 semanas después del alta siempre que sea posible.

Un servicio multidisciplinario de IC debe dar seguimiento a los pacientes con IC crónica. El tratamiento del paciente antes y después del alta debe cumplir los estándares de atención de la ICA 440,591,592. $^{2}$.

\subsection{Objetivos durante las distintas fases del tratamiento de la insuficiencia cardiaca aguda}

Durante el tratamiento de los pacientes con ICA, se puede distinguir distintas fases que requieren distintas estrategias terapéuticas (descritas en los apartados anteriores de esta sección). Los objetivos del tratamiento durante las distintas fases del abordaje de los pacientes con ICA también son diferentes y se resumen en la tabla 12.6.

Tabla 12.6

Objetivos del tratamiento en la insuficiencia cardiaca aguda

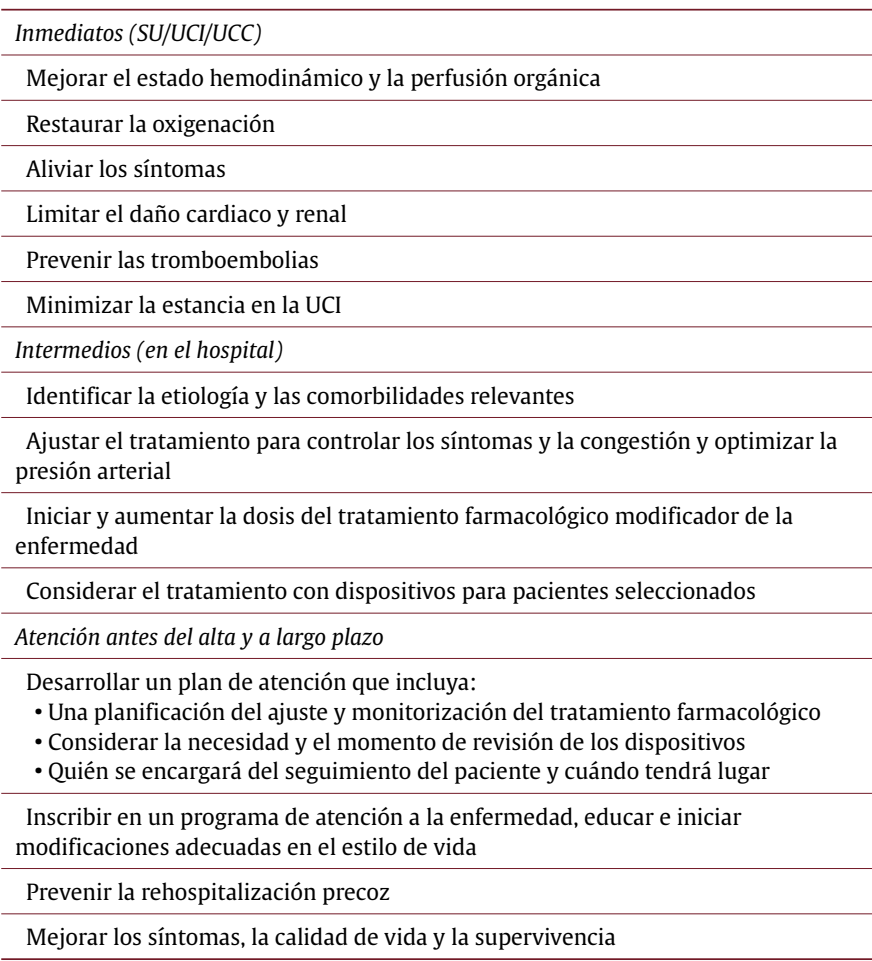

SU: servicio de urgencias; UCC: unidad de cuidados coronarios; UCI: unidad de cuidados intensivos.

\section{ASISTENCIA MECÁNICA CIRCULATORIA Y TRASPLANTE CARDIACO}

\subsection{Asistencia mecánica circulatoria}

En los pacientes con IC crónica o aguda a los que no se puede estabilizar con tratamiento farmacológico, se puede emplear sistemas de AMC para descargar el ventrículo debilitado y mantener una perfusión orgánica suficiente. A los pacientes en shock cardiogénico agudo, se los trata inicialmente y a corto plazo con un dispositivo de asistencia extracorpórea no permanente mientras se planifica una terapia más definitiva. Se puede tratar con un dispositivo de asistencia ventricular izquierda (DAVI) a los pacientes con IC crónica refractaria a pesar del tratamiento farmacológico. En la tabla 13.1 se encuentran las indicaciones actuales para el uso de dispositivos de asistencia mecánica circulatoria ${ }^{593}$. 
Tabla 131

Términos que describen varias indicaciones de asistencia mecánica circulatoria

Puente a la decisión Uso a corto plazo de la AMC (como SVE o ECMO) en /puente a puente pacientes con shock cardiogénico hasta que se estabilicen el estado hemodinámico y la perfusión de órganos finales; se excluyen las contraindicaciones de la AMC a largo plazo (daño cerebral tras reanimación) y se puede evaluar otras opciones terapéuticas, como el DAV o el trasplante cardiaco

$\begin{array}{ll}\begin{array}{l}\text { Puente a ser } \\ \text { candidato }\end{array} & \text { Uso de la AMC (normalmente DAVI) para mejorar la } \\ & \text { función de órganos vitales y conseguir que un paciente no } \\ \text { apto para trasplante lo sea }\end{array}$

Puente al trasplante Uso de la AMC (DAVI o BiVAD) para mantener con vida al paciente, que tiene un alto riesgo de muerte antes del trasplante, hasta que haya disponible un donante de órganos

Puente a la recuperación Uso de la AMC (típicamente DAVI) para mantener con vida al paciente hasta que la función cardiaca se recupere lo suficiente para retirar la AMC

Terapia de destino Uso de la AMC a largo plazo (DAVI) como alternativa a (TD) trasplante para pacientes con IC terminal no aptos para trasplante o que se encuentran largo tiempo en lista de espera para trasplante

AMC: asistencia mecánica circulatoria; BiVAD: dispositivo de asistencia biventricular; DAV: dispositivo de asistencia ventricular; DAVI: dispositivo de asistencia ventricular izquierda; ECMO: oxigenador extracorpóreo de membrana; IC: insuficiencia cardiaca; SVE: soporte vital extracorpóreo; TD: terapia de destino.

\subsubsection{Asistencia mecánica circulatoria en la insuficiencia cardiaca aguda}

Para el tratamiento de los pacientes con ICA o shock cardiogénico (INTERMACS, nivel 1), se puede emplear sistemas de asistencia mecánica a corto plazo, como dispositivos percutáneos de asistencia cardiaca, dispositivos de soporte vital extracorpóreo y oxigenador extracorpóreo de membrana (ECMO) para mantener estables a los pacientes con insuficiencia ventricular o biventricular hasta que se recupere la función cardiaca y de otros órganos. Normalmente, el uso de estos dispositivos se limita a unos días o semanas. La escala SAVE (Survival After Veno-arterial ECMO) puede ayudar a predecir la supervivencia de los pacientes tratados con ECMO por shock cardiogénico refractario (calculadora en línea: http://www.save-score.com) ${ }^{594}$.

Además, los sistemas de AMC, especialmente el dispositivo de soporte vital extracorpóreo y el ECMO, se pueden utilizar como "puente a la decisión» para pacientes con IC aguda de rápido deterioro o shock cardiogénico para estabilizar los parámetros hemodinámicos, recuperar la función de órganos vitales y ganar tiempo para evaluar la posibilidad de trasplante cardiaco o de un dispositivo de AMC más permanente ${ }^{595}$.

La evidencia sobre los beneficios de la AMC percutánea temporal en pacientes que no responden al tratamiento estándar, incluidos los inotrópicos, es escasa. En un metanálisis de 3 ECDA que compararon la AMC percutánea frente a BCIA en un total de 100 pacientes en shock cardiogénico, la AMC pareció segura y obtuvo mejores resultados hemodinámicos, pero no mejoró la mortalidad a los 30 días y se asoció con más complicaciones hemorrágicas ${ }^{596}$. En un estudio aleatorizado en pacientes de alto riesgo con disfunción del VI (estudio PROTECT II), no hubo diferencias en la incidencia de complicaciones adversas a los 30 días entre los pacientes tratados con BCIA y los tratados con un dispositivo de asistencia hemodinámica ${ }^{597}$. Con base en estos resultados no se puede recomendar la AMC percutánea como tratamiento de eficacia probada para el shock cardiogénico agudo. Para pacientes seleccionados puede servir como puente al tratamiento definitivo. En algunas ocasiones será necesario tomar la difícil decisión de retirar la AMC cuando el paciente no tenga capacidad de recuperar la función cardiaca y no sea candidato a AMC más duradera o trasplante cardiaco.

\subsubsection{Asistencia mecánica circulatoria en la fase terminal de la insuficiencia cardiaca crónica}

El trasplante cardiaco siempre ha sido una opción terapéutica limitada para los pacientes con IC crónica en fase terminal. El aumento del número de pacientes con IC crónica refractaria y el descenso del número de donantes de órganos han hecho que aumenten las listas y los tiempos de espera de estos pacientes (una media de 16 meses en la región del programa Eurotransplant) ${ }^{598}$. Más del 60\% de los pacientes reciben el trasplante en situación de urgencia, por lo que quedan pocas oportunidades para los pacientes en espera de un trasplante menos urgente. Cada año se incluye en la lista de espera un número 3 veces mayor que el número de pacientes que reciben un trasplante, y la tasa de mortalidad en lista de espera del programa Eurotransplant fue del $21,7 \%$ en $2013^{598}$.

Datos más recientes indican que los pacientes en lista de espera tratados con DAVI tienen mayor supervivencia ${ }^{599}$. Por ello, cada vez más se considera que los dispositivos de AMC, especialmente el DAVI de flujo continuo, son una alternativa al trasplante cardiaco. Inicialmente, los DAVI se desarrollaron para uso a corto plazo como «puente a tratamiento" (tabla 13.1 ${ }^{600}$, pero actualmente se utilizan durante meses o años como tratamiento permanente o de destino para pacientes que se enfrentan a una larga espera hasta el trasplante (solo el $10 \%$ de los pacientes con un dispositivo de AMC e indicación de "puente a tratamiento» reciben el trasplante durante el primer año en lista de espera) o que no son candidatos a trasplante. El número de pacientes con DAVI que no son demasiado mayores y son elegibles para trasplante aumenta constantemente. Para la mayoría de estos pacientes, el tratamiento permanente con DAVI, pese a ser candidatos a trasplante, es una realidad. Actualmente, las tasas de supervivencia a 2-3 años de pacientes que, tras una cuidadosa selección, reciben tratamiento con un dispositivo moderno de flujo continuo son excelentes y comparables a las tasas de supervivencia a corto plazo tras el trasplante cardiaco ${ }^{595}$. Sin embargo, los datos de resultados a largo plazo son pocos. En los pacientes tratados con un DAVI de flujo continuo, fundamentalmente no aptos para trasplante, la supervivencia actuarial es del $80 \%$ a 1 año y del $70 \%$ a los 2 años. Hay que destacar que se registró una supervivencia del 85\% a los 2 años en pacientes de edad $\leq 70$ años, sin diabetes, insuficiencia renal o shock cardiogénico ${ }^{601,602}$. Los pacientes tratados con un DAVI como "puente a tratamiento" tienen una tasa de supervivencia tras el trasplante similar o mejor que aquellos que no requieren o no reciben tratamiento puente ${ }^{599}$. A pesar de los avances tecnológicos, la hemorragia, la tromboembolia (ambas pueden causar ACV), la trombosis del dispositivo, las infecciones secundarias y el fallo del dispositivo siguen siendo problemas importantes que afectan a los resultados a largo plazo de los pacientes tratados con AMC ${ }^{599,603-606}$. Se recomienda que el tratamiento con estos dispositivos solo se realice en centros que dispongan de un servicio de cardiología y cirugía con especialistas en IC, además de consulta ambulatoria con personal de enfermería entrenado específicamente ${ }^{607}$

En algunos pacientes, el remodelado inverso y la mejoría de la capacidad funcional del VI permiten retirar el DAVI ( «puente a la recuperación"). Esto es más probable en pacientes más jóvenes con una causa aguda fulminante pero reversible de la IC, como miocarditis aguda o miocardiopatía periparto ${ }^{608,609}$. Los DAVI también pueden utilizarse como tratamiento "puente a ser candidato" para posibilitar la recuperación de la función de órganos vitales, mejorar la función del VD y reducir la hipertensión pulmonar, de modo que los pacientes inicialmente no aptos para trasplante puedan ser candidatos.

En un estudio reciente se probó el implante precoz de un DAV en pacientes menos graves (p. ej., los que aún no recibían inotrópicos), y reveló mejores resultados en estos pacientes que en aquellos que per- 
Tabla 13.2

Fases INTERMACS (Interagency Registry for Mechanically Assisted Circulatory Support) para la clasificación de pacientes con insuficiencia cardiaca avanzada

\begin{tabular}{|c|c|c|c|c|}
\hline Nivel INTERMACS & NYHA & Descripción & Dispositivo & $\begin{array}{l}\text { Supervivencia a } 1 \text { año } \\
\text { con DAVI }\end{array}$ \\
\hline $\begin{array}{l}\text { 1. Shock cardiogénico } \\
\text { "Crash and burn" }\end{array}$ & IV & $\begin{array}{l}\text { Inestabilidad hemodinámica pese a dosis crecientes de } \\
\text { catecolaminas o asistencia mecánica circulatoria con } \\
\text { hipoperfusión crítica de órganos diana (shock cardiogénico } \\
\text { crítico) }\end{array}$ & $\begin{array}{l}\text { SVE, ECMO, dispositivos } \\
\text { percutáneos de apoyo }\end{array}$ & $52,6 \% \pm 5,6 \%$ \\
\hline
\end{tabular}

\begin{tabular}{|c|c|c|c|c|}
\hline $\begin{array}{l}\text { 2. Deterioro progresivo a pesar } \\
\text { de apoyo inotrópico } \\
\text { "Sliding on inotropes» }\end{array}$ & IV & $\begin{array}{l}\text { Soporte inotrópico intravenoso con cifras aceptables de } \\
\text { presión arterial y deterioro rápido de la función renal, el estado } \\
\text { nutricional o los signos de congestión }\end{array}$ & SVE, ECMO, DAVI & $63,1 \% \pm 3,1 \%$ \\
\hline $\begin{array}{l}\text { 3. Estable pero dependiente } \\
\text { de inotrópicos } \\
\text { "Dependent stability» }\end{array}$ & IV & $\begin{array}{l}\text { Estabilidad hemodinámica con dosis de inotrópicos bajas } \\
\text { o intermedias, pero necesarias debido a hipotensión, } \\
\text { empeoramiento sintomático o insuficiencia renal } \\
\text { progresiva }\end{array}$ & DAVI & $78,4 \% \pm 2,5 \%$ \\
\hline $\begin{array}{l}\text { 4. Síntomas en reposo } \\
\text { «Frequent flyer» }\end{array}$ & IV ambulatorio & $\begin{array}{l}\text { Es posible retirar transitoriamente el tratamiento inotrópico, } \\
\text { pero el paciente sufre recaídas sintomáticas frecuentes, } \\
\text { habitualmente con sobrecarga de fluidos }\end{array}$ & DAVI & $78,7 \% \pm 3,0 \%$ \\
\hline $\begin{array}{l}\text { 5. Intolerancia al ejercicio } \\
\text { "Housebound» }\end{array}$ & IV ambulatorio & $\begin{array}{l}\text { Limitación absoluta de la actividad física, con estabilidad } \\
\text { en reposo, aunque habitualmente con retención moderada } \\
\text { de fluidos y cierto grado de disfunción renal }\end{array}$ & DAVI & $93,0 \% \pm 3,9 \%^{\mathrm{a}}$ \\
\hline $\begin{array}{l}\text { 6. Ejercicio limitado } \\
\text { "Walking wounded» }\end{array}$ & III & $\begin{array}{l}\text { Menor limitación de la actividad física y ausencia de congestión } \\
\text { en reposo. Fatiga fácil con actividad ligera }\end{array}$ & $\begin{array}{l}\text { DAVI/valore DAVI como } \\
\text { opción }\end{array}$ & - \\
\hline 7. «Placeholder» & III & $\begin{array}{l}\text { Paciente en NYHA II-III sin balance inestable de fluidos actual } \\
\text { ni reciente }\end{array}$ & $\begin{array}{l}\text { Valore DAVI como } \\
\text { opción }\end{array}$ & - \\
\hline
\end{tabular}

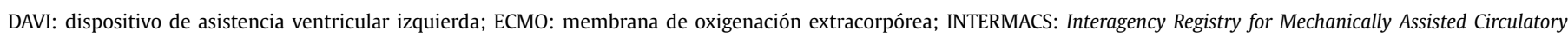
Support; NYHA: clase funcional de la New York Heart Association; SVE: soporte vital extracorpóreo.

aEstimaciones de Kaplan-Meier con error estándar de la media para la supervivencia a 1 año con terapia de DAVI. Los pacientes fueron censurados en el momento del último contacto, recuperación o trasplante cardiaco. Debido al pequeño número de datos, se combinaron las categorías 5, 6 y 7 de la clasificación INTERMACS 610 .

manecieron con tratamiento farmacológico ${ }^{605}$. Del mismo modo, el registro INTERMACS muestra mejores resultados en pacientes que se encuentran en una clase INTERMACS más alta, aunque la mayoría de los DAV se implantan en pacientes en clases $1-3^{604,610}$. Hay que recordar, además, que no hay ningún ECDA que compare el tratamiento farmacológico frente al implante de dispositivos de AMC en los pacientes candidatos a trasplante (tabla 13.2).

Típicamente, los pacientes con IC en fase terminal evaluados para AMC pueden presentar muchos signos de deterioro de la función cardiovascular ${ }^{593}$, estar en tratamiento con inotrópicos o presentar signos de deterioro funcional de órganos vitales. Los marcadores de disfunción hepática o renal, las anomalías hematológicas o de coagulación y la baja concentración sérica de albúmina se asocian con un peor pronóstico ${ }^{611,612}$.

La evaluación de la función del VD es crucial debido a que la insuficiencia del VD posoperatoria aumenta significativamente la mortalidad perioperatoria y reduce la supervivencia antes y después del trasplante. Existen múltiples enfoques para evaluar el VD (véase la sección 5.2.3). Si se estima que la insuficiencia del VD es potencialmente reversible, se puede considerar la utilización temporal (días o semanas) de un dispositivo de asistencia ventricular derecha (DAVD) extracorpóreo con bomba centrífuga, además de un DAVI. Para los pacientes con insuficiencia biventricular crónica o alto riesgo de insuficiencia del VD persistente tras el implante de un DAVI, podría ser necesario implantar un dispositivo de asistencia biventricular (BiVAD). Los pacientes que requieren apoyo con BiVAD a largo plazo deben ser candidatos a trasplante, ya que esta terapia no es adecuada como «tratamiento de destino». Los resultados de la terapia con BiVAD son inferiores a los del DAVI, por lo que la indicación de DAV se debe valorar antes de que ocurra el deterioro de la función del VD. El implante de un corazón artificial con extracción del corazón nativo se debe reservar para pacientes seleccionados a los que no se puede tratar con un DAVI (comunicación interventricular no reparable, rotura cardiaca).

Los pacientes con infección activa, disfunción renal, hepática o pulmonar grave o estado neurológico incierto tras parada cardiaca o debido a shock cardiogénico no suelen ser candidatos para "puente a tratamiento" o "terapia de destino", pero pueden serlo para "puente a ser candidato» (tabla 13.3).

\section{Tabla 13.3}

Pacientes potencialmente elegibles para implante de un dispositivo de asistencia ventricular izquierda

Pacientes con síntomas graves de duración $>2$ meses a pesar de tratamiento óptimo con fármacos y dispositivos y más de uno de los siguientes factores:

$\mathrm{FEVI}<25 \%$ y $\mathrm{VO}_{2}$ pico $<12 \mathrm{ml} / \mathrm{kg} / \mathrm{min}$ si se ha medido

Al menos 3 hospitalizaciones por IC en los últimos 12 meses sin una causa precipitante obvia

Dependencia de tratamiento inotrópico i.v.

Disfunción progresiva de órganos vitales (deterioro de la función renal o hepática) debido a perfusión reducida y no a presiones inadecuadas de llenado ventricular (PEP $\geq 20 \mathrm{mmHg}$ y PAS $\leq 80-90 \mathrm{mmHg}$ o índice cardiaco $\leq 2 \mathrm{l} / \mathrm{min} / \mathrm{m}^{2}$ )

Ausencia de disfunción ventricular derecha grave junto con regurgitación tricuspídea grave

FEVI: fracción de eyección del ventrículo izquierdo; IC: insuficiencia cardiaca; i.v.: intravenoso; PAS: presión arterial sistólica; PEP: presión de enclavamiento pulmonar; $\mathrm{VO}_{2}$ : consumo de oxígeno. 
Recomendaciones para el implante de dispositivos de asistencia mecánica circulatoria en pacientes con insuficiencia cardiaca refractaria

\begin{tabular}{|c|c|c|c|}
\hline Recomendaciones & Clase $^{\mathrm{a}}$ & Nivel $^{\mathrm{b}}$ & Ref.c \\
\hline $\begin{array}{l}\text { Se debe considerar el implante de un DAVI en } \\
\text { pacientes con IC-FEr terminal pese a tratamiento } \\
\text { óptimo con fármacos y dispositivos y candidatos } \\
\text { a trasplante cardiaco, a efectos de mejorar los } \\
\text { síntomas y reducir el riesgo de hospitalización por } \\
\text { IC y de muerte prematura (indicación de "puente } \\
\text { al trasplante») }\end{array}$ & IIa & C & \\
\hline $\begin{array}{l}\text { Se debe considerar el implante de un DAVI en } \\
\text { pacientes con IC-FEr terminal pese a tratamiento } \\
\text { óptimo con fármacos y dispositivos y que no son } \\
\text { candidatos a trasplante cardiaco, a efectos } \\
\text { de reducir el riesgo de muerte prematura }\end{array}$ & Ila & B & $\begin{array}{c}605,612 \\
613\end{array}$ \\
\hline
\end{tabular}

DAVI: dispositivo de asistencia ventricular izquierda; IC: insuficiencia cardiaca; IC-FEr: insuficiencia cardiaca con fracción de eyección reducida.

aClase de recomendación.

Nivel de evidencia.

'Referencias que respaldan las recomendaciones.

\subsection{Trasplante cardiaco}

El trasplante cardiaco es un tratamiento aceptado para la IC en fase terminal ${ }^{614,615}$. Aunque nunca se han realizado estudios aleatorizados, hay consenso en que el trasplante, siempre que se apliquen criterios de selección adecuados, mejora significativamente la supervivencia, la capacidad de ejercicio, la calidad de vida y la reincorporación laboral, comparado con el tratamiento convencional.

Aparte de la escasez de donantes de corazón, los problemas principales del trasplante son consecuencia de la poca eficacia y las complicaciones del tratamiento inmunosupresor a largo plazo (rechazo mediado por anticuerpos, infección, hipertensión, insuficiencia renal, enfermedad maligna y vasculopatía coronaria). Las indicaciones y contraindicaciones del trasplante cardiaco se han actualizado recientemente y se resumen en la tabla $13.4^{616}$. Hay que mencionar que algunas contraindicaciones son transitorias y tratables. Mientras que una infección activa sigue siendo una contraindicación relativa

Tabla 13.4

Trasplante cardiaco: indicaciones y contraindicaciones

Pacientes que considerar Con IC terminal, síntomas graves y pronóstico desfavorable sin otras alternativas de tratamiento Motivados, bien informados y emocionalmente estables

Con capacidad para cumplir el tratamiento intensivo requerido durante el posoperatorio

Contraindicaciones Infección activa

Enfermedad arterial periférica o cerebrovascular grave Hipertensión pulmonar irreversible con tratamiento farmacológico (se valorará implantar un DAVI y se lo revaluará para determinar si el paciente es candidato) Cáncer (en colaboración con los oncólogos se evaluará a cada paciente según el riesgo de recurrencia del tumor)

Insuficiencia renal irreversible (p. ej., aclaramiento

de creatinina $<30 \mathrm{ml} / \mathrm{min}$ )

Enfermedad sistémica multiorgánica

Otras comorbilidades con mal pronóstico

IMC antes del trasplante $>35$ (se recomienda la

pérdida de peso hasta alcanzar un IMC $<35$ ).

Abuso actual de alcohol o drogas

Cualquier paciente cuyo apoyo social se considere

insuficiente para alcanzar los requisitos

del tratamiento en atención ambulatoria

DAVI: dispositivo de asistencia ventricular izquierda; IC: insuficiencia cardiaca; IMC: índice de masa corporal. para el trasplante, los pacientes con VIH, hepatitis, enfermedad de Chagas o tuberculosis pueden ser considerados candidatos siempre que el equipo médico aplique medidas de tratamiento estrictas. Para los pacientes con cáncer que requieren trasplante cardiaco es necesaria una estrecha colaboración con los oncólogos para estratificar a cada paciente según el riesgo de recurrencia del tumor ${ }^{616}$.

Se debe considerar el uso de asistencia mecánica circulatoria, especialmente DAVI, para pacientes con comorbilidades potencialmente reversibles o tratables, como cáncer, obesidad, insuficiencia renal, tabaquismo o hipertensión pulmonar farmacológicamente irreversible; después se deberá revaluar a los pacientes para establecer la viabilidad del trasplante.

\section{ABORDAJE MULTIDISCIPLINARIO}

Las intervenciones quirúrgicas no farmacológicas y sin dispositivos utilizadas en el abordaje de la IC (IC-FEr e IC-FEc) se resumen en las tablas 14.1 y 14.2. La Asociación de Insuficiencia Cardiaca (FHA) de la ESC ha publicado recomendaciones prácticas detalladas sobre su uso $^{591,592}$. No hay evidencia de que estas intervenciones por sí solas mejoren la mortalidad, la morbilidad o la calidad de vida. Por esta razón no se les ha otorgado una recomendación con un nivel de evidencia. Las excepciones son la implementación de cuidados en un marco multidisciplinario, la monitorización y el ejercicio físico (véase la tabla de recomendaciones), que se tratan a continuación.

\subsection{Organización de los cuidados}

El objetivo del abordaje de la IC es proporcionar un sistema continuo de atención que abarque la ambulatoria y la hospitalaria y se extienda el tiempo necesario. La AFA/ESC ha publicado los estándares de atención que los pacientes con IC deberían esperar ${ }^{591}$. Para cumplir este objetivo es necesario que otros servicios, como rehabilitación cardiaca o cuidados paliativos, estén integrados en el sistema de aten-

Tabla 14.1

Características y componentes de los programas de atención a los pacientes con insuficiencia cardiaca

Características Se debe emplear una estrategia multidisciplinaria (cardiólogos, médicos de atención primaria, enfermeros, farmacéuticos, fisioterapeutas, dietistas, trabajadores sociales, cirujanos, psicólogos, etc.)

Se debe dirigir a pacientes sintomáticos con alto riesgo

Debe incluir a personal competente y profesionalmente capacitado $^{617}$

Componentes Manejo óptimo con fármacos y dispositivos

Educación adecuada para el paciente, con especial atención a la adherencia y el autocuidado

Paciente implicado en la monitorización de los síntomas y el uso flexible de diuréticos

Seguimiento después del alta (consultas regulares en el centro o en el domicilio; posibilidad de apoyo telefónico o monitorización a distancia)

Mayor acceso a la atención médica (mediante seguimiento en persona y contacto telefónico; posibilidad de monitorización a distancia)

Fácil acceso a la atención médica durante los episodios de descompensación

Evaluación de los cambios inexplicables de peso, estado nutricional, estado funcional, calidad de vida o resultados de pruebas de laboratorio (e intervención adecuada si es necesaria)

Acceso a opciones avanzadas de tratamiento

Provisión de apoyo psicológico a pacientes y sus familiares o cuidadores 
Recomendaciones sobre el ejercicio, la atención multidisciplinaria y la monitorización de pacientes con insuficiencia cardiaca

\begin{tabular}{|c|c|c|c|}
\hline Recomendaciones & Clase $^{\mathrm{a}}$ & Nivel $^{\mathrm{b}}$ & Ref. $^{c}$ \\
\hline $\begin{array}{l}\text { Se recomienda IC al ejercicio aeróbico regular para } \\
\text { mejorar la capacidad funcional y los síntomas }\end{array}$ & I & A & $\begin{array}{c}321, \\
618-621\end{array}$ \\
\hline $\begin{array}{l}\text { Se recomienda alentar a los pacientes estables con } \\
\text { IC-FEr al ejercicio aeróbico regular para reducir el } \\
\text { riesgo de hospitalización por IC }\end{array}$ & I & A & 618,619 \\
\hline $\begin{array}{l}\text { Se recomienda que los pacientes con IC participen } \\
\text { en un programa de atención multidisciplinaria } \\
\text { para reducir el riesgo de hospitalización por IC } \\
\text { y mortalidad }\end{array}$ & I & A & $622-625$ \\
\hline $\begin{array}{l}\text { Se puede considerar la derivación a atención } \\
\text { primaria de los pacientes con IC estable que reciben } \\
\text { tratamiento óptimo para monitorizar la eficacia del } \\
\text { tratamiento, la progresión de la enfermedad y la } \\
\text { adherencia }\end{array}$ & IIb & B & 626,627 \\
\hline $\begin{array}{l}\text { Se puede considerar la monitorización de las } \\
\text { presiones arteriales pulmonares mediante un } \\
\text { sistema inalámbrico implantable (CardioMems) } \\
\text { para pacientes sintomáticos hospitalizados } \\
\text { previamente por IC para reducir el riesgo } \\
\text { de hospitalización recurrente por IC }\end{array}$ & IIb & B & 628,629 \\
\hline $\begin{array}{l}\text { Se puede considerar la monitorización de } \\
\text { parámetros múltiples basada en DAI (estrategia } \\
\text { IN-TIME) de los pacientes con IC-FEr (FEVI } \geq 35 \% \text { ) } \\
\text { para mejorar los resultados clínicos }\end{array}$ & IIb & B & 360 \\
\hline
\end{tabular}

DAI: desfibrilador automático implantable; FEVI: fracción de eyección del ventrículo izquierdo; IC: insuficiencia cardiaca; IC-FEr: insuficiencia cardiaca con fracción de eyección reducida. IN-TIME: Implant-based multiparameter telemonitoring of patients with heart failure.

aClase de recomendación.

bNivel de evidencia.

'Referencias que respaldan las recomendaciones.

ción de los pacientes con IC. Un aspecto fundamental para poder proporcionar una atención integral son los programas de abordaje multidisciplinarios diseñados para mejorar los resultados mediante un seguimiento estructurado con educación del paciente, optimización del tratamiento médico, apoyo psicosocial y mejora del acceso a la atención médica (tabla 14.1). Estas estrategias reducen las hospitalizaciones por IC y la mortalidad de los pacientes que han recibido el alta hospitalaria ${ }^{624,625}$.

Una clave del éxito de estos programas es la coordinación de la atención a lo largo del curso de la IC a través de la red de atención proporcionada por distintos servicios del sistema de salud. Para ello es necesaria una estrecha colaboración entre el personal sanitario del ámbito de la IC (cardiólogos, enfermería y médicos de familia) y otros especialistas, como farmacéuticos, dietistas, psicoterapeutas, psicólogos, especialistas en cuidados paliativos y trabajadores sociales. El contenido y la estructura de los programas de tratamiento de la IC pueden variar entre distintos países y sistemas de salud. Los componentes que se describen en la tabla 14.1 están recomendados. Los servicios de IC deben ser de fácil acceso para los pacientes, sus familiares y otros profesionales implicados. Una línea de atención telefónica puede facilitar el acceso al asesoramiento profesional.

La página web http://ww.heartfailurematters.org ofrece información profesional a los pacientes y familias con acceso a internet.

\subsection{Planificación del alta}

Tras el alta, la rehospitalización precoz es muy frecuente y esto se podría mejorar mediante una planificación coordinada del alta. La Heart Failure Association (HFA) y la Acute Cardiovascular Care Association (ACCA) han publicado los estándares de atención que los pacientes deberían esperar ${ }^{540,631}$. La planificación del alta podría comenzar desde el momento en que el paciente está estable. La información y la educación del paciente sobre autocuidados durante la hospitalización mejoran los resultados. El alta debería planificarse para el momento en que el paciente se encuentre euvolémico y los factores precipitantes de la hospitalización hayan sido tratados. Los hospitales con seguimiento médico al poco tiempo del alta tienen una tasa de reingresos a los

30 días reducida y los que han implementado un programa de consultas ambulatorias previamente planificadas tienen una mayor reducción del número de reingresos que los que no ${ }^{632}$.

\subsection{Consejos sobre el estilo de vida}

Hay pocas pruebas de que los consejos específicos sobre el estilo de vida mejoren la calidad de vida o el pronóstico; sin embargo, proporcionar esta información se ha convertido en un componente clave de la educación para los autocuidados. Los pacientes deben recibir información suficiente y actualizada para tomar decisiones sobre las modificaciones en el estilo de vida y los autocuidados. Para los pacientes hospitalizados sería conveniente que el asesoramiento sobre el estilo de vida comience antes del alta. La información debe ser individualizada y estar adaptada a las necesidades de cada paciente, teniendo en cuenta las comorbilidades relevantes que podrían afectar a la retención de la información (trastorno cognitivo y depresión). La HFA ha publicado recomendaciones prácticas sobre esta cuestión ${ }^{591}$. Los aspectos clave que se debe tratar se encuentran en la tabla 14.2.

\subsection{Entrenamiento físico}

Varias revisiones sistemáticas y metanálisis de estudios a pequeña escala han revelado que la preparación física mediante ejercicio físico mejora la tolerancia al ejercicio, la calidad de vida relacionada con la salud y las tasas de hospitalización de los pacientes con IC. Un solo $E_{C D A}{ }^{618}$ a gran escala mostró una reducción moderada y no significativa en la variable primaria compuesta de mortalidad por todas las causas u hospitalización por todas las causas. No se observó una reducción de la mortalidad y no aparecieron problemas de seguridad $^{618,633}$. La revisión Cochrane ${ }^{619}$ más reciente sobre el ejercicio físico incluyó 33 estudios con 4.740 pacientes con IC (predominantemente IC-FEr). Se observó una tendencia hacia una reducción de la mortalidad con el ejercicio en estudios con más de 1 año de seguimiento. Comparado con el grupo de control, el entrenamiento físico redujo las tasas total de hospitalización y de hospitalización por IC, y mejoró la calidad de vida. La HFA ha publicado recomendaciones prácticas sobre entrenamiento físico ${ }^{120}$. Hay pruebas de que el entrenamiento físico es beneficioso para los pacientes con IC-FEc, ya que mejora la capacidad de ejercicio medida objetivamente por el consumo pico de oxígeno, la calidad de vida y la función diastólica evaluada mediante ecocardiografía $321,620,621,634$.

Se recomienda que los pacientes con IC, independientemente de la FEVI, realicen un programa de ejercicio adecuadamente diseñado (véase la tabla de recomendaciones).

\subsection{Seguimiento y monitorización}

Los pacientes con IC se benefician de un seguimiento regular y de la monitorización de parámetros biomédicos para garantizar la seguridad y la optimización del tratamiento médico, además de detectar la aparición de complicaciones o el progreso de la enfermedad que podrían requerir la modificación del tratamiento (p. ej., la aparición de FA o de anemia). La monitorización pueden llevarla a cabo los propios pacientes durante consultas a domicilio, en consulta de atención primaria u hospitalaria, mediante monitorización a distancia con o sin dispositivos implantados o asistencia telefónica estructurada. El método óptimo de monitorización dependerá de la organización y de los recursos locales, y también de cada paciente. Por ejemplo, durante periodos de inestabilidad o de optimización del tratamiento, es nece- 
Tabla 14.2

Aspectos clave y autocuidados para la educación del paciente y conducta profesional para optimizar el aprendizaje y facilitar las decisiones compartidas

\begin{tabular}{|c|c|c|}
\hline Tema educativo & Habilidades del paciente & Conducta profesional \\
\hline $\begin{array}{l}\text { Definición, } \\
\text { etiología y curso } \\
\text { de la IC (incluido el } \\
\text { pronóstico) }\end{array}$ & $\begin{array}{l}\text { - Comprender la causa de la IC y de los síntomas y el curso de la } \\
\text { enfermedad } \\
\text { - Tomar decisiones realistas, incluidas las relativas al tratamiento en la } \\
\text { fase terminal }\end{array}$ & $\begin{array}{l}\text { - Proporcionar información verbal y escrita teniendo en cuenta el nivel } \\
\text { educativo y los conocimientos del paciente } \\
\text { - Reconocer las barreras de comunicación y proporcionar información } \\
\text { a intervalos regulares } \\
\text { - Comunicar con delicadeza la información sobre el pronóstico en el } \\
\text { momento del diagnóstico, cuando se tomen decisiones sobre las } \\
\text { opciones de tratamiento, cuando cambien las condiciones clínicas } \\
\text { y cuando el paciente lo solicite }\end{array}$ \\
\hline
\end{tabular}

Monitorización de los • Monitorizar y reconocer cambios en los signos y síntomas síntomas $\quad$ Saber cómo y cuándo contactar con un profesional sanitario y autocuidado
- Saber cuándo ajustar el tratamiento diurético y la ingesta de líquidos según los consejos del médico
- Proporcionar información individualizada para promover el autocuidado de los pacientes:

$>$ En caso de disnea o edema creciente o un aumento de peso repentino e inesperado ( $>2 \mathrm{~kg}$ en 3 días), los pacientes deben aumentar la dosis de diuréticos y comunicarlo al equipo médico

$>$ Utilizar un régimen diurético flexible

> Proporcionar ayuda para el autocuidado, como cajas de dosificadores, si está indicado

\begin{tabular}{ll}
\hline Tratamiento & - Comprender las indicaciones, la dosificación y los efectos secundarios \\
farmacológico & de la medicación \\
& - Reconocer los efectos secundarios comunes y saber cuándo informar al \\
& equipo médico \\
& Reconocer los beneficios de la medicación prescrita
\end{tabular}

\begin{tabular}{|c|c|c|}
\hline $\begin{array}{l}\text { Dispositivos } \\
\text { implantados e } \\
\text { intervenciones } \\
\text { percutáneas/ } \\
\text { quirúrgicas }\end{array}$ & $\begin{array}{l}\text { - Comprender las indicaciones y los objetivos de la implantación } \\
\text { de dispositivos/procedimientos } \\
\text { - Reconocer las complicaciones comunes y saber cuándo informar } \\
\text { al equipo médico } \\
\text { - Reconocer la importancia y los beneficios de los procedimientos/ }\end{array}$ & $\begin{array}{l}\text { - Proporcionar información verbal y escrita sobre los beneficios y lo } \\
\text { efectos secundarios } \\
\text { - Proporcionar información verbal y escrita sobre el control del } \\
\text { funcionamiento de los dispositivos y la documentación sobre las } \\
\text { revisiones regulares }\end{array}$ \\
\hline
\end{tabular}

dispositivos implantados

\begin{tabular}{|c|c|c|}
\hline Inmunización & - Inmunizarse contra la gripe y la enfermedad neumocócica & - Asesoramiento sobre las directrices y la práctica local \\
\hline Dieta y alcohol & $\begin{array}{l}\text { - Evitar una ingesta de líquidos excesiva } \\
\text { - Reconocer la necesidad de modificar la ingesta de líquidos: } \\
>\text { Aumentar la ingesta en periodos de altas temperaturas } \\
\text { y humedad, náuseas/vómitos } \\
>\quad \text { Se puede considerar la restricción de líquidos a 1,5-2 1/día para } \\
\text { aliviar los síntomas y la congestión de los pacientes con IC grave } \\
\text { - Monitorizar el peso corporal y evitar la desnutrición } \\
\text { - Mantener una dieta y un peso saludables y evitar la ingesta de sal } \\
\text { excesiva (> } 6 \text { g/día). } \\
\text { - Abstenerse o evitar el consumo excesivo de alcohol, especialmente } \\
\text { para la miocardiopatía inducida por alcohol }\end{array}$ & $\begin{array}{l}\text { - Individualizar la información sobre ingesta de líquidos teniendo en } \\
\text { cuenta el peso y los periodos de altas temperaturas y humedad. } \\
\text { Ajustar la ingesta de líquidos en periodos de descompensación aguda } \\
\text { y considerar cambiar estas restricciones hacia el final de la vida } \\
\text { - Ajustar los consejos sobre el consumo de alcohol según la etiología de la } \\
\text { IC; p. ej., aconsejar abstinencia en caso de miocardiopatía alcohólica } \\
\text { - Aplicar las guías habituales sobre consumo de alcohol ( } 2 \text { unidades/día } \\
\text { los varones o } 1 \text { unidad/día las mujeres). Una unidad consiste en } 10 \text { ml de } \\
\text { alcohol puro (p. ej., una copa de vino, media pinta de cerveza, } 1 \text { medida } \\
\text { de licor) } \\
\text { - Para el tratamiento de la obesidad, consulte la sección } 11.5\end{array}$ \\
\hline Tabaco y drogas & - Dejar de fumar y tomar sustancias tóxicas de uso recreativo & $\begin{array}{l}\text { - Derivar al servicio especializado en abandono del tabaquismo, drogas } \\
\text { y terapias de sustitución } \\
\text { - Referir al paciente al servicio de apoyo psicológico y terapia cognitiva- } \\
\text { conductual si el paciente requiere apoyo para dejar de fumar }\end{array}$ \\
\hline
\end{tabular}

Ejercicio $\quad$ Practicar ejercicio regularmente, de intensidad suficiente para provocar una falta de aire leve o moderada

- Asesorar sobre la práctica de ejercicio teniendo en cuenta las limitaciones físicas y funcionales, como la fragilidad y las comorbilidades

- Refiera al paciente a un programa de ejercicio cuando sea apropiado

Viajes y ocio $\quad$ Preparar viajes y actividades de ocio según la capacidad física

- Monitorizar y adaptar la ingesta de líquidos según la humedad (vuelos

y climas húmedos)

- Ser consciente de las reacciones adversas a la exposición solar

Proporcionar información verbal y escrita sobre los beneficios y los efectos secundarios (véase la tabla 7.4, la tabla 7.5, la tabla 7.6,

la tabla 7.7 y la tabla 7.8 , guía práctica sobre el uso de fármacos)

- Referir a la legislación específica del país de destino sobre el permiso

de conducir para personas portadoras de un DAI

- Asesorar sobre las medidas de seguridad en aeropuertos en relación con el DAI

con algunos medicamentos (como amiodarona)

- Considerar el efecto de la altitud en la oxigenación

- Llevar la medicación en el equipaje de cabina y una lista de los tratamientos y las dosis con el nombre genérico

Trastornos del sueño • Reconocer los trastornos del sueño, su relación con la IC y saber cómo y respiración (véase mejorar el sueño

la sección 11.6

- Proporcionar consejos, p. ej., sobre la hora de administración de diuréticos, entorno para dormir y dispositivos de apoyo

- En presencia de problemas de respiración durante el sueño, proporcionar consejos sobre reducción/control del peso

morbilidades

Actividad sexual

(véase la sección

- No tener inquietudes respecto a mantener relaciones sexuales, siempre que no cause síntomas indebidos

- Reconocer los problemas con la actividad sexual, su relación con la IC disfunción eréctil y sobre tratamientos farmacológicos disponibles

- Referir a un especialista para asesoramiento sexual cuando sea necesario comorbilidades) y su tratamiento, y saber cómo tratar la disfunción eréctil

Aspectos psicológicos $\quad$ • Comprender que los síntomas de depresión y la disfunción cognitiva se encuentran más frecuentemente en las personas con IC y que pueden afectar a la adherencia

- Reconocer que pueden aparecer problemas psicológicos durante el curso de la enfermedad relacionados con los cambios en el estilo de vida, la medicación, los dispositivos implantados y otros procedimientos (incluida la asistencia mecánica y el trasplante cardiaco)
- Comunicar regularmente información sobre la enfermedad, las opciones de tratamiento y el autocuidado

- Implicar a familiares y cuidadores en el tratamiento de la IC y el autocuidado

- Referir a un especialista para apoyo psicológico cuando sea necesario 
saria una monitorización más frecuente. Los pacientes más ancianos también se benefician de una monitorización más frecuente. Algunos pacientes tendrán interés y capacidad para la automonitorización.

Las altas concentraciones de PN predicen un pronóstico desfavorable en los pacientes con IC, y la caída de la concentración de PN en la fase de recuperación de la descompensación circulatoria se asocia con un pronóstico mejor ${ }^{588-590}$. Aunque es posible monitorizar el estado clínico y ajustar el tratamiento según las concentraciones de PN de los pacientes con IC, los resultados de los estudios publicados ${ }^{635-638}$ no permiten recomendar su aplicación generalizada.

La telemedicina en la IC, o tratamiento del paciente a distancia, ha obtenido distintos resultados clínicos en los estudios realizados ${ }^{639}$. Varios metanálisis indican que se asocia a un beneficio clínico, pero varios estudios clínicos prospectivos que incluyeron a más de 3.700 pacientes no lo han confirmado. Entre ellos se incluyen los estudios Tele-HF ${ }^{640}$, TIM-HF ${ }^{641}$, INH ${ }^{642}$, WISH ${ }^{643}$ y TEHAF ${ }^{644}$. Está claro que no existe un único tipo de telemedicina y que cada abordaje debe ser evaluado por su propio mérito.

Recientemente, 2 estrategias diferentes se han demostrado eficaces para la mejora de los resultados clínicos en pacientes con IC-FEc o IC-FEr: el sistema CardioMems (probado en 550 pacientes con IC-FEr

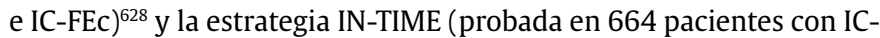
$\mathrm{FEr})^{630}$, que se puede considerar para pacientes con IC seleccionados (véase la tabla de recomendaciones).

\subsection{El paciente con edad avanzada, fragilidad y trastorno cognitivo}

El tratamiento de la IC y los autocuidados se hacen más difíciles con el envejecimiento, las comorbilidades, los trastornos cognitivos, la fragilidad y la carencia de apoyo social. La IC es también una de las principales causas de hospitalización de personas mayores, en las que se asocia con un ingreso más largo y mayor riesgo de mortalidad ${ }^{645}$.

La fragilidad es frecuente en los pacientes mayores con IC; un estudio reciente indica que puede estar presente en más del $70 \%$ de los pacientes con IC mayores de 80 años ${ }^{645}$. Los sistemas de puntuación de la fragilidad proporcionan un método objetivo para evaluar e identificar la presencia y los cambios en el nivel de fragilidad. Los pacientes con una puntuación elevada se benefician de un mayor contacto con el equipo de IC, un seguimiento más frecuente y la monitorización y el apoyo individualizados para el autocuidado.

Los métodos de clasificación de la fragilidad ${ }^{646}$ incluyen la prueba de velocidad de la marcha, la prueba Timed up-and-go (prueba cronometrada de «levántese y ande»), el cuestionario PRISMA 7, la Frail Score ${ }^{647}$, la Fried Score $e^{647,648}$ y la Short Physical Performance Battery (SPPB).

El trastorno cognitivo coexiste frecuentemente con la IC. El delirio agudo también se asocia con la IC descompensada y puede estar presente durante el ingreso. La función cognitiva se puede evaluar mediante la Mini-Mental State Examination ${ }^{649}$ o la evaluación cognitiva de Montreal ${ }^{650}$. El delirio y la IC se encuentran más frecuentemente en adultos mayores y se asocian con aumento de la mortalidad, menor capacidad para el autocuidado y hospitalizaciones más largas $^{651}$. No hay evidencia de que la medicación para la IC empeore o mejore la función cognitiva, pero su efecto en la evolución de la IC indica que se debe emplear. El apoyo de un equipo de IC multidisciplinario con la colaboración de un equipo especializado en demencia, junto con la ayuda para cumplir con la medicación, el asesoramiento individualizado para el autocuidado y la participación de familia y cuidadores, puede mejorar la adherencia a la compleja medicación para la IC y el régimen de autocuidado (véase la tabla 14.2 sobre educación del paciente y la tabla 14.3).

\subsection{Cuidados paliativos y la fase terminal}

Los cuidados paliativos incluyen el tratamiento de los síntomas, el apoyo emocional y la comunicación entre el paciente y su familia. Es
Tabla 14.3

Recomendaciones específicas sobre la monitorización y el seguimiento de pacientes mayores con insuficiencia cardiaca

Monitorizar la fragilidad, detectar y tratar las causas reversibles (cardiovasculares y no cardiovasculares) del deterioro según las clasificaciones de fragilidad

Revisar la medicación: optimizar las dosis del tratamiento para la IC lentamente y monitorizando el estado clínico a menudo. Reducir la polifarmacia: número, dosis y complejidad del régimen. Considerar la interrupción de la medicación que no tenga un efecto inmediato en los síntomas o la calidad de vida (como las estatinas). Revisar las horas de toma y las dosis de diuréticos para reducir el riesgo de incontinencia

Considerar la necesidad de referir al servicio de geriatría, al médico de atención primaria y servicios sociales, etc., para el seguimiento y apoyo de los pacientes y sus familiares

\section{Tabla 14.4}

Pacientes con insuficiencia cardiaca en fase terminal

Deterioro funcional progresivo (físico y mental) y dependencia para la mayoría de las actividades diarias

Síntomas graves de insuficiencia cardiaca con mala calidad de vida a pesar del tratamiento farmacológico y no farmacológico óptimo

Ingresos o episodios graves de descompensación frecuentes a pesar del tratamiento óptimo

El trasplante cardiaco y la asistencia mecánica circulatoria están descartados

Caquexia cardiaca

Clínicamente se considera que el paciente está al final de su vida

Tabla 14.5

Componentes clave del servicio de cuidados paliativos para pacientes con insuficiencia cardiaca

Se orienta a mejorar o mantener la calidad de vida del paciente y sus familiares en la medida de lo posible hasta el final de su vida

Evaluación frecuente de los síntomas (incluidos la disnea y el dolor) producidos por la IC avanzada y otras comorbilidades; tratamiento centrado en el alivio de los síntomas

Facilitar el acceso del paciente y sus familiares al apoyo psicológico y espiritual acorde con sus necesidades

Planificación avanzada de los cuidados, teniendo en cuenta las preferencias sobre el lugar de muerte y reanimación (puede incluir la desactivación del DAI)

DAI: dispositivo automático implantable; IC: insuficiencia cardiaca.

conveniente que estas cuestiones se introduzcan en fases más tempranas y que se intensifiquen a medida que progrese la enfermedad. La decisión de cambiar los objetivos de un tratamiento modificador de la enfermedad por un tratamiento destinado a mejorar la calidad de vida se debe tomar tras comentarlo con el paciente, el cardiólogo, enfermería y el médico de atención primaria. La familia debe participar en esas conversaciones si así lo desea el paciente (tabla 14.4) ${ }^{652,653}$.

Las recomendaciones sobre los componentes clave del servicio de cuidados paliativos se encuentran en la tabla 14.5. Los cuidados paliativos se tratan en detalle en un documento de posición de la HFA ${ }^{654}$.

Es necesaria la colaboración entre el servicio de cuidados paliativos, el equipo de IC o el médico de atención primaria, mediante una estrategia de atención compartida, para que la atención al paciente tenga la coordinación óptima. En 2 estudios piloto recientes se observó una mejoría de los síntomas y de la calidad de vida ${ }^{653,655}$, pero estos datos no son suficientes para establecer una recomendación.

Hay tratamientos y medidas específicas que pueden paliar los síntomas y mejorar la calidad de vida, pero se basan en escasa evidencia:

- Morfina (con un antiemético cuando se requieran dosis altas) para reducir la disnea, el dolor y la ansiedad ${ }^{656}$. 
- Aumento de la concentración de oxígeno inspirado para aliviar la disnea.

- Tratamiento diurético para aliviar la congestión grave y optimizar el control de los síntomas (congestión y sed).

- Reducción de los fármacos para la IC que disminuyen la PA para mantener una oxigenación suficiente y reducir el riesgo de caídas.

Estos tratamientos deberían administrarse en el domicilio del paciente. En la mayoría de los casos, la familia debería recibir apoyo social ${ }^{652}$

Tras tratarlo con el paciente y su familia, se debe establecer un plan de atención que incluya:

- Discutir la interrupción de la medicación que no tenga un efecto inmediato en los síntomas o la calidad de vida relacionada con la salud, como los fármacos para reducir el colesterol o tratar la osteoporosis.

- Documentar la decisión del paciente respecto a las medidas de reanimación.

- Desactivar el DAI al final de la vida (de manera acorde con la legislación aplicable).

- Lugar preferido de atención y muerte.

- Apoyo emocional al paciente y su familia o sus cuidadores, con derivación al servicio de apoyo psicológico o espiritual.

Como los síntomas y la calidad de vida cambian con el transcurso del tiempo, se recomienda realizar reevaluaciones periódicas. Las escalas de cuidados paliativos permiten evaluar objetivamente los síntomas y las necesidades del paciente y podrían ser útiles para establecer la eficacia del tratamiento. Entre ellas: Palliative Care Outcome Scale $^{657}$, Karnofsky Performance Status ${ }^{658}$ y Functional Assessment of Chronic Illness Therapy-Palliative Care (FACIT-Pal) ${ }^{659}$.

\section{LAGUNAS EN LA EVIDENCIA}

A menudo los médicos responsables de la atención de pacientes con IC deben tomar decisiones sobre el tratamiento sin disponer de pruebas adecuadas o el consenso de expertos. A continuación se expone una breve lista de cuestiones que merecen ser tema de futuros estudios clínicos.

\section{Definición, diagnóstico y epidemiología}

- Investigación sobre las características subyacentes, fisiopatología y diagnóstico de la IC-FEm/IC-FEc (con nuevas modalidades).

- Actualización de los datos epidemiológicos sobre la incidencia y la prevalencia de la IC que incluya a pacientes de todos los continentes.

- Sobre técnicas de imagen y biomarcadores: estudiar el efecto de estos en la mejora de los resultados clínicos (p. ej., tratamientos guiados por biomarcadores, detección de la EAC/isquemia miocárdica, RMC con realce tardío de gadolinio, ecocardiografía con strain, ecocardiografía de estrés, etc.).

- Aumentar la concienciación sobre la IC en la comunidad médica, la población general y los responsables políticos.

2. Estrategias destinadas a la prevención y la detección de la IC

- Evaluar comparativamente la eficacia clínica y la relación costeeficacia de diferentes estrategias para el cribado de la IC.

\section{Tratamiento farmacológico}

- Identificar a pacientes que no responden a los tratamientos recomendados en las guías de práctica clínica.
- Tratamientos basados en objetivos para etiologías específicas de la IC-FEr (miocarditis, miocardiopatía periparto, etc.).

- Tratamientos que mejoran directamente la función de los cardiomiocitos (activación de puentes cruzados de la actomiocina, activación de la $\mathrm{Ca}^{2+}$-ATPasa del retículo sarcoplásmico, estabilización del receptor de rianodina, modulación energética) o que actúan sobre compartimentos no miocíticos (remodelado antifibrosis/ matricial).

- Tratamientos para la IC-FEm/IC-FEc (INRA, bloqueadores beta, inhibidores solubles de la guanilciclasa, hierro intravenoso).

4. Dispositivos e intervenciones

- Indicaciones de DAI en subgrupos específicos (MAVD e IC-FEm/ICFEc) y selección óptima de los candidatos a DAI.

- Morfología o duración del QRS como factores de predicción de la respuesta a la TRC.

- TRC para pacientes con FA.

- Eficacia de la ablación de VP como estrategia de control del ritmo cardiaco de pacientes con FA.

- Estrategia intervencionista para las taquiarritmias ventriculares recurrentes y potencialmente mortales.

- Utilidad de las estrategias de monitorización a distancia en la IC.

- Corrección percutánea (no quirúrgica) de la regurgitación mitral y tricuspídea funcional.

- Identificar las indicaciones de coronariografía/revascularización para pacientes con IC y EAC estable crónica.

- Efectos de los nuevos DAVI como «tratamiento de destino» o como "puente al trasplante».

\section{Comorbilidades}

- Conocer mejor la fisiopatología y los tratamientos potenciales para poblaciones con IC específicas como:

- Muy ancianos.

- Pacientes jóvenes.

- TFG $<30 \mathrm{ml} / \mathrm{min}$.

- Pacientes diabéticos.

- IC inducida por quimioterapia cardiotóxica.

- Distrofias musculares.

- Caquexia y depresión.

- Tratamientos para los trastornos respiratorios del sueño relacionados con la IC en la IC-FEr/IC-FEc/IC-FEm.

\section{Insuficiencia cardiaca aguda}

- Evaluación prospectiva del concepto «tiempo hasta tratamiento» en la ICA.

- Investigar la influencia del fenotipo en el fracaso de los tratamientos para mejorar los resultados de la ICA.

- Mejorar la definición y el tratamiento de la resistencia a diuréticos.

- Utilidad de los nitratos en el tratamiento de la ICA.

- Tratamientos que mejoran la mortalidad y la morbilidad.

- Estrategias y tratamientos para prevenir la rehospitalización temprana tras el ingreso por ICA.

\section{Otras cuestiones pendientes}

- Algoritmos de tratamiento para los pacientes con IC excluidos de los estudios clínicos más importantes.

- Cuidados paliativos, abordaje de la fase terminal y evaluación de los resultados.

- Integración óptima de la atención multidisciplinaria, el autocuidado y la adherencia. 


\section{MENSAJES CLAVE DE LA GUÍA SOBRE QUÉ HACER Y QUÉ NO HACER}

Se recomienda la ETT para la evaluación de la estructura y la función miocárdicas de pacientes con sospecha de IC, a efectos de establecer el diagnóstico de IC-FEr, IC-FEm o IC-FEc

Se recomienda la ETT para evaluar la FEVI e identificar a los pacientes con IC que podrían ser candidatos a tratamiento basado en la evidencia con fármacos o dispositivos (DAI, TRC) que están recomendados para la IC-FEr

Recomendaciones destinadas a prevenir o retrasar la aparición de insuficiencia cardiaca manifiesta o prevenir la muerte antes de que haya síntomas

Se recomienda el tratamiento de la hipertensión para prevenir o retrasar la aparición de la IC y prolongar la vida

Se recomienda el tratamiento con IECA para pacientes con disfunción sistólica del VI asintomática e historia de infarto de miocardio para prevenir o retrasar la aparición de la IC y prolongar la vida

Se recomienda el tratamiento con bloqueadores beta para pacientes con disfunción sistólica del VI asintomática e historia de infarto de miocardio para prevenir o retrasar la aparición de la IC y prolongar la vida

Tratamientos farmacológicos indicados para pacientes con insuficiencia cardiaca sintomática y fracción de eyección reducida

Se recomienda un IECAc añadido a un bloqueador beta para pacientes con IC-FEr sintomáticos para reducir el riesgo de hospitalización por IC y muerte Se recomienda un bloqueador beta añadido a un IECAc para pacientes con IC-FEr sintomática y estable para reducir el riesgo de hospitalización por IC y muerte

Se recomienda un ARM para pacientes con IC-FEr que siguen sintomáticos a pesar del tratamiento con un IECA $\mathrm{y}$ un bloqueador beta, para reducir el riesgo de hospitalización por IC y muerte

Otros tratamientos farmacológicos recomendados para pacientes con insuficiencia cardiaca sintomática y fracción de eyección reducida seleccionados

Se recomiendan los diuréticos para mejorar los síntomas y la capacidad de ejercicio de los pacientes con signos/síntomas de congestión

Se recomienda el sacubritilo/valsartán como sustituto de un IECA para reducir adicionalmente el riesgo de hospitalización por IC y muerte de los pacientes con IC-FEr ambulatorios que siguen sintomáticos pese al tratamiento óptimo con un IECA, un bloqueador beta y un ARM

\section{Tratamientos (o combinación de tratamientos) que pueden ser perjudiciales para pacientes con insuficiencia cardiaca sintomática (NYHA II-IV) y} fracción de eyección reducida

No se recomiendan el diltiazem o el verapamilo para pacientes con IC-FEr, ya que incrementan el riesgo de empeoramiento de la IC y hospitalización por IC

No se recomienda la adición de un ARA-II (o un inhibidor de la renina) a la combinación de un IECA y un ARM para los pacientes con IC, debido al aumento de riesgo de disfunción renal e hiperpotasemia

\section{Recomendaciones sobre el implante de DAI en pacientes con insuficiencia cardiaca}

\section{Prevención secundaria}

Se recomienda el implante de un DAI para reducir el riesgo de muerte súbita y mortalidad por todas las causas de los pacientes que se han recuperado de una arritmia ventricular que cursaba inestabilidad hemodinámica y tienen una esperanza de vida $>1$ año en buen estado funcional

\section{Prevención primaria}

Se recomienda el implante de un DAI para reducir el riesgo de muerte súbita y mortalidad por todas las causas de los pacientes con IC sintomática (NYHA II-III) y FEVI $\leq 35 \%$ a pesar de TMO durante al menos 3 meses, siempre que se estime una supervivencia sustancialmente más larga que 1 año en buen estado funcional, y además tengan:

- Cardiopatía isquémica (excepto si han sufrido un IM en los últimos 40 días)

$\cdot \mathrm{MCD}$

No se recomienda el implante de un DAI durante los primeros 40 días tras el IM, ya que este tratamiento no mejora el pronóstico

\section{Recomendaciones sobre la terapia de resincronización cardiaca en pacientes con insuficiencia cardiaca}

Se recomienda la TRC para pacientes sintomáticos con IC en ritmo sinusal, con una duración del QRS $\geq 150$ ms y morfología de BRI, y FEVI $\leq 35 \%$ a pesar del TMO, a efectos de mejorar los síntomas y reducir la morbimortalidad

Se recomienda la TRC para pacientes sintomáticos con IC en ritmo sinusal, con una duración del QRS de 130-149 ms y morfología de BRI y FEVI $\leq 35 \%$ a pesar del TMO, a efectos de mejorar los síntomas y reducir la morbimortalidad

La TRC está contraindicada para los pacientes con QRS $<130 \mathrm{~ms}$

Tratamientos no recomendados para comorbilidades de los pacientes con insuficiencia cardiaca

No se recomienda la servoventilación adaptativa para pacientes con IC-FEr y apnea del sueño predominantemente central, debido al aumento de la mortalidad cardiovascular y por todas las causas

No se recomiendan las tiazolidinedionas (glitazonas) para pacientes con IC, ya que aumentan el riesgo de empeoramiento de la IC y hospitalización por IC

No se recomiendan los AINE y los inhibidores de la COX-2 para pacientes con IC, ya que aumentan el riesgo de empeoramiento de la IC y hospitalización por IC 
Mensajes clave de la guía sobre qué hacer y qué no hacer (continuación)

\begin{tabular}{|c|c|c|}
\hline Recomendaciones para el tratamiento de pacientes con insuficiencia cardiaca aguda: farmacoterapia & Clase $^{\mathrm{a}}$ & Nivel $^{\text {b }}$ \\
\hline $\begin{array}{l}\text { Se recomiendan los diuréticos de asa intravenosos para todos los pacientes con ICA ingresados con signos/síntomas de sobrecarga de fluidos, para aliviar } \\
\text { los síntomas. Se recomienda controlar regularmente los síntomas, la diuresis, la función renal y los electrolitos durante el tratamiento con diuréticos i.v. }\end{array}$ & I & $\mathrm{C}$ \\
\hline $\begin{array}{l}\text { Para los pacientes con ICA de nueva aparición o con IC crónica descompensada que no están tratados con diuréticos orales, se recomienda una dosis inicial } \\
\text { de } 20-40 \text { mg de furosemida i.v. (o equivalente); para los que no reciben tratamiento diurético indefinidamente, la dosis i.v. inicial debe ser, como mínimo, } \\
\text { equivalente a la dosis oral }\end{array}$ & I & B \\
\hline $\begin{array}{l}\text { Se recomienda la administración de diuréticos en bolos intermitentes o en infusión continua; la dosis y la duración se deben ajustar según los síntomas } \\
\text { y el estado clínico del paciente }\end{array}$ & I & B \\
\hline $\begin{array}{l}\text { Debido a problemas de seguridad, no se recomienda la administración de inotrópicos, excepto para pacientes con hipotensión o hipoperfusión } \\
\text { sintomáticas }\end{array}$ & III & A \\
\hline Recomendaciones para el tratamiento de los pacientes en shock cardiogénico & Clase $^{\mathbf{a}}$ & Nivel $^{\mathrm{b}}$ \\
\hline Se recomienda realizar inmediatamente ECG y ecocardiografía a todo paciente con sospecha de shock cardiogénico & I & C \\
\hline $\begin{array}{l}\text { Todos los pacientes en shock cardiogénico deben ser derivados rápidamente a un hospital terciario con servicio permanente de cateterismo cardiaco y UCI/ } \\
\text { UCC con capacidad para administrar asistencia mecánica circulatoria a corto plazo }\end{array}$ & I & C \\
\hline Recomendaciones sobre tratamientos modificadores de la enfermedad y basados en la evidencia para pacientes con insuficiencia cardiaca aguda & Clase $^{\mathrm{a}}$ & Nivel $^{\text {b }}$ \\
\hline $\begin{array}{l}\text { En caso de empeoramiento de la IC-FEr, se hará todo lo posible por mantener los tratamientos modificadores de la enfermedad y basados en la evidencia, } \\
\text { en ausencia de inestabilidad hemodinámica o contraindicaciones }\end{array}$ & I & $\mathrm{C}$ \\
\hline Recomendaciones sobre el ejercicio, la atención multidisciplinaria y la monitorización de pacientes con insuficiencia cardiaca & Clase $^{\mathbf{a}}$ & Nivel $^{b}$ \\
\hline Se recomienda alentar a los pacientes estables con IC-FEr al ejercicio aeróbico regular para mejorar la capacidad funcional y los síntomas & I & A \\
\hline Se recomienda alentar a los pacientes estables con IC-FEr al ejercicio aeróbico regular para reducir el riesgo de hospitalización por IC & I & A \\
\hline Se recomienda incluir a los pacientes en un programa interdisciplinario de cuidados para reducir el riesgo de hospitalización por IC & I & A \\
\hline
\end{tabular}

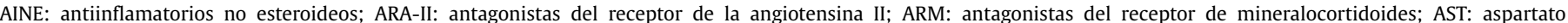

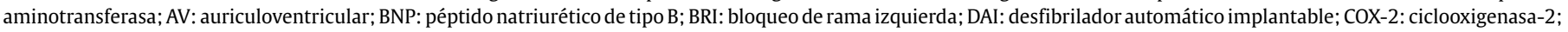

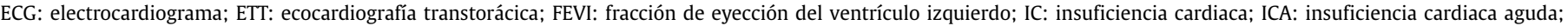

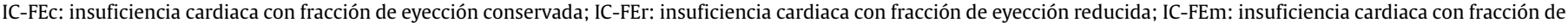

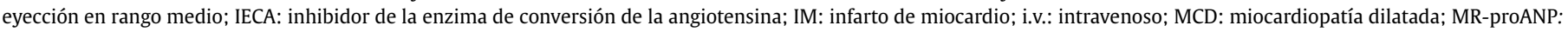

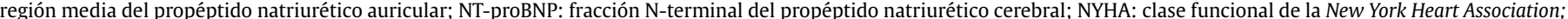

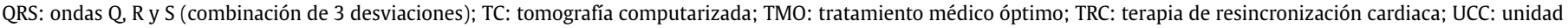
de cuidados coronarios; UCI: unidad de cuidados intensivos; VD: ventrículo derecho; VI: ventrículo izquierdo.

${ }^{a}$ Clase de recomendación.

bNivel de evidencia.

'Referencias que respaldan las recomendaciones.

\section{ANEXO WEB}

Se puede consultar las figuras y tablas del anexo en "Web addenda», disponibles en la versión electrónica de European Heart Journal y también a través de la página web de la ESC.

\section{TABLA DE CONTENIDOS}

1. Tablas

Tabla 3.2. Clasificación funcional de la New York Heart

Association basada en la gravedad de los síntomas

y la actividad física.

Tabla 3.3. Etapas de la insuficiencia cardiaca según

la ACCF/AHA 58

Tabla 3.5. Marcadores de pronóstico desfavorable en pacientes

con insuficiencia cardiaca.

.58

Tabla 4.2. Datos demográficos y comorbilidades típicas asociadas con la insuficiencia cardiaca con fracción de eyección reducida.

Tabla 4.3. Valores normales y anormales de los índices ecocardiográficos de la función diastólica del ventrículo izquierdo en reposo según edades, diferenciadas por sexo Tabla 4.4. Pruebas diagnósticas para causas específicas de insuficiencia cardiaca con fracción de eyección reducida
Tabla 7.1. Estudios clínicos más importantes sobre intervenciones terapéuticas en pacientes con insuficiencia cardiaca y fracción de eyección reducida

Tabla 7.4. Guía práctica sobre el uso de IECA (o ARA-II) para pacientes con insuficiencia cardiaca y fracción de eyección reducida.

Tabla 7.5. Guía práctica sobre el uso de bloqueadores beta para pacientes con IC y fracción de eyección reducida. Tabla 7.6. Guía práctica sobre el uso de antagonistas del receptor de mineralocorticoides para pacientes con insuficiencia cardiaca y fracción de eyección reducida

Tabla 7.7. Guía práctica sobre el uso de diuréticos para pacientes con insuficiencia cardiaca

Tabla 7.8. Guía práctica sobre el uso de ivabradina para pacientes con insuficiencia cardiaca y fracción de eyección reducida

Tabla 9.1. Estudios clínicos de fase II y III en pacientes con insuficiencia cardiaca con fracción de eyección en rango medio o conservada.

Tabla 10.1. Valoración del riesgo de ACV en pacientes con fibrilación auricular Tabla 10.2. Valoración del riesgo hemorrágico de los pacientes con fibrilación auricular 


\section{TABLAS}

Tabla 3.2

Clasificación funcional de la New York Heart Association basada en la gravedad de los síntomas y la actividad física

\begin{tabular}{ll}
\hline Clase I & $\begin{array}{l}\text { Sin limitación de la actividad física. La actividad física ordinaria no } \\
\text { causa disnea, fatiga o palpitaciones }\end{array}$ \\
\hline Clase II & $\begin{array}{l}\text { Leve limitación de la actividad física. Se siente cómodo en reposo, } \\
\text { pero la actividad física ordinaria produce disnea, fatiga } \\
\text { o palpitaciones }\end{array}$ \\
\hline Clase III & $\begin{array}{l}\text { Marcada limitación de la actividad física. Cómodo en reposo pero } \\
\text { una actividad menor que la ordinaria produce disnea, fatiga } \\
\text { o palpitaciones }\end{array}$ \\
\hline Clase IV & $\begin{array}{l}\text { Incapacidad de llevar a cabo cualquier actividad física sin sentir } \\
\text { molestias. Puede haber síntomas en reposo. Si se lleva a cabo } \\
\text { cualquier actividad física, aumenta la sensación de malestar }\end{array}$ \\
\hline
\end{tabular}

Tabla 3.3

Etapas de la insuficiencia cardiaca según la ACCF/AHA

\begin{tabular}{ll}
\hline A & $\begin{array}{l}\text { Riesgo de IC alto, pero sin enfermedad estructural cardiaca o síntomas } \\
\text { de insuficiencia cardiaca }\end{array}$ \\
\hline B & Enfermedad cardiaca estructural sin signos o síntomas de IC \\
\hline C & $\begin{array}{l}\text { Enfermedad cardiaca estructural con signos previos o presencia } \\
\text { de síntomas de IC }\end{array}$ \\
\hline D & IC refractaria que requiere intervenciones especializadas \\
\hline
\end{tabular}

Tabla 3.5

Marcadores de pronóstico desfavorable en pacientes con insuficiencia cardiaca

\begin{tabular}{|c|c|}
\hline Datos demográficos & Edad avanzada, sexo masculino, estatus socioeconómico bajo \\
\hline Gravedad de la insuficiencia cardiaca & $\begin{array}{l}\text { Clase de la NYHA avanzada, mayor duración de la IC, consumo pico de oxígeno reducido, curva pronunciada de VE-VCO } \text {, respiración } \\
\text { de Cheyne-Stokes, poca distancia recorrida en la prueba de } 6 \text { min de marcha, fuerza muscular disminuida, mala calidad de vida }\end{array}$ \\
\hline Estado clínico & $\begin{array}{l}\text { Frecuencia cardiaca alta en reposo, presión arterial baja, características clínicas de sobrecarga de fluidos (congestión pulmonar } \\
\text { y edema periférico, dilatación venosa yugular, hepatomegalia), características clínicas de hiperfusión periférica, pérdida de masa } \\
\text { corporal, fragilidad }\end{array}$ \\
\hline $\begin{array}{l}\text { Remodelado miocárdico y gravedad } \\
\text { de la disfunción cardiaca }\end{array}$ & $\begin{array}{l}\text { FEVI baja, dilatación del VI, disfunción diastólica del VI grave, presión de llenado del VI alta, regurgitación mitral, estenosis aórtica, } \\
\text { hipertrofia del VI, dilatación de la AI, disfunción del VD, hipertensión pulmonar, disincronía, zona amplia de hipocinesia o acinesia, } \\
\text { QRS ancho, sospecha de inflamación o infiltración en RMC, isquemia inducible y mala calidad de las pruebas de imagen }\end{array}$ \\
\hline $\begin{array}{l}\text { Biomarcadores de activación } \\
\text { neurohormonal }\end{array}$ & $\begin{array}{l}\text { Baja concentración de sodio y alta de péptidos natriuréticos, alta actividad de renina plasmática, altas concentraciones de aldosterona } \\
\text { y catecolaminas, endotelina-1, adrenomedulina y vasopresina }\end{array}$ \\
\hline Otros biomarcadores & $\begin{array}{l}\text { Marcadores de función renal, marcadores de inflamación, marcadores de estrés cardiaco, marcadores de daño cardiaco, marcadores } \\
\text { metabólicos, marcadores de colágeno, marcadores de disfunción y/o daño orgánico }\end{array}$ \\
\hline $\begin{array}{l}\text { Pruebas genéticas (véase la sección } \\
5.10 .1 \text { ) }\end{array}$ & Ciertas mutaciones en miocardiopatías heredadas asociadas con riesgo alto de muerte súbita cardiaca o rápida progresión de la IC \\
\hline Comorbilidades cardiovasculares & $\begin{array}{l}\text { Fibrilación auricular, arritmia ventricular, enfermedad arterial coronaria no revascularizable, historia de ACV/AIT, enfermedad arterial } \\
\text { periférica }\end{array}$ \\
\hline Comorbilidades no cardiovasculares & $\begin{array}{l}\text { Diabetes mellitus, anemia, déficit de hierro, EPOC, insuficiencia renal, disfunción hepática, apnea del sueño, disfunción cognitiva, } \\
\text { depresión }\end{array}$ \\
\hline Falta de adherencia & Falta de adherencia al tratamiento recomendado para la IC \\
\hline Complicaciones clínicas & Hospitalización por IC, parada cardiaca abortada, DAI \\
\hline
\end{tabular}

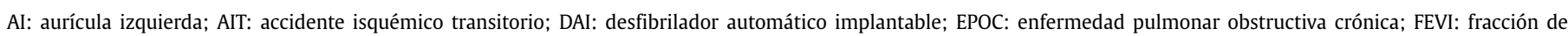

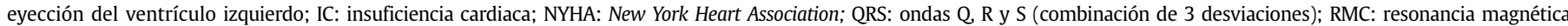
cardiaca; VD: ventrículo derecho; $\mathrm{VE}-\mathrm{VCO}_{2}$ : equivalente ventilatorio para el dióxido de carbono; VI: ventrículo izquierdo. 
Tabla 4.2

Datos demográficos y comorbilidades típicas asociadas con la insuficiencia cardiaca con fracción de eyección reducida

\begin{tabular}{l}
\hline Edad avanzada \\
\hline Hipertensión arterial \\
\hline Fibrilación auricular \\
\hline Sexo femenino \\
\hline Disfunción renal \\
\hline Síndrome metabólico \\
\hline Obesidad \\
\hline Deterioro físico \\
\hline Enfermedad pulmonar (p. ej., EPOC) \\
\hline Hipertensión pulmonar \\
\hline Apnea del sueño \\
\hline
\end{tabular}

EPOC: enfermedad pulmonar obstructiva crónica.
Tabla 4.4

Pruebas diagnósticas para causas específicas de insuficiencia cardiaca con fracción de eyección reducida

\begin{tabular}{l}
\hline Pruebas genéticas (p. ej., para ATTR y MCH; véase también la sección 5.10.1) \\
\hline Proteinuria de Bence-Jones (amiloidosis de cadena ligera) \\
\hline Gammagrafía con ${ }^{99 m}$ Tc-DPD (amiloidosis por transtiretina no hereditaria) \\
\hline Eosinofilia, receptor IL-2, ECA (sarcoidosis) \\
\hline Troponina de alta sensibilidad, CK, CK-MB (miocarditis) \\
\hline IgM de Borellia burgdorferi (borreliosis) \\
\hline Serología de VIH (miocardiopatía por VIH) \\
\hline Serología de Tryponosoma cruzi (enfermedad de Chagas) \\
\hline Ferritina sérica, pruebas genéticas (hemocromatosis) \\
\hline Actividad de la galactosidasa A leucocitaria (enfermedad de Fabry) \\
\hline Eosinofilia (endomiocarditis de Löffler)
\end{tabular}

ATTR: amiloidosis mediada por la transtiretina; CK: creatincinasa; CK-MB: banda miocárdica de la creatincinasa; DPD: ácido 3,3-difosfono-1,2-propanodicarboxílico; ECA: enzima de conversión de la angiotensina; IL-2: interleucina 2; $\mathrm{MCH}$ : miocardiopatía hipertrófica; VIH: virus de la inmunodeficiencia humana.

Tabla 4.3

Valores normales y anormales de los índices ecocardiográficos de la función diastólica del ventrículo izquierdo en reposo según edades, diferenciadas por sexo

\begin{tabular}{|c|c|c|c|c|c|c|c|c|c|}
\hline \multirow[t]{3}{*}{ Parámetros } & \multicolumn{6}{|c|}{ Función diastólica normal } & \multicolumn{3}{|c|}{ Disfunción diastólica } \\
\hline & \multicolumn{2}{|c|}{ 20-40 años } & \multicolumn{2}{|c|}{ 40-60 años } & \multicolumn{2}{|c|}{$\geq 60$ años } & \multirow{2}{*}{$\begin{array}{c}\text { Relajación } \\
\text { disminuida }\end{array}$} & \multirow{2}{*}{$\begin{array}{c}\text { Llenado } \\
\text { seudonormal }\end{array}$} & \multirow{2}{*}{$\begin{array}{l}\text { Llenado } \\
\text { restricitvo }\end{array}$} \\
\hline & Varones & Mujeres & Varones & Mujeres & Varones & Mujeres & & & \\
\hline \multicolumn{10}{|l|}{ Flujo de entrada VM } \\
\hline VM-E (m/s) & $0,79 \pm 0,14$ & $0,84 \pm 0,17$ & $0,72 \pm 0,16$ & $0,77 \pm 0,17$ & $0,67 \pm 0,15$ & $0,72 \pm 0,17$ & & & \\
\hline VM-A (m/s) & $0,50 \pm 0,13$ & $0,51 \pm 0,12$ & $0,61 \pm 0,15$ & $0,63 \pm 0,14$ & $0,73 \pm 0,16$ & $0,76 \pm 0,16$ & & & \\
\hline $\operatorname{DecT}(\mathrm{m} / \mathrm{s})$ & $179,8 \pm 46,4$ & $176,7 \pm 40,1$ & $186,6 \pm 52,8$ & $188,2 \pm 39,8$ & $217,5 \pm 69,7$ & $201,5 \pm 55,7$ & $>220$ & $140-220$ & $<140$ \\
\hline Cociente $\mathrm{E} / \mathrm{A}(\mathrm{m} / \mathrm{s})$ & $1,69 \pm 0,52$ & $1,72 \pm 0,52$ & $1,22 \pm 0,31$ & $1,26 \pm 0,43$ & $0,96 \pm 0,27$ & $0,99 \pm 0,31$ & $<1,0$ & $1,0-2,0$ & $>2,0$ \\
\hline TRIV & & & & & & & $>110$ & $60-100$ & $<60$ \\
\hline \multicolumn{10}{|l|}{ Doppler tisular } \\
\hline E' septal $(\mathrm{cm} / \mathrm{s})$ & $11,9 \pm 2,7$ & $12,3 \pm 2,3$ & $9,8 \pm 2,6$ & $9,7 \pm 2,5$ & $7,3 \pm 2,2$ & $7,9 \pm 2,3$ & $<8$ & $<8$ & $<8$ \\
\hline E' lateral $(\mathrm{cm} / \mathrm{s})$ & $16,2 \pm 3,6$ & $16,6 \pm 3,2$ & $12,6 \pm 3,0$ & $12,4 \pm 3,0$ & $9,5 \pm 2,1$ & $9,7 \pm 3,2$ & $<10$ & $<10$ & $<10$ \\
\hline e' media septal-lateral $(\mathrm{cm} / \mathrm{s})$ & $14,0 \pm 2,9$ & $14,5 \pm 2,4$ & $11,2 \pm 2,4$ & $11,1 \pm 2,5$ & $8,5 \pm 1,9$ & $8,8 \pm 2,6$ & & & \\
\hline E/e' septal & $6,9 \pm 1,7$ & $6,9 \pm 1,6$ & $7,8 \pm 2,4$ & $8,2 \pm 2,2$ & $9,8 \pm 3,0$ & $9,7 \pm 2,6$ & & & \\
\hline E/e' lateral & $5,0 \pm 1,3$ & $5,2 \pm 1,3$ & $6,1 \pm 2,2$ & $6,5 \pm 2,3$ & $7,6 \pm 2,1$ & $7,9 \pm 2,2$ & & & \\
\hline E/e' media septal-lateral $(\mathrm{cm} / \mathrm{s}$ & $5,8 \pm 1,4$ & $5,9 \pm 1,3$ & $6,7 \pm 2,1$ & $7,2 \pm 2,0$ & $8,4 \pm 2,2$ & $8,6 \pm 2,2$ & & $\geq 13$ & $\geq 13$ \\
\hline
\end{tabular}

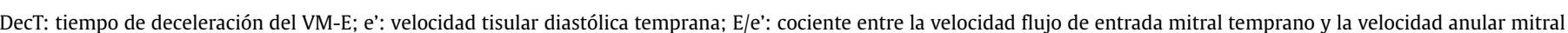

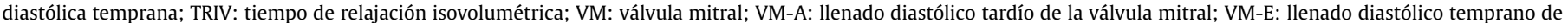
la válvula mitral.

Los valores expresan media \pm desviación estándar. Los puntos de corte de estos parámetros se han derivado de las siguientes referencias ${ }^{65,70,72,80-86}$. 
Tabla 7.1

Estudios clínicos más importantes sobre intervenciones terapéuticas en pacientes con insuficiencia cardiaca y fracción de eyección reducida

\begin{tabular}{|c|c|c|c|c|}
\hline Estudio & Fármaco & Criterios de inclusión & $\begin{array}{l}\text { Seguimiento } \\
\text { medio }\end{array}$ & $\begin{array}{l}\text { Impacto del tratamiento en la } \\
\text { variable primaria }\end{array}$ \\
\hline
\end{tabular}

IECA

0,5 años

$\begin{array}{lll}\text { CONSENSUS }^{2} & \begin{array}{l}\text { Enalapril }(\mathrm{n}=127) \text { frente } \\ \text { a placebo }(\mathrm{n}=126)\end{array} & \begin{array}{l}\text { IC congestiva, NYHA IV, } \\ \text { cardiomegalia en radiografía } \\ \text { torácica }\end{array}\end{array}$
torácica

Reducción del $40 \%$ en la mortalidad por todas las causas a los 6 meses (el 26 frente al 44\%; $\mathrm{p}=0,002)$ y del $31 \%$ a los 12 meses (el 52 frente al 36\%; $\mathrm{p}=0,001$ )

\begin{tabular}{|c|c|c|}
\hline $\begin{array}{l}\text { SOLVD- } \\
\text { TREATMENT }{ }^{168}\end{array}$ & $\begin{array}{l}\text { Enalapril }(n=1.285) \text { frente } \\
\text { a placebo }(n=1.284)\end{array}$ & $\begin{array}{l}\text { FEVI } \leq 35 \% \text {; NYHA I-IV (el } 90 \% \\
\text { en NYHA II-III) }\end{array}$ \\
\hline
\end{tabular}
Reducción del $16 \%$ en la mortalidad por todas las causas (el 35 frente al 40\%) $(p=0,004)$

$\begin{array}{ll}\text { ATLAS }^{169} & \text { Lisinopril, dosis alta } \\ & (\mathrm{n}=1.568) \text { frente a dosis } \\ & \text { baja }(\mathrm{n}=1.596)\end{array}$
baja $(\mathrm{n}=1.596)$

FEVI $\leq 30 \%$; NYHA II-IV $\quad 3,5$ años

Reducción no significativa del 8\% en la mortalidad por todas $\mathrm{p}=0,13$ ) las causas (el 43 frente al 45\%;

Reducción del 26\% en la variable combinada de mortalidad por todas las causas y hospitalización por IC $(\mathrm{p}<0,0001)$

Tendencia a reducción de la mortalidad cardiovascular en un $10 \%(\mathrm{p}=0,07)$. Reducción del $15 \%$ en la variable combinada de mortalidad por todas las causas y hospitalización por IC ( $\mathrm{p}<0,001)$

\begin{tabular}{cl}
\hline \multicolumn{2}{l}{ Bloqueadores beta } \\
\hline MERIT-HF $^{170}$ & Metoprolol CR/XL \\
& $(\mathrm{n}=1.991)$ frente a
\end{tabular}

$(\mathrm{n}=1.991)$ frente

FEVI $\leq 40 \%$, NYHA II-IV $\quad 1,0$ años

Reducción del 34\% de la mortalidad por todas las causas (el 7 frente al 11\%; p < 0,001)

$\begin{array}{ll}\text { COPERNICUS }^{171} & \text { Carvedilol }(\mathrm{n}=1.156) \\ & \text { frente a placebo }(\mathrm{n}=1.133)\end{array}$

FEVI $<25 \%$, NYHA IV

0,9 años

Reducción del 35\% de la mortalidad por todas las causas (el 11 frente al 17\%; p < 0,001)

\begin{tabular}{lllll}
\hline CIBIS-II ${ }^{172}$ & $\begin{array}{l}\text { Bisoprolol }(\mathrm{n}=1.327) \\
\text { frente a placebo } \\
(\mathrm{n}=1.320)\end{array}$ & FEVI $\leq 35 \%$, NYHA III-IV & 1,3 años & $\begin{array}{l}\text { Reducción del 34\% en la } \\
\text { mortalidad por todas las causas } \\
(\mathrm{el} \mathrm{12} \text { frente al 17\%; } \mathrm{p}<0,001)\end{array}$ \\
\hline SENIORS $^{173}$ & $\begin{array}{l}\text { Nebivolol }(\mathrm{n}=1.067) \\
\text { frente a placebo } \\
(\mathrm{n}=1.061)\end{array}$ & $\begin{array}{l}\text { Edad } \geq 70 \text { años, IC confirmada } \\
\text { como hospitalización por IC } \\
\text { en los últimos 12 meses y/o } \\
\text { FEVI } \leq 35 \% \text { en los últimos } \\
6 \text { meses }\end{array}$ & $\begin{array}{l}\text { Reducción del 14\% en la variable } \\
\text { combinada de mortalidad por } \\
\text { todas las causas y hospitalización } \\
\text { cardiovascular }(\text { el } 31 \text { frente al 35\%; } \\
\text { p }<0,04)\end{array}$ \\
\hline
\end{tabular}

ARM

\begin{tabular}{|c|c|c|c|}
\hline RALES $^{174}$ & $\begin{array}{l}\text { Espironolactona }(n=822) \\
\text { frente a placebo }(n=841)\end{array}$ & $\begin{array}{l}\text { FEVI } \leq 35 \% \text {, NYHA III-IV al } \\
\text { ingreso y NYHA IV en los } \\
\text { últimos } 6 \text { meses }\end{array}$ & 2,0 años \\
\hline EMPHASIS-HF ${ }^{175}$ & $\begin{array}{l}\text { Eplerenona }(n=1.364) \\
\text { frente a placebo } \\
(n=1.373)\end{array}$ & $\begin{array}{l}\text { NYHA II, FEVI } \leq 30 \% \text { o } \\
30-35 \% \text {, con QRS > } 130 \mathrm{~ms} \text {, } \\
\text { hospitalización cardiovascular } \\
\text { en los últimos } 6 \text { meses o BNP } \\
\leq 250 \mathrm{pg} / \mathrm{ml} \text { o NT-proBNP } \\
\leq 500 \mathrm{pg} / \mathrm{ml} \text { en varones } \\
\mathrm{y} \leq 750 \mathrm{pg} / \mathrm{ml} \text { en mujeres }\end{array}$ & 1,8 años \\
\hline
\end{tabular}

\section{Reducción del 30\% en la} 35 frente al 46\%; p < 0,001)

Reducción del $37 \%$ en la variable Reducción del $24 \%$ en la mortalidad
combinada de mortalidad cardiovascular y hospitalización cardiovascular (el 18 frente al $26 \%$; $\mathrm{p}<0,001)$ por todas las causas $(\mathrm{p}<0,008)$ y del $24 \%$ en la mortalidad cardiovascular

Reducción del 38\% en el riesgo de mortalidad cardiovascular ( $p<0,001$ ), el $41 \%$ en la muerte súbita $(p<0,001)$ y el $49 \%$ en muerte por agravamiento de la IC ( $p<0,002$ )

Reducción del $24 \%$ en la variable combinada de mortalidad por todas las causas y hospitalización por IC $(\mathrm{p}<0,001)$

Reducción del $21 \%$ en la variable combinada de mortalidad cardiovascular y hospitalización cardiovascular $(\mathrm{p}<0,001)$

\begin{tabular}{ll}
\hline INRA & \\
\hline PARADIGM-HF & \\
& Sacubitrilo/valsartán \\
$(\mathrm{n}=4.187)$ frente a
\end{tabular}
enalapril $(n=4.212)$
Reducción del 20\% de la variable combinada de muerte por causas cardiovasculares o primer ingreso por IC (el 22 frente al $27 \%$; $\mathrm{p}<0,001)$

$(p=0,01)$. Reducción del $42 \%$ en la tasa de hospitalización por IC $(\mathrm{p}<0,001)$

\begin{tabular}{|c|c|c|c|c|c|}
\hline PARADIGM-HF ${ }^{167}$ & $\begin{array}{l}\text { Sacubitrilo/valsartán } \\
(\mathrm{n}=4.187) \text { frente a } \\
\text { enalapril }(\mathrm{n}=4.212)\end{array}$ & $\begin{array}{l}\text { NYHA II-IV, FEVI } \leq 40 \% \\
\text { (corregido a } \leq 35 \% \text { ). BNP } \\
\geq 150 \mathrm{pg} / \mathrm{ml} \text { o NT-proBNP } \\
\geq 600 \mathrm{pg} / \mathrm{ml} \text { o, en caso de } \\
\text { hospitalización por IC en } \\
\text { los últimos } 12 \text { meses, BNP } \geq \\
100 \mathrm{pg} / \mathrm{ml} \text { o NT-proBNP } \\
\geq 400 \mathrm{pg} / \mathrm{ml}\end{array}$ & 2,3 años & $\begin{array}{l}\text { Reducción del } 20 \% \text { de la variable } \\
\text { combinada de muerte por causas } \\
\text { cardiovasculares o primer ingreso } \\
\text { por IC (el } 22 \text { frente al } 27 \% \\
\text { p }<0,001 \text { ) }\end{array}$ & $\begin{array}{l}\text { Reducción del } 16 \% \text { en la mortalidad } \\
\text { por todas las causas }(p<0,001) \text { y del } \\
20 \% \text { en la mortalidad cardiovascular } \\
(p=0,001) \text {. Reducción del } 21 \% \text { de la } \\
\text { tasa de hospitalización por IC } \\
(p<0,001)\end{array}$ \\
\hline \multicolumn{6}{|c|}{ Inhibidores del canal $I_{f}$} \\
\hline $\mathrm{SHIFT}^{176}$ & $\begin{array}{l}\text { Ivabradina }(\mathrm{n}=3.268) \\
\text { frente a placebo } \\
(\mathrm{n}=3.290)\end{array}$ & $\begin{array}{l}\text { FEVI } \leq 35 \% \text {, NYHA II-IV, } \\
\text { hospitalización por IC en } \\
\text { los últimos } 12 \text { meses, ritmo } \\
\text { sinusal, frecuencia cardiaca } \\
\geq 70 \mathrm{lpm}\end{array}$ & 1,9 años & $\begin{array}{l}\text { Reducción del } 18 \% \text { de la variable } \\
\text { combinada de mortalidad } \\
\text { cardiovascular u hospitalización } \\
\text { por IC (el } 24 \text { frente al } 29 \% \text {; } \\
\text { p }<0,001 \text { ) }\end{array}$ & $\begin{array}{l}\text { Reducción del } 26 \% \text { de la tasa de } \\
\text { hospitalización por IC ( } p<0,001) \text {. } \\
\text { Reducción del } 26 \% \text { de la tasa de } \\
\text { muertes relacionadas con la IC } \\
(p<0,01)\end{array}$ \\
\hline \multicolumn{6}{|l|}{ ARA-II } \\
\hline CHARM-Added ${ }^{177}$ & $\begin{array}{l}\text { Candesartán }(\mathrm{n}=1.276) \\
\text { frente a placebo } \\
(\mathrm{n}=1.272)\end{array}$ & $\begin{array}{l}\mathrm{FEVI} \leq 40 \% \text {, NYHA II-IV, } \\
\text { tratamiento con IECA }\end{array}$ & 3,4 años & $\begin{array}{l}\text { Reducción del } 15 \% \text { en la variable } \\
\text { combinada de mortalidad } \\
\text { cardiovascular u hospitalización } \\
\text { por IC (el } 38 \text { frente al } 42 \% \text {; }<<0,01 \text { ) }\end{array}$ & - \\
\hline
\end{tabular}


Tabla 7.1

Estudios clínicos más importantes sobre intervenciones terapéuticas en pacientes con insuficiencia cardiaca y fracción de eyección reducida (continuación)

\begin{tabular}{|c|c|c|c|c|c|}
\hline Estudio & Fármaco & Criterios de inclusión & $\begin{array}{l}\text { Seguimiento } \\
\text { medio }\end{array}$ & $\begin{array}{l}\text { Impacto del tratamiento en la } \\
\text { variable primaria }\end{array}$ & Otros resultados \\
\hline $\begin{array}{l}\text { CHARM- } \\
\text { Alternative }^{178}\end{array}$ & $\begin{array}{l}\text { Candesartán }(\mathrm{n}=1.013) \\
\text { frente a placebo } \\
(\mathrm{n}=1.015)\end{array}$ & $\begin{array}{l}\text { FEVI } \leq 40 \% \text {, NYHA II-IV, } \\
\text { intolerancia a IECA }\end{array}$ & 2,8 años & $\begin{array}{l}\text { Reducción del } 23 \% \text { en la variable } \\
\text { combinada de mortalidad } \\
\text { cardiovascular u hospitalización } \\
\text { por IC (el } 33 \text { frente al } 40 \% \text {; } \\
\text { p }<0,001 \text { ) }\end{array}$ & - \\
\hline Val-HeFT ${ }^{179}$ & $\begin{array}{l}\text { Valsartán }(\mathrm{n}=2.511) \\
\text { frente a placebo } \\
(\mathrm{n}=2.499)\end{array}$ & $\begin{array}{l}\text { FEVI } \leq 40 \%, \text { NYHA II-IV, } \\
\text { tratamiento con IECA, DIVI } \\
>2,9 \mathrm{~cm} / \text { Asc }\end{array}$ & 1,9 años & $\begin{array}{l}\text { La mortalidad por todas las causas } \\
\text { fue similar en ambos grupos } \\
\text { (el } 19,7 \text { frente al } 19,4 \% ; \mathrm{p}=0,80 \text { ). } \\
\text { Reducción del } 13 \% \text { de la variable } \\
\text { coprimaria combinada de muerte } \\
\text { por todas las causas, parada } \\
\text { cardiaca reanimada, ingreso } \\
\text { por IC o administración i.v. de } \\
\text { inotrópicos o vasodilatadores } \geq 4 \mathrm{~h} \\
\text { sin hospitalización (el } 29 \text { frente } \\
\text { al } 32 \% ; \mathrm{p}=0,009 \text { ) }\end{array}$ & - \\
\hline
\end{tabular}

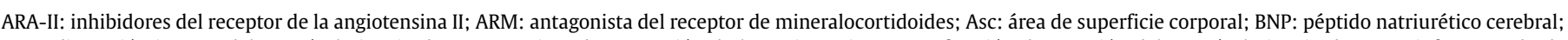

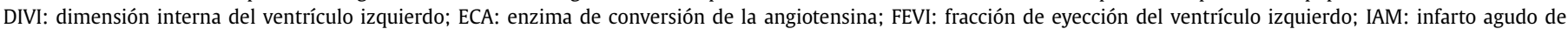

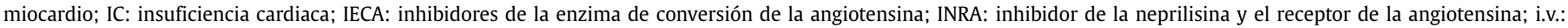

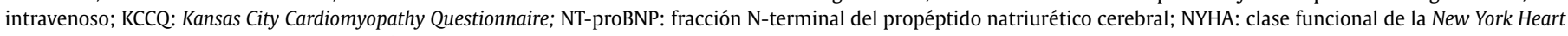
Association; QRS: ondas Q R y S (combinación de 3 desviaciones).

Tabla 7.4

Guía práctica sobre el uso de IECA (o ARA-II) para pacientes con insuficiencia cardiaca y fracción de eyección reducida ${ }^{a}$

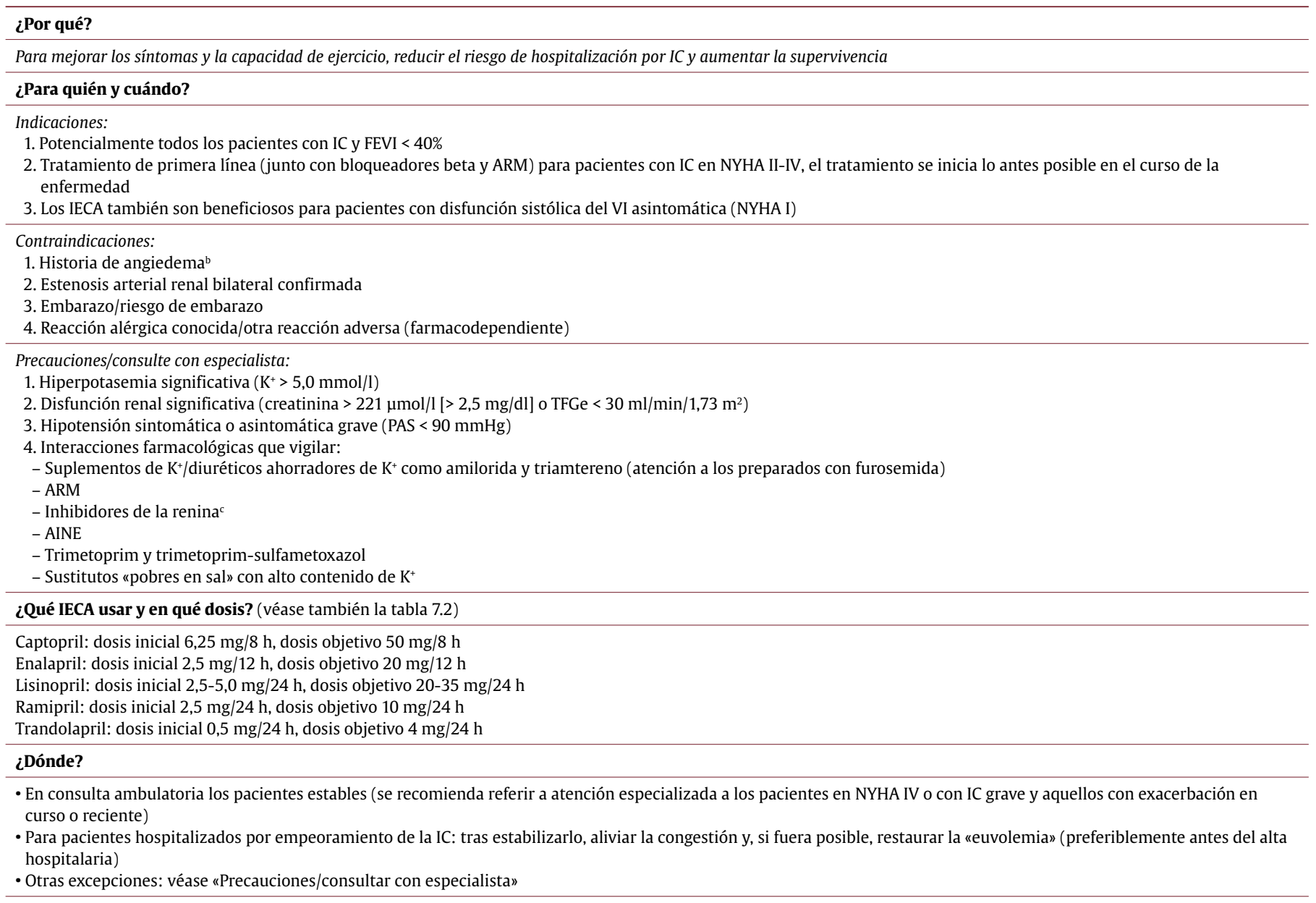


Tabla 7.4

Guía práctica sobre el uso de IECA (o ARA-II) para pacientes con insuficiencia cardiaca y fracción de eyección reducida ${ }^{\text {(continuación) }}$

\section{¿Cómo emplearlos?}

- Comprobar la función renal y electrolitos

- Comenzar con dosis bajas (véase la tabla 7.2)

- Duplicar la dosis de los pacientes ambulatorios en intervalos de no menos de 2 semanas. Se podrá aumentar más rápidamente la dosis de los pacientes hospitalizados o monitorizados más estrechamente siempre que se tolere

- Intente alcanzar la dosis objetivo (véase la tabla anterior) o, en caso contrario, la dosis tolerada más alta (recuerde que siempre es mejor alguna cantidad de IECA [o ARA-II] que ninguna)

- Nueva determinación de bioquímica sanguínea (urea/BUN, creatinina, $\mathrm{K}^{+}$) entre 1 y 2 semanas después de iniciar el tratamiento y de 1 a 2 semanas después del último aumento de la dosis

- Nuevas determinaciones de bioquímica sanguínea cada 4 meses

- Cuándo dejar de aumentar la dosis, reducirla o interrumpir el tratamiento: véase «Resolución de problemas»

- Rara vez es necesario interrumpir el tratamiento con IECA (o ARA-II), y es probable un deterioro clínico si se interrumpe. Por ello, se recomienda consultar a un especialista antes de interrumpir el tratamiento

- Personal de enfermería especializado en IC puede asistir en la educación del paciente, el seguimiento (en persona o por teléfono), la monitorización de la bioquímica sanguínea y el aumento de las dosis

\section{Resolución de problemas}

Hipotensión asintomática:

- No suele precisar cambios de tratamiento

Hipotensión sintomática:

- Los mareos/aturdimiento son comunes y a menudo mejoran con el tiempo; es importante informar al paciente

- Reconsidere la necesidad de nitratos, bloqueadores de los canales de calcioe y otros vasodilatadores y reduzca o interrumpa su dosis si es posible

- En ausencia de signos o síntomas de congestión, considere reducir la dosis de diuréticos

- Si estas medidas no resuelven el problema, consulte con un especialista

Tos:

- La tos es frecuente en pacientes con IC, pues muchos tienen enfermedad pulmonar relacionada con el tabaquismo

- La tos es también un síntoma de edema pulmonar que se debe descartar cuando la tos empeora nuevamente

- La tos inducida por un IECA no siempre obliga a interrumpir el tratamiento

- Si aparece un cuadro de tos problemático (p. ej., que impida al paciente conciliar el sueño) y se confirma que se debe al IECA (p. ej., recurre tras retirar el IECA y reiniciar la exposición), se recomienda sustituirlo por un ARA-II

Empeoramiento de la función renal e hiperpotasemia:

- Tras el tratamiento con IECA cabe esperar algún aumento de la urea (BUN), la creatinina y el potasio; si el aumento es pequeño y asintomático, no es necesario tomar medidas

- Un aumento de la creatinina de hasta un $50 \%$ sobre la basal o de $266 \mu \mathrm{mol} / \mathrm{l}$ ( $3 \mathrm{mg} / \mathrm{dl}) / \mathrm{TFGe}<25 \mathrm{ml} / \mathrm{min} / 1,73 \mathrm{~m}{ }^{2}$, el que sea menor, es aceptable

- Un aumento de potasio a $\leq 5,5 \mathrm{mmol} / \mathrm{l}$ es aceptable

- Si la urea, la creatinina o el potasio aumentan excesivamente, considere la interrupción de fármacos nefrotóxicos concomitantes (p. ej., AINE) y otros suplementos de

potasio o agentes retenedores (triamtereno, amilorida), y si no hay signos de congestión, reduzca la dosis de diuréticos

- Si persisten aumentos de creatinina o potasio mayores que los señalados a pesar del ajuste de fármacos concomitantes, se debe reducir a la mitad la dosis del IECA

(o ARA-II) y volver a determinar la bioquímica sanguínea transcurridas 1-2 semanas; si la respuesta sigue siendo insatisfactoria, se debe consultar a un especialista

- Si el potasio sube a $>5,5 \mathrm{mmol} / \mathrm{l}$ o la creatinina aumenta más del 100\% o hasta $>310 \mu \mathrm{mol} / \mathrm{l}\left(3,5 \mathrm{mg} / \mathrm{dl}\right.$ )/TFGe $<20 \mathrm{ml} / \mathrm{min} / 1,73 \mathrm{~m}{ }^{2}$, se debe interrumpir el IECA (o ARA-II)

y consultar a un especialista

- Se debe determinar la bioquímica sanguínea con frecuencia y en serie hasta que el potasio y la creatinina se hayan estabilizado

\section{Consejos para el paciente}

- Explique al paciente los beneficios que puede esperar:

- Mejora de los síntomas y de la capacidad de ejercicio

- Prevención del empeoramiento de la IC que conlleva la hospitalización

- Mayor supervivencia

- Los síntomas mejoran pocas semanas o meses después de empezar el tratamiento

- Aconseje al paciente que refiera cualquier efecto secundario importante (mareos, hipotensión sintomática, tos). Véase "Resolución de problemas»

- Aconseje al paciente que evite tomar AINE ${ }^{d}$ no prescritos por un médico (fármacos sin receta médica) y sustitutos de la sal con alto contenido de K+. Véase "Resolución de problemas»

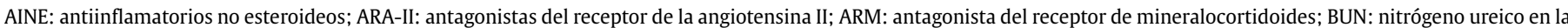

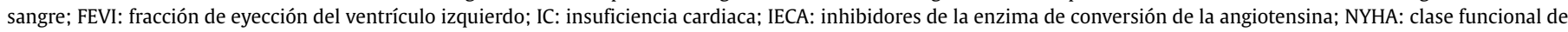
la New York Heart Association; PAS: presión arterial sistólica; TFGe: tasa de filtrado glomerular estimada; VI: ventrículo izquierdo.

aLas recomendaciones de esta tabla representan la opinión de expertos que está basada en estudios clínicos importantes (fármacos, aumento y dosis objetivo, monitorización del

paciente, beneficios del tratamiento y efectos adversos comunicados) y la experiencia clínica.

bNo está clara la seguridad de un ARA-II para pacientes que sufren angiedema con un IECA.

'No se recomiendan los inhibidores de la renina en la IC.

dEvite los AINE siempre que no sean imprescindibles.

eLos bloqueadores de los canales del calcio deben suspenderse, excepto cuando son absolutamente imprescindibles; el diltiazem y el verapamilo son potencialmente perjudiciales

en la IC con FEVI reducida debido a su acción inotrópica negativa. 
Tabla 7.5

Guía práctica sobre el uso de bloqueadores beta para pacientes con IC y fracción de eyección reducida

¿Para qué?

Para mejorar los síntomas y la capacidad de ejercicio, reducir el riesgo de hospitalización por IC y aumentar la supervivencia

¿Para quién y cuándo?

Indicaciones:

1. Potencialmente todos los pacientes con IC sistólica estable leve o moderada (FEVI < 40\%, NYHA II-III)

2. Tratamiento de primera línea, junto con un IECA y un ARM, para pacientes con IC estabilizada; iniciar el tratamiento lo antes posible en el curso de la enfermedad

3. Los bloqueadores beta también son beneficiosos para pacientes con IC grave, pero el tratamiento debe iniciarse bajo la supervisión de un especialista

Contraindicaciones:

1. BAV de segundo o tercer grado (en ausencia de un marcapasos permanente)

2. Isquemia crítica en extremidades

3. Asma (contraindicación relativa): si está indicado un bloqueador beta cardioselectivo, el asma no es una contraindicación absoluta, pero esta medicación solo debe

emplearse bajo la estrecha supervisión de un especialista, considerando los riesgos y beneficios del tratamiento ${ }^{223,224}$; la EPOC no es una contraindicación

4. Reacción alérgica conocida u otra reacción adversa (farmacológica)

Precauciones/consultar con un especialista:

1. IC grave (NYHA IV)

2. Exacerbación de la IC en curso o reciente (< 4 semanas; p. ej., hospitalización por empeoramiento de la IC), bloqueo cardiaco o frecuencia cardiaca < 50 lpm

3. Si persisten los signos de congestión, hipotensión (PAS < $90 \mathrm{mmHg}$ ), elevación de la presión venosa yugular, ascitis o edema periférico significativo, intente aliviar la

congestión y alcanzar la "euvolemia» antes de iniciar el tratamiento con bloqueadores beta

4. Interacciones de farmacológicas que se debe vigilar (debido al riesgo de bradicardia/BAV):

- Verapamilo, diltiazem (se debe interrumpir el tratamiento) ${ }^{\mathrm{b}}$

- Digoxina

- Amiodarona

- Ivabradina

¿Qué bloqueador beta usar y en qué dosis? (véase también la tabla 7.2)

Bisoprolol: dosis inicial $1,25 \mathrm{mg} / 24 \mathrm{~h}$, dosis objetivo $10 \mathrm{mg} / 24 \mathrm{~h}$

Carvedilol: dosis inicial $3,125 \mathrm{mg} / 12 \mathrm{~h}$, dosis objetivo $25 \mathrm{mg} / 12 \mathrm{~h}$

Succinato de metoprolol (CR/XL): dosis inicial 12,5-25 mg/24 h, dosis objetivo $200 \mathrm{mg} / 24 \mathrm{~h}$

Nebivolol: dosis inicial $1,25 \mathrm{mg} / 24 \mathrm{~h}$, dosis objetivo $10 \mathrm{mg} / 24 \mathrm{~h}$

\section{¿Dónde?}

- Atención ambulatoria los pacientes estables (se recomienda derivar al especialista a los pacientes en NYHA IV con IC grave o exacerbación en curso o reciente)

- Pacientes hospitalizados por empeoramiento de la IC: tras la estabilización, aliviar la congestión y, si fuera posible, restaurar la «euvolemia» (preferiblemente antes del alta

hospitalaria)

- Otras excepciones: véase «Precauciones/consultar con un especialista»

\section{¿Cómo emplearlos?}

- Inicie el tratamiento con dosis bajas en pacientes estables (véase la tabla 7.2)

- Duplique la dosis en intervalos de no menos de 2 semanas (algunos pacientes requieren un aumento de la dosis más lento)

- Intente alcanzar la dosis objetivo (véase la tabla anterior) o, en caso contrario, la dosis tolerada más alta (recuerde que siempre es mejor alguna cantidad de un bloqueador beta que

ninguna)

- Monitorice la frecuencia cardiaca, la PA y el estado clínico (síntomas, signos, especialmente los signos de congestión, y peso corporal)

- Personal de enfermería especializado en IC puede asistir en la educación del paciente, el seguimiento (en persona o por teléfono) y el aumento de las dosis

- Cuándo dejar de aumentar la dosis, reducir la dosis o interrumpir el tratamiento: véase "Resolución de problemas»

\section{Resolución de problemas}

Empeoramiento de los síntomas o signos (p. ej., aumento de la disnea, fatiga, edema, peso corporal):

- Si aumenta la congestión, aumente la dosis de diuréticos o reduzca a la mitad la dosis de bloqueadores beta (si no responde al aumento de la dosis de diuréticos)

- En caso de fatiga significativa (o bradicardia, véase más adelante), reduzca a la mitad la dosis de bloqueadores beta (raramente necesario); vuelva a examinar al paciente

en 1-2 semanas; si no mejora, consulte a un especialista

- En caso de deterioro grave, reduzca a la mitad la dosis de bloqueadores beta o interrumpa el tratamiento (raramente necesario); consulte a un especialista

Frecuencia cardiaca baja:

- Si es < 50 lpm y empeoran los síntomas, reduzca a la mitad la dosis de bloqueadores beta o, en caso de deterioro grave, interrumpa el tratamiento (raramente necesario)

- Considere la necesidad de otros fármacos reductores de la frecuencia cardiaca (p. ej., digoxina, amiodarona, diltiazem o verapamilo ${ }^{\mathrm{b}}$ )

- Realice un electrocardiograma para excluir el bloqueo cardiaco

- Consulte a un especialista

Hipotensión asintomática:

- No suele precisar ningún cambio en el tratamiento

Hipotensión sintomática:

- Ante cuadros de mareos, vértigos o confusión y PA baja, reconsidere la necesidad de nitratos, bloqueadores de los canales de calcio ${ }^{\mathrm{b}}$ y otros vasodilatadores,

y reduzca o interrumpa su dosis si es posible

- En ausencia de signos o síntomas de congestión, considere la reducción de la dosis de diuréticos

- Si con estas medidas no se soluciona el problema, consulte a un especialista

\section{Consejos para el paciente}

- Explique al paciente los beneficios que puede esperar (véase " ¿Por qué?») y mencione la posibilidad de efectos adversos temporales:

- El tratamiento mejora los síntomas, previene el empeoramiento de la IC que conlleva la hospitalización y mejora la supervivencia

- Los síntomas mejoran lentamente después de empezar el tratamiento, a los 3-6 meses o más

- Los síntomas pueden empeorar temporalmente durante el inicio del tratamiento y el ajuste de la dosis, pero a largo plazo los bloqueadores beta mejoran el bienestar

del paciente

- Aconseje al paciente que refiera cualquier signo de deterioro (véase "Resolución de problemas»); dicho deterioro se puede resolver fácilmente con el ajuste de otra medicación.

El paciente no debe interrumpir el tratamiento con bloqueadores beta sin consultar al médico

- Para detectar y tratar pronto cualquier signo de deterioro durante la fase de inicio y ajuste del tratamiento, los pacientes deben pesarse diariamente (al despertar, antes de vestirse,

tras la evacuación, antes de comer) y, en caso de un aumento persistente del peso (1,5-2,0 kg/día más de 2 días), se aumentará la dosis de diuréticos

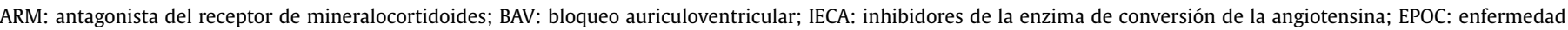

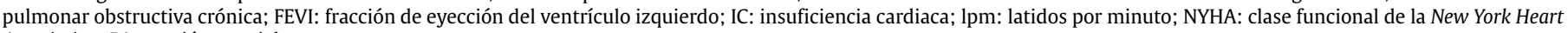
Association; PA: presión arterial.

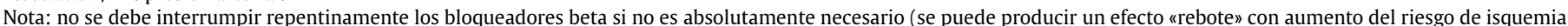
miocárdica, infarto y arritmias). Antes de interrumpir el tratamiento es conveniente consultar a un especialista.

atas recomendaciones de esta tabla representan la opinión de expertos basada en estudios clínicos importantes (fármacos, aumento y dosis objetivo, monitorización del paciente, beneficios del tratamiento y efectos adversos comunicados) y la experiencia clínica.

bos bloqueadores de los canales del calcio deben suspenderse excepto cuando sean absolutamente imprescindibles; el diltiazem y el verapamilo son potencialmente perjudiciales en la IC-FEr debido a su acción inotrópica negativa. 
Tabla 7.6

Guía práctica sobre el uso de antagonistas del receptor de mineralocorticoides para pacientes con insuficiencia cardiaca y fracción de eyección reducida

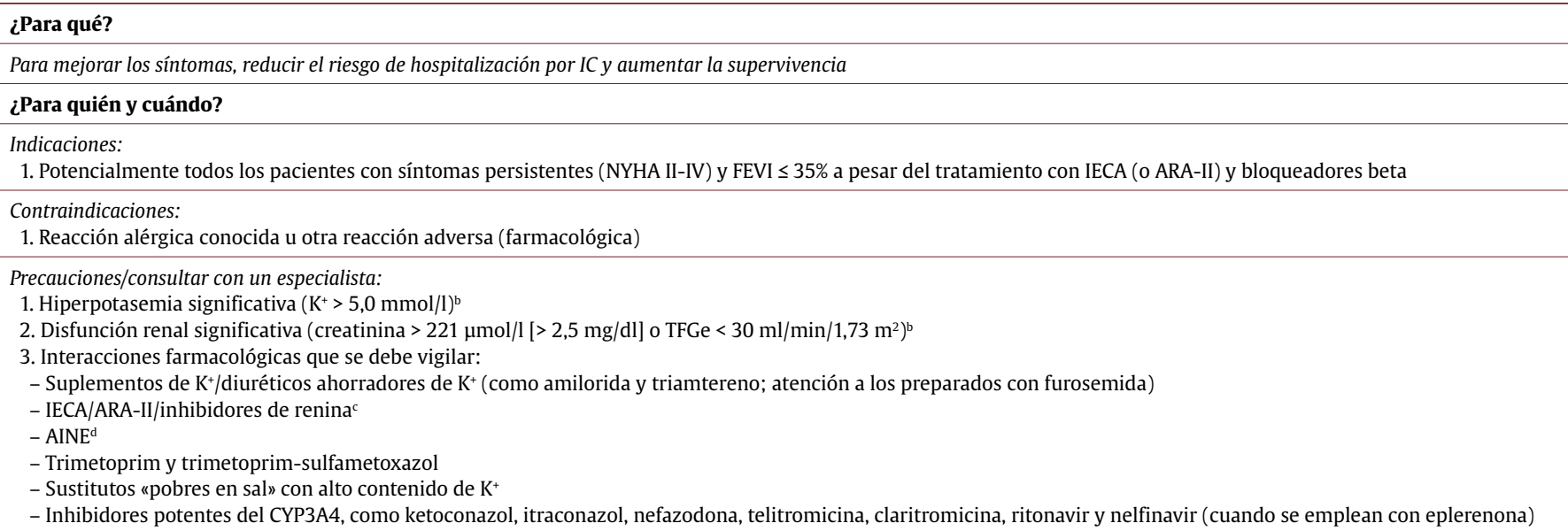

¿Qué ARM y en qué dosis? (véase también la tabla 7.2)

Eplerenona: dosis inicial $25 \mathrm{mg} / 24 \mathrm{~h}$, dosis objetivo $50 \mathrm{mg} / 24 \mathrm{~h}$

Espironolactona: dosis inicial $25 \mathrm{mg} / 24 \mathrm{~h}$, dosis objetivo $50 \mathrm{mg} / 24 \mathrm{~h}$

\section{¿Dónde?}

Atención ambulatoria $u$ hospitalaria

Excepciones: véase "Precauciones/consultar con un especialista"

\section{¿Cómo emplearlos?}

- Comprobar la función renal y electrolitos (especialmente el $K^{+}$)

- Comenzar con dosis bajas (véase más arriba)

- Considere el aumento de la dosis después de 4-8 semanas

- Compruebe la bioquímica sanguínea después de 1 y 4 semanas tras el inicio/incremento de la dosis y a las 8 y 12 semanas; después, cada 4 meses:

- Si el potasio sube a $>5,5 \mathrm{mmol} / \mathrm{l}$ o la creatinina aumenta más del $100 \%$ o hasta $>221 \mu \mathrm{mol} / \mathrm{l}(2,5 \mathrm{mg} / \mathrm{dl}) / \mathrm{TFGe}<30 \mathrm{ml} / \mathrm{min} / 1,73 \mathrm{~m}{ }^{2}$, se debe reducir la dosis a la mitad y monitorizar estrechamente la bioquímica sanguínea

- Si el potasio sube a $>6,0 \mathrm{mmol} / \mathrm{l}$ o la creatinina aumenta a $>310 \mu \mathrm{mol} / \mathrm{l}(3,5 \mathrm{mg} / \mathrm{dl}) / \mathrm{TFGe}<20 \mathrm{ml} / \mathrm{min} / 1,73 \mathrm{~m}^{2}$, se debe interrumpir inmediatamente el ARM y consultar a un especialista

- Personal de enfermería especializado en IC puede asistir en la educación del paciente, el seguimiento (en persona o por teléfono), la monitorización de la bioquímica sanguínea y el aumento de las dosis

\section{Resolución de problemas}

Empeoramiento de la función renal/hiperpotasemia:

- Véase "¿Cómo emplearlos?»

- El mayor problema es la hiperpotasemia (> 6,0 mmol/l); aunque no fue frecuente en los estudios RALES y EMPHASIS-HF, es más frecuente en la práctica clínica

- Por el contrario, el $\mathrm{K}^{+}$alto-normal es conveniente para los pacientes con IC, especialmente si están tratados con digoxina

- Es importante evitar otros fármacos retenedores de $\mathrm{K}^{+}$(diuréticos ahorradores de $\mathrm{K}^{+}$, como amilorida y triamtereno) y fármacos nefrotóxicos (AINE ${ }^{\mathrm{d}}$ )

- El riesgo de hiperpotasemia y disfunción renal cuando se administra un ARM a pacientes en tratamiento con IECA o ARM es mayor que cuando se emplea un ARM con IECA

o ARA-II solos; no se recomienda la combinación triple de IECA, ARA-II y ARM (véase las recomendaciones a continuación)

- Algunos sustitutos "pobres en sal» tienen un alto contenido de $\mathrm{K}^{+}$

- Los varones tratados con espironolactona podrían sufrir malestar pectoral y ginecomastia, aunque no es frecuente (considere el cambio a eplerenona)

\section{Consejos para el paciente}

- Explique al paciente los beneficios que puede esperar (véase "¿Por qué?»):

- El tratamiento mejora los síntomas, previene el empeoramiento de la IC que conlleva hospitalización y mejora la supervivencia

- Los síntomas mejoran transcurridas unas semanas o meses desde el inicio del tratamiento

- Aconseje al paciente que evite tomar AINEd no prescritos por un médico (fármacos sin receta médica) y sustitutos de la sal con alto contenido de $K^{+}$

- En caso de diarrea, vómitos o infección con fiebre y sudoración intensa, el paciente debe conocer el riesgo de deshidratación y trastorno de electrolitos, y consultar al médico o la enfermera

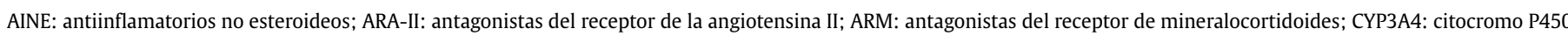

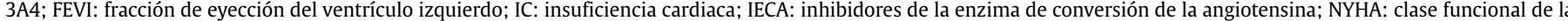
New York Heart Association; TFGe: tasa de filtrado glomerular estimada.

aLas recomendaciones de esta tabla representan la opinión de expertos basada en estudios clínicos importantes (fármacos, aumento y dosis objetivo, monitorización del paciente, beneficios del tratamiento y efectos adversos comunicados) y la experiencia clínica.

bEs muy importante tener en cuenta las precauciones y cumplir con las dosis recomendadas para evitar hiperpotasemia grave.

cLos inhibidores de la renina no están recomendados en la IC.

${ }^{\mathrm{d}}$ Evite los AINE siempre que no sean imprescindibles. 
Tabla 7.7

Guía práctica sobre el uso de diuréticos para pacientes con insuficiencia cardiaca

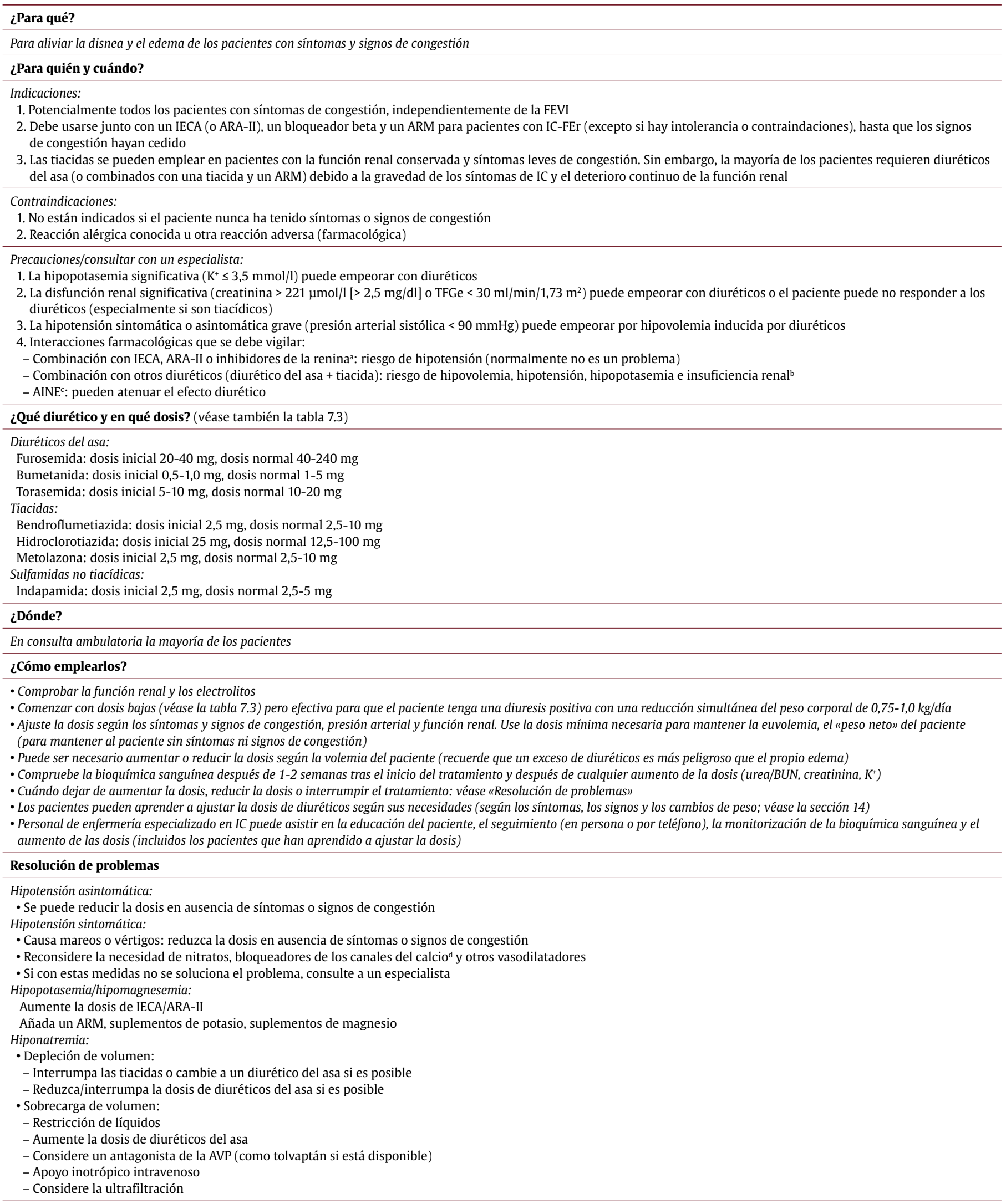


Tabla 7.7

Guía práctica sobre el uso de diuréticos para pacientes con insuficiencia cardiaca (continuación)

\section{Resolución de problemas}

Hiperuricemia/gota:

- Considere la profilaxis con alopurinol

- Para la gota sintomática, use colchicina para aliviar el dolor

- Evite los AINE

Hipovolemia/deshidratación:

- Evalúe la volemia; considere la reducción de la dosis de diuréticos

Respuesta insuficiente/resistencia a los diuréticos:

- Compruebe la adherencia y la ingesta de líquidos

- Aumente la dosis de diuréticos

- Considere cambiar furosemida por bumetadina o torasemida

- Agregue un ARM o aumente la dosis de ARM

- Combine un diurético del asa y tiacida/metolazona ${ }^{\mathrm{b}}$

- Administre un diurético del asa 2 (o más) veces al día o en ayunas

- Considere la infusión intravenosa a corto plazo de un diurético del asa

- Considere la ultrafiltración

Deterioro renal (creatinina/urea-BUN en aumento):

- Compruebe la hipovolemia/deshidratación

- Excluya el uso de otros agentes nefrotóxicos, como AINE o trimetoprim

- Retire el ARM

- En caso de tratamiento concomitante con un diurético del asa y una tiacida, se retira esta

- Considere reducir la dosis de IECA/ARA-II

- Considere la hemofiltración/diálisis

\section{Consejos para el paciente}

- Explique al paciente los beneficios que puede esperar:

- Alivia la disnea y el edema

- Los síntomas mejoran rápidamente, normalmente pocos días después del inicio del tratamiento

- Aconseje al paciente que refiera cualquier efecto adverso importante (p. ej., sed) (que evite el consumo excesivo de bebidas hipotónicas que pueden causar hiponatremia) o mareos/hipotensión sintomática. Véase «Resolución de problemas»

- Aconseje al paciente que evite tomar AINE ${ }^{d}$ no prescritos por un médico (fármacos sin receta médica) porque pueden causar resistencia a los diuréticos y deterioro renal

- El paciente puede aprender a ajustar la dosis según los síntomas, signos y cambios de peso (si se lleva un control de este)

- Podría ser necesario reducir la dosis en caso de pérdida de fluidos (p. ej., debido a diarrea/vómitos, sudoración excesiva)

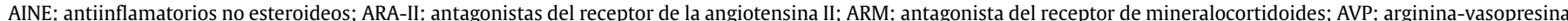

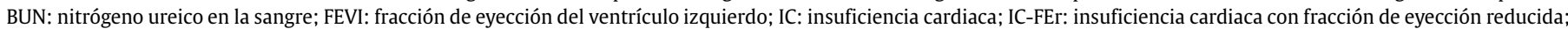
IECA: inhibidores de la enzima de conversión de la angiotensina; TFGe: tasa de filtrado glomerular estimada.

aLos inhibidores de la renina no están recomendados en la IC.

bNormalmente solo son necesarios corto tiempo. Es fundamental la estrecha monitorización de la bioquímica sanguínea.

'Evite los AINE siempre que no sean imprescindibles.

${ }^{d}$ Los bloqueadores de los canales del calcio se deben interrumpir en los pacientes con IC-FEr excepto si son imprescindibles; el diltiazem y el verapamilo son potencialmente perjudiciales para los pacientes con IC-FEr por su acción inotrópica negativa. 
Tabla 7.8

Guía práctica sobre el uso de ivabradina para pacientes con insuficiencia cardiaca y fracción de eyección reducida ${ }^{\mathrm{a}}$

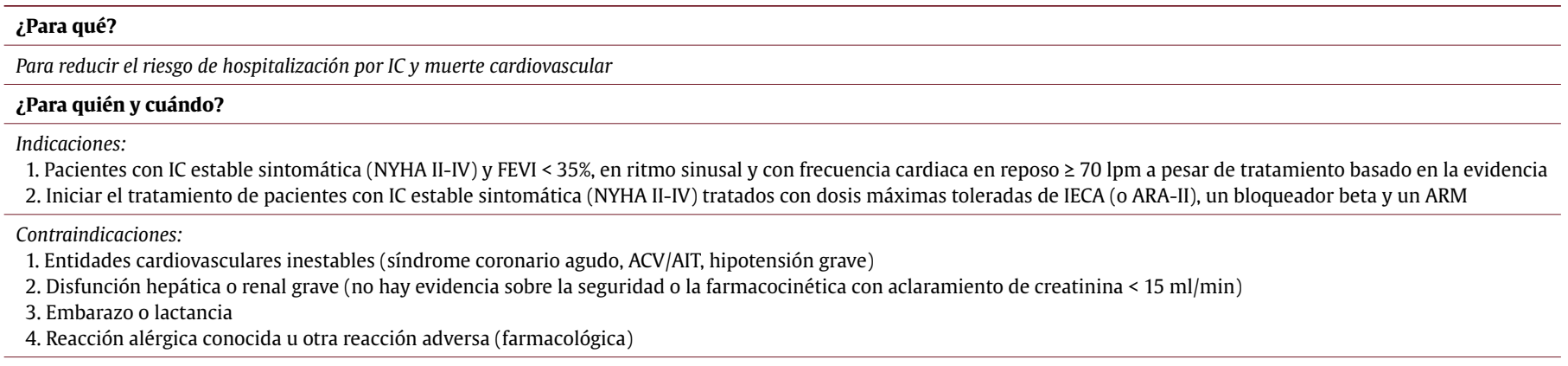

Precauciones/consultar con un especialista:

1. IC grave (NYHA IV)

2. Exacerbación de la IC en curso o reciente (< 4 semanas; p. ej., hospitalización por empeoramiento de la IC).

3. Frecuencia cardiaca $<50 \mathrm{lpm}$ durante el tratamiento

4. Disfunción hepática moderada

5. Retinopatía crónica, incluida la retinitis pigmentosa

6. Interacciones de fármacos:

- Se debe vigilar (debido al riesgo potencial de bradicardia e inducción de QT largo como consecuencia de la bradicardia):

- Verapamilo, diltiazem (se debe interrumpir el tratamiento)

- Bloqueadores beta

- Digoxina

- Amiodaron

- Se debe vigilar (fármacos inhibidores muy potentes de la isoenzima CYP3A4 del citocromo P450:

- Azoles antifúngicos (como ketoconazol, itraconazol)

- Antibióticos macrólidos (como claritromicina, eritromicina)

- Inhibidores de proteasas del VIH (nelfinavir, ritonavir)

- Nefazodona

¿Qué dosis emplear? (véase también la tabla 7.2)

Ivabradina: dosis inicial $5 \mathrm{mg} / 12 \mathrm{~h}$, dosis objetivo $7,5 \mathrm{mg} / 12 \mathrm{~h}$

¿Dónde?

- En consulta ambulatoria los pacientes estables en NYHA II-III

- Los pacientes en NYHA IV o con exacerbación reciente de la IC deben ser referidos a un especialista

- Otras excepciones: véase "Precauciones/consultar con un especialista"

\section{¿Cómo emplearlos?}

- Comience con dosis bajas ( $5 \mathrm{mg} / 12 \mathrm{~h}$ ) (véase la tabla 7.2). Para los pacientes mayores de 75 años, se puede comenzar con una dosis de $2,5 \mathrm{mg} / 12 \mathrm{~h}$

- La dosis diaria se puede aumentar a $7,5 \mathrm{mg} / 12 \mathrm{~h}$, reducir a $2,5 \mathrm{mg} / 12 \mathrm{~h}$ o suprimir dependiendo de la frecuencia cardiaca del paciente en reposo. Duplicar la dosis con un intervalo no inferior a 2 semanas (puede ser necesario un aumento más lento en algunos pacientes). Intentar alcanzar la dosis objetivo (véase arriba) o, si no es posible, la dosis máxima tolerada según la frecuencia cardiaca en reposo. Si esta se encuentra entre 50 y $60 \mathrm{lpm}$, se mantendrá la dosis actual

- Monitorice la frecuencia cardiaca, la presión arterial y el estado clínico

- Cuándo dejar de aumentar la dosis, reducirla o interrumpir el tratamiento: véase «Resolución de problemas»

- Personal de enfermería especializado en IC puede asistir en la educación del paciente, monitorizar la frecuencia cardiaca, realizar el seguimiento (en persona o por teléfono) y aumentar las dosis

\section{Resolución de problemas}

- El tratamiento se deberá reducir o interrumpir si la frecuencia cardiaca en reposo disminuye persistentemente por debajo de 50 lpm o si se presentan síntomas de bradicardia

- Considere la necesidad de emplear otros fármacos reductores de la frecuencia cardiaca o que interfieren con el metabolismo hepático de la ivabradina

- Realice un electrocardiograma para excluir alteraciones del ritmo distintas de la bradicardia sinusal

- Considere posibles causas secundarias de bradiarritmia (p. ej., disfunción tiroidea)

- Si un paciente sufre FA persistente/continua durante el tratamiento con ivabradina, se deberá interrumpirlo

- Los fenómenos visuales normalmente son transitorios, desaparecen durante los primeros meses del tratamiento con ivabradina y no se asocian con retinopatía seria.

No obstante, si genera malestar al paciente, se considerará la interrupción del tratamiento

- En caso de intolerancia a la lactosa o galactosa (componentes del comprimido de ivabradina) y si aparecen síntomas, puede ser necesario suprimir su administración

\section{Consejos para el paciente}

- Explique al paciente los beneficios que puede esperar (véase "¿Para qué?»):

- El tratamiento previene el empeoramiento de la IC que conlleva la hospitalización y reduce el riesgo de muerte cardiovascular

- Para detectar la bradicardia, aconseje a los pacientes que midan y registren el pulso cardiaco regularmente

- Aconseje a los pacientes que refieran al médico o la enfermera los efectos secundarios. Los efectos secundarios debidos a bradicardia sintomática son disnea, fatiga, síncope y mareos; otros efectos secundarios son los trastornos visuales luminosos (fosfenos)

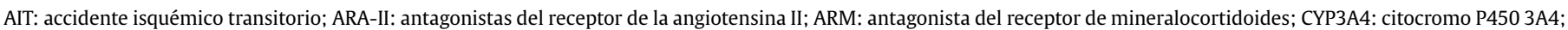

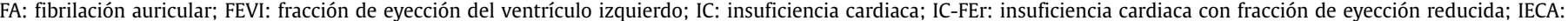

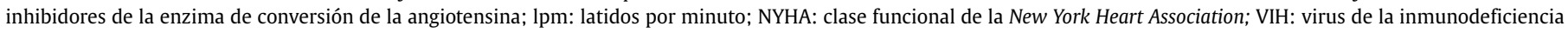
humana.

aLas recomendaciones de esta tabla representan la opinión de expertos basada en estudios clínicos importantes (fármacos, aumento y dosis objetivo, monitorización del paciente, beneficios del tratamiento y efectos adversos comunicados) y la experiencia clínica. 
Tabla 9.1

Estudios clínicos de fase II y III en pacientes con insuficiencia cardiaca con fracción de eyección en rango medio o conservada

\begin{tabular}{|c|c|c|c|c|}
\hline Estudio & Intervención & Criterios de inclusión & Seguimiento medio & Objetivos primarios \\
\hline PEP-CH 320 & $\begin{array}{l}\text { Perindopril frente } \\
\text { a placebo }\end{array}$ & $\begin{array}{l}\text { Índice de motilidad parietal del VI } \geq 1,4 \\
\text { (corresponde a FEVI } \geq 40 \% \text { ), IC sintomática } \\
\text { tratado con diuréticos, disfunción diastólica en } \\
\text { ecocardiografía, edad } \geq 70 \text { años }\end{array}$ & 2,1 años & $\begin{array}{l}\text { Sin diferencias en la variable combinada de } \\
\text { mortalidad por todas las causas u hospitalización } \\
\text { cardiovascular (el } 36 \text { frente al } 37 \%, p=0,35 \text { ) }\end{array}$ \\
\hline I-PRESERVE ${ }^{318}$ & $\begin{array}{l}\text { Irbesartán frente } \\
\text { a placebo }\end{array}$ & $\begin{array}{l}\text { FEVI } \geq 45 \% \text {, NYHA III-IV confirmada o NYHA II } \\
\text { con hospitalización por IC en los últimos } \\
6 \text { meses, edad } \geq 60 \text { años }\end{array}$ & 4,1 años & $\begin{array}{l}\text { Sin diferencias en la variable combinada de } \\
\text { mortalidad por todas las causas u hospitalización } \\
\text { por IC (el } 24 \text { frente al } 25 \% \text { p }=0,54 \text { ) }\end{array}$ \\
\hline $\begin{array}{l}\text { CHARM- } \\
\text { Preserved }^{319}\end{array}$ & $\begin{array}{l}\text { Candesartán frente } \\
\text { a placebo }\end{array}$ & $\begin{array}{l}\text { FEVI }>40 \% \text {, NYHA II-IV, historia de } \\
\text { hospitalización por causas cardiacas }\end{array}$ & 3,0 años & $\begin{array}{l}\text { Tendencia a reducción del } 11 \% \text { en la variable } \\
\text { combinada de mortalidad cardiovascular u } \\
\text { hospitalización por IC (el } 22 \text { frente al } 24 \% ; p=0,12 \\
\text { sin ajustar, } p=0,051 \text { ajustado) }\end{array}$ \\
\hline ALDO-DHF ${ }^{330}$ & $\begin{array}{l}\text { Espironolactona } \\
\text { frente a placebo }\end{array}$ & $\begin{array}{l}\mathrm{FEVI} \geq 50 \% \text {, NYHA II-III, } \mathrm{VO}_{2} \text { pico } \leq 25 \mathrm{ml} / \mathrm{min} / \\
\mathrm{kg} \text {, disfunción diastólica en ecocardiografía o } \\
\text { fibrilación auricular, edad } \geq 50 \text { años }\end{array}$ & 1,0 año & $\begin{array}{l}\text { Reducción de } 1,5 \text { en } E / e^{\prime}(p=0,81) \text {. Sin cambios } \\
\text { en } \mathrm{VO}_{2} \text { pico }(p=0,81)\end{array}$ \\
\hline TOPCAT $^{310}$ & $\begin{array}{l}\text { Espironolactona } \\
\text { frente a placebo }\end{array}$ & $\begin{array}{l}\text { FEVI } \geq 45 \%, \geq 1 \text { signo de IC, } \geq 1 \text { síntoma de IC, } \\
\text { hospitalizción por IC en los últimos } 12 \text { meses o } \\
\text { BNP } \geq 100 \mathrm{pg} / \mathrm{ml} \text { o NT-proBNP } \geq 360 \mathrm{pg} / \mathrm{ml} \text {, edad } \\
\geq 50 \text { años }\end{array}$ & 3,3 años & $\begin{array}{l}\text { Sin diferencias en la variable combinada de } \\
\text { mortalidad cardiovascular, parada cardiaca abortada } \\
\text { u hospitalización por IC (el } 19 \text { frente al } 20 \% ; \mathrm{p}=0,14 \text { ) }\end{array}$ \\
\hline SENIORS ${ }^{173}$ & $\begin{array}{l}\text { Nebivolol frente } \\
\text { a placebo }\end{array}$ & $\begin{array}{l}\text { IC confirmada como ingreso por IC en los últimos } \\
12 \text { meses y/o FEVI } \leq 35 \% \text { en los últimos } 6 \text { meses, } \\
\text { edad } \geq 70 \text { años, el } 36 \% \text { con FEVI > 35\% }\end{array}$ & 1,8 años & $\begin{array}{l}\text { Reducción del } 14 \% \text { en la variable combinada de } \\
\text { mortalidad por todas las causas u hospitalización } \\
\text { cardiovascular (el } 31 \text { frente al } 35 \% ; p=0,04 \text { ) }\end{array}$ \\
\hline DIG-PEF ${ }^{323}$ & $\begin{array}{l}\text { Digoxina frente } \\
\text { a placebo }\end{array}$ & IC con FEVI > 45\%, ritmo sinusal & 3,1 años & $\begin{array}{l}\text { Sin diferencias en la variable combinada de } \\
\text { mortalidad por IC u hospitalización por IC (el } 21 \\
\text { frente al } 24 \% ; \mathrm{p}=0,14 \text { ) }\end{array}$ \\
\hline PARAMOUNT $^{309}$ & $\begin{array}{l}\text { Sacubitrilo/valsartán } \\
\text { frente a valsartán }\end{array}$ & $\begin{array}{l}\text { IC con FEVI } \geq 45 \% \text {, NYHA II-III, NT-proBNP } \\
>400 \mathrm{pg} / \mathrm{ml}\end{array}$ & 12 semanas & $\begin{array}{l}\text { Reducción de NT-proBNP: cociente de cambio } \\
\text { sacubitrilo/valsartán, 0,77 (IC95\%, 0,64-0,92; } \\
\mathrm{p}=0,005 \text { ) }\end{array}$ \\
\hline RELAX $^{311}$ & $\begin{array}{l}\text { Sildenafilo frente } \\
\text { a placebo }\end{array}$ & $\begin{array}{l}\text { IC con FEVI } \geq 45 \% \text {, NYHA II-IV, } \mathrm{VO}_{2} \text { pico }<60 \% \text { de } \\
\text { los valores de referencia, NT-proBNP }>400 \mathrm{pg} / \mathrm{ml} \\
\text { o presiones altas de llenado del VI }\end{array}$ & 24 semanas & Sin cambios en $\mathrm{VO}_{2}$ pico $(\mathrm{p}=0,90)$ \\
\hline
\end{tabular}

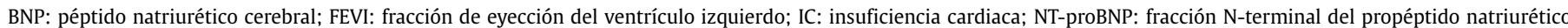
cerebral; NYHA: clase funcional de la New York Heart Association; VI: ventrículo izquierdo; $\mathrm{VO}_{2}$ : consumo de oxígeno.

Tabla 10.1

Valoración del riesgo de ACV en pacientes con fibrilación auricular

\begin{tabular}{lc}
\hline $\mathrm{CHA}_{2} \mathrm{DS}_{2}$ VASC & \\
\hline IC congestiva o disfunción del VI & 1 \\
\hline Hipertensión & 1 \\
\hline Edad $\geq 75$ años & 2 \\
\hline Diabetes mellitus & 1 \\
\hline ACV, AIT o tromboembolia & 2 \\
\hline Enfermedad vascular (infarto de miocardio previo, enfermedad arterial & 1 \\
\hline periférica o placa aórtica) & 1 \\
\hline Edad 65-74 años & 9 \\
\hline Sexo (mujer) & \\
\hline Puntuación máxima & \\
\hline$C H A_{2} D S_{2}$-VASc 0 en varones o 1 en mujeres: sin tratamiento antitrombótico & \\
\hline$C H A_{2} D S_{2}$-VASc 1 en varones o 2 en mujeres: considere anticoagulantes orales & \\
\hline$C H A_{2} D S_{2}$-VASc $\geq 2$ en varones o $\geq 3$ en mujeres: se recomienda anticoagulación oral & \\
\hline
\end{tabular}

ACV: accidente cerebrovascular; AIT: accidente isquémico transitorio; $\mathrm{CHA}_{2} \mathrm{DS}_{2}-\mathrm{VASc}$ : insuficiencia cardiaca congestiva o disfunción ventricular izquierda, hipertensión, edad $\geq 75$ (doble), diabetes, ictus (doble)-enfermedad vascular, edad 65-74 y sexo (mujer); IC: insuficiencia cardiaca; VI: ventrículo izquierdo.
Tabla $\mathbf{1 0 . 2}$

Valoración del riesgo hemorrágico de los pacientes con fibrilación auricular

\begin{tabular}{lc}
\hline HAS-BLED & \\
\hline Hipertensión (presión arterial sistólica > $160 \mathrm{mmHg})$ & 1 \\
\hline Función hepática o renal anormal (1 punto cada una) & 1 o 2 \\
\hline ACV & 1 \\
\hline Predisposición al sangrado & 1 \\
\hline INR lábil (con warfarina) & 1 \\
\hline Edad avanzada (> 65 años) & 1 \\
\hline $\begin{array}{l}\text { Fármacos (p. ej., uso concomitante de ácido acetilsalicílico y AINE) } \\
\text { o consumo excesivo de alcohol (1 punto cada uno) }\end{array}$ & 9 \\
\hline \begin{tabular}{l} 
Puntuación máxima \\
\hline $\begin{array}{l}\text { HAS-BLED } \geq 3 \text { puntos indica que se debe ser cautos cuando se prescriba } \\
\text { anticoagulación oral, revisar regularmente y tratar los factores de riesgo hemorrágico } \\
\text { reversibles }\end{array}$
\end{tabular} \\
\hline
\end{tabular}

ACV: accidente cerebrovascular; INR: razón internacional normalizada; HAS-BLED (hipertensión, función renal/hepática anormal, ictus, historia o predisposición al sangrado, INR lábil, ancianos, drogas/alcohol). 


\section{APÉNDICE}

\section{Comité de la ESC para las guías de práctica clínica (CPG)}

José Luis Zamorano (coordinador) (España), Victor Aboyans (Francia), Stephan Achenbach (Alemania), Stefan Agewall (Noruega), Lina Badimon (España), Gonzalo Barón-Esquivias (España), Helmut Baumgartner (Alemania), Jeroen J. Bax (Países Bajos), Héctor Bueno (España), Scipione Carerj (Italia), Veronica Dean (Francia), Çetin Erol (Turkey), Donna Fitzsimons (Reino Unido), Oliver Gaemperli (Suiza), Paulus Kirchhof (Alemania/Reino Unido), Philippe Kolh (Bélgica), Patrizio Lancellotti (Bélgica), Gregory Y.H. Lip (Reino Unido), Petros Nihoyannopoulos (Reino Unido), Massimo F. Piepoli (Italia), Piotr Ponikowski (Polonia), Marco Roffi (Suiza), Adam Torbicki (Polonia), Antonio Vaz Carneiro (Portugal) y Stephan Windecker (Suiza).

Sociedades nacionales de cardiología de la ESC que han colaborado activamente en el proceso de revisión de la Guía ESC 2016 sobre el diagnóstico y tratamiento de la insuficiencia cardiaca crónica y aguda

Alemania: Sociedad Alemana de Cardiología, Andreas Luchner; Antigua República Yugoslava de Macedonia: Sociedad Macedonia de Cardiología, Elizabeta Srbinovska-Kostovska; Armenia: Asociación Armenia de Cardiólogos, Hamayak S. Sisakian; Azerbaiyán: Sociedad Azerbaiyana de Cardiología, Elnur Isayev; Bélgica: Sociedad Belga de Cardiología, Wilfried Mullens; Bielorrusia: Sociedad Cientifíca Bielorrusa de Cardiólogos, Alena Kurlianskaya; Bulgaria: Sociedad Búlgara de Cardiología, Mariya Tokmakova; Chipre: Sociedad Chipriota de Cardiología, Petros Agathangelou; Dinamarca: Sociedad Danesa de Cardiología, Henrik Wiggers; Egipto: Sociedad Epigcia de Cardiología, Mahmoud Hassanein; Eslovaquia: Sociedad Eslovaca de Cardiología, Eva Goncalvesová; Eslovenia: Sociedad Eslovena de Cardiología, Mitja Lainscak; España: Sociedad Española de Cardiolo- gía, Beatriz Díaz Molina; Estonia: Sociedad Estonia de Cardiología, Tiina Uuetoa; Federación Rusa: Sociedad Rusa de Cardiología, Evgeny Shlyakhto; Finlandia: Sociedad Finlandesa de Cardiología, Jyri Lommi; Francia: Sociedad Francesa de Cardiología, Yves Juillière; Georgia: Sociedad Georgiana de Cardiología, Alexander Aladashvili; Grecia: Sociedad Cardiológica Helena, Christina Chrysohoou; Hungría: Sociedad Húngara de Cardiología, Noémi Nyolczas; Islandia: Sociedad Islandesa de Cardiología, Gestur Thorgeirsson; Israel: Sociedad del Corazón del Israel, Jean Marc Weinstein; Italia: Federación Italiana de Cardiología, Andrea Di Lenarda; Kazajistán: Asociación de Cardiólogos de Kazajstán, Nazipa Aidargaliyeva; Kirguistán: Sociedad de Cardiología de Kirgizistán, Medet Beishenkulov; Kosovo: Sociedad de Cardiología de Kosovo, Gani Bajraktari; Letonia: Sociedad Letona de Cardiología, Ginta Kamzola; Líbano: Sociedad Libanesa de Cardiología, Tony Abdel-Massih; Lituania: Sociedad Lituana de Cardiología, Jelena Čelutkienè; Luxemburgo: Sociedad de Cardiología de Luxemburgo, Stéphanie Noppe; Malta: Sociedad Maltesa de Cardiología, Andrew Cassar; Marruecos: Sociedad Marroquí de Cardiología, Saadia Abir-Khalil; Moldavia: Sociedad Moldava de Cardiología, Eleonora Vataman; Noruega: Sociedad Noruega de Cardiología, Rune Mo; Países Bajos: Sociedad Holandesa de Cardiología, Petra van Pol; Polonia: Sociedad Polaca de Cardiología, Ewa Straburzyńska-Migaj; Portugal: Sociedad Portuguesa de Cardiología, Cândida Fonseca; Reino Unido: Sociedad Cardiovascular Británica, Ceri Davies; República Checa: Sociedad Checa de Cardiología, Vojtech Melenovsky; Rumania: Sociedad Rumana de Cardiología, Ovidiu Chioncel; San Marino: Sociedad de Cardiología de San Marino, Marco Zavatta; Serbia: Sociedad de Cardiología de Serbia, Petar Otasevic; Suecia: Sociedad Sueca de Cardiología, Maria Schaufelberger; Suiza: Sociedad Suiza de Cardiología, Thomas Suter; Turquía: Sociedad Turca de Cardiología, Mehmet Birhan Yılmaz; Ucrania: Asociación Ucraniana de Cardiología, Leonid Voronkov.

El texto CME de la «Guía ESC 2016 sobre el diagnóstico y tratamiento de la insuficiencia cardiaca crónica y aguda» está acreditado por el European Board for Accreditation in

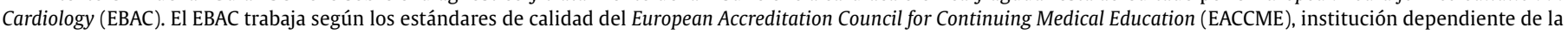

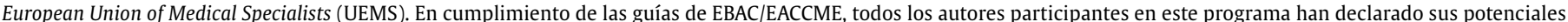

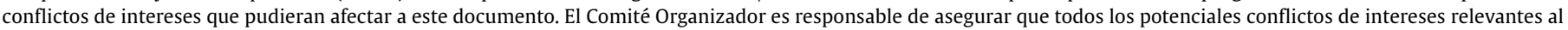
programa sean declarados a los participantes antes de iniciar las actividades CME.

Las preguntas sobre esta CME para este artículo están disponibles en European Heart Journal: http://www.oxforde-learning.com/eurheartj y en la página web de la Sociedad Europea de Cardiología (http://www.escardio.org/guidelines).

\section{BIBLIOGRAFÍA}

1. Filippatos G, Khan SS, Ambrosy AP, Cleland JGF, Collins SP, Lam CSP, Angermann CE, Ertl G, Dahlström U, Hu D, Dickstein K, Perrone S V, Ghadanfar M, Bermann G, Noe A, Schweizer A, Maier T, Gheorghiade M. International REgistry to assess medical Practice with lOngitudinal obseRvation for Treatment of Heart Failure (REPORT-HF): rationale for and design of a global registry. Eur J Heart Fail. 2015;17:527-33.

2. The CONSENSUS Trial Study Group. Effects of enalapril on mortality in severe congestive heart failure. Results of the Cooperative North Scandinavian Enalapril Survival Study (CONSENSUS). N Engl J Med 1987;316:1429-1435.

3. McMurray JJJ V. Improving outcomes in heart failure: a personal perspective. Eur Heart J. 2015;36:3467-70.

4. Wang TJ. Natural history of asymptomatic left ventricular systolic dysfunction in the community. Circulation. 2003;108:977-982.

5. The SOLVD Investigators. Effect of enalapril on mortality and the development of heart failure in asymptomatic patients with reduced left ventricular ejection fractions. N Engl J Med. 1992;327:685-91.

6. Butler J, Fonarow GC, Zile MR, Lam CS, Roessig L, Schelbert EB, Shah SJ, Ahmed A Bonow RO, Cleland JGF, Cody RJ, Chioncel O, Collins SP, Dunnmon P, Filippatos G, Lefkowitz MP, Marti CN, McMurray JJ, Misselwitz F, Nodari S, O'Connor C, Pfeffer MA, Pieske B, Pitt B, Rosano G, Sabbah HN, Senni M, Solomon SD, Stockbridge N, Teerlink JR, Georgiopoulou VV, Gheorghiade M. Developing therapies for heart failure with preserved ejection fraction: current state and future directions. JACC Heart Fail. 2014;2:97-112.

7. McMurray JJ V, Adamopoulos S, Anker SD, Auricchio A, Böhm M, Dickstein K, Falk V, Filippatos G, Fonseca C, Gómez-Sanchez MA, Jaarsma T, Køber L, Lip GYH, Maggioni A Pietro, Parkhomenko A, Pieske BM, Popescu BA, Rønnevik PK, Rutten FH, Schwitter J, Seferovic P, Stepinska J, Trindade PT, Voors AA, Zannad F, Zeiher
A, Bax JJ, Baumgartner H, Ceconi C, Dean V, Deaton C, Fagard R, Funck-Brentano C, Hasdai D, Hoes A, Kirchhof P, Knuuti J, Kolh P, McDonagh T, Moulin C, Reiner Z, Sechtem U, Sirnes PA, Tendera M, Torbicki A, Vahanian A. Windecker S, Bonet LA, Avraamides P, Ben Lamin HA, Brignole M, Coca A, Cowburn P, Dargie H, Elliott P, Flachskampf FA, Guida GF, Hardman S, Iung B, Merkely B, Mueller C, Nanas JN, Nielsen OW, Orn S, Parissis JT, Ponikowski P, Members AF, McMurray JJ V, Adamopoulos S, Anker SD, Auricchio A, Böhm M, Dickstein K, Falk V, Filippatos G, Fonseca C, Gómez-Sanchez MA, Jaarsma T, Køber L, Lip GYH, Maggioni A Pietro, Parkhomenko A, Pieske BM, Popescu BA, Rønnevik PK, Rutten FH, Schwitter J, Seferovic P, Stepinska J, Trindade PT, Voors AA, Zannad F, Zeiher A, Guidelines ESCC for P, Reviewers D. ESC Guidelines for the diagnosis and treatment of acute and chronic heart failure 2012: The Task Force for the Diagnosis and Treatment of Acute and Chronic Heart Failure 2012 of the European Society of Cardiology. Developed in collaboration with the Heart. Eur J Heart Fail. 2012;14:803-69.

8. McMurray JJ V. Clinical practice. Systolic heart failure. N Engl J Med. 2010;3623:228-38.

9. Chen J, Normand SLT, Wang Y, Krumholz HM. National and regional trends in heart failure hospitalization and mortality rates for Medicare beneficiaries, 1998-2008. JAMA. 2011;306:1669-78.

10. Dunlay SM, Redfield MM, Weston SA, Therneau TM, Hall Long K, Shah ND, Roger VL. Hospitalizations after heart failure diagnosis a community perspective. J Am Coll Cardiol. 2009;54:1695-702.

11. Metra M, Ponikowski P, Dickstein K, McMurray JJ V, Gavazzi A, Bergh CH, Fraser AG, Jaarsma T, Pitsis A, Mohacsi P, Böhm M, Anker S, Dargie H, Brutsaert D, Komajda M. Advanced chronic heart failure: a position statement from the Study Group on Advanced Heart Failure of the Heart Failure Association of the European Society of Cardiology. Eur J Heart Fail. 9:684-94.

12. Yancy CW, Jessup M, Bozkurt B, Butler J, Casey DE, Drazner MH, Fonarow GC, Geraci SA, Horwich T, Januzzi JL, Johnson MR, Kasper EK, Levy WC, Masoudi FA, McBride PE, McMurray JJ V, Mitchell JE, Peterson PN, Riegel B, Sam F, Stevenson 
LW, Tang WHW, Tsai EJ, Wilkoff BL. 2013 ACCF/AHA Guideline for the Management of Heart Failure: executive summary: a report of the American College of Cardiology Foundation/American Heart Association Task Force on Practice Guidelines. Circulation. 2013;128:1810-52.

13. Killip T 3rd, Kimball JT. Treatment of myocardial infarction in a coronary care unit. A two year experience with 250 patients. Am J Cardiol. 1967;20:457-64.

14. Mosterd A, Hoes AW. Clinical epidemiology of heart failure. Heart. 2007;93: 1137-46.

15. Redfield MM, Jacobsen SJ, Burnett JC, Mahoney DW, Bailey KR, Rodeheffer RJ. Burden of systolic and diastolic ventricular dysfunction in the community: appreciating the scope of the heart failure epidemic. JAMA. 2003;289:194-202.

16. Bleumink GS, Knetsch AM, Sturkenboom MCJM, Straus SMJM, Hofman A, Deckers JW, Witteman JCM, Stricker BHC. Quantifying the heart failure epidemic: prevalence, incidence rate, lifetime risk and prognosis of heart failure The Rotterdam Study. Eur Heart J England. 2004;25:1614-9.

17. Ceia F, Fonseca C, Mota T, Morais H, Matias F, De Sousa A, Oliveira AG. Prevalence of chronic heart failure in Southwestern Europe: the EPICA study. Eur J Heart Fail. 2002;4:531-9.

18. van Riet EES, Hoes AW, Limburg A, Landman MAJ, van der Hoeven H, Rutten FH. Prevalence of unrecognized heart failure in older persons with shortness of breath on exertion. Eur J Heart Fail. 2014;16:772-7.

19. Filippatos G, Parissis JT. Heart failure diagnosis and prognosis in the elderly: the proof of the pudding is in the eating. Eur J Heart Fail. 2011;13:467-71.

20. Rutten FH, Cramer MJM, Grobbee DE, Sachs APE, Kirkels JH, Lammers JWJ, Hoes AW. Unrecognized heart failure in elderly patients with stable chronic obstructive pulmonary disease. Eur Heart J. 2005;26:1887-94.

21. Boonman-de Winter LJM, Rutten FH, Cramer MJM, Landman MJ, Liem AH, Rutten GEHM, Hoes AW. High prevalence of previously unknown heart failure and left ventricular dysfunction in patients with type 2 diabetes. Diabetologia. 2012;55:2154-62.

22. van Riet EES, Hoes AW,Wagenaar KP, Limburg A, Landman MAJ, Rutten FH. Epidemiology of heart failure: the prevalence of heart failure and ventricular dysfunction in older adults over time. A systematic review. Eur J Heart Fail. 2016.

23. Abhayaratna WP, Smith WT, Becker NG, Marwick TH, Jeffery IM, McGill DA Prevalence of heart failure and systolic ventricular dysfunction in older Australians: the Canberra Heart Study. Med J Aust. 2006;184:151-4.

24. Tiller D, Russ M, Greiser KH, Nuding S, Ebelt H, Kluttig A, Kors JA, Thiery J, Bruegel M, Haerting J, Werdan K. Prevalence of symptomatic heart failure with reduced and with normal ejection fraction in an elderly general population-the CARLA study. PLoS One. 2013;8:e59225.

25. Mureddu GF, Agabiti N, Rizzello V, Forastiere F, Latini R, Cesaroni G, Masson S, Cacciatore G, Colivicchi F, Uguccioni M, Perucci CA, Boccanelli A. Prevalence of preclinical and clinical heart failure in the elderly. A population-based study in Central Italy. Eur J Heart Fail. 2012;14:718-29.

26. Badano LP, Albanese MC, De Biaggio P, Rozbowsky P, Miani D, Fresco C, Fioretti PM. Prevalence, clinical characteristics, quality of life, and prognosis of patients with congestive heart failure and isolated left ventricular diastolic dysfunction. J Am Soc Echocardiogr. 2004;17:253-61.

27. Philbin EF, Rocco TA, Lindenmuth NW, Ulrich K, Jenkins PL. Systolic versus diastolic heart failure in community practice: clinical features, outcomes, and the use of angiotensin-converting enzyme inhibitors. Am J Med. 2000;109:605-13.

28. Magaña-Serrano JA, Almahmeed W, Gómez E, Al-Shamiri M, Adgar D, Sosner P, Herpin D. Prevalence of heart failure with preserved ejection fraction in Latin American, Middle Eastern, and North African Regions in the I PREFER study (Identification of Patients With Heart Failure and PREserved Systolic Function: an epidemiological regional study. Am J Cardiol. 2011;108:1289-96.

29. Peyster E, Norman J, Domanski M. Prevalence and predictors of heart failure with preserved systolic function: community hospital admissions of a racially and gender diverse elderly population. J Card Fail. 2004;10:49-54.

30. Hellermann JP, Jacobsen SJ, Reeder GS, López-Jiménez F, Weston SA, Roger VL. Heart failure after myocardial infarction: prevalence of preserved left ventricular systolic function in the community. Am Heart J. 2003;145:742-8.

31. Gerber Y, Weston SA, Redfield MM, Chamberlain AM, Manemann SM, Jiang R, Killian JM, Roger VL. A contemporary appraisal of the heart failure epidemic in Olmsted County, Minnesota, 2000 to 2010. JAMA Intern Med. 2015;175: 996-1004.

32. Owan TE, Hodge DO, Herges RM, Jacobsen SJ, Roger VL, Redfield MM. Trends in prevalence and outcome of heart failure with preserved ejection fraction. N Engl J Med. 2006;355:251-9.

33. Meta-analysis Global Group in Chronic Heart Failure (MAGGIC). The survival of patients with heart failure with preserved or reduced left ventricular ejection fraction: an individual patient data meta-analysis. Eur Heart J. 2012;33:1750-7.

34. Lam CSP, Solomon SD. The middle child in heart failure: heart failure with midrange ejection fraction (40-50\%). Eur J Heart Fail. 2014;16:1049-55.

35. Maggioni AP, Dahlström U, Filippatos G, Chioncel O, Leiro MC, Drozdz J, Fruhwald F, Gullestad L, Logeart D, Fabbri G, Urso R, Metra M, Parissis J, Persson H, Ponikowski P, Rauchhaus M, Voors AA, Nielsen OW, Zannad F, Tavazzi L, Crespo Leiro M, Drozdz J, Fruhwald F, Gullestad L, Logeart D, Fabbri G, Urso R, Metra M, Parissis J, Persson H, Ponikowski P, Rauchhaus M, Voors AA, Nielsen OW, Zannad F, Tavazzi L. EURObservational Research Programme: regional differences and 1-year follow-up results of the Heart Failure Pilot Survey (ESC-HF Pilot). Eur J Heart Fail. 2013;15:808-17.

36. Pocock SJ, Ariti CA, McMurray JJV, Maggioni A, Køber L, Squire IB, Swedberg K, Dobson J, Poppe KK, Whalley GA, Doughty RN. Predicting survival in heart failure: a risk score based on 39372 patients from 30 studies. Eur Heart J. 2013;34: 1404-13.
37. Rahimi K, Bennett D, Conrad N, Williams TM, Basu J, Dwight J, Woodward M, Patel A, McMurray J, MacMahon S. Risk prediction in patients with heart failure. JACC Heart Fail. 2014;2:440-6.

38. Ouwerkerk W, Voors AA, Zwinderman AH. Factors influencing the predictive power of models for predicting mortality and/or heart-failure hospitalization in patients with heart failure. JACC Heart Fail. 2014;2:429-36.

39. Lupón J, de Antonio M, Vila J, Peñafiel J, Galán A, Zamora E, Urrutia A, Bayes-Genis A. Development of a novel heart failure risk tool: the Barcelona bioheart failure risk calculator (BCN bio-HF calculator). PLoS One. 2014;9:e85466.

40. Levy WC. The Seattle Heart Failure Model: prediction of survival in heart failure. Circulation. 2006;113:1424-33.

41. Mozaffarian D, Anker SD, Anand I, Linker DT, Sullivan MD, Cleland JGF, Carson PE, Maggioni AP, Mann DL, Pitt B, Poole-Wilson PA, Levy WC. Prediction of mode of death in heart failure: the Seattle Heart Failure Model. Circulation. 2007:116:392-8.

42. Davie P, Francis CM, Caruana L, Sutherland GR, McMurray JJ. Assessing diagnosis in heart failure: which features are any use? QJM. 1997;90:335-9.

43. Mant J, Doust J, Roalfe A, Barton P, Cowie MR, Glasziou P, Mant D, McManus RJ, Holder R, Deeks J, Fletcher K, Qume M, Sohanpal S, Sanders S, Hobbs FDR. Systematic review and individual patient data meta-analysis of diagnosis of heart failure, with modelling of implications of different diagnostic strategies in primary care. Health Technol Assess. 2009;13:1-207, iii.

44. Oudejans I, Mosterd A, Bloemen JA, Valk MJ, Van Velzen E, Wielders JP, Zuithoff NP, Rutten FH, Hoes AW. Clinical evaluation of geriatric outpatients with suspected heart failure: value of symptoms, signs, and additional tests. Eur J Heart Fail. 2011;13:518-27.

45. Fonseca C. Diagnosis of heart failure in primary care. Heart Fail Rev. 2006;11: 95-107.

46. Kelder JC, Cramer MJ, van Wijngaarden J, van Tooren R, Mosterd A, Moons KGM Lammers JW, Cowie MR, Grobbee DE, Hoes AW. The diagnostic value of physical examination and additional testing in primary care patients with suspected heart failure. Circulation. 2011:124:2865-73.

47. Boonman-de Winter LJM, Rutten FH, Cramer MJ, Landman MJ, Zuithoff NPA, Liem $\mathrm{AH}$, Hoes AW. Efficiently screening heart failure in patients with type 2 diabetes. Eur J Heart Fail. 2015;17:187-95.

48. Rutten FH, Moons KGM, Cramer MJM, Grobbee DE, Zuithoff NPA, Lammers JWJ, Hoes AW. Recognising heart failure in elderly patients with stable chronic obstructive pulmonary disease in primary care: cross sectional diagnostic study BMJ. 2005;331:1379.

49. HawkinsNM, Petrie MC, Jhund PS, ChalmersGW, Dunn FG, McMurray JJV. Heart failure and chronic obstructive pulmonary disease: diagnostic pitfalls and epidemiology. Eur J Heart Fail. 2009;11:130-9.

50. Daniels LB, Clopton P, Bhalla V, Krishnaswamy P, Nowak RM, McCord J, Hollander JE, Duc P, Omland T, Storrow AB, Abraham WT, Wu AHB, Steg PG, Westheim A, Knudsen CW, Pérez A, Kazanegra R, Herrmann HC, McCullough PA, Maisel AS. How obesity affects the cut-points for B-type natriuretic peptide in the diagnosis of acute heart failure. Results from the Breathing Not Properly Multinational Study. Am Heart J. 2006;151:999-1005.

51. Wong CM, Hawkins NM, Jhund PS, MacDonald MR, Solomon SD, Granger CB, Yusuf S, Pfeffer MA, Swedberg K, Petrie MC, McMurray JJ V. Clinical characteristics and outcomes of young and very young adults with heart failure: the CHARM programme (Candesartan in Heart Failure Assessment of Reduction in Mortality and Morbidity). J Am Coll Cardiol. 2013;62:1845-54.

52. Wong CM, Hawkins NM, Petrie MC, Jhund PS, Gardner RS, Ariti CA, Poppe KK Earle N, Whalley GA, Squire IB, Doughty RN, McMurray JJV. Heart failure in younger patients: the Meta-analysis Global Group in Chronic Heart Failure (MAGGIC). Eur Heart J. 2014;35:2714-21.

53. Thibodeau JT, Turer AT, Gualano SK, Ayers CR, Vélez-Martínez M, Mishkin JD Patel PC, Mammen PPA, Markham DW, Levine BD, Drazner MH. Characterization of a novel symptom of advanced heart failure: bendopnea. JACC Heart Fail. 2014;2:24-31.

54. Roberts E, Ludman AJ, Dworzynski K, Al-Mohammad A, Cowie MR, McMurray JJV, Mant J. The diagnostic accuracy of the natriuretic peptides in heart failure: systematic review and diagnostic meta-analysis in the acute care setting. BMJ. 2015;350:h910.

55. Maisel A, Mueller C, Adams K, Anker SD, Aspromonte N, Cleland JGF, Cohen-Sola A, Dahlstrom U, DeMaria A, DiSomma S, Filippatos GS, Fonarow GC, Jourdain P, Komajda M, Liu PP, McDonagh T, McDonald K, Mebazaa A, Nieminen MS, Peacock WF, Tubaro M, Valle R, Vanderhyden M, Yancy CW, Zannad F, Braunwald E. State of the art: using natriuretic peptide levels in clinical practice. Eur J Heart Fail. 2008;10:824-39.

56. Zaphiriou A, Robb S, Murray-Thomas T, Méndez G, Fox K, McDonagh T, Hardman SMC, Dargie HJ, Cowie MR. The diagnostic accuracy of plasma BNP and NTproBNP in patients referred from primary care with suspected heart failure: results of the UK natriuretic peptide study. Eur J Heart Fail. 2005;7:537-41.

57. Fuat A, Murphy JJ, Hungin APS, Curry J, Mehrzad AA, Hetherington A, Johnston JI Smellie WSA, Duffy V, Cawley P. The diagnostic accuracy and utility of a B-type natriuretic peptide test in a community population of patients with suspected heart failure. Br J Gen Pract. 2006;56:327-33.

58. Yamamoto K, Burnett JC, Bermudez EA, Jougasaki M, Bailey KR, Redfield MM Clinical criteria and biochemical markers for the detection of systolic dysfunction. J Card Fail. 2000;6:194-200.

59. Cowie MR, Struthers AD, Wood DA, Coats AJ, Thompson SG, Poole-Wilson PA Sutton GC. Value of natriuretic peptides in assessment of patients with possible new heart failure in primary care. Lancet. 1997;350:1349-53.

60. Krishnaswamy P, Lubien E, Clopton P, Koon J, Kazanegra R, Wanner E, Gardetto N, García A, DeMaría A, Maisel AS. Utility of B-natriuretic peptide levels in 
identifying patients with left ventricular systolic or diastolic dysfunction. Am J Med. 2001;111:274-9.

61. Kelder JC, Cramer MJ, Verweij WM, Grobbee DE, Hoes AW. Clinical utility of three B-type natriuretic peptide assays for the initial diagnostic assessment of new slow-onset heart failure. J Card Fail. 2011;17:729-34.

62. Madamanchi C, Alhosaini H, Sumida A, Runge MS. Obesity and natriuretic peptides, BNP and NT-proBNP: Mechanisms and diagnostic implications for heart failure. Int J Cardiol. 2014;176:611-7.

63. Davie AP, Francis CM, Love MP, Caruana L, Starkey IR, Shaw TR, Sutherland GR, McMurray JJ. Value of the electrocardiogram in identifying heart failure due to left ventricular systolic dysfunction. BMJ. 1996;312:222.

64. Thomas JT, Kelly RF, Thomas SJ, Stamos TD, Albasha K, Parrillo JE, Calvin JE. Utility of history, physical examination, electrocardiogram, and chest radiograph for differentiating normal from decreased systolic function in patients with heart failure. Am J Med. 2002;112:437-45.

65. Paulus WJ, Tschope C, Sanderson JE, Rusconi C, Flachskampf FA, Rademakers FE, Marino P, Smiseth OA, De Keulenaer G, Leite-Moreira AF, Borbely A, Edes I, Handoko ML, Heymans S, Pezzali N, Pieske B, Dickstein K, Fraser AG, Brutsaert DL How to diagnose diastolic heart failure: a consensus statement on the diagnosis of heart failure with normal left ventricular ejection fraction by the Heart Failure and Echocardiography Associations of the European Society of Cardiology. Eur Heart J. 2007;28:2539-50.

66. Marwick TH, Raman SV, Carrió I, Bax JJ. Recent developments in heart failure imaging. JACC Cardiovasc Imaging. 2010;3:429-39.

67. Dokainish H, Nguyen JS, Bobek J, Goswami R, Lakkis NM. Assessment of the American Society of Echocardiography-European Association of Echocardiography guidelines for diastolic function in patients with depressed ejection fraction: an echocardiographic and invasive haemodynamic study. Eur J Echocardiogr. 2011;12:857-64

68. Kirkpatrick JN, Vannan MA, Narula J, Lang RM. Echocardiography in heart failure: applications, utility, and new horizons. J Am Coll Cardiol. 2007:50:381-96.

69. Nagueh SF, Bhatt R, Vivo RP, Krim SR, Sarvari SI, Russell K, Edvardsen T, Smiseth $\mathrm{OA}$, Estep JD. Echocardiographic evaluation of hemodynamics in patients with decompensated systolic heart failure. Circ Cardiovasc Imaging. 2011;4:220-7.

70. Caballero L, Kou S, Dulgheru R, Gonjilashvili N, Athanassopoulos GD, Barone D, Baroni M, Cardim N, Gómez de Diego JJ, Oliva MJ, Hagendorff A, Hristova K, López T, Magne J, Martínez C, de la Morena G, Popescu BA, Penicka M, Ozyigit T, Rodrigo Carbonero JD, Salustri A, Van De Veire N, Von Bardeleben RS, Vinereanu D, Voigt JU, Zamorano JL, Bernard A, Donal E, Lang RM, Badano LP, Lancellotti P. Echocardiographic reference ranges for normal cardiac Doppler data: results from the NORRE Study. Eur Heart J Cardiovasc Imaging. 2015;16: 1031-41.

71. Garbi M, McDonagh T, Cosyns B, Bucciarelli-Ducci C, Edvardsen T, Kitsiou A, Nieman K, Lancellotti P. Appropriateness criteria for cardiovascular imaging use in heart failure: report of literature review. Eur Heart J Cardiovasc Imaging. 2015;16:147-53.

72. Lang RM, Badano LP, Mor-Avi V, Afilalo J, Armstrong A, Ernande L, Flachskampf FA, Foster E, Goldstein SA, Kuznetsova T, Lancellotti P, Muraru D, Picard MH, Rietzschel ER, Rudski L, Spencer KT, TsangW, Voigt JU. Recommendations for cardiac chamber quantification by echocardiography in adults: an update from the American Society of Echocardiography and the European Association of Cardiovascular Imaging. Eur Heart J Cardiovasc Imaging. 2015;16:233-70.

73. Gimelli A, Lancellotti P, Badano LP, Lombardi M, Gerber B, Plein S, Neglia D, Edvardsen T, Kitsiou A, Scholte AJHA, Schroder S, Cosyns B, Gargiulo P, Zamorano JL, Perrone-Filardi P. Non-invasive cardiac imaging evaluation of patients with chronic systolic heart failure: a report from the European Association of Cardiovascular Imaging (EACVI). Eur Heart J. 2014;35:3417-25.

74. Voigt JU, Pedrizzetti G, Lysyansky P, Marwick TH, Houle H, Baumann R, Pedri S, Ito Y, Abe Y, Metz S, Song JH, Hamilton J, Sengupta PP, Kolias TJ, d'Hooge J, Aurigemma GP, Thomas JD, Badano LP. Definitions for a common standard for 2D speckle tracking echocardiography: consensus document of the EACVI/ASE/ Industry Task Force to standardize deformation imaging. Eur Heart J Cardiovasc Imaging. 2015;16:1-11.

75. Ewald B, Ewald D, Thakkinstian A, Attia J. Meta-analysis of B type natriuretic peptide and $\mathrm{N}$-terminal pro $\mathrm{B}$ natriuretic peptide in the diagnosis of clinical heart failure and population screening for left ventricular systolic dysfunction. Intern Med J. 2008;38:101-13.

76. Doust JA, Glasziou PP, Pietrzak E, Dobson AJ. A systematic review of the diagnostic accuracy of natriuretic peptides for heart failure. Arch Intern Med. 2004;164:1978-84.

77. Gustafsson F, Steensgaard-Hansen F, Badskjaer J, Poulsen AH, Corell P, Hildebrandt $\mathrm{P}$. Diagnostic and prognostic performance of $\mathrm{N}$-terminal ProBNP in primary care patients with suspected heart failure. J Card Fail. 2005;11:S15-S20.

78. NielsenOW, Rasmussen V, Christensen NJ, Hansen JF. Neuroendocrine testing in community patients with heart disease: plasma N-terminal proatrial natriuretic peptide predicts morbidity and mortality stronger than catecholamines and heart rate variability. Scand J Clin Lab Invest. 2004;64:619-28.

79. Kelly JP, Mentz RJ, Mebazaa A, Voors AA, Butler J, Roessig L, Fiuzat M, Zannad F, Pitt B, O'Connor CM, Lam CSP. Patient selection in heart failure with preserved ejection fraction clinical trials. J Am Coll Cardiol. 2015;65:1668-82.

80. Cohen GI, Pietrolungo JF, Thomas JD, Klein AL. A practical guide to assessment of ventricular diastolic function using Doppler echocardiography. J Am Coll Cardiol. 1996;27:1753-60.

81. Gilman G, Nelson TA, Hansen WH, Khandheria BK, Ommen SR. Diastolic function: a sonographer's approach to the essential echocardiographic measurements of left ventricular diastolic function. J Am Soc Echocardiogr. 2007;20:199-209.
82. Nagueh SF, Appleton CP, Gillebert TC, Marino PN, Oh JK, Smiseth OA, Waggoner AD, Flachskampf FA, Pellikka PA, Evangelisa A. Recommendations for the evaluation of left ventricular diastolic function by echocardiography. Eur J Echocardiogr. 2009;10:165-93.

83. Nishimura RA, Appleton CP, RedfieldMM, Ilstrup DM, Holmes DR, Tajik AJ. Noninvasive doppler echocardiographic evaluation of left ventricular filling pressures in patients with cardiomyopathies: a simultaneous Doppler echocardiographic and cardiac catheterization study. J Am Coll Cardiol. 1996;28:1226-33.

84. Ommen SR, Nishimura RA, Appleton CP, Miller FA, Oh JK, Redfield MM, Tajik AJ. Clinical utility of Doppler echocardiography and tissue doppler imaging in the estimation of left ventricular filling pressures: a comparative simultaneous Dopplercatheterization study. Circulation. 2000;102:1788-94.

85. Erdei T, Smiseth OA, Marino P, Fraser AG. A systematic review of diastolic stress tests in heart failure with preserved ejection fraction, with proposals from the EU-FP7 MEDIA study group. Eur J Heart Fail. 2014;16:1345-61.

86. Donal E, Lund LH, Oger E, Reynaud A, Schnell F, Persson H, Drouet E, Linde C, Daubert $\mathrm{C}$, KaRen investigators. Value of exercise echocardiography in heart failure with preserved ejection fraction: a substudy from the KaRen study. Eur Heart J Cardiovasc Imaging. 2016;17:106-13.

87. Borlaug BA, Nishimura RA, Sorajja P, Lam CSP, Redfield MM. Exercise hemodynamics enhance diagnosis of early heart failure with preserved ejection fraction. Circ Heart Fail. 2010;3:588-95.

88. Elliott PM, Anastasakis A, Borger MA, Borggrefe M, Cecchi F, Charron P, Hagege AA, Lafont A, Limongelli G, Mahrholdt H, McKenna WJ, Mogensen J, Nihoyannopoulos P, Nistri S, Pieper PG, Pieske B, Rapezzi C, Rutten FH, Tillmanns C, Watkins H. 2014 ESC Guidelines on diagnosis and management of hypertrophic cardiomyopathy: the Task Force for the Diagnosis and Management of Hypertrophic Cardiomyopathy of the European Society of Cardiology (ESC). Eur Heart J. 2014;35:2733-79.

89. Cosyns B, Plein S, Nihoyanopoulos P, Smiseth O, Achenbach S, Andrade MJ, Pepi M, Ristic A, Imazio M, Paelinck B, Lancellotti P. European Association of Cardiovascular Imaging (EACVI) position paper: multimodality imaging in pericardial disease. Eur Heart J Cardiovasc Imaging. 2015;16:12-31.

90. Caforio ALP, Pankuweit S, Arbustini E, Basso C, Gimeno-Blanes J, Felix SB, Fu M, Helio T, Heymans S, Jahns R, Klingel K, Linhart A, Maisch B, McKenna W, Mogensen J, Pinto YM, Ristic A, Schultheiss H-P, Seggewiss H, Tavazzi L, Thiene G, Yilmaz A, Charron P, Elliott PM. Current state of knowledge on aetiology, diagnosis, management, and therapy of myocarditis: a position statement of the European Society of Cardiology Working Group on Myocardial and Pericardial Diseases. Eur Heart J. 2013;34:2636-48.

91. González JA, Kramer CM. Role of imaging techniques for diagnosis, prognosis and management of heart failure patients: cardiac magnetic resonance. Curr Heart Fail Rep. 2015;12:276-83.

92. Peix A, Mesquita CT, Paez D, Pereira CC, Felix R, Gutierrez C, Jaimovich R, Ianni BM, Soares J, Olaya P, Rodriguez MV, Flotats A, Giubbini R, Travin M, García E V. Nuclear medicine in the management of patients with heart failure: guidance from an expert panel of the International Atomic Energy Agency (IAEA). Nucl Med Commun. 2014;35:818-23.

93. Cooper LT, Baughman KL, Feldman AM, Frustaci A, Jessup M, Kuhl U, Levine GN, Narula J, Starling RC, Towbin J, Virmani R. The role of endomyocardial biopsy in the management of cardiovascular disease: a scientific statement from the American Heart Association, the American College of Cardiology, and the European Society of Cardiology Endorsed by the Heart Failure Society of America and the Heart Failure Association of the European Society of Cardiology. Eur Heart J. 2007;28:3076-93.

94. Charron P, Arad M, Arbustini E, Basso C, Bilinska Z, Elliott P, Helio T, Keren A, McKenna WJ, Monserrat L, Pankuweit S, Perrot A, Rapezzi C, Ristic A, Seggewiss $\mathrm{H}$, Van Langen I, Tavazzi L. Genetic counselling and testing in cardiomyopathies: a position statement of the European Society of Cardiology Working Group on Myocardial and Pericardial Diseases. Eur Heart J. 2010;31:2715-28.

95. Lang RM, Badano LP, Tsang W, Adams DH, Agricola E, Buck T, Faletra FF, Franke A, Hung J, Pérez de Isla L, Kamp O, Kasprzak JD, Lancellotti P, Marwick TH, McCulloch ML, Monaghan MJ, Nihoyannopoulos P, Pandian NG, Pellikka PA, Pepi M, Roberson DA, Shernan SK, Shirali GS, Sugeng L, Ten Cate FJ, Vannan MA, Zamorano JL, Zoghbi WA. EAE/ASE recommendations for image acquisition and display using three-dimensional echocardiography. J Am Soc Echocardiogr. 2012;25:3-46.

96. Rudski LG, Lai WW, Afilalo J, Hua L, Handschumacher MD, Chandrasekaran K, Solomon SD, Louie EK, Schiller NB. Guidelines for the echocardiographic assessment of the right heart in adults: a report from the American Society of Echocardiography. Endorsed by the European Association of Echocardiography, a registered branch of the European Society of Cardiology, and the Canadian Society of Echocardiography. J Am Soc Echocardiogr. 2010;23:685-713.

97. Galie` N, Humbert M, Vachiery JL, Gibbs S, Lang I, Torbicki A, Simonneau G, Peacock A, Vonk Noordegraaf A, Beghetti M, Ghofrani A, Gómez Sanchez MA, Hansmann G, Klepetko W, Lancellotti P, Matucci M, McDonagh T, Pierard LA, Trindade PT, Zompatori M, Hoeper M. 2015 ESC/ERS Guidelines for the diagnosis and treatment of pulmonary hypertension. Eur Heart J. 2015;37:ehv317.

98. Smith BCF, Dobson G, Dawson D, Charalampopoulos A, Grapsa J, Nihoyannopoulos P. Three-dimensional speckle tracking of the right ventricle: toward optimal quantification of right ventricular dysfunction in pulmonary hypertension. J Am Coll Cardiol. 2014;64:41-51.

99. Sicari R, Nihoyannopoulos P, Evangelista A, Kasprzak J, Lancellotti P, Poldermans D, Voigt JU, Zamorano JL. Stress Echocardiography Expert Consensus StatementExecutive Summary: European Association of Echocardiography (EAE) (a registered branch of the ESC). Eur Heart J. 2009;30:278-89. 
100. Garnier F, Eicher JC, Jazayeri S, Bertaux G, Bouchot O, Aho LS, Wolf JE, Laurent G. Usefulness and limitations of contractile reserve evaluation in patients with lowflow, low-gradient aortic stenosis eligible for cardiac resynchronization therapy. Eur J Heart Fail. 2014;16:648-54.

101. Hundley WG, Bluemke DA, Finn JP, Flamm SD, Fogel MA, Friedrich MG, Ho VB, Jerosch-Herold M, Kramer CM, Manning WJ, Patel M, Pohost GM, Stillman AE, White RD, Woodard PK, Harrington RA, Anderson JL, Bates ER, Bridges CR, Eisenberg MJ, Ferrari VA, Grines CL, Hlatky MA, Jacobs AK, Kaul S, Lichtenberg RC, Lindner JR, Moliterno DJ, Mukherjee D, Rosenson RS, Schofield RS, Shubrooks SJ, Stein JH, Tracy CM, Weitz HH, Wesley DJ. ACCF/ACR/AHA/NASCI/SCMR 2010 expert consensus document on cardiovascular magnetic resonance: a report of the american college of cardiology foundation task force on expert consensus documents. Circulation. 2010;121:2462-508.

102. Kilner PJ, Geva T, Kaemmerer H, Trindade PT, Schwitter J, Webb GD. Recommendations for cardiovascular magnetic resonance in adults with congenital heart disease from the respective working groups of the European Society of Cardiology. Eur Heart J. 2010;31:794-805.

103. Moon JC, Messroghli DR, Kellman P, Piechnik SK, Robson MD, Ugander M, Gatehouse PD, Arai AE, Friedrich MG, Neubauer S, Schulz-Menger J, Schelbert EB. Myocardial T1 mapping and extracellular volume quantification: a Society for Cardiovascular Magnetic Resonance (SCMR) and CMR Working Group of the European Society of Cardiology consensus statement. J Cardiovasc Magn Reson. 2013;15:92.

104. Yoshida A, Ishibashi-Ueda $H$, Yamada N, Kanzaki $H$, Hasegawa T, Takahama $H$, Amaki M, Asakura M, Kitakaze M. Direct comparison of the diagnostic capability of cardiac magnetic resonance and endomyocardial biopsy in patients with heart failure. Eur J Heart Fail. 2013;15:166-75.

105. Bonow RO, Castelvecchio S, Panza JA, Berman DS, Velázquez EJ, Michler RE, She L, Holly TA, Desvigne-Nickens P, Kosevic D, Rajda M, Chrzanowski L, Deja M, Lee KL, White H, Oh JK, Doenst T, Hill JA, Rouleau JL, Menicanti L. Severity of remodeling, myocardial viability, and survival in ischemic LV dysfunction after surgical revascularization. JACC Cardiovasc Imaging. 2015;8:1121-9.

106. McDiarmid AK, Loh H, Nikitin N, Cleland JG, Ball SG, Greenwood JP, Plein S, Sparrow P. Predictive power of late gadolinium enhancement for myocardial recovery in chronic ischaemic heart failure: a HEART sub-study. ESC Heart Fail. 2014;1:146-53.

107. Cleland JGF, Calvert M, Freemantle N, Arrow Y, Ball SG, Bonser RS, Chattopadhyay S, Norell MS, Pennell DJ, Senior R. The heart failure revascularisation trial (HEART). Eur J Heart Fail. 2011;13:227-33.

108. Haneder S, Kucharczyk W, Schoenberg SO, Michaely HJ. Safety of magnetic resonance contrast media: a review with special focus on nephrogenic systemic fibrosis. Top Magn Reson Imaging. 2015;24:57-65.

109. Beller GA, Heede RC. SPECT imaging for detecting coronary artery disease and determining prognosis by noninvasive assessment of myocardial perfusion and myocardial viability. J Cardiovasc Transl Res. 2011;4:416-24.

110. González-López E, Gallego-Delgado M, Guzzo-Merello G, de Haro-Del Moral FJ, Cobo-Marcos M, Robles C, Bornstein B, Salas C, Lara-Pezzi E, Alonso-Pulpon L, García-Pavia P. Wild-type transthyretin amyloidosis as a cause of heart failure with preserved ejection fraction. Eur Heart J. 2015;36:2585-94.

111. Beanlands RSB, Nichol G, Huszti E, Humen D, Racine N, Freeman M, Gulenchyn KY, Garrard L, deKemp R, Guo A, Ruddy TD, Benard F, Lamy A, Iwanochko RM. F-18-fluorodeoxyglucose positron emission tomography imaging-assisted management of patients with severe left ventricular dysfunction and suspected coronary disease: a randomized, controlled trial (PARR-2). J Am Coll Cardiol. 2007:50:2002-12.

112. Windecker S, Kolh P, Alfonso F, Collet J-P, Cremer J, Falk V, Filippatos G, Hamm C, Head SJ, Juni P, Kappetein AP, Kastrati A, Knuuti J, Landmesser U, Laufer G, Neumann F-J, Richter DJ, Schauerte P, Sousa Uva M, Stefanini GG, Taggart DP, Torracca L, Valgimigli M, Wijns W. 2014 ESC/EACTS Guidelines on myocardial revascularization: the Task Force on Myocardial Revascularization of the European Society of Cardiology (ESC) and the European Association for CardioThoracic Surgery (EACTS). Developed with the special contribution of the European Association of Percutaneous Cardiovascular Interventions (EAPCI). Eur Heart J. 2014;35:2541-619.

113. Montalescot G, Sechtem U, Achenbach S, Andreotti F, Arden C, Budaj A, Bugiardini R, Crea F, Cuisset T, Di Mario C, Ferreira JR, Gersh BJ, Gitt AK, Hulot J-S, Marx N, Opie LH, Pfisterer M, Prescott E, Ruschitzka F, Sabaté M, Senior R, Taggart DP, van der Wall EE, Vrints CJM, Zamorano JL, Baumgartner H, Bax JJ, Bueno H, Dean V, Deaton C, Erol C, Fagard R, Ferrari R, Hasdai D, Hoes AW, Kirchhof P, Knuuti J, Kolh P, Lancellotti P, Linhart A, Nihoyannopoulos P, Piepoli MF, Ponikowski P, Sirnes PA, Tamargo JL, Tendera M, Torbicki A, Wijns W, Windecker S, Valgimigli M, Claeys MJ, Donner-Banzhoff N, Frank H, Funck-Brentano C, Gaemperli O, GonzálezJuanatey JR, Hamilos M, Husted S, James SK, Kervinen K, Kristensen SD, Maggioni A Pietro, Pries AR, Romeo F, Rydén L, Simoons ML, Steg PG, Timmis A, Yildirir A. 2013 ESC guidelines on the management of stable coronary artery disease. Eur Heart J. 2013;34:2949-3003.

114. Roffi M, Patrono C, Collet J-P, Mueller C, Valgimigli M, Andreotti F, Bax JJ, Borger MA, Brotons C, Chew DP, Gencer B, Hasenfuss G, Kjeldsen K, Lancellotti P, Landmesser U, Mehilli J, Mukherjee D, Storey RF, Windecker S. 2015 ESC Guidelines for the management of acute coronary syndromes in patients presenting without persistent ST-segment elevation. Eur Heart J. 2015; ehv320.

115. Jolicoeur EM, Dunning A, Castelvecchio S, Dabrowski R, Waclawiw MA, Petrie MC, Stewart R, Jhund PS, Desvigne-Nickens P, Panza JA, Bonow RO, Sun B, San TR, AlKhalidi HR, Rouleau JL, Velázquez EJ, Cleland JGF. Importance of angina in patients with coronary disease, heart failure, and left ventricular systolic dysfunction: insights from STICH. J Am Coll Cardiol. 2015;66:2092-100.
116. Allman KC, Shaw LJ, Hachamovitch R, Udelson JE. Myocardial viability testing and impact of revascularization on prognosis in patients with coronary artery disease and left ventricular dysfunction: a meta-analysis. J Am Coll Cardiol. 2002;39: 1151-8.

117. Ling LF, Marwick TH, Flores DR, Jaber WA, Brunken RC, Cerqueira MD, Hachamovitch R. Identification of therapeutic benefit from revascularization in patients with left ventricular systolic dysfunction inducible ischemia versus hibernating myocardium. Circ Cardiovasc Imaging. 2013;6:363-72.

118. Bonow RO, Maurer G, Lee KL, Holly TA, Binkley PF, Desvigne-Nickens P, Drozdz J Farsky PS, Feldman AM, Doenst T, Michler RE, Berman DS, Nicolau JC, Pellikka PA Wrobel K, Alotti N, Asch FM, Favaloro LE, She L, Velázquez EJ, Jones RH, Panza JA. Myocardial viability and survival in ischemic left ventricular dysfunction. N Engl J Med. 2011;364:1617-25.

119. Corra`U, Piepoli MF, Adamopoulos S, Agostoni P, Coats AJS, Conraads V, Lambrinou E, Pieske B, Piotrowicz E, Schmid J-P, Seferovic' PM, Anker SD, Filippatos G, Ponikowski PP. Cardiopulmonary exercise testing in systolic heart failure in 2014: the evolving prognostic role: a position paper from the committee on exercise physiology and training of the heart failure association of the ESC. Eur J Heart Fail. 2014;16:929-41.

120. Piepoli MF, Conraads V, Corra` U, Dickstein K, Francis DP, Jaarsma T, McMurray J, Pieske B, Piotrowicz E, Schmid J-P, Anker SD, Solal AC, Filippatos GS, Hoes AW, Gielen S, Giannuzzi P, Ponikowski PP. Exercise training in heart failure: from theory to practice. A consensus document of the Heart Failure Association and the European Association for Cardiovascular Prevention and Rehabilitation. Eur J Heart Fail. 2011;13:347-57.

121. Volpicelli G, Elbarbary M, Blaivas M, Lichtenstein DA, Mathis G, Kirkpatrick AW, Melniker L, Gargani L, Noble VE, Via G, Dean A, Tsung JW, Soldati G, Copetti R, Bouhemad B, Reissig A, Agricola E, Rouby JJ, Arbelot C, Liteplo A, Sargsyan A, Silva F, Hoppmann R, Breitkreutz R, Seibel A, Neri L, Storti E, Petrovic T. International evidence-based recommendations for point-of-care lung ultrasound. Intensive Care Med. 2012;38:577-91.

122. Roma-Rodrigues C, Fernandes AR. Genetics of hypertrophic cardiomyopathy: advances and pitfalls in molecular diagnosis and therapy. Appl Clin Genet. 2014;7:195-208.

123. McNally EM, Golbus JR, Puckelwartz MJ. Genetic mutations and mechanisms in dilated cardiomyopathy. J Clin Invest. 2013;123:19-26.

124. Priori SG, Wilde AA, Horie M, Cho Y, Behr ER, Berul C, Blom N, Brugada J, Chiang CE, Huikuri H, Kannankeril P, Krahn A, Leenhardt A, Moss A, Schwartz PJ, Shimizu W, Tomaselli G, Tracy C. HRS/EHRA/APHRS expert consensus statement on the diagnosis and management of patients with inherited primary arrhythmia syndromes: document endorsed by HRS, EHRA, and APHRS in May 2013 and by ACCF, AHA, PACES, and AEPC in June 2013. Heart Rhythm. 2013;10:1932-63.

125. Arbustini E, Narula N, Tavazzi L, Serio A, Grasso M, Favalli V, Bellazzi R, Tajik JA, Bonow RD, Fuster V, Narula J. The MOGE(S) classification of cardiomyopathy for clinicians. J Am Coll Cardiol. 2014;64:304-18.

126. Kostis JB, Davis BR, Cutler J, Grimm RH, Berge KG, Cohen JD, Lacy CR, Perry HM, Blaufox MD, Wassertheil-Smoller S, Black HR, Schron E, Berkson DM, Curb JD, Smith WM, McDonald R, Applegate WB, SHEP Cooperative Research Group. Prevention of heart failure by antihypertensive drug treatment in older persons with isolated systolic hypertension. JAMA. 1997;278:212-6.

127. Beckett NS, Peters R, Fletcher AE, Staessen JA, Liu L, Dumitrascu D, Stoyanovsky V, Antikainen RL, Nikitin Y, Anderson C, Belhani A, Forette F, Rajkumar C, Thijs L, Banya W, Bulpitt CJ. Treatment of hypertension in patients 80 years of age or older. N Engl J Med. 2008;358:1887-98.

128. Sciarretta S, Palano F, Tocci G, Baldini R, Volpe M. Antihypertensive treatment and development of heart failure in hypertension. Arch Intern Med. 2011;171: 384-94.

129. Wright JT, Williamson JD, Whelton PK, Snyder JK, Sink KM, Rocco M V, Reboussin DM, Rahman M, Oparil S, Lewis CE, Kimmel PL, Johnson KC, Goff DC, Fine LJ, Cutler JA, Cushman WC, Cheung AK, Ambrosius WT, SPRINT Research Group. A randomized trial of intensive versus standard blood-pressure control. N Engl J Med. 2015;373:2103-16.

130. Zinman B, Wanner C, Lachin JM, Fitchett D, Bluhmki E, Hantel S, Mattheus M, Devins T, Johansen OE, Woerle HJ, Broedl UC, Inzucchi SE, EMPA-REG OUTCOME Investigators. Empagliflozin, cardiovascular outcomes, and mortality in type 2 diabetes. N Engl J Med. 2015;373:2117-28.

131. Suskin N, Sheth T, Negassa A, Yusuf S. Relationship of current and past smoking to mortality and morbidity in patients with left ventricular dysfunction. J Am Coll Cardiol. 2001;37:1677-82.

132. Dorans KS, Mostofsky E, Levitan EB, Hakansson N,Wolk A, Mittleman MA. Alcohol and incident heart failure among middle-aged and elderly men: the cohort of Swedish men. Circ Heart Fail. 2015;8:422-7.

133. Goncalves A, Claggett B, Jhund PS, RosamondW, Deswal A, Aguilar D, Shah AM, Cheng S, Solomon SD. Alcohol consumption and risk of heart failure: the Atherosclerosis Risk in Communities Study. Eur Heart J. 2015;36:939-45.

134. Larsson SC, Orsini N, Wolk A. Alcohol consumption and risk of heart failure: a dose-response meta-analysis of prospective studies. Eur J Heart Fail. 2015; 17: 367-73.

135. Pandey A, Garg S, Khunger M, Darden D, Ayers C, Kumbhani DJ, Mayo HG, de Lemos JA, Berry JD. Dose-response relationship between physical activity and risk of heart failure: a meta-analysis. Circulation. 2015;132:1786-94.

136. Ledwidge M, Gallagher J, Conlon C, Tallon E, O'Connell E, Dawkins I,Watson C, O'Hanlon R, Bermingham M, Patle A, Badabhagni MR, Murtagh G, Voon V, Tilson L, Barry M, McDonald L, Maurer B, McDonald K. Natriuretic peptide-based screening and collaborative care for heart failure: the STOP-HF randomized trial. JAMA. 2013;310:66-74. 
137. Scirica BM, Morrow DA, Cannon CP, Ray KK, Sabatine MS, Jarolim P, Shui A, McCabe $\mathrm{CH}$, Braunwald E. Intensive statin therapy and the risk of hospitalization for heart failure after an acute coronary syndrome in the PROVE IT-TIMI 22 study. J Am Coll Cardiol. 2006;47:2326-31.

138. Afilalo J, Majdan AA, Eisenberg MJ. Intensive statin therapy in acute coronary syndromes and stable coronary heart disease: a comparative meta-analysis of randomised controlled trials. Heart. 2007;93:914-21.

139. Kjekshus J, Pedersen TR, Olsson AG, Faergeman O, Pyörälä K. The effects of simvastatin on the incidence of heart failure in patients with coronary heart disease. J Card Fail. 1997;3:249-54.

140. Protection H, Collaborative S, Emberson JR, Ng LL, Armitage J, Bowman L, Parish $\mathrm{S}$, Collins R. N-terminal pro-B-type natriuretic peptide, vascular disease risk, and cholesterol reduction among 20,536 patients in the MRC/BHF Heart Protection Study. J Am Coll Cardiol. 2007;49:311-9.

141. Kenchaiah S, Evans JC, Levy D, Wilson PWF, Benjamin EJ, Larson MG, Kannel WB Vasan RS. Obesity and the risk of heart failure. N Engl J Med. 2002;347:305-13.

142. Dagenais GR, Pogue J, Fox K, Simoons ML, Yusuf S. Angiotensin-convertingenzyme inhibitors in stable vascular disease without left ventricular systolic dysfunction or heart failure: a combined analysis of three trials. Lancet. 2006;368:581-8.

143. Huelsmann M, Neuhold S, Resl M, Strunk G, Brath H, Francesconi C, Adlbrecht C, Prager R, Luger A, Pacher R, Clodi M. PONTIAC (NT-proBNP selected prevention of cardiac events in a population of diabetic patients without a history of cardiac disease): a prospective randomized controlled trial. J Am Coll Cardiol. 2013;62:1365-72.

144. Jong P, Yusuf S, Rousseau MF, Ahn SA, Bangdiwala SI. Effect of enalapril on 12year survival and life expectancy in patients with left ventricular systolic dysfunction: a follow-up study. Lancet. 2003;361:1843-8.

145. Pfeffer MA, Braunwald E, Moyé LA, Basta L, Brown EJ, Cuddy TE, Davis BR Geltman EM, Goldman S, Flaker GC, Klein M, Lamas GA, Packer M, Rouleau JLJ, Rouleau JLJ, Rutherford J,Wertheimer JH, Hawkins CM. Effect of captopril on mortality and morbidity in patients with left ventricular dysfunction after myocardial infarction. N Engl J Med. 1992;327:669-77.

146. Dargie HJ. Effect of carvedilol on outcome after myocardial infarction in patients with left-ventricular dysfunction: the CAPRICORN randomised trial. Lancet. 2001;357:1385-90.

147. Montalescot G, Pitt B, López de Sa E, Hamm CW, Flather M, Verheugt F, Shi H, Turgonyi E, Orri M, Vincent J, Zannad F, Noll G, Weir R, O'Neill B, Bohm M, Hillis WS, Grieve A, Rouleau J-L, Gerasimos F, Fitchett D, Lepage S, Madan M, Sussex B Tremblay G, Welsh R, Wong G, Hutyra M, Kettner J, Ostadal P, Spinar J, Vojacek J, Barboteu M, Collet J-P, Coste P, Cottin Y, Ducos D, Galinier M, Teiger E, Zemour G, Bauersachs J, Hambrecht R, Hauf G, Heuer H, Mudra H, Munzel T, Steiner S, Strasser R, Sydow K, Tschope C, Wachter R, Werner N, Alexopoulos D, Babalis D, Pyrgakis V, Dezsi C, Lupkovics G, Polgar P, Tomcsanyi J, Herrman J, ten Berg JM, Gorny J, Kubica J, Lewczuk J, Zmuda W, Hranai M, Kovar F, Margoczy R, Micko K, Sumbal J, Genover XB, Ortiz AF, Sala MF, García CG, Munoz CP, Rey Blas JR, Soriano FR, Adamson D, Alamgir F, Chauhan A, Lip G, Martin T, McCann G, Newby D, Smith D. Early eplerenone treatment in patients with acute ST-elevation myocardial infarction without heart failure: the Randomized Double-Blind Reminder Study. Eur Heart J. 2014;35:2295-302.

148. Pitt B, RemmeW, Zannad F, Neaton J, Martínez F, Roniker B, Bittman R, Hurley S, Kleiman J, Gatlin M. Eplerenone, a selective aldosterone blocker, in patients with left ventricular dysfunction after myocardial infarction. $N$ Engl J Med. 2003;348:1309-21.

149. Moss AJ, Zareba W, Hall WJ, Klein H, Wilber DJ, Cannom DS, Daubert JP, Higgin SL, BrownMW, Andrews ML. Prophylactic implantation of a defibrillator in patients with myocardial infarction and reduced ejection fraction. $\mathrm{N}$ Engl J Med. 2002;346:877-83

150. Beckett NS, Peters R, Fletcher AE, Staessen JA, Liu L, Dumitrascu D, Stoyanovsky V, Antikainen RL, Nikitin Y, Anderson C, Belhani A, Forette F, Rajkumar C, Thijs L, Banya W, Bulpitt CJ. Treatment of hypertension in patients 80 years of age or older. N Engl J Med. 2008;358:1887-98.

151. Sciarretta S, Palano F, Tocci G, Baldini R, Volpe M. Antihypertensive treatment and development of heart failure in hypertension: a Bayesian network meta-analysis of studies in patients with hypertension and high cardiovascular risk. Arch Intern Med. 2011:171:384-94

152. Preiss D, Campbell RT, Murray HM, Ford I, Packard CJ, Sattar N, Rahimi K, Colhoun HM, Waters DD, LaRosa JC, Amarenco P, Pedersen TR, Tikkanen MJ, Koren M] Poulter NR, Sever PS, Ridker PM, MacFadyen JG, Solomon SD, Davis BR, Simpson LM, Nakamura H, Mizuno K, Marfisi RM, Marchioli R, Tognoni G, Athyros VG, Ray KK, Gotto AM, Clearfield MB, Downs JR, McMurray JJ. The effect of statin therapy on heart failure events: a collaborative meta-analysis of unpublished data from major randomized trials. Eur Heart J. 2015;36:1536-46.

153. Udell JA, Cavender MA, Bhatt DL, Chatterjee S, Farkouh ME, Scirica BM. Glucoselowering drugs or strategies and cardiovascular outcomes in patient with or at risk for type 2 diabetes: a meta-analysis of randomised controlled trials. Lancet Diabetes Endocrinol. 2015;3:356-66.

154. Padwal R, McAlister F a, McMurray JJ V, Cowie MR, Rich M, Pocock S, Swedberg K, Maggioni A, Gamble G, Ariti C, Earle N, Whalley G, Poppe KK, Doughty RN, Bayes-Genis A. The obesity paradox in heart failure patients with preserved versus reduced ejection fraction: a meta-analysis of individual patient data. Int J Obes. 2014;38:1110-4.

155. Held C, Gerstein HC, Yusuf S, Zhao F, Hilbrich L, Anderson C, Sleight P, Teo K, ONTARGET/TRANSCEND Investigators. Glucose levels predict hospitalization for congestive heart failure in patients at high cardiovascular risk. Circulation. 2007; $115: 1371-5$.
156. Desai AS, Fang JC, Maisel WH, Baughman KL. Implantable defibrillators for the prevention of mortality in patients with nonischemic cardiomyopathy: a metaanalysis of randomized controlled trials. JAMA. 2004;292:2874-9.

157. Kadish A, Dyer A, Daubert JP, Quigg R, Estes NAM, Anderson KP, Calkins H, Hoch D, Goldberger J, Shalaby A, Sanders WE, Schaechter A, Levine JH, Defibrillators in Non-Ischemic Cardiomyopathy Treatment Evaluation (DEFINITE) Investigators. Prophylactic defibrillator implantation in patients with nonischemic dilated cardiomyopathy. N Engl J Med. 2004;350:2151-8.

158. Hohnloser SH, Kuck KH, Dorian P, Roberts RS, Hampton JR, Hatala R, Fain E, Gent $\mathrm{M}$, Connolly SJ. Prophylactic use of an implantable cardioverter-defibrillator after acute myocardial infarction. N Engl J Med. 2004;351:2481-8.

159. Stewart S, Jenkins A, Buchan S, McGuire A, Capewell S, McMurray JJJV. The current cost of heart failure to the National Health Service in the UK. Eur J Heart Fail. 2002;4:361-71.

160. Gheorghiade M, Shah AN, Vaduganathan M, Butler J, Bonow RO, Rosano GMC, Taylor S, Kupfer S, Misselwitz F, Sharma A, Fonarow GC. Recognizing hospitalized heart failure as an entity and developing new therapies to improve outcomes: academics', clinicians', industry's, regulators', and payers' perspectives. Heart Fail Clin. 2013;9:285-90, v-vi.

161. Ambrosy AP, Fonarow GC, Butler J, Chioncel O, Greene SJ, Vaduganathan M, Nodari S, Lam CSP, Sato N, Shah AN, Gheorghiade M. The global health and economic burden of hospitalizations for heart failure. J Am Coll Cardiol. 2014;63:1123-33.

162. McMurray JJ, Packer M, Desai AS, Gong J, Lefkowitz MP, Rizkala AR, Rouleau JL, Shi VC, Solomon SD, Swedberg K, Zile MR, PARADIGM-HF Investigators and Committees. Angiotensin-neprilysin inhibition versus enalapril in heart failure. N Engl J Med. 2014;371:993-1004.

163. Garg R, Yusuf S. Overview of randomized trials of angiotensin-converting enzyme inhibitors on mortality and morbidity in patients with heart failure. JAMA. 1995;273:1450-6.

164. Packer M, Poole-Wilson PA, Armstrong PW, Cleland JGF, Horowitz JD, Massie BM, Ryden L, Thygesen K, Uretsky BF, Rydén L, Thygesen K, Uretsky BF, ATLAS Study Group. Comparative effects of low and high doses of the angiotensin-converting enzyme inhibitor, lisinopril, on morbidity and mortality in chronic heart failure. Circulation. 1999;100:2312-8.

165. SOLVD Investigattors. Effect of enalapril on survival in patients with reduced left ventricular ejection fractions and congestive heart failure. $\mathrm{N}$ Engl J Med. 1991;325:293-302.

166. Maggioni AP, Anker SD, Dahlström U, Filippatos G, Ponikowski P, Zannad F, Amir O, Chioncel O, Leiro MC, Drozdz J, Erglis A, Fazlibegovic E, Fonseca C, Fruhwald F, Gatzov P, Goncalvesova E, Hassanein M, Hradec J, Kavoliuniene A, Lainscak M, Logeart D, Merkely B, Metra M, Persson H, Seferovic P, Temizhan A, Tousoulis D, Tavazzi L. Are hospitalized or ambulatory patients with heart failure treated in accordance with European Society of Cardiology guidelines? Evidence from 12 440 patients of the ESC Heart Failure Long-Term Registry. Eur J Heart Fail. 2013; $15: 1173-84$

167. Hjalmarson A, Goldstein S, Fagerberg B, Wedel H, Waagstein F, Kjekshus J, Wikstrand J, ElAllaf D, Vítovec J, Aldershvile J, Halinen M, Dietz R, Neuhaus KL, Jánosi A, Thorgeirsson G, Dunselman PH, Gullestad L, Kuch J, Herlitz J, Rickenbacher P, Ball S, Gottlieb S, Deedwania P. MERIT-HF Study Group. Effects of controlled-release metoprolol on total mortality, hospitalizations, and wellbeing in patients with heart failure: the Metoprolol CR/XL Randomized Intervention Trial in congestive Heart Failure (MERIT-HF). JAMA. 2000;283:1295-302.

168. Packer M, Coats AJ, Fowler MB, Katus HA, Krum H, Mohacsi P, Rouleau JL, Tendera M, Castaigne A, Roecker EB, Schultz MK, DeMets DL. Effect of carvedilol on survival in severe chronic heart failure. N Engl J Med. 2001;344:1651-8.

169. Packer M, Bristow MR, Cohn JN, Colucci WS, Fowler MB, Gilbert EM, Shusterman $\mathrm{NH}$. The effect of carvedilol on morbidity and mortality in patients with chronic heart failure. N Engl J Med. 1996;334:1349-55.

170. Effect of metoprolol CR/XL in chronic heart failure: Metoprolol CR/XL Randomised Intervention Trial in Congestive Heart Failure (MERIT-HF). Lancet. 1999;353:2001-7.

171. Packer M. Effect of carvedilol on the morbidity of patients with severe chronic heart failure: results of the Carvedilol Prospective Randomized Cumulative Survival (COPERNICUS) Study. Circulation. 2002;106:2194-9.

172. CIBIS-II Investigators and Committees. The Cardiac Insufficiency Bisoprolol Study II (CIBIS-II): a randomised trial. Lancet. 1999;353:9-13.

173. Flather MD, Shibata MC, Coats AJS, Van Veldhuisen DJ, Parkhomenko A, Borbola J, Cohen-Solal A, Dumitrascu D, Ferrari R, Lechat P, Soler-Soler J, Tavazzi L, Spinarova L, Toman J, Böhm M, Anker SD, Thompson SG, Poole-Wilson PA, SENIORS Investigators. Randomized trial to determine the effect of nebivolol on mortality and cardiovascular hospital admission in elderly patients with heart failure (SENIORS). Eur Heart J. 2005;26:215-25.

174. Pitt B, Zannad F, Remme WJ, Cody R, Castaigne A, Pérez A, Palensky J, Wittes J. The effect of spironolactone on morbidity and mortality in patients with severe heart failure. N Engl J Med. 1999;341:709-17.

175. Zannad F, McMurray JJV, Krum H, Van Veldhuisen DJ, Swedberg K, Shi H, Vincent J, Pocock SJ, Pitt B. Eplerenone in patients with systolic heart failure and mild symptoms. N Engl J Med. 2011;364:11-21.

176. Willenheimer $\mathrm{R}$, van Veldhuisen DJ, Silke B, Erdmann E, Follath F, Krum $\mathrm{H}$, Ponikowski P, Skene A, van de Ven L, Verkenne P, Lechat P, CIBIS III Investigators. Effect on survival and hospitalization of initiating treatment for chronic heart failure with bisoprolol followed by enalapril, as compared with the opposite sequence: results of the randomized Cardiac Insufficiency Bisoprolol Study (CIBIS) III. Circulation. 2005;112:2426-35.

177. Kotecha D, Holmes J, Krum H, Altman DG, Manzano L, Cleland JGF, Lip GYH, Coats AJS, Andersson B, Kirchhof P, von Lueder TG, Wedel H, Rosano G, Shibata MC, 
Rigby A, Flather MD. Efficacy of b blockers in patients with heart failure plus atrial fibrillation: an individual-patient data meta-analysis. Lancet. 2014;384: 2235-43.

178. Faris RF, Flather M, Purcell H, Poole-Wilson PA, Coats AJ. Diuretics for heart failure. Cochrane Database Syst Rev. 2012;2:CD003838.

179. Faris R, Flather M, Purcell H, Henein M, Poole-Wilson P, Coats A. Current evidence supporting the role of diuretics in heart failure: a meta analysis of randomised controlled trials. Int J Cardiol. 2002;82:149-58.

180. Swedberg K, Komajda M, Böhm M, Borer JS, Ford I, Dubost-Brama A, Lerebours G, Tavazzi L. Ivabradine and outcomes in chronic heart failure (SHIFT): a randomised placebo-controlled study. Lancet. 2010;376:875-85.

181. Swedberg K, Komajda M, Böhm M, Borer J, Robertson M, Tavazzi L, Ford I. Effects on outcomes of heart rate reduction by ivabradine in patients with congestive heart failure: is there an influence of beta-blocker dose?: findings from the SHIFT (Systolic Heart failure treatment with the I(f) inhibitor ivabradine Trial) study. J Am Coll Cardiol. 2012;59:1938-45.

182. Granger CB, McMurray JJV, Yusuf S, Held P, Michelson EL, Olofsson B, Ostergren J, Pfeffer MA, Swedberg K. Effects of candesartan in patients with chronic heart failure and reduced left-ventricular systolic function intolerant to angiotensinconverting-enzyme inhibitors: the CHARM-Alternative trial. Lancet. 2003;362: 772-6.

183. Taylor AL, Ziesche S, Yancy C, Carson P, D’Agostino R, Ferdinand K, Taylor M, Adams K, Sabolinski M,Worcel M, Cohn JN. Combination of isosorbide dinitrate and hydralazine in blacks with heart failure. N Engl J Med. 2004:351:2049-57.

184. Cohn JN, Archibald DG, Ziesche S, Franciosa JA, Harston WE, Tristani FE, Dunkman WB, Jacobs W, Francis GS, Flohr KH, Goldman S, Cobb FR, Shah PM, Saunders R, Fletcher RD, Loeb HS, Hughes VC, Baker B. Effect of vasodilator therapy on mortality in chronic congestive heart failure. N Engl J Med. 1986;314:1547-52.

185. Digitalis Investigation Group. The effect of digoxin on mortality and morbidity in patients with heart failure. N Engl J Med. 1997;336:525-33.

186. Tavazzi L, Maggioni AP, Marchioli R, Barlera S, Franzosi MG, Latini R, Lucci D, Nicolosi GL, Porcu M, Tognoni G. Effect of n-3 polyunsaturated fatty acids in patients with chronic heart failure (the GISSI-HF trial): a randomised, doubleblind, placebo-controlled trial. Lancet. 2008;372:1223-30.

187. King JB, Bress AP, Reese AD, Munger MA. Neprilysin inhibition in heart failure with reduced ejection fraction: a clinical review. Pharmacother J Hum Pharmacol Drug Ther. 2015;35:823-37.

188. Mangiafico S, Costello-Boerrigter LC, Andersen IA, Cataliotti A, Burnett JC. Neutral endopeptidase inhibition and the natriuretic peptide system: an evolving strategy in cardiovascular therapeutics. Eur Heart J. 2013;34:886-93.

189. Vodovar N, Paquet C, Mebazaa A, Launay JM, Hugon J, Cohen-Solal A. Neprilysin, cardiovascular, and Alzheimer's diseases: the therapeutic split? Eur Heart J. 2015;36:902-5

190. Yasojima K, McGeer EG, McGeer PL. Relationship between beta amyloid peptide generating molecules and neprilysin in Alzheimer disease and normal brain Brain Res. 2001;919:115-21.

191. Vepsalainen S, Helisalmi S, Mannermaa A, Pirttila T, Soininen H, Hiltunen M. Combined risk effects of IDE and NEP gene variants on Alzheimer disease. J Neurol Neurosurg Psychiatry. 2009;80:1268-70.

192. Langenickel TH, Tsubouchi C, Ayalasomayajula S, Pal P, Valentin M-A, Hinder M, Jhee S, Gevorkyan H, Rajman I. The effect of LCZ696 on amyloid-b concentrations in cerebrospinal fluid in healthy subjects. Br J Clin Pharmacol 2015 Dec 12. doi:10.1111/bcp.12861 [Epub ahead of print]

193. Böhm M, Borer J, Ford I, González-Juanatey JR, Komajda M, López-Sendon J, Reil JC, Swedberg K, Tavazzi L. Heart rate at baseline influences the effect of ivabradine on cardiovascular outcomes in chronic heart failure: analysis from the SHIFT study. Clin Res Cardiol. 2013;102:11-22.

194. Cohn JN, Tognoni G. A randomized trial of the angiotensin-receptor blocker valsartan in chronic heart failure. N Engl J Med. 2001;345:1667-75.

195. Ouyang AJ, Lv YN, Zhong HL,Wen JH,Wei XH, Peng HW, Zhou J, Liu LL. Metaanalysis of digoxin use and risk of mortality in patients with atrial fibrillation. Am J Cardiol. 2015;115:901-6.

196. Vamos M, Erath JW, Hohnloser SH. Digoxin-associated mortality: a systematic review and meta-analysis of the literature. Eur Heart J. 2015;36:1831-8.

197. Ziff OJ, Lane DA, Samra M, Griffith M, Kirchhof P, Lip GYH, Steeds RP, Townend J, Kotecha D. Safety and efficacy of digoxin: systematic review and meta-analysis of observational and controlled trial data. BMJ. 2015;351:h4451.

198. Van Gelder IC, Groenveld HF, Crijns HJGM, Tuininga YS, Tijssen JGP, Alings AM, Hillege HL, Bergsma-Kadijk JA, Cornel JH, Kamp O, Tukkie R, Bosker HA, Van Veldhuisen DJ, Van den Berg MP, RACE II Investigators. Lenient versus strict rate control in patients with atrial fibrillation. N Engl J Med. 2010;362:1363-73.

199. Bavishi C, Khan AR, Ather S. Digoxin in patients with atrial fibrillation and heart failure: a meta-analysis. Int J Cardiol. 2015;188:99-101.

200. Freeman JV, Reynolds K, Fang M, Udaltsova N, Steimle A, Pomernacki NK, Borowsky LH, Harrison TN, Singer DE, Go AS. Digoxin and risk of death in adults with atrial fibrillation: the ATRIA-CVRN Study. Circ Arrhythmia Electrophysiol 2015;8:49-58.

201. Washam JB, Stevens SR, Lokhnygina Y, Halperin JL, Breithardt G, Singer DE, Mahaffey KW, Hankey GJ, Berkowitz SD, Nessel CC, Fox KAA, Califf RM, Piccini JP. Patel MR. Digoxin use in patients with atrial fibrillation and adverse cardiovascular outcomes: a retrospective analysis of the Rivaroxaban Once Daily Oral Direct Factor Xa Inhibition Compared with Vitamin K Antagonism for Prevention of Stroke and Embolism Trial in Atrial Fibrillation (ROCKET AF). Lancet 2015;385: 2363-2370.

202. Mulder BA, Van Veldhuisen DJ, Crijns HJGM, Tijssen JGP, Hillege HL, Alings M, Rienstra M, Groenveld HF, Van den Berg MP, Van Gelder IC, RACE II investigators.
Lenient vs. strict rate control in patients with atrial fibrillation and heart failure: a post-hoc analysis of the RACE II study. Eur J Heart Fail. 2013;15:1311-8.

203. Lucas M, Kimmig M, Karalis G. Do omega-3 polyunsaturated fatty acids prevent cardiovascular disease? A review of the randomized clinical trials. Lipid Insights. 2013;6:13-20.

204. Reiner Z, Catapano AL, De Backer G, Graham I, Taskinen M-R, Wiklund O, Agewal $S$, Alegria E, Chapman MJ, Durrington P, Erdine S, Halcox J, Hobbs R, Kjekshus J, Filardi PP, Riccardi G, Storey RF, Wood D, Bax J, Vahanian A, Auricchio A, Baumgartner H, Ceconi C, Dean V, Deaton C, Fagard R, Filippatos G, FunckBrentano C, Hasdai D, Hobbs R, Hoes A, Kearney P, Knuuti J, Kolh P, McDonagh T, Moulin C, Poldermans D, Popescu BA, Reiner Z, Sechtem U, Sirnes PA, Tendera M, Torbicki A, Vardas P, Widimsky P, Windecker S, Reviewers: D, Funck-Brentano C, Poldermans D, Berkenboom G, De Graaf J, Descamps O, Gotcheva N, Griffith K, Guida GF, Gulec S, Henkin Y, Huber K, Kesaniemi YA, Lekakis J, Manolis AJ, Marques-Vidal P, Masana L, McMurray J, Mendes M, Pagava Z, Pedersen T, Prescott E, Rato Q Rosano G, Sans S, Stalenhoef A, Tokgozoglu L, Viigimaa M, Wittekoek ME, Zamorano JL. ESC/EAS Guidelines for the management of dyslipidaemias: the Task Force for the management of dyslipidaemias of the European Society of Cardiology (ESC) and the European Atherosclerosis Society (EAS). Eur Heart J. 2011;32:1769-818.

205. Kjekshus J, Apetrei E, Barrios V, Böhm M, Cleland JGF, Cornel JH, Dunselman P, Fonseca C, Goudev A, Grande P, Gullestad L, Hjalmarson A , Hradec J, Jánosi A, Kamenský G, Komajda M, Korewicki J, Kuusi T, Mach F, Mareev V, McMurray JJV, Ranjith N, Schaufelberger M, Vanhaecke J, van Veldhuisen DJ, Waagstein F, Wedel $\mathrm{H}$, Wikstrand J. Rosuvastatin in older patients with systolic heart failure. N Engl J Med. 2007;357:2248-61.

206. Homma S, Thompson JLP, Pullicino PM, Levin B, Freudenberger RS, Teerlink JR, Ammon SE, Graham S, Sacco RL, Mann DL, Mohr JP, Massie BM, Labovitz AJ, Anker SD, Lok DJ, Ponikowski P, Estol CJ, Lip GYH, Di Tullio MR, Sanford AR, Mejia V, Gabriel AP, del Valle ML, Buchsbaum R, Shunichi H, Thompson JLP, Pullicino PM, Levin B, Freudenberger RS, Teerlink JR, Ammon SE, Graham S, Sacco RL, Mann DL, Mohr JP, Massie BM, Labovitz AJ, Lip GYH, Tullio MR, Di, Sanford AR, Mejia V, Gabriel AP, Valle ML, Buchsbaum R, Investigators W. Warfarin and aspirin in patients with heart failure and sinus rhythm. N Engl J Med. 2012;366:1859-69.

207. Lip GYH, Ponikowski P, Andreotti F, Anker SD, Filippatos G, Homma S, Morais J, Pullicino P, Rasmussen LH, Marin F, Lane DA. Thrombo-embolism and antithrombotic therapy for heart failure in sinus rhythm. A joint consensus document from the ESC Heart Failure Association and the ESC Working Group on Thrombosis. Eur J Heart Fail. 2012;14:681-95.

208. Gheorghiade M, Bö hm M, Greene SJ, Fonarow GC, Lewis EF, Zannad F, Solomon SD, Baschiera F, Botha J, Hua TA, Gimpelewicz CR, Jaumont X, Lesogor A, Maggioni AP, ASTRONAUT Investigators and Coordinators. Effect of aliskiren on postdischarge mortality and heart failure readmissions among patients hospitalized for heart failure: the ASTRONAUT randomized trial. JAMA 2013;309:1125-35.

209. Hernández AV, Usmani A, Rajamanickam A, Moheet A. Thiazolidinediones and risk of heart failure in patients with or at high risk of type 2 diabetes mellitus: a meta-analysis and meta-regression analysis of placebo-controlled randomized clinical trials. Am J Cardiovasc Drugs. 2011;11:115-28.

210. Komajda M, McMurray JJV, Beck-Nielsen H, Gomis R, Hanefeld M, Pocock SJ, Curtis PS, Jones NP, Home PD. Heart failure events with rosiglitazone in type 2 diabetes: data from the RECORD clinical trial. Eur Heart J. 2010;31:824-31.

211. Mamdani M, Juurlink DN, Lee DS, Rochon PA, Kopp A, Naglie G, Austin PC, Laupacis A, Stukel TA. Cyclo-oxygenase-2 inhibitors versus non-selective nonsteroidal anti-inflammatory drugs and congestive heart failure outcomes in elderly patients: a population-based cohort study. Lancet. 2004;363:1751-6.

212. Huerta C, Varas-Lorenzo C, Castellsague J, García Rodríguez LA. Non-steroidal anti-inflammatory drugs and risk of first hospital admission for heart failure in the general population. Heart. 2006;92:1610-5.

213. Scott P a, Kingsley GH, Scott DL. Non-steroidal anti-inflammatory drugs and cardiac failure: meta-analyses of observational studies and randomised controlled trials. Eur J Heart Fail. 2008;10:1102-7.

214. Goldstein RE, Boccuzzi SJ, Cruess D, Nattel S. Diltiazem increases late-onset congestive heart failure in postinfarction patients with early reduction in ejection fraction. The Adverse Experience Committee and the Multicenter Diltiazem Postinfarction Research Group. Circulation. 1991;83:52-60.

215. Packer M, O'Connor CM, Ghali JK, Pressler ML, Carson PE, Belkin RN, Miller AB, Neuberg GW, Frid D,Wertheimer JH, Cropp AB, DeMets DL, Prospective Randomized Amlodipine Survival Evaluation Study Group. Effect of amlodipine on morbidity and mortality in severe chronic heart failure. $\mathrm{N}$ Engl J Med. 1996;335:1107-14.

216. Cohn JN, Ziesche S, Smith R, Anand I, Dunkman WB, Loeb H, Cintron G, Boden W, Baruch L, Rochin P, Loss L. Effect of the calcium antagonist felodipine as supplementary vasodilator therapy in patients with chronic heart failure treated with enalapril: V-HeFT III. Vasodilator-Heart Failure Trial (V-HeFT) Study Group. Circulation. 1997:96:856-63.

217. Abraham WT, Zile MR, Weaver FA, Butter C, Ducharme A, Halbach M, Klug D, Lovett EG, Muller-Ehmsen J, Schafer JE, Senni M, Swarup V,Wachter R, Little WC. Baroreflex activation therapy for the treatment of heart failure with a reduced ejection fraction. JACC Heart Fail. 2015;3:487-96.

218. Zannad F, De Ferrari GM, Tuinenburg AE, Wright D, Brugada J, Butter C, Klein H, Stolen C, Meyer S, Stein KM, Ramuzat A, Schubert B, Daum D, Neuzil P, Botman C, Castel MA, D'Onofrio A, Solomon SD, Wold N, Ruble SB. Chronic vagal stimulation for the treatment of low ejection fraction heart failure: results of the NEural Cardiac TherApy foR Heart Failure (NECTAR-HF) randomized controlled trial. Eur Heart J. 2015;36:425-33. 
219. Ponikowski P, Javaheri S, Michalkiewicz D, Bart BA, Czarnecka D, Jastrzebski M, Kusiak A, Augostini R, Jagielski D, Witkowski T, Khayat RN, Oldenburg O, Gutleben K-J, Bitter T, Karim R, Iber C, Hasan A, Hibler K, Germany R, Abraham WT. Transvenous phrenic nerve stimulation for the treatment of central sleep apnoea in heart failure. Eur Heart J. 2012;33:889-94.

220. Abraham WT, Jagielski D, Oldenburg O, Augostini R, Krueger S, Kolodziej A, Gutleben K-J, Khayat R, Merliss A, Harsch MR, Holcomb RG, Javaheri S, Ponikowski P. Phrenic nerve stimulation for the treatment of central sleep apnea. JACC Heart Fail. 2015;3:360-9.

221. Kadish A, Nademanee $K$, Volosin $K$, Krueger S, Neelagaru S, Raval N, Obel O, Weiner S, Wish M, Carson P, Ellenbogen K, Bourge R, Parides M, Chiacchierini RP, Goldsmith R, Goldstein S, Mika Y, Burkhoff D, Abraham WT. A randomized controlled trial evaluating the safety and efficacy of cardiac contractility modulation in advanced heart failure. Am Heart J. 2011;161:329-37.e2

222. Borggrefe MM, Lawo T, Butter C, Schmidinger H, Lunati M, Pieske B, Misier AR, Curnis A, Böcker D, Remppis A, Kautzner J, Stühlinger M, Leclerq C, Táborský M, Frigerio M, Parides M, Burkhoff D, Hindricks G. Randomized, double blind study of non-excitatory, cardiac contractility modulation electrical impulses for symptomatic heart failure. Eur Heart J. 2008;29:1019-28.

223. Wyse DG, Friedman PL, Epstein AE. A comparison of antiarrhythmic-drug therapy with implantable defibrillators in patients resuscitated from near-fatal ventricular arrhythmias. The Antiarrhythmics versus Implantable Defibrillators (AVID) Investigators. N Engl J Med. 1997;337:1576-83.

224. Connolly SJ, Hallstrom AP, Cappato R, Schron EB, Kuck KH, Zipes DP, Greene HL Boczor S, Domanski M, Follmann D, Gent M, Roberts RS. Meta-analysis of the implantable cardioverter defibrillator secondary prevention trials. AVID, CASH and CIDS studies. Antiarrhythmics vs Implantable Defibrillator study. Cardiac Arrest Study Hamburg. Canadian Implantable Defibrillator Study. Eur Heart J. 2000;21:2071-8

225. Connolly SJ, Gent M, Roberts RS, Dorian P, Roy D, Sheldon RS, Mitchell LB, Green MS, Klein GJ, O’Brien B. Canadian implantable defibrillator study (CIDS) : randomized trial of the implantable cardioverter defibrillator against amiodarone. Circulation. 2000;101:1297-302.

226. Kuck KH, Cappato R, Siebels J, Rüppel R. Randomized comparison of antiarrhythmic drug therapy with implantable defibrillators in patients resuscitated from cardiac arrest: the Cardiac Arrest Study Hamburg (CASH). Circulation. 2000;102:748-54.

227. Bardy GH, Lee KL, Mark DB, Poole JE, Packer DL, Boineau R, Domanski M, Troutman C, Anderson J, Johnson G, McNulty SE, Clapp-Channing N, Davidson-Ray LD, Fraulo ES, Fishbein DP, Luceri RM, Ip JH. Amiodarone or an implantable cardioverterdefibrillator for congestive heart failure. N Engl J Med. 2005;352:225-37.

228. Steinbeck G, Andresen D, Seidl K, Brachmann J, Hoffmann E, Wojciechowski D, Kornacewicz-Jach Z, Sredniawa B, Lupkovics G, Hofgärtner F, Lubinski A Rosenqvist M, Habets A,Wegscheider K, Senges J. Defibrillator implantation early after myocardial infarction. N Engl J Med. 2009;361:1427-36.

229. Sanders GD, Hlatky MA, Owens DK. Cost-effectiveness of implantable cardioverter-defibrillators. N Engl J Med. 2005;353:1471-80.

230. Steinberg BA, Al-Khatib SM, Edwards R, Han J, Bardy GH, Bigger JT, Buxton AE Moss AJ, Lee KL, Steinman R, Dorian P, Hallstrom A, Cappato R, Kadish AH, Kudenchuk PJ, Mark DB, Inoue LYT, Sanders GD. Outcomes of implantable cardioverter-defibrillator use in patients with comorbidities: results from a combined analysis of 4 randomized clinical trials. JACC Heart Fail. 2014:2:623-9.

231. Raphael CE, Finegold JA, Barron AJ, Whinnett ZI, Mayet J, Linde C, Cleland JGF, Levy WC, Francis DP. The effect of duration of follow-up and presence of competing risk on lifespan-gain from implantable cardioverter defibrillator therapy: who benefits the most? Eur Heart J. 2015;36:1676-88.

232. Miller RJH, Howlett JG, Exner DV, Campbell PM, Grant ADM, Wilton SB. Baseline functional class and therapeutic efficacy of common heart failure interventions: a systematic review and meta-analysis. Can J Cardiol. 2015;31:792-9.

233. Hess PL, Al-Khatib SM, Han JY, Edwards R, Bardy GH, Bigger JT, Buxton A, Cappato R, Dorian P, Hallstrom A, Kadish AH, Kudenchuk PJ, Lee KL, Mark DB, Moss AJ, Steinman R, Inoue LYT, Sanders G. Survival benefit of the primary prevention implantable cardioverter-defibrillator among older patients: does age matter? An analysis of pooled data from 5 clinical trials. Circ Cardiovasc Qual Outcomes. 2015;8:179-86.

234. Merchant FM, Jones P,Wehrenberg S, Lloyd MS, Saxon LA. Incidence of defibrillator shocks after elective generator exchange following uneventful first battery life. J Am Heart Assoc. 2014;3:e001289.

235. Yap S-C, Schaer BA, Bhagwandien RE, Kuhne M, Dabiri Abkenari L, Osswald S, SziliTorok T, Sticherling C, Theuns DA. Evaluation of the need of elective implantable cardioverter-defibrillator generator replacement in primary prevention patients without prior appropriate ICD therapy. Heart. 2014;100:1188-92.

236. Kini V, Soufi MK, Deo R, Epstein AE, Bala R, Riley M, Groeneveld PW, Shalaby A, DixitS.Appropriateness of primarypreventionimplantablecardioverterdefibrillators at the time of generator replacement: are indications still met? J Am Coll Cardiol. 2014;63:2388-94.

237. Erkapic D, Sperzel J, Stiller S, Meltendorf U, Mermi J, Wegscheider K, Hügl B. Long-term benefit of implantable cardioverter/defibrillator therapy after elective device replacement: Results of the INcidence free SUrvival after ICD REplacement (INSURE) trial-a prospective multicentre study. Eur Heart J. 2013;34:130-7.

238. Alsheikh-Ali AA, Homer M, Maddukuri PV, Kalsmith B, Estes NAM, Link MS Time-dependence of appropriate implantable defibrillator therapy in patients with ischemic cardiomyopathy. J Cardiovasc Electrophysiol. 2008;19:784-9.

239. Opreanu M, Wan C, Singh V, Salehi N, Ahmad J, Szymkiewicz SJ, Thakur RK. Wearable cardioverter-defibrillator as a bridge to cardiac transplantation: a national database analysis. J Heart Lung Transplant. 2015;34:1305-9.
240. Zishiri ET, Williams S, Cronin EM, Blackstone EH, Ellis SG, Roselli EE, Smedira NG, Gillinov AM, Glad JA, Tchou PJ, Szymkiewicz SJ, Chung MK. Early risk of mortality after coronary artery revascularization in patients with left ventricular dysfunction and potential role of the wearable cardioverter defibrillator. Circ Arrhythm Electrophysiol. 2013;6:117-28.

241. Chung MK, Szymkiewicz SJ, Shao M, Zishiri E, Niebauer MJ, Lindsay BD, Tchou PJ. Aggregate national experience with the wearable cardioverter-defibrillator. J Am Coll Cardiol. 2010;56:194-203.

242. Effect of prophylactic amiodarone on mortality after acute myocardial infarction and in congestive heart failure: meta-analysis of individual data from 6500 patients in randomised trials. Amiodarone Trials Meta-Analysis Investigators. Lancet. 1997;350:1417-24.

243. Andrey JL, Gómez-Soto FM, Romero SP, Escobar MA, García-Egido AA, GarcíaArjona R, Gómez F, GAMIC (Grupo para Atencion Medica Integrada de Cadiz). Mortality of newly diagnosed heart failure treated with amiodarone: a propensity-matched study. Int J Cardiol. 2011;151:175-81.

244. Torp-Pedersen C, Metra M, Spark P, Lukas MA, Moullet C, Scherhag A, Komajda M, Cleland JGF, Remme W, Di Lenarda A, Swedberg K, Poole-Wilson PA. The safety of amiodarone in patients with heart failure. J Card Fail. 2007;13:340-5.

245. Piepoli M, Villani GQ, Ponikowski P, Wright A, Flather MD, Coats AJ. Overview and meta-analysis of randomised trials of amiodarone in chronic heart failure. Int J Cardiol. 1998;66:1-10

246. Chatterjee S, Ghosh J, Lichstein E, Aikat S, Mukherjee D. Meta-analysis of cardiovascular outcomes with dronedarone in patients with atrial fibrillation or heart failure. Am J Cardiol. 2012;110:607-13.

247. Køber L, Torp-Pedersen C, McMurray JJV, Gøtzsche O, Lévy S, Crijns H, Amlie J, Carlsen J. Increased mortality after dronedarone therapy for severe heart failure. N Engl J Med. 2008;358:2678-87.

248. Echt DS, Liebson PR, Mitchell LB, Peters RW, Obias-Manno D, Barker AH, Arensberg D, Baker A, Friedman L, Greene HL, Huther ML, Richardson DW. Mortality and morbidity in patients receiving encainide, flecainide, or placebo. The Cardiac Arrhythmia Suppression Trial. N Engl J Med. 1991;324:781-8.

249. Theuns DAMJ, Smith T, Hunink MGM, Bardy GH, Jordaens L. Effectiveness of prophylactic implantation of cardioverter-defibrillators without cardiac resynchronization therapy in patients with ischaemic or non-ischaemic heart disease: a systematic review and meta-analysis. Europace. 2010;12:1564-70.

250. Cook NR, Ridker PM. Advances in measuring the effect of individual predictors of cardiovascular risk: the role of reclassification measures. Ann Intern Med 2009;150:795-802.

251. Moss AJ, Hall WJ, Cannom DS, Daubert JP, Higgins SL, Klein H, Levine JH, Saksena S, Waldo AL, Wilber D, Brown MW, Heo M. Improved survival with an implanted defibrillator in patients with coronary disease at high risk for ventricular arrhythmia. Multicenter Automatic Defibrillator Implantation Trial Investigators. N Engl J Med. 1996;335:1933-40.

252. Moss AJ, Schuger C, Beck CA, Brown MW, Cannom DS, Daubert JP, Estes NAM, Greenberg H, Hall WJ, Huang DT, Kautzner J, Klein H, McNitt S, Olshansky B, Shoda M, Wilber D, ZarebaW. Reduction in inappropriate therapy and mortality through ICD programming. N Engl J Med. 2012;367:2275-83.

253. Gasparini M, Proclemer A, Klersy C, Kloppe A, Lunati M, Ferrer JBM, Hersi A, Gulaj M, Wijfels MCEF, Santi E, Manotta L, Arenal A. Effect of long-detection interval vs standard-detection interval for implantable cardioverter-defibrillators on antitachycardia pacing and shock delivery: the ADVANCE III randomized clinical trial. JAMA. 2013;309:1903-11.

254. Cleland JGF, Buga L. Device therapy: defibrillators-a shocking therapy for cardiomyopathy? Nat Rev Cardiol. 2010;7:69-70.

255. Stewart GC, Weintraub JR, Pratibhu PP, Semigran MJ, Camuso JM, Brooks K, Tsang SW, Anello MS, Nguyen VT, Lewis EF, Nohria A, Desai AS, Givertz MM, Stevenson LW. Patient expectations from implantable defibrillators to prevent death in heart failure. J Card Fail. 2010;16:106-13.

256. Bardy GH, Smith WM, Hood M a, Crozier IG, Melton IC, Jordaens L, Theuns D, Park RE, Wright DJ, Connelly DT, Fynn SP, Murgatroyd FD, Sperzel J, Neuzner J, Spitzer SG, Ardashev AV, Oduro A, Boersma L, Maass AH, Van Gelder IC, Wilde AA, van Dessel PF, Knops RE, Barr CS, Lupo P, Cappato R, Grace AA. An entirely subcutaneous implantable cardioverter-defibrillator. N Engl J Med. 2010;363:36-44.

257. Aziz S, Leon AR, El-Chami MF. The subcutaneous defibrillator. J Am Coll Cardiol. 2014:63:1473-9.

258. Olde Nordkamp LRA, Knops RE, Bardy GH, Blaauw Y, Boersma LVA, Bos JS, Delnoy PPHM, van Dessel PFHM, Driessen AHG, de Groot JR, Herrman JPR, Jordaens LJLM, Kooiman KM, Maass AH, Meine M, Mizusawa Y, Molhoek SG, van Opstal J, Tijssen JGP, Wilde AAM. Rationale and design of the PRAETORIAN trial: a Prospective, RAndomizEd comparison of subcuTaneOus and tRansvenous ImplANtable cardioverter-defibrillator therapy. Am Heart J. 2012;163:753-760.e2.

259. Burke MC, Gold MR, Knight BP, Barr CS, Theuns DAMJ, Boersma LVA, Knops RE, Weiss R, Leon AR, Herre JM, Husby M, Stein KM, Lambiase PD. Safety and efficacy of the totally subcutaneous implantable defibrillator: 2-year results from a pooled analysis of the IDE Study and EFFORTLESS Registry. J Am Coll Cardiol. 2015;65:1605-15.

260. Priori SG, Blomström-Lundqvist C, Mazzanti A, Blom N, Borggrefe M, Camm J, Elliott PM, Fitzsimons D, Hatala R, Hindricks G, Kirchhof P, Kjeldsen K, Kuck K-H, Hernández-Madrid A, Nikolaou N, Norekva ${ }^{\circ}$ TM, Spaulding C, Van Veldhuisen DJ. 2015 ESC Guidelines for the management of patients with ventricular arrhythmias and the prevention of sudden cardiac death: the Task Force for the Management of Patients with Ventricular Arrhythmias and the Prevention of Sudden Cardiac Death of the Europe. Eur Heart J. 2015;36:2793-867.

261. Cazeau S, Leclercq C, Lavergne T, Walker S, Varma C, Linde C, Garrigue S, Kappenberger L, Haywood GA, Santini M, Bailleul C, Mabo P, Lazarus A, Ritter P, 
Levy T, McKennaW, Daubert J-C. Effects of multisite biventricular pacing in patients with heart failure and intraventricular conduction delay. N Engl J Med. 2001;344:873-80.

262. Cleland J, Daubert J, Erdmann E, Freemantle N, Gras D, Kappenberger L, Tavazzi L. The effect of cardiac resynchronization on morbidity and mortality in heart failure. N Engl J Med. 2005;352:1539-49.

263. Cleland JGF, Daubert J-C, Erdmann E, Freemantle N, Gras D, Kappenberger L, Tavazzi L. Longer-term effects of cardiac resynchronization therapy on mortality in heart failure [the CArdiac REsynchronization-Heart Failure (CARE-HF) trial extension phase]. Eur Heart J. 2006;27:1928-32.

264. Cleland JGF, Freemantle N, Erdmann E, Gras D, Kappenberger L, Tavazzi L, Daubert J-CC. Long-term mortality with cardiac resynchronization therapy in the Cardiac Resynchronization-Heart Failure (CARE-HF) trial. Eur J Heart Fail. 2012;14: 628-34.

265. Bristow MR, Saxon LA, Boehmer J, Krueger S, Kass DA, De Marco T, Carson P, DiCarlo L, DeMets D, White BG, DeVries DW, Feldman AM. Cardiacresynchronization therapy with or without an implantable defibrillator in advanced chronic heart failure. N Engl J Med. 2004;350:2140-50.

266. Cleland JG, Abraham WT, Linde C, Gold MR, Young JB, Claude Daubert J, Sherfesee L,Wells GA, Tang ASL. An individual patient meta-analysis of five randomized trials assessing the effects of cardiac resynchronization therapy on morbidity and mortality in patients with symptomatic heart failure. Eur Heart J. 2013;34: 3547-56.

267. Tang ASL, Wells GA, Talajic M, Arnold MO, Sheldon R, Connolly S, Hohnloser SH, Nichol G, Birnie DH, Sapp JL, Yee R, Healey JS, Rouleau JL. Cardiac-resynchronization therapy for mild-to-moderate heart failure. N Engl J Med. 2010;363:2385-95.

268. Moss AJ, Hall WJ, Cannom DS, Klein H, Brown MW, Daubert JP, Estes NAM, Foster E, Greenberg H, Higgins SL, Pfeffer MA, Solomon SD, Wilber D, ZarebaW. Cardiacresynchronization therapy for the prevention of heart-failure events. N Engl J Med. 2009;361:1329-38.

269. Goldenberg I, Kutyifa V, Klein HU, Cannom DS, Brown MW, Dan A, Daubert JP Estes NAM, Foster E, Greenberg H, Kautzner J, Klempfner R, Kuniss M, Merkely B, Pfeffer MA, Quesada A, Viskin S, McNitt S, Polonsky B, Ghanem A, Solomon SD, Wilber D, ZarebaW, Moss AJ. Survival with cardiac-resynchronization therapy in mild heart failure. N Engl J Med. 2014;370:1694-701.

270. Linde C, Abraham WT, Gold MR, St John Sutton M, Ghio S, Daubert C. Randomized trial of cardiac resynchronization in mildly symptomatic heart failure patients and in asymptomatic patients with left ventricular dysfunction and previous heart failure symptoms. J Am Coll Cardiol. 2008;52:1834-43.

271. Daubert C, Gold MR, Abraham WT, Ghio S, Hassager C, Goode G, Szili-Török T, Linde C, REVERSE Study Group. Prevention of disease progression by cardiac resynchronization therapy in patients with asymptomatic or mildly symptomatic left ventricular dysfunction: insights from the European cohort of the REVERSE trial. J Am Coll Cardiol. 2009;54:1837-46.

272. Linde C, Gold MR, Abraham WT, St John Sutton M, Ghio S, Cerkvenik J, Daubert C. Long-term impact of cardiac resynchronization therapy in mild heart failure: 5 -year results from the REsynchronization reVErses Remodeling in Systolic left vEntricular dysfunction (REVERSE) study. Eur Heart J. 2013;34:2592-9.

273. Woods B, Hawkins N, Mealing S, Sutton A, Abraham WT, Beshai JF, Klein H, Sculpher M, Plummer CJ, Cowie MR. Individual patient data network metaanalysis of mortality effects of implantable cardiac devices. Heart. 2015;101: 1800-6.

274. Curtis AB,Worley SJ, Adamson PB, Chung ES, Niazi I, Sherfesee L, Shinn T, St John Sutton M. Biventricular pacing for atrioventricular block and systolic dysfunction. N Engl J Med. 2013;368:1585-93.

275. Brignole M, Botto G, Mont L, Iacopino S, De Marchi G, Oddone D, Luzi M, Tolosana JM, Navazio A, Menozzi C. Cardiac resynchronization therapy in patients undergoing atrioventricular junction ablation for permanent atrial fibrillation: a randomized trial. Eur Heart J. 2011;32:2420-9.

276. Leclercq C,Walker S, Linde C, Clementy J, Marshall AJ, Ritter P, Djiane P, Mabo P, Levy T, Gadler F, Bailleul C, Daubert J-C. Comparative effects of permanent biventricular and right-univentricular pacing in heart failure patients with chronic atrial fibrillation. Eur Heart J. 2002;23:1780-7.

277. Stavrakis S, Garabelli P, Reynolds DW. Cardiac resynchronization therapy after atrioventricular junction ablation for symptomatic atrial fibrillation: a metaanalysis. Europace. 2012;14:1490-7.

278. MacDonald MR, Connelly DT, Hawkins NM, Steedman T, Payne J, Shaw M, Denvir M, Bhagra S, Small S, Martin W, McMurray JJ, Petrie MC. Radiofrequency ablation for persistent atrial fibrillation in patients with advanced heart failure and severe left ventricular systolic dysfunction: a randomised controlled trial. Heart. 2011;97:740-7.

279. Jones DG, Haldar SK, Hussain W, Sharma R, Francis DP, Rahman-Haley SL, McDonagh TA, Underwood SR, Markides V, Wong T. A randomized trial to assess catheter ablation versus rate control in the management of persistent atrial fibrillation in heart failure. J Am Coll Cardiol. 2013;61:1894-903.

280. Upadhyay GA, Choudhry NK, Auricchio A, Ruskin J, Singh JP. Cardiac resynchronization in patients with atrial fibrillation: a meta-analysis of prospective cohort studies. J Am Coll Cardiol. 2008;52:1239-46.

281. Gasparini M, Leclercq C, Lunati M, Landolina M, Auricchio A, Santini M, Boriani G, Lamp B, Proclemer A, Curnis A, Klersy C, Leyva F. Cardiac resynchronization therapy in patients with atrial fibrillation. The CERTIFY Study (Cardiac Resynchronization Therapy in Atrial Fibrillation Patients Multinational Registry). JACC Heart Fail. 2013;1:500-7.

282. Gage RM, Burns KV, Bank AJ. Echocardiographic and clinical response to cardiac resynchronization therapy in heart failure patients with and without previous right ventricular pacing. Eur J Heart Fail. 2014;16:1199-205.
283. Ruschitzka F, AbrahamWT, Singh JP, Bax JJ, Borer JS, Brugada J, Dickstein K, Ford I, Gorcsan J, Gras D, Krum H, Sogaard P, Holzmeister J. Cardiac-resynchronization therapy in heart failure with a narrow QRS complex. N Engl J Med. 2013;369: 1395-405.

284. Steffel J, Robertson M, Singh JP, Abraham WT, Bax JJ, Borer JS, Dickstein K, Ford I, Gorcsan J, Gras D, Krum H, Sogaard P, Holzmeister J, Brugada J, Ruschitzka F. The effect of QRS duration on cardiac resynchronization therapy in patients with a narrow QRS complex: a subgroup analysis of the EchoCRT trial. Eur Heart J. 2015;36:1983-9.

285. Zusterzeel R, Selzman KA, Sanders WE, Caños DA, O'Callaghan KM, Carpenter JL Piña IL, Strauss DG. Cardiac resynchronization therapy in women: US Food and Drug Administration meta-analysis of patient-level data. JAMA Intern Med. 2014;174:1340-8.

286. Sohaib SMMA, Finegold JA, Nijjer SS, Hossain R, Linde C, Levy WC, Sutton R, Kanagaratnam P, Francis DP, Whinnett ZI. Opportunity to increase life span in narrow QRS cardiac resynchronization therapy recipients by deactivating ventricular pacing: evidence from randomized controlled trials. JACC Heart Fail. 2015;3:327-36.

287. Cleland JGF, Calvert MJ, Verboven Y, Freemantle N. Effects of cardiac resynchronization therapy on long-term quality of life: an analysis from the Cardiac Resynchronisation-Heart Failure (CARE-HF) study. Am Heart J. 2009;157:457-66.

288. Cleland JGF, Mareev Y, Linde C. Reflections on EchoCRT: sound guidance on QRS duration and morphology for CRT? Eur Heart J. 2015;36:1948-51.

289. Linde C, Stahlberg M, Benson L, Braunschweig F, Edner M, Dahlstrom U, Alehagen $\mathrm{U}$, Lund LH. Gender, underutilization of cardiac resynchronization therapy, and prognostic impact of QRS prolongation and left bundle branch block in heart failure. Europace. 2015;17:424-31.

290. Doshi RN, Daoud EG, Fellows C, Turk K, Duran A, Hamdan MH, Pires LA, PAVE Study Group. Left ventricular-based cardiac stimulation post AV nodal ablation evaluation (the PAVE study). J Cardiovasc Electrophysiol. 2005;16:1160-5.

291. Funck RC, Mueller HH, Lunati M, Piorkowski C, De Roy L, Paul V, Wittenberg M, Wuensch D, Blanc JJ. Characteristics of a large sample of candidates for permanent ventricular pacing included in the Biventricular Pacing for Atrio-ventricular Block to Prevent Cardiac Desynchronization Study (BioPace). Europace. 2014;16:354-62.

292. Chung ES, Leon AR, Tavazzi L, Sun J-P, Nihoyannopoulos P, Merlino J, Abraham WT, Ghio S, Leclercq C, Bax JJ, Yu C-M, Gorcsan J, StJohn Sutton M, De Sutter J Murillo J. Results of the Predictors of Response to CRT (PROSPECT) Trial. Circulation. 2008;117:2608-16

293. Wikstrom G, Blomström-Lundqvist C, Andren B, Lönnerholm S, Blomström P, Freemantle N, Remp T, Cleland JGF. The effects of aetiology on outcome in patients treated with cardiac resynchronization therapy in the CARE-HF trial. Eur Heart J. 2009;30:782-8.

294. Khan FZ, Virdee MS, Palmer CR, Pugh PJ, O’Halloran D, Elsik M, Read P a, Begley D, Fynn SP, Dutka DP. Targeted left ventricular lead placement to guide cardiac resynchronization therapy: the TARGET study: a randomized, controlled trial. J Am Coll Cardiol. 2012;59:1509-18.

295. Saba S, Marek J, Schwartzman D, Jain S, Adelstein E, White P, Oyenuga OA, Onish T, Soman P, Gorcsan J. Echocardiography-guided left ventricular lead placement for cardiac resynchronization therapy: results of the Speckle Tracking Assisted Resynchronization Therapy for Electrode Region Trial. Circ Heart Fail. 2013;6: 427-34.

296. Kosmala W, Marwick TH. Meta-analysis of effects of optimization of cardiac resynchronization therapy on left ventricular function, exercise capacity, and quality of life in patients with heart failure. Am J Cardiol. 2014;113:988-94.

297. Whinnett ZI, Francis DP, Denis A, Willson K, Pascale P, Van Geldorp I, De Guillebon M, Ploux S, Ellenbogen K, Haïssaguerre M, Ritter P, Bordachar P. Comparison of different invasive hemodynamic methods for AV delay optimization in patients with cardiac resynchronization therapy: Implications for clinical trial design and clinical practice. Int J Cardiol. 2013;168:2228-37.

298. Kuck KH, Bordachar P, Borggrefe M, Boriani G, Burri H, Leyva F, Schauerte P Theuns D, Thibault B, Kirchhof P, Hasenfuss G, Dickstein K, Leclercq C, Linde C, Tavazzi L, Ruschitzka F. New devices in heart failure: an European Heart Rhythm Association report: developed by the European Heart Rhythm Association; endorsed by the Heart Failure Association. Europace. 2014;16:109-28.

299. Singh JP, Kandala J, Camm AJ. Non-pharmacological modulation of the autonomic tone to treat heart failure. Eur Heart J. 2014;35:77-85.

300. Solomon SD, Zile M, Pieske B, Voors A, Shah A, Kraigher-Krainer E, Shi V, Bransford T, Takeuchi M, Gong J, Lefkowitz M, Packer M, McMurray JJ. The angiotensin receptor neprilysin inhibitor LCZ696 in heart failure with preserved ejection fraction: a phase 2 double-blind randomised controlled trial. Lancet. 2012;380:1387-95.

301. Pitt B, Pfeffer MA, Assmann SF, Boineau R, Anand IS, Claggett B, Clausell N, Desa AS, Díaz R, Fleg JL, Gordeev I, Harty B, Heitner JF, Kenwood CT, Lewis EF, O’Meara E, Probstfield JL, Shaburishvili T, Shah SJ, Solomon SD, Sweitzer NK, Yang S, McKinlay SM. Spironolactone for heart failure with preserved ejection fraction. N Engl J Med. 2014;370:1383-92.

302. Redfield MM, Chen HH, Borlaug BA, Semigran MJ, Lee KL, Lewis G, LeWinter MM Rouleau JL, Bull DA, Mann DL, Deswal A, Stevenson LW, Givertz MM, Ofili EO, O'Connor CM, Felker GM, Goldsmith SR, Bart BA, McNulty SE, Ibarra JC, Lin G, Oh JK, Patel MR, Kim RJ, Tracy RP, Velázquez EJ, Anstrom KJ, Hernández AF, Mascette AM, Braunwald E, RELAX Trial. Effect of phosphodiesterase-5 inhibition on exercise capacity and clinical status in heart failure with preserved ejection fraction: a randomized clinical trial. JAMA. 2013;309:1268-77.

303. Senni M, Paulus WJ, Gavazzi A, Fraser AG, Díez J, Solomon SD, Smiseth OA, Guazzi M, Lam CSP, Maggioni AP, Tschope C, Metra M, Hummel SL, Edelmann F, Ambrosio 
G, Stewart Coats AJ, Filippatos GS, Gheorghiade M, Anker SD, Levy D, Pfeffer MA, Stough WG, Pieske BM. New strategies for heart failure with preserved ejection fraction: the importance of targeted therapies for heart failure phenotypes. Eur Heart J. 2014;35:2797-815.

304. Ferrari R, Böhm M, Cleland JGF, Paulus WJS, Pieske B, Rapezzi C, Tavazzi L. Heart failure with preserved ejection fraction: uncertainties and dilemmas. Eur J Heart Fail. 2015;17:665-71.

305. Ather S, Chan W, Bozkurt B, Aguilar D, Ramasubbu K, Zachariah AA, Wehrens XHT, Deswal A. Impact of noncardiac comorbidities on morbidity and mortality in a predominantly male population with heart failure and preserved versus reduced ejection fraction. J Am Coll Cardiol. 2012;59:998-1005.

306. Henkel DM, Redfield MM,Weston SA, Gerber Y, Roger VL. Death in heart failure: a community perspective. Circ Heart Fail 2008;1:91-97.

307. Fukuta H, Goto T, Wakami K, Ohte N. Effects of drug and exercise intervention on functional capacity and quality of life in heart failure with preserved ejection fraction: a meta-analysis of randomized controlled trials. Eur J Prev Cardiol. 2016:23:78-85.

308. Lewis EF, Lamas GA, O’Meara E, Granger CB, Dunlap ME, McKelvie RS, Probstfield JL, Young JB, Michelson EL, Halling K, Carlsson J, Olofsson B, McMurray JJV, Yusuf S, Swedberg K, Pfeffer MA. Characterization of health-related quality of life in heart failure patients with preserved versus low ejection fraction in CHARM. Eur J Heart Fail. 2007;9:83-91.

309. Massie BM, Carson PE, McMurray JJ, Komajda M, McKelvie R, Zile MR, Anderson S, Donovan M, Iverson E, Staiger C, Ptaszynska A. Irbesartan in patients with heart failure and preserved ejection fraction. N Engl J Med. 2008;359:2456-67.

310. Yusuf S, Pfeffer MA, Swedberg K, Granger CB, Held P, McMurray JJ V, Michelson EL, Olofsson B, Ostergren J. Effects of candesartan in patients with chronic heart failure and preserved left-ventricular ejection fraction: the CHARM-Preserved Trial. Lancet. 2003;362:777-81.

311. Cleland JGF, Tendera M, Adamus J, Freemantle N, Polonski L, Taylor J. The perindopril in elderly people with chronic heart failure (PEP-CHF) study. Eur Heart J. 2006;27:2338-45.

312. Mulder BA, van Veldhuisen DJ, Crijns HJGM, Böhm M, Cohen-Solal A, Babalis D, Roughton M, Flather MD, Coats AJS, Van Gelder IC. Effect of nebivolol on outcome in elderly patients with heart failure and atrial fibrillation: insights from SENIORS. Eur J Heart Fail. 2012;14:1171-8.

313. van Veldhuisen DJ, Cohen-Solal A, Böhm M, Anker SD, Babalis D, Roughton M, Coats AJS, Poole-Wilson PA, Flather MD. Beta-blockade with nebivolol in elderly heart failure patients with impaired and preserved left ventricular ejection fraction. J Am Coll Cardiol. 2009;53:2150-8.

314. Ahmed A, Rich MW, Fleg JL, Zile MR, Young JB, Kitzman DW, Love TE, Aronow WS, Adams KF, Gheorghiade M. Effects of digoxin on morbidity and mortality in diastolic heart failure: the ancillary digitalis investigation group trial. Circulation. 2006; 114:397-403.

315. McMurray JJ V, Ostergren J, Swedberg K, Granger CB, Held P, Michelson EL, Olofsson B, Yusuf S, Pfeffer MA. Effects of candesartan in patients with chronic heart failure and reduced left-ventricular systolic function taking angiotensinconverting-enzyme inhibitors: the CHARM-Added trial. Lancet. 2003;362: 767-71.

316. Kirchof P, Benussi S et al. 2016 ESC Guidelines for the management of atria fibrillation developed in collaboration with EACTS. Eur Heart J. 2016. doi 10.1093/eurheartj/ehw210. Forthcoming.

317. Mancia G, Fagard R, Narkiewicz K, Redon J, Zanchetti A, Böhm M, Christiaens T, Cifkova R, De Backer G, Dominiczak A, Galderisi M, Grobbee DE, Jaarsma T, Kirchhof P, Kjeldsen SE, Laurent S, Manolis AJ, Nilsson PM, Ruilope LM, Schmieder RE, Sirnes PA, Sleight P, Viigimaa M, Waeber B, Zannad F, Redon J, Dominiczak A, Narkiewicz K, Nilsson PM, Burnier M, Viigimaa M, Ambrosioni E, Caufield M, Coca A, Olsen MH, Schmieder RE, Tsioufis C, van de Borne P, Zamorano JL, Achenbach S, Baumgartner H, Bax JJ, Bueno H, Dean V, Deaton C, Erol C, Fagard R, Ferrari R, Hasdai D, Hoes AW, Kirchhof P, Knuuti J, Kolh P, Lancellotti P, Linhart A, Nihoyannopoulos P, Piepoli MF, Ponikowski P, Sirnes PA, Tamargo JL, Tendera M, Torbicki A, Wijns W, Windecker S, Clement DL, Coca A, Gillebert TC, Tendera M, Rosei EA, Ambrosioni E, Anker SD, Bauersachs J, Hitij JB, Caulfield M, De Buyzere M, De Geest S, Derumeaux GA, Erdine S, Farsang C, Funck-Brentano C, Gerc V Germano G, Gielen S, Haller H, Hoes AW, Jordan J, Kahan T, Komajda M, Lovic D, Mahrholdt H, Olsen MH, Ostergren J, Parati G, Perk J, Polonia J, Popescu BA, Reiner Z, Rydén L, Sirenko Y, Stanton A, Struijker-Boudier H, Tsioufis C, van de Borne P, Vlachopoulos C, Volpe M, Wood DA. 2013 ESH/ESC guidelines for the management of arterial hypertension: the Task Force for the Management of Arterial Hypertension of the European Society of Hypertension (ESH) and of the European Society of Cardiology (ESC). Eur Heart J. 2013;34:2159-219.

318. Sakata Y, Shiba N, Takahashi J, Miyata S, Nochioka K, Miura M, Takada T, Saga C, Shinozaki T, Sugi M, Nakagawa M, Sekiguchi N, Komaru T, Kato A, Fukuchi M, Nozaki E, Hiramoto T, Inoue K, Goto T, Ohe M, Tamaki K, Ibayashi S, Ishide N, Maruyama Y, Tsuji I, Shimokawa H. Clinical impacts of additive use of olmesartan in hypertensive patients with chronic heart failure: the supplemental benefit of an angiotensin receptor blocker in hypertensive patients with stable heart failure using olmesartan (SUPPORT) trial. Eur Heart J. 2015;36:915-23.

319. Rydén L, Grant PJ, Anker SD, Berne C, Cosentino F, Danchin N, Deaton C, Escaned J, Hammes H-P, Huikuri H, Marre M, Marx N, Mellbin L, Ostergren J, Patrono C, Seferovic P, Uva MS, Taskinen M-R, Tendera M, Tuomilehto J, Valensi P, Zamorano JL, Achenbach S, Baumgartner H, Bax JJ, Bueno H, Dean V, Erol C, Fagard R, Ferrari R, Hasdai D, Hoes AW, Kirchhof P, Knuuti J, Kolh P, Lancellotti P, Linhart A, Nihoyannopoulos P, Piepoli MF, Ponikowski P, Sirnes PA, Tamargo JL, Torbicki A, Wijns W, Windecker S, De Backer G, Ezquerra EA, Avogaro A, Badimon L, Baranova E, Betteridge J, Ceriello A, Funck-Brentano C, Gulba DC, Kjekshus JK, Lev E,
Mueller C, Neyses L, Nilsson PM, Perk J, Reiner Z, Sattar N, Schächinger V, Scheen A, Schirmer H, Strömberg A, Sudzhaeva S, Viigimaa M, Vlachopoulos C, Xuereb RG. ESC Guidelines on diabetes, pre-diabetes, and cardiovascular diseases developed in collaboration with the EASD. Eur Heart J. 2013;34:3035-87.

320. Gilbert RE, Krum H. Heart failure in diabetes: effects of anti-hyperglycaemic drug therapy. Lancet 2015;385:2107-2117.

321. Edelmann F, Gelbrich G, Düngen H-D, Fröhling S, Wachter R, Stahrenberg R, Binder L, Töpper A, Lashki DJ, Schwarz S, Herrmann-Lingen C, Lö ffler M, Hasenfuss G, Halle M, Pieske B. Exercise training improves exercise capacity and diastolic function in patients with heart failure with preserved ejection fraction. J Am Coll Cardiol. 2011;58:1780-91.

322. Katritsis DG, Siontis GCM, Camm AJ. Prognostic significance of ambulatory ECG monitoring for ventricular arrhythmias. Prog Cardiovasc Dis. 2013;56:133-42.

323. Camm AJ, Corbucci G, Padeletti L. Usefulness of continuous electrocardiographic monitoring for atrial fibrillation. Am J Cardiol. 2012;110:270-6.

324. Turakhia MP, Ullal AJ, Hoang DD, Than CT, Miller JD, Friday KJ, Pérez MV, Freeman JV, Wang PJ, Heidenreich PA. Feasibility of extended ambulatory electrocardiogram monitoring to identify silent atrial fibrillation in high-risk patients: the Screening Study for Undiagnosed Atrial Fibrillation (STUDY-AF). Clin Cardiol. 2015;38: 285-92.

325. Camm AJ, Kirchhof P, Lip GYH, Schotten U, Savelieva I, Ernst S, Van Gelder IC, AlAttar N, Hindricks G, Prendergast B, Heidbuchel H, Alfieri O, Angelini A, Atar D, Colonna P, De Caterina R, De Sutter J, Goette A, Gorenek B, Heldal M, Hohloser SH, Kolh P, Le Heuzey JY, Ponikowski P, Rutten FH, Vahanian A, Auricchio A, Bax J, Ceconi C, Dean V, Filippatos G, Funck-Brentano C, Hobbs R, Kearney P, McDonagh T, Popescu BA, Reiner Z, Sechtem U, Sirnes PA, Tendera M, Vardas PE, Widimsky P, Agladze V, Aliot E, Balabanski T, Blomstrom-Lundqvist C, Capucci A, Crijns H, Dahlof B, Folliguet T, Glikson M, Goethals M, Gulba DC, Ho SY, Klautz RJM, Kose S, McMurray J, PerroneFilardi P, Raatikainen P, Salvador MJ, Schalij MJ, Shpektor A, Sousa J, Stepinska J, Uuetoa H, Zamorano JL, Zupan I. Guidelines for the management of atrial fibrillation: the Task Force for the Management of Atrial Fibrillation of the European Society of Cardiology (ESC). Eur Heart J. 2010;31:2369-429.

326. Cintra FD, Leite RP, Storti LJ, Bittencourt LA, Poyares D, Castro L de S, Tufik S, Paola A de. Sleep apnea and nocturnal cardiac arrhythmia: a populational study. Arq Bras Cardiol. 2014;103:368-74.

327. Gilat H, Vinker S, Buda I, Soudry E, Shani M, Bachar G. Obstructive sleep apnea and cardiovascular comorbidities: a large epidemiologic study. Medicine (Baltimore). 2014;93:e45.

328. Vizzardi E, Sciatti E, Bonadei I, D’Aloia A, Curnis A, Metra M. Obstructive sleep apnoea-hypopnoea and arrhythmias. J Cardiovasc Med 2014;1.

329. Bloch Thomsen PE, Jons C, Raatikainen MJP, MoerchJoergensen R, Hartikainen J, Virtanen V, Boland J, Anttonen O, Gang UJ, Hoest N, Boersma LVA, Platou ES, Becker D, Messier MD, Huikuri HV. Long-term recording of cardiac arrhythmias with an implantable cardiac monitor in patients with reduced ejection fraction after acute myocardial infarction: the Cardiac Arrhythmias and Risk Stratification After Acute Myocardial Infarction (CARISMA) study. Circulation. 2010;122:1258-64.

330. Faggiano P, D'Aloia A, Gualeni A, Gardini A, Giordano A. Mechanisms and immediate outcome of in-hospital cardiac arrest in patients with advanced heart failure secondary to ischemic or idiopathic dilated cardiomyopathy. Am J Cardiol. 2001;87:655-7, A10-A11.

331. Smit MD, Moes ML, Maass AH, Achekar ID, Van Geel PP, Hillege HL, van Veldhuisen DJ, Van Gelder IC. The importance of whether atrial fibrillation or heart failure develops first. Eur J Heart Fail. 2012;14:1030-40.

332. Swedberg K, Olsson LG, Charlesworth A, Cleland J, Hanrath P, Komajda M, Metra $\mathrm{M}$, Torp-Pedersen C, Poole-Wilson P. Prognostic relevance of atrial fibrillation in patients with chronic heart failure on long-term treatment with betablockers: results from COMET. Eur Heart J. 2005;26:1303-8.

333. Hoppe UC, Casares JM, Eiskjaer H, Hagemann A, Cleland JGF, Freemantle N, Erdmann E. Effect of cardiac resynchronization on the incidence of atrial fibrillation in patients with severe heart failure. Circulation. 2006;114:18-25.

334. Calvo N, Bisbal F, Guiu E, Ramos P, Nadal M, Tolosana JM, Arbelo E, Berruezo A, Sitges M, Brugada J, Mont L. Impact of atrial fibrillation-induced tachycardiomyopathy in patients undergoing pulmonary vein isolation. Int J Cardiol. 2013;168:4093-7.

335. Morris PD, Robinson T, Channer KS, Reversible heart failure: toxins, tachycardiomyopathy and mitochondrial abnormalities. Postgrad Med J. 2012;88:706-12.

336. Pedersen OD, Bagger $H$, Køber L, Torp-Pedersen C. Trandolapril reduces the incidence of atrial fibrillation after acute myocardial infarction in patients with left ventricular dysfunction. Circulation. 1999;100:376-80.

337. Ducharme A, Swedberg K, Pfeffer MA, Cohen-Solal A, Granger CB, Maggioni AP, Michelson EL, McMurray JJ V, Olsson L, Rouleau JL, Young JB, Olofsson B, Puu M, Yusuf S. Prevention of atrial fibrillation in patients with symptomatic chronic heart failure by candesartan in the Candesartan in Heart failure: Assessment of Reduction in Mortality and morbidity (CHARM) program. Am Heart J. 2006;152:86-92.

338. McMurray J, Køber L, Robertson M, Dargie H, Colucci W, López-Sendon J, Remme W, Sharpe DN, Ford I. Antiarrhythmic effect of carvedilol after acute myocardial infarction. J Am Coll Cardiol. 2005;45:525-30.

339. Swedberg K, Zannad F, McMurray JJV, Krum H, van Veldhuisen DJ, Shi H, Vincent J, Pitt B. Eplerenone and atrial fibrillation in mild systolic heart failure. J Am Coll Cardiol. 2012;59:1598-603.

340. Han M, Zhang Y, Sun S, Wang Z, Wang J, Xie X, Gao M, Yin X, Hou Y. Reninangiotensin system inhibitors prevent the recurrence of atrial fibrillation. J Cardiovasc Pharmacol. 2013;62:405-15. 
341. Martin RIR, Pogoryelova O, Koref MS, Bourke JP, Teare MD, Keavney BD. Atrial fibrillation associated with ivabradine treatment: meta-analysis of randomised controlled trials. Heart. 2014;100:1506-10.

342. Hess PL, Jackson KP, Hasselblad V, Al-Khatib SM. Is cardiac resynchronization therapy an antiarrhythmic therapy for atrial fibrillation? A systematic review and meta-analysis. Curr Cardiol Rep. 2013;15:330.

343. Brodsky MA, Allen BJ,Walker CJ, Casey TP, Luckett CR, Henry WL. Amiodarone for maintenance of sinus rhythm after conversion of atrial fibrillation in the setting of a dilated left atrium. Am J Cardiol. 1987;60:572-5.

344. Deedwania PC, Singh BN, Ellenbogen K, Fisher S, Fletcher R, Singh SN. Spontaneous conversion and maintenance of sinus rhythm by amiodarone in patients with heart failure and atrial fibrillation: observations from the veterans affairs congestive heart failure survival trial of antiarrhythmic therapy (CHF-STAT). The Department of Veterans Affairs CHF-STAT Investigators. Circulation. 1998;98:2574-9.

345. Shelton RJ, Clark AL, Goode K, Rigby AS, Houghton T, Kaye GC, Cleland JGF. A randomised, controlled study of rate versus rhythm control in patients with chronic atrial fibrillation and heart failure: (CAFE-II Study). Heart. 2009;95: 924-30.

346. Capucci A, Villani GQ, Aschieri D, Rosi A, Piepoli MF. Oral amiodarone increases the efficacy of direct-current cardioversion in restoration of sinus rhythm in patients with chronic atrial fibrillation. Eur Heart J. 2000;21:66-73.

347. Connolly SJ, Camm AJ, Halperin JL, Joyner C, Alings M, Amerena J, Atar D, Avezum Á, Blomström P, Borggrefe M, Budaj A, Chen S-A, Ching CK, Commerford P, Dans A, Davy J-M, Delacrétaz E, Di Pasquale G, Díaz R, Dorian P, Flaker G, Golitsyn S, González-Hermosillo A, Granger CB, Heidbüchel H, Kautzner J, Kim JS, Lanas F, Lewis BS, Merino JL, Morillo C, Murin J, Narasimhan C, Paolasso E, Parkhomenko A, Peters NS, Sim K-H, Stiles MK, Tanomsup S, Toivonen L, Tomcsányi J, TorpPedersen C, Tse H-F, Vardas P, Vinereanu D, Xavier D, Zhu J-R, Zhu JR, BaretCormel L, Weinling E, Staiger C, Yusuf S, Chrolavicius S, Afzal R, Hohnloser SH. Dronedarone in high-risk permanent atrial fibrillation. $\mathrm{N}$ Engl J Med. 2011;365:2268-76.

348. Hofmann R, Steinwender C, Kammler J, Kypta A, Leisch F. Effects of a high dose intravenous bolus amiodarone in patients with atrial fibrillation and a rapid ventricular rate. Int J Cardiol. 2006;110:27-32.

349. Hofmann R, Wimmer G, Leisch F. Intravenous amiodarone bolus immediately controls heart rate in patients with atrial fibrillation accompanied by severe congestive heart failure. Heart. 2000;84:635.

350. Li SJ, Sartipy U, Lund LH, Dahlström U, Adiels M, Petzold M, Fu M. Prognostic significance of resting heart rate and use of b-blockers in atrial fibrillation and sinus rhythm in patients with heart failure and reduced ejection fraction: findings from the Swedish Heart Failure Registry. Circ Heart Fail. 2015;8:871-9.

351. Mareev Y, Cleland JGF. Should $\beta$-blockers be used in patients with heart failure and atrial fibrillation? Clin Ther. 2015;37:2215-24.

352. Hagens VE, Crijns HJGM, Van Veldhuisen DJ, Van Den Berg MP, Rienstra M, Ranchor AV, Bosker HA, Kamp O, Tijssen JGP, Veeger NJGM, Van Gelder IC. Rate control versus rhythm control for patients with persistent atrial fibrillation with mild to moderate heart failure: results from the RAte Control versus Electrical cardioversion (RACE) study. Am Heart J. 2005;149:1106-11.

353. Van Gelder IC, Hagens VE, Bosker HA, Kingma JH, Kamp O, Kingma T, Said SA, Darmanata JI, Timmermans AJM, Tijssen JGP, Crijns HJGM. A comparison of rate control and rhythm control in patients with recurrent persistent atrial fibrillation. N Engl J Med. 2002;347:1834-40.

354. Van Gelder IC, Wyse DG, Chandler ML, Cooper HA, Olshansky B, Hagens VE, Crijns HJGM, RACE and AFFIRM Investigators. Does intensity of rate-control influence outcome in atrial fibrillation? An analysis of pooled data from the RACE and AFFIRM studies. Europace. 2006;8:935-42.

355. Allen LA, Fonarow GC, Simon DN, Thomas LE, Marzec LN, Pokorney SD, Gersh BJ, Go AS, Hylek EM, Kowey PR, Mahaffey KW, Chang P, Peterson ED, Piccini JP. Digoxin use and subsequent outcomes among patients in a contemporary atrial fibrillation cohort. J Am Coll Cardiol. 2015;65:2691-8.

356. Gheorghiade M, Fonarow GC, van Veldhuisen DJ, Cleland JGF, Butler J, Epstein AE Patel K, Aban IB, Aronow WS, Anker SD, Ahmed A. Lack of evidence of increased mortality among patients with atrial fibrillation taking digoxin: findings from post hoc propensity-matched analysis of the AFFIRM trial. Eur Heart J. 2013:34:1489-97.

357. Turakhia MP, Santangeli P, Winkelmayer WC, Xu X, Ullal AJ, Than CT, Schmitt S, Holmes TH, Frayne SM, Phibbs CS, Yang F, Hoang DD, Ho PM, Heidenreich PA. Increased mortality associated with digoxin in contemporary patients with atrial fibrillation. J Am Coll Cardiol. 2014;64:660-8.

358. Khand AU, Rankin AC, Martin W, Taylor J, Gemmell I, Cleland JGF. Carvedilol alone or in combination with digoxin for the management of atrial fibrillation in patients with heart failure? J Am Coll Cardiol. 2003;42:1944-51.

359. Roy D, Talajic M, Nattel S, Wyse DG, Dorian P, Lee KL, Bourassa MG, Arnold JMO, Buxton AE, Camm AJ, Connolly SJ, Dubuc M, Ducharme A, Guerra PG, Hohnloser SH, Lambert J, Le Heuzey J-Y, O'Hara G, Pedersen OD, Rouleau J-L, Singh BN, Stevenson LW, Stevenson WG, Thibault B, Waldo AL. Rhythm control versus rate control for atrial fibrillation and heart failure. N Engl J Med. 2008;358:2667-77.

360. Khan MN, Jais P, Cummings J, Di Biase L, Sanders P, Martin DO, Kautzner J, Hao S, Themistoclakis S, Fanelli R, Potenza D, Massaro R, Wazni O, Schweikert R, Saliba W, Wang P, Al-Ahmad A, Beheiry S, Santarelli P, Starling RC, Dello Russo A, Pelargonio G, Brachmann J, Schibgilla V, Bonso A, Casella M, Raviele A, Haissaguerre M, Natale A. Pulmonary-vein isolation for atrial fibrillation in patients with heart failure. N Engl J Med. 2008;359:1778-85.

361. Ganesan AN, Nandal S, Lüker J, Pathak RK, Mahajan R, Twomey D, Lau DH, Sanders P. Catheter ablation of atrial fibrillation in patients with concomitant left ventricular impairment: a systematic review of efficacy and effect on ejection fraction. Heart Lung Circ. 2015;24:270-80.

362. Marrouche NF, Brachmann J. Catheter ablation versus standard conventiona treatment in patients with left ventricular dysfunction and atrial fibrillation (CASTLE-AF) - study design. Pacing Clin Electrophysiol. 2009;32:987-94.

363. Khan AR, Khan S, Sheikh MA, Khuder S, Grubb B, Moukarbel GV. Catheter ablation and antiarrhythmic drug therapy as first- or second-line therapy in the management of atrial fibrillation: systematic review and meta-analysis. Circ Arrhythm Electrophysiol. 2014;7:853-60.

364. Lafuente-Lafuente C, Valembois L, Bergmann J-F, Belmin J. Antiarrhythmics for maintaining sinus rhythm after cardioversion of atrial fibrillation. Cochrane Database Syst Rev. 2012;5:CD005049.

365. A multicentre, randomized trial on the benefit/risk profile of amiodarone, flecainide and propafenone in patients with cardiac disease and complex ventricular arrhythmias. Antiarrhythmic Drug Evaluation Group (A.D.E.G.). Eur Heart J. 1992;13:1251-8.

366. Ruff CT, Giugliano RP, Braunwald E, Hoffman EB, Deenadayalu N, Ezekowitz MD, Camm AJ, Weitz JI, Lewis BS, Parkhomenko A, Yamashita T, Antman EM Comparison of the efficacy and safety of new oral anticoagulants with warfarin in patients with atrial fibrillation: a meta-analysis of randomised trials. Lancet. 2014;383:955-62.

367. Xiong Q Lau YC, Senoo K, Lane DA, Hong K, Lip GYH. Non-vitamin K antagonist oral anticoagulants (NOACs) in patients with concomitant atrial fibrillation and heart failure: a systemic review and meta-analysis of randomized trials. Eur J Heart Fail. 2015;17:1192-200.

368. Sardar P, Chatterjee S, Lavie CJ, Giri JS, Ghosh J, Mukherjee D, Lip GYH. Risk of major bleeding in different indications for new oral anticoagulants: insights from a meta-analysis of approved dosages from 50 randomized trials. Int J Cardiol. 2015;179:279-87.

369. Sardar P, Chatterjee S, Chaudhari S, Lip GYH. New oral anticoagulants in elderly adults: evidence from a meta-analysis of randomized trials. J Am Geriatr Soc. 2014;62:857-64

370. Heidbuchel H, Verhamme P, Alings M, Antz M, Diener H-C, HackeW, Oldgren J, Sinnaeve P, Camm AJ, Kirchhof P. Updated European Heart Rhythm Association practical guide on the use of non-vitamin $\mathrm{K}$ antagonist anticoagulants in patients with non-valvular atrial fibrillation. Europace. 2015;17:1467-507.

371. Connolly SJ, Ezekowitz MD, Yusuf S, Eikelboom J, Oldgren J, Parekh A, Pogue J, Reilly PA, Themeles E, Varrone J, Wang S, Alings M, Xavier D, Zhu J, Díaz R, Lewis BS, Darius H, Diener H-C, Joyner CD,Wallentin L. Dabigatran versus warfarin in patients with atrial fibrillation. N Engl J Med. 2009;361:1139-51.

372. Patel MR, Mahaffey KW, Garg J, Pan G, Singer DE, Hacke W, Breithardt G, Halperin JL, Hankey GJ, Piccini JP, Becker RC, Nessel CC, Paolini JF, Berkowitz SD, Fox KAA, Califf RM. Rivaroxaban versus warfarin in nonvalvular atrial fibrillation. N Engl J Med. 2011;365:883-91.

373. Giugliano RP, Ruff CT, Braunwald E, Murphy SA, Wiviott SD, Halperin JL, Waldo AL, Ezekowitz MD, Weitz JI, Špinar J, Ruzyllo W, Ruda M, Koretsune Y, Betcher J, Shi M, Grip LT, Patel SP, Patel I, Hanyok JJ, Mercuri M, Antman EM. Edoxaban versus warfarin in patients with atrial fibrillation. N Engl J Med. 2013;369:2093-104

374. Granger CB, Alexander JH, McMurray JJV, Lopes RD, Hylek EM, Hanna M, AlKhalidi HR, Ansell J, Atar D, Avezum A, Bahit MC, Díaz R, Easton JD, Ezekowitz JA, Flaker G, García D, Geraldes M, Gersh BJ, Golitsyn S, Goto S, Hermosillo AG, Hohnloser SH, Horowitz J, Mohan P, Jansky P, Lewis BS, López-Sendon JL, Pais P, Parkhomenko A, Verheugt FWA, Zhu J, Wallentin L. Apixaban versus warfarin in patients with atrial fibrillation. N Engl J Med. 2011;365:981-92.

375. Connolly SJ, Eikelboom J, Joyner C, Diener HC, Hart R, Golitsyn S, Flaker G, Avezum A, Hohnloser SH, Díaz R, Talajic M, Zhu J, Pais P, Budaj A, Parkhomenko A, Jansky P, Commerford P, Tan RS, Sim K-H, Lewis BS, Van Mieghem W, Lip GYH Kim JH, Lanas-Zanetti F, González-Hermosillo A, Dans AL, Munawar M, O’Donnell M, Lawrence J, Lewis G, Afzal R, Yusuf S. Apixaban in patients with atrial fibrillation. N Engl J Med. 2011;364:806-17.

376. Lip GYH, Nieuwlaat R, Pisters R, Lane DA, Crijns HJGM. Refining clinical risk stratification for predicting stroke and thromboembolism in atrial fibrillation using a novel risk factor-based approach: the Euro Heart Survey on atrial fibrillation. Chest. 2010;137:263-72.

377. Pisters R, Lane DA, Nieuwlaat R. A novel user-friendly score (HAS BLED) to asses 1 -year risk of major bleeding in patients with atrial fibrillation. Chest J. 2010;138:1093-100.

378. Connolly SJ, Ezekowitz MD, Yusuf S, Reilly PA, Wallentin L. Newly identified events in the RE-LY trial. N Engl J Med. 2010;363:1875-6.

379. Hart RG, Pearce LA, Aguilar MI. Meta-analysis: antithrombotic therapy to prevent stroke in patients who have nonvalvular atrial fibrillation. Ann Intern Med 2007:146:857-67.

380. Eikelboom JW, Connolly SJ, Brueckmann M, Granger CB, Kappetein AP, Mack MJ, Blatchford J, Devenny K, Friedman J, Guiver K, Harper R, Khder Y, Lobmeyer MT Maas H, Voigt J-U, Simoons ML, Van deWerf F. Dabigatran versus warfarin in patients with mechanical heart valves. N Engl J Med. 2013;369:1206-14.

381. Holmes DR, Doshi SK, Kar S, Price MJ, Sanchez JM, Sievert H, Valderrabano M Reddy VY. Left atrial appendage closure as an alternative to warfarin for stroke prevention in atrial fibrillation: a patient-level meta-analysis. J Am Coll Cardiol. 2015;65:2614-23.

382. Price MJ, Reddy VY, Valderrábano M, Halperin JL, Gibson DN, Gordon N, Huber $\mathrm{KC}$, Holmes DR. Bleeding outcomes after left atrial appendage closure compared with long-term warfarin: a pooled, patient-level analysis of the WATCHMAN randomized trial experience. JACC Cardiovasc Interv. 2015;8:1925-32.

383. Cleland JG, Massie BM, Packer M. Sudden death in heart failure: vascular or electrical? Eur J Heart Fail. 1999;1:41-5. 
384. Desai AS, McMurray JJ V, Packer M, Swedberg K, Rouleau JL, Chen F, Gong J, Rizkala AR, Brahimi A, Claggett B, Finn P V, Hartley LH, Liu J, Lefkowitz M, Shi V, Zile MR, Solomon SD. Effect of the angiotensin-receptor-neprilysin inhibitor LCZ696 compared with enalapril on mode of death in heart failure patients. Eur Heart J. 2015;36:1990-7.

385. Velázquez EJ, Lee KL, Deja MA, Jain A, Sopko G, Marchenko A, Ali IS, Pohost G, Gradinac S, Abraham WT, Yii M, Prabhakaran D, Szwed H, Ferrazzi P, Petrie MC, O’Connor CM, Panchavinnin P, She L, Bonow RO, Rankin GR, Jones RH, Rouleau J-L, STICH Investigators. Coronary-artery bypass surgery in patients with left ventricular dysfunction. N Engl J Med. 2011;364:1607-16.

386. Panza JA, Holly TA, Asch FM, She L, Pellikka PA, Velázquez EJ, Lee KL, Borges-Neto S, Farsky PS, Jones RH, Berman DS, Bonow RO. Inducible myocardial ischemia and outcomes in patients with coronary artery disease and left ventricular dysfunction. J Am Coll Cardiol. 2013;61:1860-70.

387. Carson P, Wertheimer J, Miller A, O'Connor CM, Pina IL, Selzman C, Sueta C, She L, Greene D, Lee KL, Jones RH, Velázquez EJ. The STICH trial (Surgical Treatment for Ischemic Heart Failure): mode-of-death results. JACC Heart Fail. 2013;1: 400-8.

388. Oseroff O, Retyk E, Bochoeyer A. Subanalyses of secondary prevention implantable cardioverter-defibrillator trials: antiarrhythmics versus implantable defibrillators (AVID), Canadian Implantable Defibrillator Study (CIDS), and Cardiac Arrest Study Hamburg (CASH). Curr Opin Cardiol. 2004;19:26-30.

389. Brignole M, Auricchio A, Baron-Esquivias G, Bordachar P, Boriani G, Breithardt O-A, Cleland J, Deharo J-C, Delgado V, Elliott PM, Gorenek B, Israel CW, Leclercq C, Linde C, Mont L, Padeletti L, Sutton R, Vardas PE, Zamorano JL, Achenbach S, Baumgartner H, Bax JJ, Bueno H, Dean V, Deaton C, Erol C, Fagard R, Ferrari R, Hasdai D, Hoes AW, Kirchhof P, Knuuti J, Kolh P, Lancellotti P, Linhart A, Nihoyannopoulos P, Piepoli MF, Ponikowski P, Sirnes PA, Tamargo JL, Tendera M, Torbicki A, Wijns W, Windecker S, Blomstrom-Lundqvist C, Badano LP, Aliyev F, Bänsch D, Bsata W, Buser P, Charron P, Daubert J-C, Dobreanu D, Faerestrand S, Le Heuzey J-Y, Mavrakis H, McDonagh T, Merino JL, Nawar MM, Nielsen JC, Pieske B, Poposka L, Ruschitzka F, Van Gelder IC, Wilson CM. 2013 ESC Guidelines on cardiac pacing and cardiac resynchronization therapy: the Task Force on cardiac pacing and resynchronization therapy of the European Society of Cardiology (ESC). Developed in collaboration with the European Heart Rhythm Association. Eur Heart J. 2013;34:2281-29.

390. Blondé-Cynober F, Morineau G, Estrugo B, Fillie E, Aussel C, Vincent J-P. Diagnostic and prognostic value of brain natriuretic peptide (BNP) concentrations in very elderly heart disease patients: specific geriatric cut-off and impacts of age, gender, renal dysfunction, and nutritional status. Arch Gerontol Geriatr. 2011;52:106-10.

391. HawkinsNM, Virani S, Ceconi C. Heart failure and chronic obstructive pulmonary disease: the challenges facing physicians and health services. Eur Heart J. 2013;34:2795-807.

392. Enjuanes C, Klip IT, Bruguera J, Cladellas M, Ponikowski P, Banasiak W, van Veldhuisen DJ, van der Meer P, Jankowska EA, Comín-Colet J. Iron deficiency and health-related quality of life in chronic heart failure: results from a multicenter European study. Int J Cardiol. 2014;174:268-75.

393. Braunstein JB, Anderson GF, Gerstenblith G, Weller W, Niefeld M, Herbert R, Wu AW. Noncardiac comorbidity increases preventable hospitalizations and mortality among Medicare beneficiaries with chronic heart failure. J Am Coll Cardiol. 2003;42:1226-33.

394. Muzzarelli S, Leibundgut G, Maeder MT, Rickli H, Handschin R, Gutmann M, Jeker U, Buser P, Pfisterer M, Brunner-La Rocca H-P. Predictors of early readmission or death in elderly patients with heart failure. Am Heart J. 2010;160:308-14.

395. Reddel HK, Bateman ED, Becker A, Boulet L-P, Cruz AA, Drazen JM, Haahtela T, Hurd SS, Inoue $\mathrm{H}$, de Jongste JC, Lemanske RF, Levy ML, O'Byrne PM, Paggiaro P Pedersen SE, Pizzichini E, Soto-Quiroz M, Szefler SJ,Wong GWK, FitzGerald JM. A summary of the new GINA strategy: a roadmap to asthma control. Eur Respir J. 2015;46:622-39.

396. Global Initiative for Asthma. Global Strategy for Asthma Management and Prevention, Available at http://ginasthma.org/gina-report-global-strategy-forasthmamanagement-and-prevention (date last accessed 12 February 2016).

397. Eschenhagen T, Force T, Ewer MS, De Keulenaer GW, Suter TM, Anker SD, Avkiran M, De Azambuja E, Balligand JL, Brutsaert DL, Condorelli G, Hansen A, Heyman S, Hill J a, Hirsch E, Hilfiker-Kleiner D, Janssens S, De Jong S, Neubauer G, Pieske B, Ponikowski P, Pirmohamed M, Rauchhaus M, Sawyer D, Sugden PH, Wojta J, Zannad F, Shah AM. Cardiovascular side effects of cancer therapies: a position statement from the Heart Failure Association of the European Society of Cardiology. Eur J Heart Fail. 2011;13:1-10.

398. Paulus WJ, Tschöpe C. A novel paradigm for heart failure with preserved ejection fraction. J Am Coll Cardiol. 2013;62:263-71.

399. Fox K, Ford I, Steg PG, Tardif J-C, Tendera M, Ferrari R. Ivabradine in stable coronary artery disease without clinical heart failure. $N$ Engl J Med. 2014;371:1091-9.

400. Marazzi G, Wajngarten M, Vitale C, Patrizi R, Pelliccia F, Gebara O, Pierri H, Ramires JAF, Volterrani M, Fini M, Rosano GMC. Effect of free fatty acid inhibition on silent and symptomatic myocardial ischemia in diabetic patients with coronary artery disease. Int J Cardiol. 2007;120:79-84.

401. Vitale C, Spoletini I, MalorniW, Perrone-Filardi P, Volterrani M, Rosano GMC Efficacy of trimetazidine on functional capacity in symptomatic patients with stable exertional angina-the VASCO-angina study. Int J Cardiol. 2013;168:1078 81.

402. Vitale C, Wajngaten M, Sposato B, Gebara O, Rossini P, Fini M, Volterrani M, Rosano GMC. Trimetazidine improves left ventricular function and quality of life in elderly patients with coronary artery disease. Eur Heart J. 2004;25:1814-21.
403. Gao D, Ning N, Niu X, Hao G, Meng Z. Trimetazidine: a meta-analysis of randomised controlled trials in heart failure. Heart. 2011;97:278-86.

404. Tuunanen H, Engblom E, Naum A, Nagren K, Scheinin M, Hesse B, Juhani Airaksinen KE, Nuutila P, Iozzo P, Ukkonen H, Opie LH, Knuuti J. Trimetazidine, a metabolic modulator, has cardiac and extracardiac benefits in idiopathic dilated cardiomyopathy. Circulation. 2008;118:1250-8.

405. Marazzi G, Gebara O, Vitale C, Caminiti G, Wajngarten M, Volterrani M, Ramires JAF, Rosano G, Fini M. Effect of trimetazidine on quality of life in elderly patients with ischemic dilated cardiomyopathy. Adv Ther. 2009;26:455-61.

406. Rosano G, Vitale C, Sposato B, Mercuro G, Fini M. Trimetazidine improves left ventricular function in diabetic patients with coronary artery disease: a doubleblind placebo-controlled study. Cardiovasc Diabetol. 2003;2:16.

407. Wijeysundera HC, Hansen MS, Stanton E, Cropp a. S, Hall C, Dhalla NS, Ghali J, Rouleau JL. Neurohormones and oxidative stress in nonischemic cardiomyopathy: Relationship to survival and the effect of treatment with amlodipine. Am Heart J. 2003;146:291-7.

408. IONA Study Group. Effect of nicorandil on coronary events in patients with stable angina: the Impact Of Nicorandil in Angina (IONA) randomised trial. Lancet. 2002;359:1269-75.

409. Cohn JN, Johnson G, Ziesche S, Cobb F, Francis G, Tristani F, Smith R, Dunkman WB, Loeb H, Wong M, Bhat G, Goldman S, Fletcher RD, Doherty J, Hughes CV, Carson P, Cintron G, Shabetai R, Haakenson C. A comparison of enalapril with hydralazine-isosorbide dinitrate in the treatment of chronic congestive heart failure. N Engl J Med. 1991;325:303-10.

410. Fox K, Ford I, Steg PG, Tendera M, Ferrari R. Ivabradine for patients with stable coronary artery disease and left-ventricular systolic dysfunction (BEAUTIFUL): a randomised, double-blind, placebo-controlled trial. Lancet. 2008;372: 807-16.

411. Fox K, Ford I, Steg PG, Tendera M, Robertson M, Ferrari R. Relationship between ivabradine treatment and cardiovascular outcomes in patients with stable coronary artery disease and left ventricular systolic dysfunction with limiting angina: a subgroup analysis of the randomized, controlled BEAUTIFUL trial. Eur Heart J. 2009;30:2337-45.

412. Pursnani S, Korley F, Gopaul R, Kanade P, Chandra N, Shaw RE, Bangalore S. Percutaneous coronary intervention versus optimal medical therapy in stable coronary artery disease: a systematic review and meta-analysis of randomized clinical trials. Circ Cardiovasc Interv. 2012;5:476-90.

413. Trikalinos TA, Alsheikh-Ali AA, Tatsioni A, Nallamothu BK, Kent DM. Percutaneous coronary interventions for non-acute coronary artery disease: a quantitative 20year synopsis and a network meta-analysis. Lancet. 2009;373:911-8.

414. von Haehling S, Anker SD. Prevalence, incidence and clinical impact of cachexia: facts and numbers-update 2014. J Cachexia Sarcopenia Muscle. 2014;5:261-3.

415. von Haehling S, Lainscak M, Springer J, Anker SD. Cardiac cachexia: a systematic overview. Pharmacol Ther. 2009;121:227-52.

416. Evans WJ, Morley JE, Argilés J, Bales C, Baracos V, Guttridge D, Jatoi A, KalantarZadeh K, Lochs H, Mantovani G, Marks D, Mitch WE, Muscaritoli M, Najand A, Ponikowski P, Rossi Fanelli F, Schambelan M, Schols A, Schuster M, Thomas D, Wolfe R, Anker SD. Cachexia: a new definition. Clin Nutr. 2008;27:793-9.

417. Akashi YJ, Springer J, Anker SD. Cachexia in chronic heart failure: prognostic implications and novel therapeutic approaches. Curr Heart Fail Rep. 2005;2: 198-203.

418. Anker SD, Chua TP, Ponikowski P, Harrington D, Swan JW, Kox WJ, Poole-Wilson PA, Coats AJ. Hormonal changes and catabolic/anabolic imbalance in chronic heart failure and their importance for cardiac cachexia. Circulation. 1997;96: 526-34.

419. Fülster S, Tacke M, Sandek A, Ebner N, Tschöpe C, DoehnerW, Anker SD, Von Haehling S. Muscle wasting in patients with chronic heart failure: results from the studies investigating co-morbidities aggravating heart failure (SICA-HF). Eur Heart J. 2013;34:512-9.

420. Morley JE, Anker SD, von Haehling S. Prevalence, incidence, and clinical impact of sarcopenia: facts, numbers, and epidemiology-update 2014. J Cachexia Sarcopenia Muscle. 2014;5:253-9.

421. von Haehling S, Anker SD. Treatment of cachexia: an overview of recent developments. J Am Med Dir Assoc. 2014;15:866-72.

422. Jones AL, Barlow M, Barrett-Lee PJ, Canney PA, Gilmour IM, Robb SD, Plummer CJ, Wardley AM, Verrill MW. Management of cardiac health in trastuzumab-treated patients with breast cancer: updated United Kingdom National Cancer Research Institute recommendations for monitoring. Br J Cancer. 2009;100:684-92.

423. van Dalen EC, Caron HN, Dickinson HO, Kremer LCM. Cardioprotective interventions for cancer patients receiving anthracyclines. Cochrane Database Syst Rev. 2005;6:CD003917.

424. Ezaz G, Long JB, Gross CP, Chen J. Risk prediction model for heart failure and cardiomyopathy after adjuvant trastuzumab therapy for breast cancer. J Am Heart Assoc. 2014;3:e000472.

425. Suter TM, Ewer MS. Cancer drugs and the heart: Importance and management. Eur Heart J. 2013;34:1102-11.

426. Zamorano J-L, Lancelotti P et al. 2016 Position paper on anticancer treatments and cardiovascular toxicity. Eur Heart J. 2016. doi: 10.1093/eurheartj/ehw211. Forthcoming.

427. Tjeerdsma G, Szabó BM, van Wijk LM, Brouwer J, Tio RA, Crijns HJ, van Veldhuisen DJ. Autonomic dysfunction in patients with mild heart failure and coronary artery disease and the effects of add-on beta-blockade. Eur J Heart. Fail 2001;3:33-9.

428. Fan H, YuW, Zhang Q, Cao H, Li J,Wang J, Shao Y, Hu X. Depression after heart failure and risk of cardiovascular and all-cause mortality: a meta-analysis. Prev Med. 2014;63:36-42. 
429. Díez-Quevedo C, Lupón J, González B, Urrutia A, Cano L, Cabanes R, Altimir S, Coll R, Pascual T, de Antonio M, Bayes-Genis A. Depression, antidepressants, and longterm mortality in heart failure. Int J Cardiol. 2013;167:1217-25.

430. Newhouse A, Jiang W. Heart failure and depression. Heart Fail Clin. 2014;10:295304.

431. Lahlou-Laforêt K, Ledru F, Niarra R, Consoli SM. Validity of beck depression inventory for the assessment of depressive mood in chronic heart failure Patients. J Affect Disord. 2015;184:256-60.

432. Ski CF, Thompson DR, Hare DL, Stewart AG, Watson R. Cardiac Depression Scale: Mokken scaling in heart failure patients. Health Qual Life Outcomes. 2012;10:141.

433. Tu RH, Zeng ZY, Zhong GQ, Wu WF, Lu YJ, Bo ZD, He Y, Huang WQ Yao LM. Effects of exercise training on depression in patients with heart failure: a systematic review and meta-analysis of randomized controlled trials. Eur J Heart Fail. 2014;16:749-57.

434. Blumenthal JA, Babyak MA, O'Connor C, Keteyian S, Landzberg J, Howlett J, KrausW, Gottlieb S, Blackburn G, Swank A, Whellan DJ. Effects of exercise training on depressive symptoms in patients with chronic heart failure: the HF-ACTION randomized trial. JAMA. 2012;308:465-74.

435. O'Connor CM, Jiang W, Kuchibhatla M, Silva SG, Cuffe MS, Callwood DD, Zakhary B, Stough WG, Arias RM, Rivelli SK, Krishnan R. Safety and efficacy of sertraline for depression in patients with heart failure: results of the SADHART-CHF (Sertraline Against Depression and Heart Disease in Chronic Heart Failure) trial. J Am Coll Cardiol. 2010;56:692-9.

436. Bakris GL, Fonseca V, Katholi RE, McGill JB, Messerli FH, Phillips RA, Raskin P Wright JT, Oakes R, Lukas MA, Anderson KM, Bell DSH, GEMINI Investigators for the. Metabolic effects of carvedilol vs metoprolol in patients with type 2 diabetes mellitus and hypertension: a randomized controlled trial. JAMA. 2004;292: 2227-36.

437. Aguilar D, Bozkurt B, Ramasubbu K, Deswal A. Relationship of hemoglobin A1C and mortality in heart failure patients with diabetes. J Am Coll Cardiol. 2009;54:422-8.

438. Gerstein HC, Swedberg K, Carlsson J, McMurray JJ V, Michelson EL, Olofsson B, Pfeffer MA, Yusuf S. The hemoglobin A1c level as a progressive risk factor for cardiovascular death, hospitalization for heart failure, or death in patients with chronic heart failure: an analysis of the Candesartan in Heart failure: Assessment of Reduction in Mortality and Morbidity (CHARM) program. Arch Intern Med. 2008;168:1699-704.

439. Goode KM, John J, Rigby AS, Kilpatrick ES, Atkin SL, Bragadeesh T, Clark AL, Cleland JGF. Elevated glycated haemoglobin is a strong predictor of mortality in patients with left ventricular systolic dysfunction who are not receiving treatment for diabetes mellitus. Heart. 2009;95:917-23.

440. MacDonald MR, Eurich DT, Majumdar SR, Lewsey JD, Bhagra S, Jhund PS, Petrie MC, McMurray JJ V, Petrie JR, McAlister FA. Treatment of type 2 diabetes and outcomes in patients with heart failure: a nested case-control study from the U.K. General Practice Research Database. Diabetes Care. 2010;33:1213-8.

441. Boussageon R, Supper I, Bejan-Angoulvant T, Kellou N, Cucherat M, Boissel J-P, Kassai B, Moreau A, Gueyffier F, Cornu C. Reappraisal of metformin efficacy in the treatment of type 2 diabetes: a meta-analysis of randomised controlled trials. PLoS Med. 2012;9:e1001204.

442. Monami M, Dicembrini I, Mannucci E. Dipeptidyl peptidase-4 inhibitors and heart failure: a meta-analysis of randomized clinical trials. Nutr Metab Cardiovasc Dis. 2014;24:689-97.

443. Savarese G, Perrone-Filardi P, D’Amore C, Vitale C, Trimarco B, Pani L, Rosano GMC. Cardiovascular effects of dipeptidyl peptidase-4 inhibitors in diabetic patients: a meta-analysis. Int J Cardiol. 2015;181:239-44.

444. Giagulli VA, Moghetti P, Kaufman JM, Guastamacchia E, Iacoviello M, Triggiani V. Managing erectile dysfunction in heart failure. Endocr Metab Immune Disord Drug Targets. 2013;13:125-34

445. Vlachopoulos C, Jackson G, Stefanadis C, Montorsi P. Erectile dysfunction in the cardiovascular patient. Eur Heart J. 2013;34:2034-46.

446. Guazzi M, Vicenzi M, Arena R, Guazzi MD. PDE5 inhibition with sildenafil improves left ventricular diastolic function, cardiac geometry, and clinical status in patients with stable systolic heart failure: results of a 1-year, prospective, randomized, placebo-controlled study. Circ Heart Fail. 2011;4:8-17.

447. Giannetta E, Feola T, Gianfrilli D, Pofi R, Dall'Armi V, Badagliacca R, Barbagallo F, Lenzi A, Isidori AM, Dall'Armi V, Badagliacca R, Barbagallo F, Lenzi A, Isidori AM. Is chronic inhibition of phosphodiesterase type 5 cardioprotective and safe? A meta-analysis of randomized controlled trials. BMC Med. 2014;12:185.

448. Anker SD. Uric acid and survival in chronic heart failure: validation and application in metabolic, functional, and hemodynamic staging. Circulation. 2003; 107:1991-7.

449. Zhang W. EULAR evidence-based recommendations for gout. Part II: management. Report of a task force of the EULAR Standing Committee for International Clinical Studies Including Therapeutics (ESCISIT). Ann Rheum Dis. 2006;65:1312-24.

450. Uric acid and xanthine oxidase in heart failure - Emerging data and therapeutic implications. Doehner W, Jankowska EA, Springer J, Lainscak M, Anker SD. Int J Cardiol. 2015 Aug 11. pii: S0167-5273(15)30319-3. doi: 10.1016/j.ijcard. 2015.08.089. [Epub ahead of print]

451. Desai AS. Hyperkalemia in patients with heart failure: incidence, prevalence, and management. Curr Heart Fail Rep. 2009;6:272-80.

452. Mahoney BA, Smith WA, Lo D, Tsoi K, Tonelli M, Clase C. Emergency interventions for hyperkalaemia. Cochrane Database Syst Rev. 2005;2:CD003235.

453. Packham DK, Rasmussen HS, Lavin PT, El-Shahawy MA, Roger SD, Block G, Qunibi W, Pergola P, Singh B. Sodium zirconium cyclosilicate in hyperkalemia. N Engl J Med. 2015;372:222-31.
454. Weir MR, Bakris GL, Bushinsky DA, Mayo MR, Garza D, Stasiv Y, Wittes J, ChristSchmidt $\mathrm{H}$, Berman L, Pitt B. Patiromer in patients with kidney disease and hyperkalemia receiving RAAS inhibitors. N Engl J Med. 2015;372:211-21.

455. Anker SD, Kosiborod M, Zannad F, Piña IL, McCullough PA, Filippatos G, van der Meer P, Ponikowski P, Rasmussen HS, Lavin PT, Singh B, Yang A, Deedwania P. Maintenance of serum potassium with sodium zirconium cyclosilicate (ZS-9) in heart failure patients: results from a phase 3 randomized, double-blind, placebocontrolled trial. Eur J Heart Fail. 2015;17:1050-6.

456. Pitt B, Bakris GL, Bushinsky DA, Garza D, Mayo MR, Stasiv Y, Christ-Schmidt H Berman L, Weir MR. Effect of patiromer on reducing serum potassium and preventing recurrent hyperkalaemia in patients with heart failure and chronic kidney disease on RAAS inhibitors. Eur J Heart Fail. 2015;17:1057-65.

457. Tavazzi L, Maggioni AP, Marchioli R, Barlera S, Franzosi MG, Latini R, Lucci D, Nicolosi GL, Porcu M, Tognoni G. Effect of rosuvastatin in patients with chronic heart failure (the GISSI-HF trial): a randomised, double-blind, placebo-controlled trial. Lancet. 2008;372:1231-9.

458. Major cardiovascular events in hypertensive patients randomized to doxazosin vs chlorthalidone. ALLHAT Collaborative Research Group. JAMA. 2000;283: 1967-75

459. Lip GYH, Skjøth F, Overvad K, Rasmussen LH, Larsen TB. Blood pressure and prognosis in patients with incident heart failure: the Diet, Cancer and Health (DCH) cohort study. Clin Res Cardiol. 2015;104:1088-96.

460. Cohn JN, Pfeffer MA, Rouleau J, Sharpe N, Swedberg K, Straub M, Wiltse C, Wright T], MOXCON Investigators. Adverse mortality effect of central sympathetic inhibition with sustained-release moxonidine in patients with heart failure (MOXCON). Eur J Heart Fail. 2003;5:659-67.

461. Maggioni AP, Anand I, Gottlieb SO, Latini R, Tognoni G, Cohn JN. Effects of valsartan on morbidity and mortality in patients with heart failure not receiving angiotensin-converting enzyme inhibitors. J Am Coll Cardiol. 2002;40:1414-21.

462. Pitt B, Anker SD, Bushinsky DA, KitzmanDW, Zannad F, Huang I-Z. Evaluation of the efficacy and safety of RLY5016, a polymeric potassium binder, in a doubleblind, placebo-controlled study in patients with chronic heart failure (the PEARL-HF) trial. Eur Heart J. 2011;32:820-8.

463. Packer M, Bristow MR, Cohn JN, Colucci WS, Fowler MB, Gilbert EM, Shusterman NH, U.S. Carvedilol Heart Failure Study Group. The effect of carvedilol on morbidity and mortality in patients with chronic heart failure. N Engl J Med. 1996;334:1349-55.

464. Dorszewski A, Göhmann E, Dorsźewski B, Werner GS, Kreuzer H, Figulla HR Vasodilation by urapidil in the treatment of chronic congestive heart failure in addition to angiotensin-converting enzyme inhibitors is not beneficial: results of a placebo-controlled, double-blind study. J Card Fail. 1997;3:91-6.

465. Bayliss J, Norell MS, Canepa-Anson R, Reid C, Poole-Wilson P, Sutton G. Clinical importance of the renin-angiotensin system in chronic heart failure: double blind comparison of captopril and prazosin. Br Med J (Clin Res Ed). 1985;290:1861-5.

466. Jankowska EA, von Haehling S, Anker SD, Macdougall IC, Ponikowski P. Iron deficiency and heart failure: diagnostic dilemmas and therapeutic perspectives. Eur Heart J. 2013;34:816-26.

467. Jankowska EA, Kasztura M, Sokolski M, Bronisz M, Nawrocka S, Oles'kowskaFlorek W, Zymlin'ski R, Biegus J, Siwołowski P, Banasiak W, Anker SD, Filippatos G, Cleland JGF, Ponikowski P. Iron deficiency defined as depleted iron stores accompanied by unmet cellular iron requirements identifies patients at the highest risk of death after an episode of acute heart failure. Eur Heart J. 2014;35:2468-76.

468. Jankowska EA, Malyszko J, Ardehali H, Koc-Zorawska E, Banasiak W, von Haehling S, Macdougall IC, Weiss G, McMurray JJV, Anker SD, Gheorghiade M, Ponikowski P. Iron status in patients with chronic heart failure. Eur Heart J. 2013;34:827-34.

469. Anker SD, Comin Colet J, Filippatos G, Willenheimer R, Dickstein K, Drexler H, Luscher TF, Bart B, Banasiak W, Niegowska J, Kirwan BA, Mori C, von Eisenhart Rothe B, Pocock SJ, Poole-Wilson PA, Ponikowski P. Ferric carboxymaltose in patients with heart failure and iron deficiency. N Engl J Med. 2009;361:2436-48.

470. Ponikowski P, van Veldhuisen DJ, Comin-Colet J, Ertl G, Komajda M, Mareev V McDonagh T, Parkhomenko A, Tavazzi L, Levesque V, Mori C, Roubert B, Filippatos $G$, Ruschitzka F, Anker SD. Beneficial effects of long-term intravenous iron therapy with ferric carboxymaltose in patients with symptomatic heart failure and iron deficiency. Eur Heart J. 2015;36:657-68.

471. Filippatos G, Farmakis D, Colet JC, Dickstein K, Lüscher TF, Willenheimer R, Parissis J, Gaudesius G, Mori C, von Eisenhart Rothe B, Greenlaw N, Ford I, Ponikowski P, Anker SD. Intravenous ferric carboxymaltose in iron-deficient chronic heart failure patients with and without anaemia: a subanalysis of the FAIR-HF trial. Eur J Heart Fail. 2013;15:1267-76.

472. Effects of intravenous iron therapy in iron-deficient patients with systolic heart failure: a meta-analysis of randomized controlled trials. Jankowska EA, Tkaczyszyn M, Suchocki T, Drozd M, von Haehling S, Doehner W, Banasiak W, Filippatos G, Anker SD, Ponikowski P. Eur J Heart Fail. 2016 Jan 28. doi: 10.1002/ ejhf.473. [Epub ahead of print].

473. Angermann C, Pia M, Erdmann E, Levy P, Simonds AK, Somers VK, Zannad F, Cowie MR, Woehrle H, Wegscheider K, Angermann C, D'Ortho M-P, Erdmann E, Levy P, Simonds AK, Somers VK, Zannad F, Teschler H. Adaptive servo-ventilation for central sleep apnea in systolic heart failure. N Engl J Med. 2015;373:1095-105.

474. O'Meara E, Rouleau JL, White M, Roy K, Blondeau L, Ducharme A, Neagoe P-E Sirois MG, Lavoie J, Racine N, Liszkowski M, Madore F, Tardif J-C, de Denus S, ANCHOR Investigators. Heart failure with anemia: novel findings on the roles of renal disease, interleukins, and specific left ventricular remodeling processes. Circ Heart Fail. 2014;7:773-81.

475. Swedberg K, Young JB, Anand IS, Cheng S, Desai AS, Díaz R, Maggioni AP McMurray JJV, O'Connor C, Pfeffer MA, Solomon SD, Sun Y, Tendera M, van 
Veldhuisen DJ. Treatment of anemia with darbepoetin alfa in systolic heart failure. N Engl J Med. 2013;368:1210-9.

476. Damman K, Valente MAE, Voors AA, O’Connor CM, van Veldhuisen DJ, Hillege HL. Renal impairment, worsening renal function, and outcome in patients with heart failure: an updated meta-analysis. Eur Heart J. 2014;35:455-69.

477. Filippatos G, Farmakis D, Parissis J. Renal dysfunction and heart failure: things are seldom what they seem. Eur Heart J. 2014;35:416-8.

478. Chawla LS, Eggers PW, Star RA, Kimmel PL. Acute kidney injury and chronic kidney disease as interconnected syndromes. N Engl J Med. 2014;371:58-66.

479. Damman K, Testani JM. The kidney in heart failure: an update. Eur Heart J. 2015;36:1437-44.

480. Clark H, Krum H, Hopper I. Worsening renal function during renin-angiotensinaldosterone system inhibitor initiation and long-term outcomes in patients with left ventricular systolic dysfunction. Eur J Heart Fail. 2014;16:41-8.

481. Brenner S, Güder G, Berliner D, Deubner N, Fröhlich K, Ertl G, Jany B, Angermann CE, Stö rk S. Airway obstruction in systolic heart failure - COPD or congestion? Int J Cardiol. 2013;168:1910-6.

482. Güder G, Brenner S, Stö rk S, Hoes A, Rutten FH. Chronic obstructive pulmonary disease in heart failure: accurate diagnosis and treatment. Eur J Heart Fail. 2014; $16: 1-10$.

483. Perk J, De Backer G, Gohlke H, Graham I, Reiner Z, Verschuren M, Albus C, Benlian P, Boysen G, Cifkova R, Deaton C, Ebrahim S, Fisher M, Germano G, Hobbs R, Hoes A, Karadeniz S, Mezzani A, Prescott E, Ryden L, Scherer M, Syvänne M, Scholte op, Reimer WJM, Vrints C, Wood D, Zamorano JL, Zannad F, European Association for Cardiovascular Prevention \& Rehabilitation (EACPR), ESC Committee for Practice Guidelines (CPG). European Guidelines on cardiovascular disease prevention in clinical practice (version 2012). The Fifth Joint Task Force of the European Society of Cardiology and Other Societies on Cardiovascular Disease Prevention in Clinical Practice. Eur Heart J. 2012;33:1635-701.

484. McKelvie RS, Moe GW, Cheung A, Costigan J, Ducharme A, Estrella-Holder E Ezekowitz JA, Floras J, Giannetti N, Grzeslo A, Harkness K, Heckman GA, Howlett JG, Kouz S, Leblanc K, Mann E, O’Meara E, Rajda M, Rao V, Simon J, Swiggum E Zieroth S, Arnold JMO, Ashton T, D'Astous M, Dorian P, Haddad H, Isaac DL, Leblan MH, Liu P, Sussex B, Ross HJ. The 2011 Canadian Cardiovascular Society heart failure management guidelines update: focus on sleep apnea, renal dysfunction, mechanical circulatory support, and palliative care. Can J Cardiol. 2011;27:319-38.

485. Khayat R, Jarjoura D, Porter K, Sow A, Wannemacher J, Dohar R, Pleister A Abraham WT. Sleep disordered breathing and post-discharge mortality in patients with acute heart failure. Eur Heart J. 2015;36:1463-9.

486. Nakamura S, Asai K, Kubota Y, Murai K, Takano H, Tsukada YT, Shimizu W. Impact of sleep-disordered breathing and efficacy of positive airway pressure on mortality in patients with chronic heart failure and sleep-disordered breathing: a meta-analysis. Clin Res Cardiol. 2015;104:208-16.

487. Gottlieb DJ, Yenokyan G, Newman AB, O'Connor GT, Punjabi NM, Quan SF, Redline S, Resnick HE, Tong EK, Diener-West M, Shahar E. Prospective study of obstructive sleep apnea and incident coronary heart disease and heart failure: the Sleep Heart Health Study. Circulation. 2010;122:352-60.

488. Imadojemu VA, Sinoway LI, Leuenberger UA. Vascular dysfunction in sleep apnea. Am J Respir Crit Care Med. 2004;169:328-9.

489. Randerath WJ, Nothofer G, Priegnitz C, Anduleit N, Treml M, Kehl V, GaletkeW. Long-term auto-servoventilation or constant positive pressure in heart failure and coexisting central with obstructive sleep apnea. Chest. 2012:142:440-7.

490. Yumino D, Kasai T, Kimmerly D, Amirthalingam V, Floras JS, Bradley TD. Differing effects of obstructive and central sleep apneas on stroke volume in patients with heart failure. Am J Respir Crit Care Med. 2013;187:433-8.

491. Bradley TD, Logan AG, Kimoff RJ, Series F, Morrison D, Ferguson K, Belenkie I, Pfeifer M, Fleetham J, Hanly P, Smilovitch M, Tomlinson G, Floras JS. Continuous positive airway pressure for central sleep apnea and heart failure. $\mathrm{N}$ Engl J Med. $2005 \cdot 353 \cdot 2025-33$.

492. Costanzo MR, Augostini R, Goldberg LR, Ponikowski P, Stellbrink C, Javaheri S Design of the remede System Pivotal Trial: a prospective, randomized study in the use of respiratory rhythm management to treat central sleep apnea. J Card Fail. 2015;21:892-902.

493. Vahanian A, Alfieri O, Andreotti F, Antunes MJ, Baron-Esquivias G, Baumgartner $\mathrm{H}$, Borger MA, Carrel TP, De Bonis M, Evangelista A, Falk V, Iung B, Lancellotti $\mathrm{P}$, Pierard L, Price S, Schafers HJ, Schuler G, Stepinska J, Swedberg K, Takkenberg J, Von Oppell UO, Windecker S, Zamorano JL, Zembala M, Bax JJ, Baumgartner $\mathrm{H}$ Ceconi C, Dean V, Deaton C, Fagard R, Funck-Brentano C, Hasdai D, Hoes A Kirchhof P, Knuuti J, Kolh P, McDonagh T, Moulin C, Popescu BA, Reiner Z, Sechtem U, Sirnes PA, Tendera M, Torbicki A, Vahanian A, Windecker S, Popescu BA, Von Segesser L, Badano LP, Bunc M, Claeys MJ, Drinkovic N, Filippatos G, Habib G Kappetein AP, Kassab R, Lip GYH, Moat N, Nickenig G, Otto CM, Pepper J, Piazza N, Pieper PG, Rosenhek R, Shuka N, Schwammenthal E, Schwitter J, Mas PT, Trindade PT,Walther T. Guidelines on the management of valvular heart disease (version 2012): the Joint Task Force on the Management of Valvular Heart Disease of the European Society of Cardiology (ESC) and the European Association for Cardio-Thoracic Surgery (EACTS). Eur Heart J. 2012;33:2451-96.

494. Nishimura RA, Otto CM, Bonow RO, Carabello BA, Erwin JP, Guyton RA, O’Gara PT, Ruiz CE, Skubas NJ, Sorajja P, Sundt TM, Thomas JD, American College of Cardiology/American Heart Association Task Force on Practice Guidelines. 2014 AHA/ACC guideline for the management of patients with valvular heart disease: executive summary: a report of the American College of Cardiology/American Heart Association Task Force on Practice Guidelines. J Am Coll Cardiol. 2014:63:2438-88

495. Smith CR, Leon MB, Mack MJ, Miller DC, Moses JW, Svensson LG, Tuzcu EM, Webb JG, Fontana GP, Makkar RR, Williams M, Dewey T, Kapadia S, Babaliaros V,
Thourani VH, Corso P, Pichard AD, Bavaria JE, Herrmann HC, Akin JJ, Anderson WN,Wang D, Pocock SJ. Transcatheter versus surgical aorticvalve replacement in high-risk patients. N Engl J Med. 2011;364:2187-98.

496. Leon MB, Smith CR, Mack M, Miller DC, Moses JW, Svensson LG, Tuzcu EM, Webb JG, Fontana GP, Makkar RR, Brown DL, Block PC, Guyton RA, Pichard AD, Bavaria JE, Herrmann HC, Douglas PS, Petersen JL, Akin JJ, Anderson WN, Wang D, Pocock S. Transcatheter aortic-valve implantation for aortic stenosis in patients who cannot undergo surgery. N Engl J Med. 2010;363:1597-607.

497. Reardon MJ, Adams DH, Kleiman NS, Yakubov SJ, Coselli JS, Deeb GM, Gleason TG, Lee JS, Hermiller JB, Chetcuti S, Heiser J, Merhi W, Zorn GL, Tadros P, Robinson N, Petrossian G, Hughes GC, Harrison JK, Maini B, Mumtaz M, Conte JV, Resar JR, Aharonian V, Pfeffer T, Oh JK, Qiao H, Popma JJ. 2-Year outcomes in patients undergoing surgical or self-expanding transcatheter aortic valve replacement. J Am Coll Cardiol. 2015;66:113-21.

498. Adams DH, Popma JJ, Reardon MJ, Yakubov SJ, Coselli JS, Deeb GM, Gleason TG, Buchbinder M, Hermiller J, Kleiman NS, Chetcuti S, Heiser J, Merhi W, Zorn G, Tadros P, Robinson N, Petrossian G, Hughes GC, Harrison JK, Conte J, Maini B, Mumtaz M, Chenoweth S, Oh JK. Transcatheter aortic-valve replacement with a self-expanding prosthesis. N Engl J Med. 2014;370:1790-8

499. Lancellotti P, Tribouilloy C, Hagendorff A, Popescu BA, Edvardsen T, Pierard LA, Badano L, Zamorano JL. Recommendations for the echocardiographic assessment of native valvular regurgitation: an executive summary from the European Association of Cardiovascular Imaging. Eur Heart J Cardiovasc Imaging. 2013;14:611-44.

500. Chaliki HP, Mohty D, Avierinos JF, Scott CG, Schaff H V, Tajik AJ, Enriquez-Sarano M. Outcomes after aortic valve replacement in patients with severe aortic regurgitation and markedly reduced left ventricular function. Circulation. 2002:106:2687-93.

501. Smith PK, Puskas JD, Ascheim DD, Voisine P, Gelijns AC, Moskowitz AJ, Hung JW, Parides MK, Ailawadi G, Perrault LP, Acker MA, Argenziano M, Thourani V, Gammie JS, Miller MA, Pagé P, Overbey JR, Bagiella E, Dagenais F, Blackstone EH, Kron IL, Goldstein DJ, Rose EA, Moquete EG, Jeffries N, Gardner TJ, O'Gara PT, Alexander JH, Michler RE. Surgical treatment of moderate ischemic mitral regurgitation. N Engl J Med. 2014;371:2178-88.

502. Acker MA, Parides MK, Perrault LP, Moskowitz AJ, Gelijns AC, Voisine P, Smith PK, Hung JW, Blackstone EH, Puskas JD, Argenziano M, Gammie JS, Mack M, Ascheim DD, Bagiella E, Moquete EG, Ferguson TB, Horvath KA, Geller NL, Miller MA, Woo YJ, D’Alessandro DA, Ailawadi G, Dagenais F, Gardner TJ, O'Gara PT, Michler RE, Kron IL. Mitral-valve repair versus replacement for severe ischemic mitral regurgitation. N Engl J Med. 2014;370:23-32.

503. De Bonis M, Al-Attar N, Antunes M, Borger M, Casselman F, Falk V, Folliguet T, Iung B, Lancellotti P, Lentini S, Maisano F, Messika-Zeitoun D, Muneretto C, Pibarot P, Pierard L, Punjabi P, Rosenhek R, Suwalski P, Vahanian A. Surgical and interventional management of mitral valve regurgitation: a position statement from the European Society of Cardiology Working Groups on Cardiovascular Surgery and Valvular Heart Disease. Eur Heart J. 2016;37:133-9.

504. D'ascenzo F, Moretti C, Marra WG, Montefusco A, Omede P, Taha S, Castagno D, Gaemperli O, Taramasso M, Frea S, Pidello S, Rudolph V, Franzen O, Braun D, Giannini C, Ince H, Perl L, Zoccai G, Marra S, D’Amico M, Maisano F, Rinaldi M, Gaita F. Meta-analysis of the usefulness of mitraclip in patients with functional mitral regurgitation. Am J Cardiol. 2015;116:325-31.

505. Nickenig G, Estevez-Loureiro R, Franzen O, Tamburino C, Vanderheyden M, Lü scher TF, Moat N, Price S, Dall'Ara G, Winter R, Corti R, Grasso C, Snow TM, Jeger R, Blankenberg S, Settergren M, Tiroch K, Balzer J, Petronio AS, Büttner H-J, Ettori F, Sievert H, Fiorino MG, Claeys M, Ussia GP, Baumgartner H, Scandura S, Alamgir F, Keshavarzi F, Colombo A, Maisano F, Ebelt H, Aruta P, Lubos E, Plicht B, Schueler R, Pighi M, Di Mario C, Transcatheter Valve Treatment Sentinel Registry Investigators of the EURObservational Research Programme of the European Society of Cardiology. Percutaneous mitral valve edge-to-edge repair: in-hospital results and 1-year follow-up of 628 patients of the 2011-2012 pilot European Sentinel Registry. J Am Coll Cardiol. 2014;64:875-84.

506. Puls M, Lubos E, Boekstegers P, von Bardeleben RS, Ouarrak T, Butter C, Zuern CS, Bekeredjian R, Sievert H, Nickenig G, Eggebrecht H, Senges J, Schillinger W. Oneyear outcomes and predictors of mortality after MitraClip therapy in contemporary clinical practice: results from the German transcatheter mitral valve interventions registry. Eur Heart J. 2016;37:703-12.

507. Pérez-Ayuso RM, Arroyo V, Planas R, Gaya J, Bory F, Rimola A, Rivera F, Rodes J. Randomized comparative study of efficacy of furosemide versus spironolactone in nonazotemic cirrhosis with ascites. Relationship between the diuretic response and the activity of the renin-aldosterone system. Gastroenterology. 1983;84:961-8.

508. Schofer J, Bijuklic K, Tiburtius C, Hansen L, Groothuis A, Hahn RT. First-in-human transcatheter tricuspid valve repair in a patient with severely regurgitant tricuspid valve. J Am Coll Cardiol. 2015;65:1190-5.

509. Herrmann HC, Pibarot P, Hueter I, Gertz ZM, Stewart WJ, Kapadia S, Tuzcu EM, Babaliaros V, Thourani V, Szeto WY, Bavaria JE, Kodali S, Hahn RT, Williams M, Miller DC, Douglas PS, Leon MB. Predictors of mortality and outcomes of therapy in low-flow severe aortic stenosis: a Placement of Aortic Transcatheter Valves (PARTNER) trial analysis. Circulation. 2013;127:2316-26.

510. Ponikowski P, Jankowska EA. Pathogenesis and clinical presentation of acute heart failure. Rev Esp Cardiol (Engl Ed). 2015;68:331-7.

511. Metra M, Felker GM, Zaca` V, Bugatti S, Lombardi C, Bettari L, Voors AA, Gheorghiade M, Dei Cas L. Acute heart failure: multiple clinical profiles and mechanisms require tailored therapy. Int J Cardiol. 2010;144:175-9.

512. Filippatos G, Zannad F. An introduction to acute heart failure syndromes: definition and classification. Heart Fail Rev. 2007;12:87-90. 
513. Alla F, Zannad F, Filippatos G. Epidemiology of acute heart failure syndromes. Heart Fail Rev. 2007;12:91-5.

514. Nohria A, Tsang SW, Fang JC, Lewis EF, Jarcho JA, Mudge GH, Stevenson LW. Clinical assessment identifies hemodynamic profiles that predict outcomes in patients admitted with heart failure. J Am Coll Cardiol. 2003;41:1797-804.

515. Stevenson LW. Design of therapy for advanced heart failure. Eur J Heart Fail. 2005; 7:323-31.

516. Maisel AS, Peacock WF, McMullin N, Jessie R, Fonarow GC, Wynne J, Mills RM. Timing of immunoreactive B-type natriuretic peptide levels and treatment delay in acute decompensated heart failure: an ADHERE (Acute Decompensated Heart Failure National Registry) analysis. J Am Coll Cardiol. 2008;52:534-40.

517. Peacock WF, Emerman C, Costanzo MR, Diercks DB, Lopatin M, Fonarow GC. Early vasoactive drugs improve heart failure outcomes. Congest Heart Fail. 15:256-64.

518. Wuerz RC, Meador SA. Effects of prehospital medications on mortality and length of stay in congestive heart failure. Ann Emerg Med. 1992;21:669-74.

519. Chakko S,Woska D, Martínez H, de Marchena E, Futterman L, Kessler KM, Myerberg RJ. Clinical, radiographic, and hemodynamic correlations in chronic congestive heart failure: conflicting results may lead to inappropriate care. Am J Med. 1991;90:353-9.

520. Wang CS, FitzGerald JM, Schulzer M, Mak E, Ayas NT. Does this dyspneic patient in the emergency department have congestive heart failure? JAMA. 2005; $294: 1944-56$

521. Kelder JC, Cowie MR, McDonagh TA, Hardman SM, Grobbee DE, Cost B, Hoes AW. Quantifying the added value of BNP in suspected heart failure in general practice: an individual patient data meta-analysis. Heart. 2011;97:959-63.

522. Gupta DK,Wang TJ. Natriuretic peptides and cardiometabolic health. Circ J. 2015;79:1647-55

523. Zois NE, Bartels ED, Hunter I, Kousholt BS, Olsen LH, Goetze JP. Natriuretic peptides in cardiometabolic regulation and disease. Nat Rev Cardiol. 2014;11: 403-12.

524. Nishikimi T, Kuwahara K. Current biochemistry, molecular biology, and clinical relevance of natriuretic peptides. J Cardiol. 2011;57:131-40.

525. Felker GM, Mentz RJ, Teerlink JR, Voors AA, Pang PS, Ponikowski P, Greenberg BH, Filippatos G, Davison BA, Cotter G, Prescott MF, Hua TA, López-Pintado S, Severin T, Metra M. Serial high sensitivity cardiac troponin T measurement in acute heart failure: insights from the RELAX-AHF study. Eur J Heart Fail. 2015;17:1262-70.

526. Konstantinides S V, Torbicki A, Agnelli G, Danchin N, Fitzmaurice D, Galiè N, Gibbs JSR, Huisman MV, Humbert M, Kucher N, Lang I, Lankeit M, Lekakis J, Maack C, Mayer E, Meneveau N, Perrier A, Pruszczyk P, Rasmussen LH, Schindler TH, Svitil P, Vonk Noordegraaf A, Zamorano JL, Zompatori M, Task Force for the Diagnosis and Management of Acute Pulmonary Embolism of the European Society of Cardiology (ESC). 2014 ESC Guidelines on the diagnosis and management of acute pulmonary embolism. Eur Heart J. 2014;35:3033-73.

527. Maisel A, Neath SX, Landsberg J, Mueller C, Nowak RM, Peacock WF, Ponikowski P, Mö ckel M, Hogan C, Wu AHB, Richards M, Clopton P, Filippatos GS, Di Somma S, Anand I, Ng LL, Daniels LB, Christenson RH, Potocki M, McCord J, Terracciano G, Hartmann O, Bergmann A, Morgenthaler NG, Anker SD. Use of procalcitonin for the diagnosis of pneumonia in patients presenting with a chief complaint of dyspnoea: results from the BACH (Biomarkers in Acute Heart Failure) trial. Eur J Heart Fail. 2012;14:278-86.

528. van Deursen VM, Damman K, Hillege HL, van Beek AP, van Veldhuisen DJ, Voors AA. Abnormal liver function in relation to hemodynamic profile in heart failure patients. J Card Fail. 2010;16:84-90.

529. Biegus J, Zymlin' ski R, Sokolski M, Nawrocka S, Siwołowski P, Szachniewicz J, Jankowska EA, Banasiak W, Ponikowski P. Liver function tests in patients with acute heart failure. Pol Arch Med Wewne?trznej. 2012;122:471-9.

530. Nikolaou M, Parissis J, Yilmaz MB, Seronde MF, Kivikko M, Laribi S, Paugam-Burtz C, Cai D, Pohjanjousi P, Laterre PF, Deye N, Poder P, Cohen-Solal A, Mebazaa A. Liver function abnormalities, clinical profile, and outcome in acute decompensated heart failure. Eur Heart J. 2013;34:742-9.

531. Moe GW, Howlett J, Januzzi JL, Zowall H. N-terminal pro-B-type natriuretic peptide testing improves the management of patients with suspected acute heart failure: primary results of the Canadian prospective randomized multicenter IMPROVE-CHF study. Circulation. 2007;115:3103-10.

532. Maisel A, Mueller C, Nowak R, Peacock WF, Landsberg JW, Ponikowski P, Mockel M, Hogan C, Wu AHB, Richards M, Clopton P, Filippatos GS, Di_Somma S, Anand I, Ng L, Daniels LB, Neath SX, Christenson R, Potocki M, McCord J, Terracciano G, Kremastinos D, Hartmann O, von Haehling S, Bergmann A, Morgenthaler NG Anker SD, Di Somma S, Anand I, Ng L, Daniels LB, Neath SX, Christenson R, Potocki M, McCord J, Terracciano G, Kremastinos D, Hartmann O, von Haehling $S$, Bergmann A, Morgenthaler NG, Anker SD. Mid-region pro-hormone markers for diagnosis and prognosis in acute dyspnea. J Am Coll Cardiol. 2010;55:2062-76.

533. Mueller C, Scholer A, Laule-Kilian K, Martina B, Schindler C, Buser P, Pfisterer M, Perruchoud AP. Use of B-type natriuretic peptide in the evaluation and management of acute dyspnea. N Engl J Med. 2004;350:647-54.

534. Krishnaswamy P, Nowak RM, McCord J, Hollander JE, Duc P, Omland T, Storrow AB, Abraham WT, Wu AHB, Clopton P, Steg PG, Westheim A, KnudsenCW, Pérez A, Kazanegra R, Herrmann HC, McCullough PA. Rapid measurement of B-type natriuretic peptide in the emergency diagnosis of heart failure. $\mathrm{N}$ Engl J Med. 2002;347:161-7.

535. Task Force on the management of ST-segment elevation acute myocardial infarction of the European Society of Cardiology (ESC), Steg PG, James SK, Atar D Badano LP, Blömstrom-Lundqvist C, Borger MA, Di Mario C, Dickstein K, Ducrocq G, Fernandez-Aviles F, Gershlick AH, Giannuzzi P, Halvorsen S, Huber K, Juni P, Kastrati A, Knuuti J, Lenzen MJ, Mahaffey KW, Valgimigli M, van 't Hof A Widimsky P, Zahger D. ESC Guidelines for the management of acute myocardial infarction in patients presenting with ST-segment elevation. Eur Heart J. 2012;33:2569-619.

536. Levy P, Compton S, Welch R, Delgado G, Jennett A, Penugonda N, Dunne R Zalenski R. Treatment of severe decompensated heart failure with high-dose intravenous nitroglycerin: a feasibility and outcome analysis. Ann Emerg Med. 2007;50:144-52.

537. Cotter G, Metzkor E, Kaluski E, Faigenberg Z, Miller R, Simovitz A, Shaham O, Marghitay D, Koren M, Blatt A, Moshkovitz Y, Zaidenstein R, Golik A. Randomised trial of high-dose isosorbide dinitrate plus low-dose furosemide versus highdose furosemide plus low-dose isosorbide dinitrate in severe pulmonary oedema. Lancet. 1998;351:389-93.

538. Peterson PN, Rumsfeld JS, Liang L, Albert NM, Hernández AF, Peterson ED, Fonarow GC, Masoudi FA. A validated risk score for in-hospital mortality in patients with heart failure from the American Heart Association get with the guidelines program. Circ Cardiovasc Qual Outcomes. 2010;3:25-32.

539. Adams KF, Abraham WT, Yancy CW, Boscardin WJ. Risk stratification for inhospita mortality in acutely decompensated heart failure classification and regression tree analysis. JAMA. 2015;293:572-80.

540. Mebazaa A, Yilmaz MB, Levy P, Ponikowski P, Peacock WF, Laribi S, Ristic AD Lambrinou E, Masip J, Riley JP, McDonagh T, Mueller C, DeFilippi C, Harjola VP Thiele H, Piepoli MF, Metra M, Maggioni A, McMurray J, Dickstein K, Damman K, Seferovic PM, Ruschitzka F, Leite-Moreira AF, Bellou A, Anker SD, Filippatos G. Recommendations on pre-hospital and early hospital management of acute heart failure: a consensus paper from the HFA of the ESC, the European Society of Emergency Medicine and the Society of Academic Emergency Medicine. Eur J Heart Fail. 2015; 17:544-58.

541. Weng CL, Zhao YT, Liu QH, Fu CJ, Sun F, Ma YL, Chen YW, He QY. Meta-analysis: noninvasive ventilation in acute cardiogenic pulmonary edema. Ann Intern Med. 2010;152:590-600

542. Gray AJ, Goodacre S, Newby DE, Masson MA, Sampson F, Dixon S, Crane S, Elliott $\mathrm{M}$, Nicholl J. A multicentre randomised controlled trial of the use of continuous positive airway pressure and non-invasive positive pressure ventilation in the early treatment of patients presenting to the emergency department with severe acute cardiogenic pulmonary oedema: the 3CPO Trial. Health Technol Assess. 2009;13:1-106.

543. Vital FMR, Ladeira MT, Atallah AN. Non-invasive positive pressure ventilation (CPAP or bilevel NPPV) for cardiogenic pulmonary oedema. Cochrane Database Syst Rev. 2013;5:CD005351.

544. Park M, Sangean MC, Volpe MDS, Feltrim MIZ, Nozawa E, Leite PF, Passos Amato $\mathrm{MB}$, Lorenzi-Filho G. Randomized, prospective trial of oxygen, continuous positive airway pressure, and bilevel positive airway pressure by face mask in acute cardiogenic pulmonary edema. Crit Care Med. 2004;32:2407-15.

545. Gray A, Goodacre S, Newby DE, Masson M, Sampson F, Nicholl J, 3CPO Trialists. Noninvasive ventilation in acute cardiogenic pulmonary edema. $\mathrm{N}$ Engl J Med. 2008;359:142-51.

546. Rawles JM, Kenmure AC. Controlled trial of oxygen in uncomplicated myocardial infarction. Br Med J. 1976;1:1121-3.

547. Park JH, Balmain S, Berry C, Morton JJ, McMurray JJV. Potentially detrimental cardiovascular effects of oxygen in patients with chronic left ventricular systolic dysfunction. Heart. 2010;96:533-8.

548. Felker GM, Lee KL, Bull DA, Redfield MM, Stevenson LW, Goldsmith SR, LeWinter MM, Deswal A, Rouleau JL, Ofili EO, Anstrom KJ, Hernández AF, McNulty SE, Velázquez EJ, Kfoury AG, Chen HH, Givertz MM, Semigran MJ, Bart BA, Mascette AM, Braunwald E, O'Connor CM. Diuretic strategies in patients with acute decompensated heart failure. N Engl J Med. 2011;364:797-805.

549. Jentzer JC, DeWald TA, Hernández AF. Combination of loop diuretics with thiazide-type diuretics in heart failure. J Am Coll Cardiol. 2010;56:1527-34.

550. O’Connor CM, Starling RC, Hernández AF, Armstrong PW, Dickstein K, Hasselblad V, Heizer GM, Komajda M, Massie BM, McMurray JJV, Nieminen MS, Reist CJ, Rouleau JL, Swedberg K, Adams KF, Anker SD, Atar D, Battler A, Botero R, Bohidar NR, Butler J, Clausell N, Corbalán R, Costanzo MR, Dahlstrom U, Deckelbaum LI, Díaz R, Dunlap ME, Ezekowitz JA, Feldman D, Felker GM, Fonarow GC, Gennevois D, Gottlieb SS, Hill JA, Hollander JE, Howlett JG, Hudson MP, Kociol RD, Krum H, Laucevicius A, Levy WC, Méndez GF, Metra M, Mittal S, Oh BH, Pereira NL, Ponikowski P, Tang WHW, Wilson WH, Tanomsup S, Teerlink JR, Triposkiadis $\mathrm{F}$, Troughton RW, Voors AA, Whellan DJ, Zannad F, Califf RM. Effect of nesiritide in patients with acute decompensated heart failure. N Engl J Med. 2011;365:32-43.

551. Wakai A, McCabe A, Kidney R, Brooks SC, Seupaul RA, Diercks DB, Salter N, Fermann GJ, Pospisil C. Nitrates for acute heart failure syndromes. Cochrane Database Syst Rev. 2013;8:CD005151.

552. Mebazaa A, Parissis J, Porcher R, Gayat E, Nikolaou M, Boas FV, Delgado JF, Follath F. Short-term survival by treatment among patients hospitalized with acute heart failure: the global ALARM-HF registry using propensity scoring methods. Intensive Care Med. 2011;37:290-301.

553. Sharon A, Shpirer I, Kaluski E, Moshkovitz Y, Milovanov O, Polak R, Blatt A, Simovitz A, Shaham O, Faigenberg Z, Metzger M, Stav D, Yogev R, Golik A, Krakover R, Vered Z, Cotter G. High-dose intravenous isosorbide-dinitrate is safe and better than Bi-PAP ventilation combined with conventional treatment for severe pulmonary edema. J Am Coll Cardiol. 2000;36:832-7.

554. Publication Committee for the VMAC Investigators (Vasodilatation in the Management of Acute CHF). Intravenous nesiritide vs nitroglycerin for treatment of decompensated congestive heart failure: a randomized controlled trial. JAMA 2002;287:1531-40

555. Cohn JN, Franciosa JA, Francis GS, Archibald D, Tristani F, Fletcher R, Montero A Cintron G, Clarke J, Hager D, Saunders R, Cobb F, Smith R, Loeb H, Settle H. Effect of short-term infusion of sodium nitroprusside on mortality rate in acute 
myocardial infarction complicated by left ventricular failure: results of a Veterans Administration cooperative study. N Engl J Med. 1982;306:1129-35.

556. Elkayam U, Tasissa G, Binanay C, Stevenson LW, Gheorghiade M, Warnica JW Young JB, Rayburn BK, Rogers JG, DeMarco T, Leier C V. Use and impact of inotropes and vasodilator therapy in hospitalized patients with severe heart failure. Am Heart J. 2007;153:98-104.

557. Belletti A, Castro ML, Silvetti S, Greco T, Biondi-Zoccai G, Pasin L, Zangrillo A, Landoni $\mathrm{G}$. The effect of inotropes and vasopressors on mortality: a meta-analysis of randomized clinical trials. Br J Anaesth. 2015;115:656-75.

558. De Backer D, Biston P, Devriendt J, Madl C, Chochrad D, Aldecoa C, Brasseur A Defrance P, Gottignies P, Vincent JL. Comparison of dopamine and norepinephrine in the treatment of shock. N Engl J Med. 2010;362:779-89.

559. Gong B, Li Z, YatWong PC. Levosimendan treatment for heart failure: a systematic review and meta-analysis. J Cardiothorac Vasc Anesth. 2015;29:1415-25.

560. Tang X, Liu P, Li R, Jing Q, Lv J, Liu L, Liu Y. Milrinone for the treatment of acute heart failure after acute myocardial infarction: a systematic review and metaanalysis. Basic Clin Pharmacol Toxicol. 2015;117:186-94.

561. Cuffe MS, Califf RM, Adams KF, Benza R, Bourge R, Colucci WS, Massie BM O'Connor CM, Pina I, Quigg R, Silver MA, Gheorghiade M, Outcomes of a Prospective Trial of Intravenous Milrinone for Exacerbations of Chronic Heart Failure (OPTIME-CHF) Investigators. Short-term intravenous milrinone for acute exacerbation of chronic heart failure: a randomized controlled trial. JAMA. 2002;287:1541-7.

562. O'Connor CM, Gattis WA, Uretsky BF, Adams KF, McNulty SE, Grossman SH, McKenna WJ, Zannad F, Swedberg K, Gheorghiade M, Califf RM. Continuous intravenous dobutamine is associated with an increased risk of death in patients with advanced heart failure: insights from the Flolan International Randomized Survival Trial (FIRST). Am Heart J. 1999;138:78-86.

563. Wang XC, Zhu DM, Shan YX. Dobutamine therapy is associated with worse clinical outcomes compared with nesiritide therapy for acute decompensated heart failure: a systematic review and meta-analysis. Am J Cardiovasc Drugs. 2015;15:429-37.

564. Dentali F, Douketis JD, Gianni M, LimW, CrowtherM a. Meta-analysis: anticoagulant prophylaxis to prevent symptomatic venous thromboembolism in hospitalized medical patients. Ann Intern Med. 2007;146:278-88.

565. Clemo H, Wood M, Gilligan D, Ellenbogen K. Intravenous amiodarone for acute heart rate control in the critically ill patient with atrial tachyarrhythmias. Am J Cardiol. 1998;81:594-8.

566. Hou ZY, Chang MS, Chen CY, Tu MS, Lin SL, Chiang HT, Woosley RL. Acute treatment of recent-onset atrial fibrillation and flutter with a tailored dosing regimen of intravenous amiodarone. A randomized, digoxin-controlled study. Eur Heart J. 1995;16:521-8.

567. Delle Karth G, Geppert A, Neunteufl T, Priglinger U, Haumer M, Gschwandtner M Siostrzonek P, Heinz G. Amiodarone versus diltiazem for rate control in critically ill patients with atrial tachyarrhythmias. Crit Care Med. 2001;29:1149-53.

568. Iakobishvili Z, Cohen E, Garty M, Behar S, Shotan A, Sandach A, Gottlieb S, Mager A, Battler A, Hasdai D. Use of intravenous morphine for acute decompensated heart failure in patients with and without acute coronary syndromes. Acute Card Care. 2011;13:76-80.

569. Peacock WF, Hollander JE, Diercks DB, Lopatin M, Fonarow G, Emerman CL. Morphine and outcomes in acute decompensated heart failure: an ADHERE analysis. Emerg Med J. 2008;25:205-9.

570. Cox ZL, Lenihan DJ. Loop diuretic resistance in heart failure: resistance etiologybased strategies to restoring diuretic efficacy. J Card Fail. 2014;20:61122.

571. Mentz RJ, Kjeldsen K, Rossi GP, Voors AA, Cleland JGF, Anker SD, Gheorghiade M, Fiuzat M, Rossignol P, Zannad F, Pitt B, O'Connor C, Felker GM. Decongestion in acute heart failure. Eur J Heart Fail. 2014;16:471-82.

572. Mebazaa A, Nieminen MS, Filippatos GS, Cleland JG, Salon JE, Thakkar R, Padley RJ, Huang B, Cohen-Solal A. Levosimendan vs. dobutamine: outcomes for acute heart failure patients on b-blockers in SURVIVE. Eur J Heart Fail. 2009;11:304-11.

573. Pathak A, Lebrin M, Vaccaro A, Senard JM, Despas F. Pharmacology of levosimendan: inotropic, vasodilatory and cardioprotective effects. J Clin Pharm Ther. 2013;38:341-9.

574. Papp Z, Edes I, Fruhwald S, De Hert SG, Salmenpera M, Leppikangas H, Mebazaa A, Landoni G, Grossini E, Caimmi P, Morelli A, Guarracino F, Schwinger RH, Meye S, Algotsson L, Wikstrom BG, Jorgensen K, Filippatos G, Parissis JT, González MJ, Parkhomenko A, Yilmaz MB, Kivikko M, Pollesello P, Follath F. Levosimendan: molecular mechanisms and clinical implications: consensus of experts on the mechanisms of action of levosimendan. Int J Cardiol. 2012;159:82-7.

575. Delaney A, Bradford C, McCaffrey J, Bagshaw SM, Lee R. Levosimendan for the treatment of acute severe heart failure: a meta-analysis of randomised controlled trials. Int J Cardiol. 2010;138:281-9.

576. Monsieurs KG, Nolan JP, Bossaert LL, Greif R, Maconochie IK, Nikolaou NI, Perkins GD, Soar J, Truhlár` A, Wyllie J, Zideman DA. European Resuscitation Council Guidelines for Resuscitation 2015: Section 1. Executive summary. Resuscitation. 2015;95:1-80.

577. Gheorghiade M, Konstam MA, Burnett JC, Grinfeld L, Maggioni AP, Swedberg K, Udelson JE, Zannad F, Cook T, Ouyang J, Zimmer C, Orlandi C, Efficacy of Vasopressin Antagonism in Heart Failure Outcome Study With Tolvaptan (EVEREST) Investigators. Short-term clinical effects of tolvaptan, an ora vasopressin antagonist, in patients hospitalized for heart failure: the EVEREST Clinical Status Trials. JAMA. 2007;297:1332-43.

578. Bart BA, Goldsmith SR, Lee KL, Givertz MM, O'Connor CM, Bull DA, Redfield MM Deswal A, Rouleau JL, LeWinter MM, Ofili EO, Stevenson LW, Semigran MJ, Felke GM, Chen HH, Hernández AF, Anstrom KJ, McNulty SE, Velázquez EJ, Ibarra JC
Mascette AM, Braunwald E. Ultrafiltration in decompensated heart failure with cardiorenal syndrome. N Engl J Med. 2012;367:2296-304.

579. Costanzo MR, Guglin ME, Saltzberg MT, Jessup ML, Bart BA, Teerlink JR, Jaski BE, Fang JC, Feller ED, Haas GJ, Anderson AS, Schollmeyer MP, Sobotka PA. Ultrafiltration versus intravenous diuretics for patients hospitalized for acute decompensated heart failure. J Am Coll Cardiol. 2007;49:675-83.

580. Costanzo MR, Saltzberg MT, Jessup M, Teerlink JR, Sobotka PA. Ultrafiltration is associated with fewer rehospitalizations than continuous diuretic infusion in patients with decompensated heart failure: results from UNLOAD. J Card Fail. 2010;16:277-84.

581. Mullens W, Abrahams Z, Francis GS, Taylor DO, Starling RC, Tang WHW. Prompt reduction in intra-abdominal pressure following large-volume mechanical fluid removal improves renal insufficiency in refractory decompensated heart failure. J Card Fail. 2008;14:508-14.

582. Fuhrmann JT, Schmeisser A, Schulze MR, Wunderlich C, Schoen SP, Rauwolf T, Weinbrenner C, Strasser RH. Levosimendan is superior to enoximone in refractory cardiogenic shock complicating acute myocardial infarction. Crit Care Med. 2008;36:2257-66

583. Russ MA, Prondzinsky R, Christoph A, Schlitt A, Buerke U, Sö ffker G, Lemm H, Swyter M, Wegener N, Winkler M, Carter JM, Reith S, Werdan K, Buerke M. Hemodynamic improvement following levosimendan treatment in patients with acute myocardial infarction and cardiogenic shock. Crit Care Med. 2007;35:2732-9.

584. Felker GM, Benza RL Chandler AB, Leimberger JD, Cuffe MS, Califf RM, Gheorghiade M, O'Connor CM. Heart failure etiology and response tomilrinone in decompensated heart failure. J Am Coll Cardiol. 2003;41:997-1003.

585. Thiele H, Zeymer U, Neumann FJ, Ferenc M, Olbrich HG, Hausleiter J, Richardt G, Hennersdorf M, Empen K, Fuernau G, Desch S, Eitel I, Hambrecht R, Fuhrmann J, Böhm M, Ebelt H, Schneider S, Schuler G, Werdan K. Intraaortic balloon support for myocardial infarction with cardiogenic shock. N Engl J Med. 2012;367: 1287-96.

586. Thiele H, Zeymer U, Neumann FJ, Ferenc M, Olbrich HGG, Hausleiter J, de Waha A, Richardt G, Hennersdorf M, Empen K, Fuernau G, Desch S, Eitel I, Hambrecht R, Lauer B, Böhm M, Ebelt H, Schneider S, Werdan K, Schuler G, De Waha A, Richardt G, Hennersdorf M, Empen K, Fuernau G, Desch S, Eitel I, Hambrecht R, Lauer B, Böhm M, Ebelt H, Schneider S, Werdan K, Schuler G. Intra-aortic balloon counterpulsation in acute myocardial infarction complicated by cardiogenic shock (IABP-SHOCK II): final 12 month results of a randomised, open-label trial. Lancet. 2013;382:1638-45.

587. Prins KW, Neill JM, Tyler JO, Eckman PM, Duval S. Effects of beta-blocker withdrawal in acute decompensated heart failure: a systematic review and metaanalysis. JACC Heart Fail. 2015;3:647-53.

588. Santaguida PL, Don-Wauchope AC, Oremus M, McKelvie R, Ali U, Hill SA, Balion C, Booth RA, Brown JA, Bustamam A, Sohel N, Raina P. BNP and NT-proBNP as prognostic markers in persons with acute decompensated heart failure: a systematic review. Heart Fail Rev. 2014;19:453-70.

589. Savarese G, Musella F, D’Amore C, Vassallo E, Losco T, Gambardella F, Cecere M, Petraglia L, Pagano G, Fimiani L, Rengo G, Leosco D, Trimarco B, Perrone-Filardi P. Changes of natriuretic peptides predict hospital admissions in patients with chronic heart failure: a meta-analysis. JACC Heart Fail. 2014;2:148-58.

590. Volpe M, Rubattu S, Burnett J. Natriuretic peptides in cardiovascular diseases: current use and perspectives. Eur Heart J. 2014;35:419-25.

591. Lainscak M, Blue L, Clark AL, Dahlström U, Dickstein K, Ekman I, McDonagh T, McMurray JJ, Ryder M, Stewart S, Strömberg A, Jaarsma T. Self-care management of heart failure: practical recommendations from the Patient Care Committee of the Heart Failure Association of the European Society of Cardiology. Eur J Heart Fail. 2011;13:115-26.

592. McDonagh TA, Blue L, Clark AL, Dahlström U, Ekman I, Lainscak M, McDonald K, Ryder M, Strömberg A, Jaarsma T. European Society of Cardiology Heart Failure Association Standards for delivering heart failure care. Eur J Heart Fail. 2011;13:235-41.

593. Stewart GC, Givertz MM. Mechanical circulatory support for advanced heart failure: patients and technology in evolution. Circulation. 2012;125:1304-15.

594. Schmidt M, Burrell A, Roberts L, Bailey M, Sheldrake J, Rycus PT, Hodgson C, Scheinkestel C, Cooper DJ, Thiagarajan RR, Brodie D, Pellegrino V, Pilcher D. Predicting survival after ECMO for refractory cardiogenic shock: the survival after veno-arterial-ECMO (SAVE)-score. Eur Heart J. 2015;36:1-11.

595. Riebandt J, Haberl T, Mahr S, Laufer G, Rajek A, Steinlechner B, Schima H, Zimpfer D. Preoperative patient optimization using extracorporeal life support improves outcomes of INTERMACS level I patients receiving a permanent ventricular assist device. Eur J Cardiothorac Surg. 2014;46:486-92.

596. Cheng JM, den Uil CA, Hoeks SE, van der Ent M, Jewbali LSD, van Domburg RT Serruys PW. Percutaneous left ventricular assist devices vs. intra-aortic balloon pump counterpulsation for treatment of cardiogenic shock: a meta-analysis of controlled trials. Eur Heart J. 2009;30:2102-8.

597. O'NeillWW, Kleiman NS, Moses J, Henriques JPS, Dixon S, Massaro J, Palacios I, Maini B, Mulukutla S, Džavík V, Popma J, Douglas PS, Ohman M. A prospective, randomized clinical trial of hemodynamic support with impella 2.5 versus intraaortic balloon pump in patients undergoing high-risk percutaneous coronary intervention: the PROTECT II study. Circulation. 2012;126:1717-27.

598. Rahmel A, ed. Eurotransplant International Foundation Annual Report 2013. Leiden, The Netherlands: CIP-Gegevens Koninklijke Bibliotheek, 2013.

599. Trivedi JR, Cheng A, Singh R, Williams ML, Slaughter MS. Survival on the heart transplant waiting list: impact of continuous flow left ventricular assist device as bridge to transplant. Ann Thorac Surg. 2014;98:830-4.

600. Miller LW, Pagani FD, Russell SD, John R, Boyle AJ, Aaronson KD, Conte J V, Naka Y, Mancini D, Delgado RM, MacGillivray TE, Farrar DJ, Frazier OH. Use of a 
continuous-flow device in patients awaiting heart transplantation. $\mathrm{N}$ Engl J Med. 2007;357:885-96.

601. Kirklin JK, Naftel DC, Pagani FD, Kormos RL, Stevenson LW, Blume ED, Miller MA Baldwin J, Young JB. Sixth INTERMACS annual report: a 10,000-patient database. J Heart Lung Transplant. 2014;33:555-64.

602. Westaby S. Cardiac transplant or rotary blood pump: contemporary evidence. J Thorac Cardiovasc Surg. 2013;145:24-31.

603. Teuteberg JJ, Slaughter MS, Rogers JG, McGee EC, Pagani FD, Gordon R, Rame E, Acker M, Kormos RL, Salerno C, Schleeter TP, Goldstein DJ, Shin J, Starling RC, Wozniak T, Malik AS, Silvestry S, Ewald GA, Jorde UP, Naka Y, Birks E, Najarian KB Hathaway DR, Aaronson KD. The HVAD left ventricular assist device: risk factors for neurological events and risk mitigation strategies. JACC Heart Fail. 2015;3:818-28.

604. Kirklin JK, Naftel DC, Pagani FD, Kormos RL, Stevenson LW, Blume ED, Myers SL, Miller MA, Baldwin JT, Young JB. Seventh INTERMACS annual report: 15,000 patients and counting. J Heart Lung Transplant. 2015;34:1495-504.

605. Estep JD, Starling RC, Horstmanshof DA, Milano CA, Selzman CH, Shah KB, Loebe M, Moazami N, Long JW, Stehlik J, Kasirajan V, Haas DC, O'Connell JB, Boyle AJ, Farrar DJ, Rogers JG. Risk assessment and comparative effectiveness of left ventricular assist device and medical management in ambulatory heart failure patients: results from the ROADMAP study. J AmColl Cardiol. 2015;66: 1747-61.

606. Thompson JS, Matlock DD, Mcllvennan CK, Jenkins AR, Allen LA. Development of a decision aid for patients with advanced heart failure considering a destination therapy left ventricular assist device. JACC Heart Fail. 2015;3:965-76.

607. Lambrinou E, Kalogirou F, Lamnisos D, Sourtzi P. Effectiveness of heart failure management programmes with nurse-led discharge planning in reducing readmissions: a systematic review and meta-analysis. Int J Nurs Stud. 2012;49: 610-24.

608. Birks EJ, Tansley PD, Hardy J, George RS, Bowles CT, Burke M, Banner NR, Khaghani A, Yacoub MH. Left ventricular assist device and drug therapy for the reversal of heart failure. N Engl J Med. 2006;355:1873-84.

609. Dandel M, Knosalla C, Hetzer R. Contribution of ventricular assist devices to the recovery of failing hearts: a review and the Berlin Heart Center Experience. Eur J Heart Fail. 2014;16:248-63.

610. Jorde UP, Kushwaha SS, Tatooles AJ, Naka Y, Bhat G, Long JW, Horstmanshof DA, Kormos RL, Teuteberg JJ, Slaughter MS, Birks EJ, Farrar DJ, Park SJ. Results of the destination therapy post-food and drug administration approval study with a continuous flow left ventricular assist device: a prospective study using the INTERMACS registry (Interagency Registry for Mechanically Assisted Circulatory Support). J Am Coll Cardiol. 2014;63:1751-7.

611. Khazanie P, Rogers JG. Patient selection for left ventricular assist devices. Congest Heart Fail. 2011;17:227-34.

612. Rose EA, Gelijns AC, Moskowitz AJ, Heitjan DF, Stevenson LW, Dembitsky W, Long JW, Ascheim DD, Tierney AR, Levitan RG, Watson JT, Meier P, Ronan NS, Shapiro PA, Lazar RM, Miller LW, Gupta L, Frazier OH, Desvigne-Nickens P, Oz MC, Poirier VL. Long-term use of a left ventricular assist device for end-stage heart failure. $\mathrm{N}$ Engl J Med. 2001;345:1435-43.

613. Slaughter MS, Rogers JG, Milano C a, Russell SD, Conte J V, Feldman D, Sun B, Tatooles AJ, Delgado RM, Long JW, Wozniak TC, Ghumman W, Farrar DJ, Frazier $\mathrm{OH}$. Advanced heart failure treated with continuous-flow left ventricular assist device. N Engl J Med. 2009;361:2241-51.

614. Banner NR, Bonser RS, Clark AL, Clark S, Cowburn PJ, Gardner RS, Kalra PR, McDonagh T, Rogers CA, Swan L, Parameshwar J, Thomas HL, Williams SG. UK guidelines for referral and assessment of adults for heart transplantation. Heart. 2011;97:1520-7.

615. Mehra M, Kobashigawa J, Starling R, Russell S, Uber P, Parameshwar J, Mohacsi P, Augustine S, Aaronson K, Barr M. Listing criteria for heart transplantation: International Society for Heart and Lung Transplantation guidelines for the care of cardiac transplant candidates-2006. J Heart Lung Transplant. 2006;25: $1024-42$.

616. Mehra MR, Canter CE, Hannan MM, Semigran MJ, Uber PA, Baran DA, DanzigerIsakov L, Kirklin JK, Kirk R, Kushwaha SS, Lund LH, Potena L, Ross HJ, Taylor DO, Verschuuren EAM, Zuckermann A. The 2016 International Society for Heart Lung Transplantation listing criteria for heart transplantation: a 10-year update. J Heart Lung Transplant. 2016;35:1-23.

617. McDonagh TA, Gardner RS, Lainscak M, Nielsen OW, Parissis J, Filippatos G, Anker SD. Heart failure association of the European Society of Cardiology specialist heart failure curriculum. Eur J Heart Fail. 2014;16:151-62.

618. O'Connor CM, Whellan DJ, Lee KL, Keteyian SJ, Cooper LS, Ellis SJ, Leifer ES, Kraus WE, Kitzman DW, Blumenthal JA, Rendall DS, Miller NH, Fleg JL, Schulman KA, McKelvie RS, Zannad F, Piña IL, HF-ACTION Investigators. Efficacy and safety of exercise training in patients with chronic heart failure: HF-ACTION randomized controlled trial. JAMA. 2009;301:1439-50.

619. Taylor RS, Sagar VA, Davies EJ, Briscoe S, Coats AJ, Dalal H, Lough F, Rees K, Singh S. Exercise-based rehabilitation for heart failure. Cochrane Database Syst Rev. 2014;4:CD003331.

620. Nolte K, Herrmann-Lingen C, Wachter R, Gelbrich G, Dungen HD, Duvinage A, Hoischen N, Von Oehsen K, Schwarz S, Hasenfuss G, Halle M, Pieske B, Edelmann F. Effects of exercise training on different quality of life dimensions in heart failure with preserved ejection fraction: the Ex-DHF-P trial. Eur J Prev Cardiol. 2015;22:582-93.

621. IsmailH,McFarlane JR,Nojoumian AH, Dieberg G, Smart NA. Clinical outcomes and cardiovascular responses to different exercise training intensities in patients with heart failure: a systematic review and meta-analysis. JACC Heart Fail. 2013;1:514-22.
622. Phillips CO, Wright SM, Kern DE, Singa RM, Shepperd S, Rubin HR. Comprehensive discharge planning with postdischarge support for older patients with congestive heart failure: a meta-analysis. JAMA. 2004;291:1358-67.

623. Stewart S, Vandenbroek AJ, Pearson S, Horowitz JD. Prolonged beneficial effects of a home-based intervention on unplanned readmissions and mortality among patients with congestive heart failure. Arch Intern Med. 1999;159:257-61.

624. McAlister FA, Stewart S, Ferrua S, McMurray JJ. Multidisciplinary strategies for the management of heart failure patients at high risk for admission: a systematic review of randomized trials. J Am Coll Cardiol. 2004;44:810-9.

625. Feltner C, Jones CD, Cené CW, Zheng ZJ, Sueta CA, Coker-Schwimmer EJLL, Arvanitis M, Lohr KN, Middleton JC, Jonas DE. Transitional care interventions to prevent readmissions for persons with heart failure: a systematic review and meta-analysis. Ann Intern Med. 2014;160:774-84.

626. Schou M, Gustafsson F, Videbaek L, Tuxen C, Keller N, Handberg J, Sejr Knudsen A, Espersen G, Markenvard J, Egstrup K, Ulriksen H, Hildebrandt PR. Extended heart failure clinic follow-up in low-risk patients: a randomized clinical trial (NorthStar). Eur Heart J. 2013;34:432-42.

627. Luttik MLA, Jaarsma T, van Geel PP, Brons M, Hillege HL, Hoes AW, de Jong R, Linssen G, Lok DJA, Berge M, van Veldhuisen DJ. Long-term follow-up in optimally treated and stable heart failure patients: primary care vs. heart failure clinic. Results of the COACH-2 study. Eur J Heart Fail. 2014;16:1241-8.

628. AbrahamWT, Adamson PB, Bourge RC, Aaron MF, Costanzo MR, Stevenson LW, Strickland W, Neelagaru S, Raval N, Krueger S, Weiner S, Shavelle D, Jeffries B, Yadav JS. Wireless pulmonary artery haemodynamic monitoring in chronic heart failure: a randomised controlled trial. Lancet. 2011;377:658-66.

629. Abraham WT, Stevenson LW, Bourge RC, Lindenfeld JA, Bauman JG, Adamson PB Sustained efficacy of pulmonary artery pressure to guide adjustment of chronic heart failure therapy: complete follow-up results from the CHAMPION randomised trial. Lancet. 2016;387:453-61.

630. Hindricks G, Taborsky M, Glikson M, Heinrich U, Schumacher B, Katz A Brachmann J, Lewalter T, Goette A, Block M, Kautzner J, Sack S, Husser D, Piorkowski C, Søgaard P. Implant-based multiparameter telemonitoring of patients with heart failure (IN-TIME): a randomised controlled trial. Lancet. 2014;384:583-90.

631. Mueller C, Christ M, Cowie M, Cullen L, Maisel AS, Masip J, Miro O, McMurray J, Peacock FW, Price S, DiSomma S, Bueno H, Zeymer U, Mebazaa A. European Society of Cardiology-Acute Cardiovascular Care Association position paper on acute heart failure: a call for interdisciplinary care. Eur Heart J Acute Cardiovasc Care 2015 Jun 29. pii: 2048872615593279 [Epub ahead of print].

632. Bradley EH, Sipsma H, Horwitz LI, Ndumele CD, Brewster AL, Curry LA, Krumholz HM. Hospital strategy uptake and reductions in unplanned readmission rates for patients with heart failure: a prospective study. J Gen Intern Med. 2015:30:605-11.

633. Conraads VM, Deaton C, Piotrowicz E, Santaularia N, Tierney S, Piepoli MF, Pieske B, Schmid JP, Dickstein K, Ponikowski PP, Jaarsma T. Adherence of heart failure patients to exercise: barriers and possible solutions: a position statement of the Study Group on Exercise Training in Heart Failure of the Heart Failure Association of the European Society of Cardiology. Eur J Heart Fail. 2012;14:451-8.

634. Kitzman DW, Brubaker PH, Herrington DM, Morgan TM, Stewart KP, Hundley WG, Abdelhamed A, Haykowsky MJ. Effect of endurance exercise training on endothelial function and arterial stiffness in older patients with heart failure and preserved ejection fraction: a randomized, controlled, single-blind trial. J Am Coll Cardiol. 2013;62:584-92.

635. Balion C, McKelvie R, Don-Wauchope AC, Santaguida PL, Oremus M, Keshavarz H, Hill SA, Booth RA, Ali U, Brown JA, BustamamA, Sohel N, Raina P. B-type natriuretic peptide-guided therapy: a systematic review. Heart Fail Rev. 2014;19:553-64.

636. Troughton RW, Frampton CM, Brunner-La Rocca HP, Pfisterer M, Eurlings LWM Erntell H, Persson H, O'Connor CM, Moertl D, Karlstrom P, Dahlstrom U, Gaggin HK, Januzzi JL, Berger R, Richards AM, Pinto YM, Nicholls MG. Effect of B-type natriuretic peptide-guided treatment of chronic heart failure on total mortality and hospitalization: an individual patient meta-analysis. Eur Heart 2014;35:1559-67.

637. De Vecchis R, Esposito C, Di Biase G, Ariano C, Giasi A, Cioppa C. B-type natriuretic peptide-guided versus symptom-guided therapy in outpatients with chronic heart failure: a systematic review with meta-analysis. J Cardiovasc Med (Hagerstown). 2014;15:122-34.

638. Troughton R, Michael Felker G, Januzzi JL. Natriuretic peptide-guided heart failure management. Eur Heart J. 2014;35:16-24.

639. Anker SD, Koehler F, Abraham WT. Telemedicine and remote management of patients with heart failure. Lancet. 2011;378:731-9.

640. Chaudhry SI, Mattera JA, Curtis JP, Spertus JA, Herrin J, Lin Z, Phillips CO, Hodshon B V, Cooper LS, Krumholz HM. Telemonitoring in patients with heart failure. N Engl J Med. 2010;363:2301-9.

641. Koehler F, Winkler S, Schieber M, Sechtem U, Stangl K, Böhm M, Boll H, Kim SS, Koehler K, Lücke S, Honold M, Heinze P, Schweizer T, Braecklein M, Kirwan BA Gelbrich G, Anker SD. Telemedical Interventional Monitoring in Heart Failure (TIM-HF), a randomized, controlled intervention trial investigating the impact of telemedicine on mortality in ambulatory patients with heart failure: study design. Eur J Heart Fail. 2010;12:1354-62.

642. AngermannCE, Störk S, GelbrichG, FallerH, JahnsR, Frantz S,LoefflerM, ErtlG.Mode of action and effects of standardized collaborative disease management on mortality and mobidity in patient with systolic heart failure. Circ Heart Fail. 2012;5:25-35

643. Lyng P, Persson H, Hgg-Martinell A, Hgglund E, Hagerman I, Langius-Eklf A, Rosenqvist M, Lynga P, Persson H, Hagg-Martinell A, Hagglund E, Hagerman I, Langius-Eklof A, Rosenqvist $\mathrm{M}$. Weight monitoring in patients with severe heart failure (WISH). A randomized controlled trial. Eur J Heart Fail. 2012;14:438-44. 
644. Boyne JJJ, Vrijhoef HJM, Crijns HJGM, DeWeerd G, Kragten J, Gorgels APM. Tailored telemonitoring in patients with heart failure: results of a multicentre randomized controlled trial. Eur J Heart Fail. 2012;14:791-801.

645. Vidán MT, Sánchez E, Fernández-Avilés F, Serra-Rexach JA, Ortiz J, Bueno $\mathrm{H}$ FRAIL-HF, a study to evaluate the clinical complexity of heart failure in nondependent older patients: rationale, methods and baseline characteristics. Clin Cardiol. 2014;37:725-32.

646. Turner G, Clegg A. Best practice guidelines for the management of frailty: a British Geriatrics Society, Age UK and Royal College of General Practitioners report. Age Ageing. 2014;43:744-8.

647. Woo J, Leung J, Morley JE. Comparison of frailty indicators based on clinical phenotype and the multiple deficit approach in predicting mortality and physical limitation. J Am Geriatr Soc. 2012;60:1478-86.

648. Fried LP, Tangen CM,Walston J, Newman AB, Hirsch C, Gottdiener J, Seeman T, Tracy R, Kop WJ, Burke G, McBurnie MA. Frailty in older adults: evidence for a phenotype. J Gerontol A Biol Sci Med Sci. 2001;56:M146-56.

649. Folstein MF, Folstein SE, McHugh PR. "Mini-mental state". A practical method for grading the cognitive state of patients for the clinician. J Psychiatr Res. 1975;12:189-98.

650. Nasreddine ZS, Phillips NA, Bedirian V, Charbonneau S, Whitehead V, Collin I Cummings JL, Chertkow H. The Montreal Cognitive Assessment, MoCA: a brie screening tool for mild cognitive impairment. J Am Geriatr Soc. 2005;53:695-9.

651. Cannon JA, McMurray JJ, Quinn TJ. 'Hearts and minds': association, causation and implication of cognitive impairment in heart failure. Alzheimers Res Ther. 2015;7:22

652. Denvir MA, Murray SA, Boyd KJ. Future care planning: a first step to palliative care for all patients with advanced heart disease. Heart. 2015;101:1002-7.
653. Evangelista LS, Lombardo D, Malik S, Ballard-Hernández J, Motie M, Liao S. Examining the effects of an outpatient palliative care consultation on symptom burden, depression, and quality of life in patients with symptomatic heart failure. J Card Fail. 2012;18:894-9.

654. Jaarsma T, Beattie JM, Ryder M, Rutten FH, McDonagh T, Mohacsi P, Murray SA, Grodzicki T, Bergh I, Metra M, Ekman I, Angermann C, Leventhal M, Pitsis A, Anker SD, Gavazzi A, Ponikowski P, Dickstein K, Delacretaz E, Blue L, Strasser F, McMurray J. Palliative care in heart failure: a position statement from the palliative care workshop of the Heart Failure Association of the European Society of Cardiology. Eur J Heart Fail. 2009;11:433-43.

655. Brännström M, Boman K. Effects of person-centred and integrated chronic heart failure and palliative home care. PREFER: a randomized controlled study. Eur J Heart Fail. 2014;16:1142-51.

656. Johnson MJ, McDonagh TA, Harkness A, McKay SE, Dargie HJ. Morphine for the relief of breathlessness in patients with chronic heart failure-a pilot study. Eur J Heart Fail. 2002;4:753-6.

657. Palliative Care Outcome Scale (POS). Available at http://pos-pal.org (last accessed 2 December 2015)

658. Johnson MJ, Bland JM, Davidson PM, Newton PJ, Oxberry SG, Abernethy AP, Currow DC. The relationship between two performance scales: New York Heart Association Classification and Karnofsky Performance Status Scale. J Pain Symptom Manage. 2014;47:652-8.

659. Lyons KD, Bakitas M, Hegel MT, Hanscom B, Hull J, Ahles TA. Reliability and validity of the Functional Assessment of Chronic Illness Therapy- Palliative care (FACIT-Pal) scale. J Pain Symptom Manage. 2009;37:23-32. 